\title{
THEORIES AND NARRATIVES: PACIFIC WOMEN IN TERTIARY EDUCATION AND THE SOCIAL CONSTRUCTION OF ETHNIC IDENTITIES IN AOTEAROA NEW ZEALAND
}

By

Diane Lysette Mara

\author{
A thesis \\ submitted to the Victoria University of Wellington \\ in fulfilment of the requirements for the degree of \\ Doctor of Philosophy \\ in Education
}

Victoria University of Wellington

2006 


\section{ABSTRACT}

This thesis explores the possible influence of tertiary education on ethnic identity using a social constructionist approach developed by the sociologists Stephen Cornell and Douglas Hartmann. Cornell and Hartmann describe six key sites within which ethnic identity is constructed. They view ethnic identity construction as an ongoing dynamic between the cultural identities which group members bring with them, the processes of assignment made by others within the sites, and how this interplay often promotes the assertion of newly created or revived identities. Constructions sites are situations where different cultural groups interact and where they may be subject to laws, regulations and prevailing beliefs. Although Cornell and Hartmann discuss various social institutions as construction sites they do not specifically refer to educational institutions. This study builds on their approach by examining social interactions within tertiary education from the perspectives of individual Pacific women and investigates whether this institution is a site for ethnic identity formation and change. If so, what implications does this have for Pacific students and the institutions in which they are studying? The sample consisted of twenty Pacific women graduates belonging to most of the Pacific populations in Aotearoa New Zealand. Using a semi-structured interview, information was collected about their socialization in family and church and then about their experience of tertiary education and their own responses to this. When their narratives were analysed it could be seen that the women defined themselves in both primordialist and circumstantialist terms. The narratives also provided illustrations of their assignment by "others" in the form of negative stereotyping and lower expectations held by lecturers of Pacific students. The women felt that within tertiary education institutions they were treated differently from students from other ethnic groups. The consequence was increased awareness of their cultural difference and they asserted their ethnic identities in a range of ways, including finding other Pacific students to study with, or by withdrawal behaviour in class. Such treatment, together with the effects of targeted provisions at tertiary institutions, acted to strengthen the ethnic boundaries between Pacific students and others. Implications for tertiary education institutions include the desirability of consulting Pacific students about the effects of support provided on the basis of cultural identification and the need to discover whether special provisions which make Pacific students more visible leads to their academic success or encourages them to drop out. 


\section{DEDICATION}

This work is dedicated to the memory of my father Nu'utaivava Natapu Mara (1922-1986) and my mother Joyce Elizabeth Riley (1921-1959), whom I thank for my dual heritage. 


\section{CONTENTS}

\section{ABSTRACT 1 \\ DEDICATION 2}

$\begin{array}{lr}\text { ACKNOWLEDGEMENTS } & 8\end{array}$

CHAPTER 1: INTRODUCTION AND OVERVIEW 9

$\begin{array}{lr}\text { Introduction } & 9\end{array}$

$\begin{array}{ll}\text { Overview of chapters } & 12\end{array}$

CHAPTER 2: MY OWN NARRATIVE

$\begin{array}{ll}\text { My family background } & 15\end{array}$

What does it mean to be Tahitian? 16

$\begin{array}{ll}\text { Why did I go to university? } & 19\end{array}$

How did I cope with my tertiary studies? $\quad 20$

My participation in other Pacific communities and the wider society 21

$\begin{array}{ll}\text { Further tertiary study and education policy reforms } & 22\end{array}$

The outcomes of a tertiary education and qualifications: reflections 23

$\begin{array}{ll}\text { Conclusion } & 24\end{array}$

CHAPTER 3: SITUATING PACIFIC GROUPS IN AOTEAROA NEW ZEALAND 2

$\begin{array}{ll}\text { Overview } & 26\end{array}$

The current status of Pacific peoples in Aotearoa New Zealand 26

Policy responses to the social position of Pacific peoples 28

Pacific identities in Aotearoa New Zealand: a range of definitions and $\begin{array}{ll}\text { perspectives } & 31\end{array}$

The blurring of Pacific ethnic boundaries 35

$\begin{array}{ll}\text { Maintaining Pacific ethnic boundaries } & 37\end{array}$

Pacific women in Aotearoa New Zealand 43

$\begin{array}{ll}\text { Summary } & 46\end{array}$

CHAPTER 4: TERTIARY EDUCATION, FAMILY AND CHURCH 48

$\begin{array}{ll}\text { Introduction and overview } & 48\end{array}$

$\begin{array}{ll}\text { Pacific students in tertiary education } & 48\end{array}$

$\begin{array}{ll}\text { Pacific family and church settings } & 61\end{array}$

$\begin{array}{ll}\text { The family } & 61\end{array}$

The church 63

The wider society and Pacific women 67

The tertiary education institution as part of the wider society 69

$\begin{array}{ll}\text { Summary } & 71\end{array}$

CHAPTER 5: $\quad$ IDENTITY AND ETHNICITY 72

$\begin{array}{ll}\text { Introduction and overview } & 72\end{array}$

$\begin{array}{ll}\text { Identity, group identity and identity politics } & 72\end{array}$

$\begin{array}{ll}\text { The terms ethnicity and ethnic identity } & 78\end{array}$

$\begin{array}{ll}\text { Summary } & 81\end{array}$ 
CHAPTER 6: $\quad$ ETHNICITY, GENDER AND IDENTITY 82

Introduction $\quad 82$

Ethnic identity in the tertiary setting 83

Pacific women: ethnicity and gender 86

$\begin{array}{ll}\text { Ethnicity, gender and power } & 89\end{array}$

Power and assertion in indigenous research methodologies 90

$\begin{array}{ll}\text { Power and Pacific ways of knowing and being } & 91\end{array}$

$\begin{array}{ll}\text { Summary } & 94\end{array}$

CHAPTER 7: CONSTRUCTING \& SITUATING ETHNIC IDENTITIES 96

Overview 96

Definitions of ethnicity, race and identity 98

$\begin{array}{lr}\text { Boundaries } & 99\end{array}$

Perceived position 100

$\begin{array}{ll}\text { Meanings } & 101\end{array}$

Comprehensiveness: "thick" and "thin" identity 102

Assertions of kinship and ethnic group identification 107

Contextual factors and construction sites for ethnic identity 108

Peoples' contributions to the making of their own identities 110

Some implications for Pacific ethnic groups in Aotearoa New Zealand 115

Implications of Cornell and Hartmann's approach for this study 116

$\begin{array}{ll}\text { Summary } & 119\end{array}$

CHAPTER 8: METHODOLOGY ISSUES AND RESEARCH

$\begin{array}{ll}\text { METHODS } & 120\end{array}$

Overview 120

$\begin{array}{ll}\text { Introduction } & 120\end{array}$

$\begin{array}{ll}\text { Theoretical and methodological perspectives } & 121\end{array}$

$\begin{array}{ll}\text { Interviewing and the semi-structured interview } & 124\end{array}$

Narratives, biographies, life stories and personal accounts 126

Reflexivity and relationships between the researcher and the participants 128

$\begin{array}{ll}\text { Qualitative data analysis } & 131\end{array}$

Ethical considerations and confidentiality 133

Research Methods used in this study 136

The main research question $\quad 136$

The research approach 136

$\begin{array}{ll}\text { The interview process } & 139\end{array}$

The sample 140

Recruitment of the sample $\quad 141$

Ethical and cultural considerations 141

$\begin{array}{ll}\text { Summary } & 143\end{array}$

CHAPTER 9: DESCRIPTION OF SAMPLE $\quad 144$

Introduction 144

Description of the interview sample of Pacific women graduates 144

$\begin{array}{ll}\text { Summary } & 149\end{array}$ 
Analysis of the Narratives: Overview 150

CHAPTER 11: RESULTS III: FAMILY AND CHURCH

Family 160

$\begin{array}{ll}\text { Church } & 164\end{array}$

$\begin{array}{ll}\text { Summary of results } & 170\end{array}$

CHAPTER 12: RESULTS IV: TERTIARY EDUCATION 174

$\begin{array}{ll}\text { Introduction } & 174\end{array}$

Moving into tertiary education $\quad 175$

Initial experiences on entering the tertiary institution 177

Responses to the ethnicity of the women in the tertiary institutions 182

Responses to their treatment as Pacific ethnic group members 191

Summary of results: indicators of ethnic identity construction within tertiary settings 195

CHAPTER 13: SUMMARY OF FINDINGS 199

Introduction 199

The nature of the construction of ethnic identity 199

Family and church 202

Moving into tertiary education 204

Treatment within tertiary education 205

Narratives and theories $\quad 207$

CHAPTER 14: DISCUSSION AND CONCLUSION 210

Introduction 210

Implications for tertiary education institutions 226

Reflections on the narrative approach $\quad 227$

$\begin{array}{ll}\text { Suggestions for future research } & 228\end{array}$

Conclusion 230

$\begin{array}{ll}\text { EPILOGUE } & 232\end{array}$

$\begin{array}{ll}\text { REFERENCES } & 233\end{array}$

\section{TABLE}

Table 1: $\quad$ Participant Sample: Tertiary-educated Pacific women 148

\section{FIGURES}

Figure 1: Two Axes of Variation in Ethnic or Racial Identity A Constructionist Approach

Figure 2: Tentative Theoretical Framework: Ethnic identity construction of Pacific women in tertiary education settings 138

Figure 3: Revised Framework for ethnic identity construction: Pacific women graduates 


\section{APPENDICES}

Appendix A: Newspaper clipping: war hero rolls back the years

Appendix B: Participant Information Sheet

Appendix C: Some Facts about Yourself

Appendix D: Areas of questioning for face-to-face interviews

250

Appendix E: Interview Schedule

251 


\section{Consider yourself fortunate when all kinds of trials come your way ... Make sure that your endurance carries you all the way without failing ... Happy is the person who remains faithful under trials ...}

E au mau taeae ra, ia roohia outou e te ati e rave rahi te huru ra, a parau outou e, e mea oaoa ana e ïa.

Ua ite hoi outou e, na taua tamataraa i to outou faaroo ra e faatupu i te faaoromai tamau.

E tuu atu hoi i ta te faaoromai tamau ra ohipa ia tia roa, ia maitai roa outou eiaha ei hapa, eiaha ei mea toe.

Te ere ra râ te hoê o outou i te ite, e ani oia i te Atua ra, o tei horoa hua mai i te maitai i te taata atoa ra, ma te patoi ore; e e horoahia mai ta na.

E ao to te taata e faaoromai i te ati, ua tia-ana e-hia mai hoi oia ra, e roaa ïa ia na te korona ora, i ta te Fatu i parau mai e no te feia i hinaaro ia na ra.

Eiaha e vare, e au mau taeae here e.

Te mau mea maitatai i homai-hia mai, e te mau mea tia roa e maitai roa i, no nia ïa i te Metua o te mara-marama, aore roa e hirohirouri ia na ra, aore hoi e huru-ê-raa e vahi iti noa e.

Te Episetole a te Aposetolo ra a Iakobo 1: 2-5, 12, 16-17.

Te Faufaa Apî (The Letter of James, New Testament) 


\section{ACKNOWLEDGEMENTS}

I wish to acknowledge the organisations that have employed me during the eight years of my doctoral studies. My employers have been the New Zealand Council for Educational Research (NZCER), the Wellington College of Education (now Victoria University of Wellington), and the Ministry of Social Development. In particular I thank the Director of NZCER Robyn Baker and my manager Linda Mitchell for their forbearance and patience in the closing stages of my work. My three employers have generously supported me in a number of ways including assistance with tuition fees and by granting periods of study leave. These were valuable times when I could devote myself exclusively to my studies.

I wish to thank the Faculty of Humanities and Social Sciences of Victoria University of Wellington for two research grants in 2001 and 2002 that enabled me to complete fieldwork in Auckland, and that paid for the transcriptions of interview data. In particular, I want to thank Susan Kaiser and Michelle Paine for their many hours of transcription. My thanks also to Jane Dudley for arranging for the balance of the transcriptions to be completed. I want to thank Christine Williams and Suzanne Hay for helping me with the formatting of my thesis. My grateful thanks also to Dr Graham Langton and Annamaria Apáthy for their support and editorial advice.

My two supervisors, Dr Geraldine McDonald (Education) and Dr David Pearson (Sociology), have travelled this long road with me. I thank them both for their patience, care and attention, for their considerable combined scholarship, and for the depth of knowledge they have shared with me. Most of all, I thank them for the great discussions we had as the thesis took shape.

Although the names of the women who participated in this research are confidential, I want to thank them all, for without their stories, and the time they set aside for me to record them, this thesis would not have been possible.

There were many people who supported me throughout the thesis writing time, too many to name individually. However, I pay tribute to my friends and colleagues within PACIFICA Inc (Pacific Womens' Council). You are all wonderful, strong Pacific women and you inspired me to keep going. Thank you also to my Island Bay Presbyterian Church family, you have kept me in your prayers for so long. Mauruuru outou pa'atoa. 


\section{CHAPTER 1: INTRODUCTION AND OVERVIEW}

\section{Introduction}

As the wider society of New Zealand wrestles with what it means to be a New Zealander, so have Pacific peoples become more interested in how their identities in New Zealand are changing over time. As increasing numbers of Pacific peoples are born in this country questions arise about the implications for them as New Zealanders with a Pacific heritage. Geographical relocation and urbanisation processes, inter-generational changes, and opportunities for upward social mobility have all been influential factors. Increasing intermarriage between the different Pacific groups and with tangata whenua, in tandem with the social, economic and political changes in the past sixty years, have also shaped and reshaped the meanings of being Pacific peoples residing in Aotearoa New Zealand.

For all Pacific communities in this country education and the achievement of educational qualifications have been and continue to be a very high priority. To date most of the research that has been carried out about Pacific students in the New Zealand education system, and about Pacific education generally, has been aimed at finding "solutions” to "problems of under-achievement”. The overall picture of participation and achievement for Pacific students is still not positive across all levels of education and schooling, including tertiary and there is still some way to go to address present inequalities (Coxon et al., 2002; Ministry of Education, 2005).

Pasikale (2001, 1996) has described the particular characteristics of Pacific Island learners as placing a great deal of importance on the affective domain of learning and on respect for the authority of the teacher. In schools and tertiary institutions, she argues, Pacific students have to "behave out of their cultural context" (1996: 64). Further, Pacific students face the consequences of the negative assumptions and expectations made by many educators within the New Zealand tertiary education system. But to date, there has been little research in Aotearoa New Zealand from the point of view of those few Pacific students who have achieved academic success. Nor has any study examined closely what happens to Pacific students when they enter tertiary education and how their cultural backgrounds affect their experience in this setting. 
For over three decades, as a Pacific student, lecturer, and researcher I have had a personal and academic interest in Pacific education and in the achievement of Pacific students. Pacific women, in my experience, go into tertiary education with strongly held beliefs acquired through the processes of socialisation in a variety of institutions, in their own homelands, and in Aotearoa New Zealand; two examples being within the family and church. Since meanings and beliefs are important components of identity I was very interested to find out what happens when beliefs are challenged in tertiary education and what effect that would have on Pacific women and their identity. Hence, in this study, I interviewed 20 Pacific women graduates who were academic "successes" to find out about the ways in which their cultural identities were responded to when they went into tertiary education. Their narratives were the source of information that would assist me in describing the processes they were subjected to, and, how they in turn responded, when they participated in tertiary education. So I developed my research question:

\section{Is tertiary education a site for the construction of ethnic identity?}

Although this question appears to be a closed one, in order to answer it fully I anticipated that responses to more probing questions on this topic would be required. These questions concern what Pacific women take with them when they enter tertiary study; how did the institutions respond to them; what other settings might be associated with the formation of identity; and, lastly, what relationship therefore exists between the three settings of tertiary education, family and church.

This study focuses on the processes of identity construction and, after surveying the literature, I decided to use the constructionist approach to ethnic identity developed by Cornell and Hartmann (1998). Their model provides the framework for analysing the narratives of the women's experiences and for explaining the findings of this study. It also shaped my thinking about how to conceptualise the relationships between identity, experience, and the changing circumstances which Pacific migrants confront.

From the outset, it needs to be made clear that the term ethnic identity is used in a particular way in this study, and that it does not have the same meaning as cultural identity. People acquire a cultural identity as part of the socialization processes they experience from birth as a result of which they come to hold various beliefs, values and ideals that frame their social existence. Their beliefs 
and values are expressed in particular cultural behaviours and practices. In comparison to cultural identity, an ethnic identity is formed when people are in contact with population groups from different cultural backgrounds. While the identity of people from Pacific countries has been a subject for research, previous studies have tended to focus on the cultural aspect of identity rather than view its construction as a process involving more than one ethnic group.

Research in the field of Pacific identity has also largely been carried out from anthropological or psychological viewpoints. Sociological research to date has employed more structuralist approaches, focusing on the social positioning of Pacific peoples. Some studies have assumed that context plays a role in explanations of Pacific cultural identities but none have made context explicit in their theoretical approaches or in their analyses. Even more importantly, studies on cultural identity have been told mostly by “outsiders” or, conversely, from the point of view of the "insiders”, but not from both perspectives. Each perspective on its own does not tell the whole story about how ethnic identities are formed nor does it adequately explain the processes of formation within particular social settings.

In terms of Pacific identities, and their relationship to participation and achievement in tertiary education, Anae et al. (2002) researched the views of students, parents and communities, and tertiary education providers around issues of recruitment, participation and achievement levels. The study was commissioned by the Ministry of Education in their attempts to find ways to enhance Pacific academic success. Educational policies and initiatives in the area of Pacific education are based on the underlying assumption that cultural identity affects achievement for Pacific students. Studies such as Anae et al., and MacAlpine Petelo (2003) have recently cast more light on the experiences of Pacific students thereby providing suggestions to tertiary institutions and their responses to ethnic differences. This thesis is different from both these studies in that it explores social relations and processes within the tertiary education setting and analyses student narratives to find examples or illustrations of ethnic identity construction.

This thesis argues the existence of a relationship between family and church settings, and the tertiary setting where, it is argued, ethnic identity construction takes place. Such a relationship differs from one woman to another, but examples 
from the narratives illustrate the nature of the cultural identities each woman took with them into the tertiary setting. It is also argued that the social processes of ethnic identity construction take place for Pacific women because the tertiary setting is one where ethnic identity is salient to other groups of students and lecturers (in particular from dominant ethnic groups) who, for example, hold certain stereotypes about Pacific students. However, it is equally a setting where the women themselves have opportunities to assert their cultural identities. That is, through analysing the women's narratives the nature of these interactive processes for Pacific women in tertiary education in Aotearoa New Zealand can be examined so that the construction of ethnic identity for this grouping of students can be better understood.

\section{Overview of chapters}

Given my remarks about situating myself within the research milieu of this thesis, it is appropriate therefore that this thesis begins with my own narrative which includes the story of my father who came to New Zealand in 1948, from French Polynesia, with his English wife. Thus, in the chapter that follows, I relate my experiences within the educational institutions I attended and my story draws upon incidents and perspectives that I asked my twenty women research participants to share with me in our interviews. I conclude in Chapter 2 with some reflections on my father's identity and its influence on my experiences.

In Chapter 3 current statistics about Pacific peoples in Aotearoa are provided in order to place this study within the historical and geographical context of Pacific settlement in Aotearoa New Zealand since the 1950s. I include more recent government policy responses to the situation of Pacific peoples. The premise on which difference is based also plays a role in defining to some extent who does and who does not belong to this over-arching group, referred to using a range of terms including "Pacific” or "Pasifika”.

In Chapter 4 literature is reviewed pertaining to tertiary education as a social institution, the position of Pacific students within such institutions, and studies relating to the two settings important to Pacific peoples: the family and the church. Research specifically referring to Pacific peoples is featured in this chapter.

In Chapter 5 the terms race, ethnicity and ethnic identity are considered as key terms in this study and the specific meanings pertaining to them. Discussion of 
some research from overseas is followed by a summary of key local research about Pacific identities in Aotearoa New Zealand.

Given that the participants in this study were Pacific women, in Chapter 6 literature is examined that makes the connection between critical feminist perspectives on the social construction of gender and its relationship to associated approaches to ethnicity and identity. The perceived shortcomings of the feminist approach are noted where the issue is about processes of identity formation rather than social justice outcomes. Where possible I make reference to studies about and by Pacific women. I also include the work of Pacific women researchers who have begun to push the boundaries of what is defined as Pacific knowledge and Pacific research methodology in contrast to the prevailing Western approaches to research.

In Chapter 7 the work of Stephen Cornell and Douglas Hartmann (1998) is introduced. These authors have described a constructionist approach to ethnic identity which takes into account the historical and contextual factors relating to ethnic identity formation and the contributions and actions of ethnic group members themselves in defining their own ethnic identity. This is the first time that Cornell and Hartmann's work has been applied in the New Zealand context to the construction of the ethnic identities of Pacific women within selected social settings, notably tertiary education institutions. Their concepts and ideas have provided a vital foundation for my work. I have applied their ideas and concepts to Pacific cultural groups and the changing circumstances they find themselves in as migrant groups and in particular within one social institution, tertiary education.

Chapter 8 has two sections. The first is a review of literature highlighting particular methodological issues pertinent to this study. These include theoretical perspectives, semi-structured interview approaches, reflexivity and researcherparticipant relationships as well as confidentiality and ethical issues. In the second section, the methods used in this study, including the interview process and the recruitment of the sample, are outlined. The closely linked section that follows, Chapter 9, then provides key information about the Pacific women participants (as collected in a questionnaire). This group of women graduates is a select group in that the proportion of Pacific postgraduates across all tertiary institutions in Aotearoa New Zealand remains very small. 
Chapter 10 analyses the material from their narratives, drawing out examples about their own identities and how they think those identities have been constructed. In Chapter 11 the narratives are analysed in terms of two settings: the family and the church. In Chapter 12 the women talk about their treatment as Pacific women, in relation to their cultural backgrounds, within tertiary education and about how they responded to that treatment. I also examine what the women took with them in terms of their cultural identity into their tertiary institutions as I bring together the ideas and concepts that characterise a constructionist approach to describing ethnic identity and its formation.

In Chapter 13 all the analyses of the narratives highlighting key findings and the main themes emerging from the data are summarised.

Finally, in Chapter 14, I bring together all the analyses of the previous chapters and answer the research questions in some detail. This includes discussing the revision of a diagram I presented to the participants that represented my initial views of the relationship between tertiary education, family and church settings, and showing, in diagrammatic form, how the findings in my research altered the way I had initially framed my research. I reflect on the usefulness of the narrative approach taken in this study, which is outlined previously in Chapter 8, since there is some debate about the use of the narrative approach in researching group identity. I end the chapter by suggesting areas of future research that would follow on from this study, making concluding remarks about what I have learned as a result of my study. 


\section{CHAPTER 2: MY OWN NARRATIVE}

\section{My family background}

I was born in Auckland New Zealand as a first generation New Zealander of a Tahitian father and an English mother. My parents met and married in England during World War II. Dad was a wireless operator and air gunner, and flew in Lancaster bombers with the Free French Air Force in the Lorraine Squadron. He was highly decorated for his war exploits by the French government, receiving the Medaille Militaire, Croix de Guerre with three palms, Medaille de Résistance, and Légion d’Honneur (Robie, 1982:3: Appendix A).

My father was born on the small island of Rurutu in the Austral Islands, $600 \mathrm{~km}$ southwest of Tahiti, in French Polynesia. He enlisted in the Free French airforce at the age of 19. Dad and Mum had a wonderful social life in England (as young people did during the war). I think they were both excellent ballroom dancers and I remember Dad saying how he and Mum had danced to Victor Sylvester at the Albert Hall. My mother, I understand, was well-educated and was working in the Foreign Office in London as a clerk when the war broke out. My mother and father communicated in French at the beginning of their relationship and Dad often told very amusing stories of his first faltering attempts at speaking English.

At the end of the war, my mother and father married in London in a little French church in Soho Square and then emigrated to Rurutu, upsetting my English grandparents both by marrying and by leaving England. When my mother was pregnant with my older brother she became ill so my parents left Rurutu and Tahiti and came on to New Zealand where my brother was born in 1948 and where they ended up settling. My mother being a British subject meant they could both stay here, even though Dad was classified as an "alien” because he was a French citizen. I was born in 1951. My parents talked about having difficulty getting accommodation because of Dad's race. When my mother went to find housing for the two of them, she had no problems. Initially Dad worked at KM Manufacturing in Parnell, Auckland, making hats, and then he got a job on the wharf as a cargo worker. Up to, and including their arrival in New Zealand my parents had both lived in a range of social and cultural contexts.

My mother died of leukemia when I was seven and a few years later my father remarried. His second wife was a New Zealand Päkehä. My family now 
comprises my older brother and three younger siblings, (2 sisters and 1 brother), 7 nieces and 1 nephew, 3 great nieces, and 3 great nephews. Our extended family now includes Tahitian, Chinese-Tahitian, Päkehä New Zealand, New Zealand Mäori, Niuean and Cook Island heritages and, most recently, Indian (from Dubai).

\section{What does it mean to be Tahitian?}

I asked all my interviewees to talk about what it meant for them to be Samoan, Cook Island, Tongan, Niuean, and of mixed heritage where that applied. It is therefore important for me to describe my meanings in regards to my cultural identity as Tahitian. At a surface level I think it means being someone who is born in Tahiti, or considers Tahiti "home”, or has an ancestral connection. It means being able to speak the Maohi language (and dialects) and the French language, and being someone who lives according to values and beliefs that are attributed to, or characteristic of, being Tahitian. These values are primarily in terms of family (feti'i), including a large network of extended family, and secondly in terms of Christian values, beliefs and practices. My cultural identity was constructed within my own family and in line with the sets of values that we lived by in Aotearoa New Zealand, mainly prescribed by my father's languages and his involvement with the small Tahitian and other Pacific communities, mainly the Cook Islands community.

Spirituality is expressed as going to church regularly, having a knowledge of the Bible, and an active prayer life. There is a further spiritual dimension to being Tahitian that I appreciated more fully when I went "back home” to my father's island in 1987 and then again in 1990. We went to church there and found that on every day of the week, community life in my Dad's village of Avera centred around church activities. Spirituality also has a pre-Christian aspect and includes beliefs and legends pertaining to geography and land forms; the sea itself and our ancestors' travels across its vast expanse; the stars and how they help us to navigate and locate ourselves; and an individual's dreams and visions (conscious and unconscious), which are often a topic of conversation and social interaction amongst Tahitian people. I locate myself at some points within these definitions while being clear that I have lived most of my life in another social and cultural context, that is far removed in distance, time, and generation. For example, above the village of Avera is a mountain called Manu Reva and there are also caves on 
the island in which spirits live. These features are part of the geography of my heritage. They are in my consciousness when I think of "home”.

I experienced my Tahitian cultural identity through my father, how he lived, how he ensured we lived as a family in an alien culture, and also through the various ways in which he created and capitalised on opportunities to retain his language and his culture. In other words, my identity is what I learned within our own family and within the various institutions and social and cultural contexts in Aotearoa New Zealand. However, from the time of their arrival in this country, my parents lived as working class people. I was not fully conscious of our social class positioning or our ethnic or social status until I became a tertiary student.

In the 1960s my Dad set up the Tahiti Nui Club, which attracted some local Tahitian people (and others) in Auckland to get together for socials and dances, including celebrating Bastille Day (14 July) each year. To coincide with these celebrations my father started up an Island music band (he was a skilled guitarist, drummer and ukulele player) of mainly Rarotongan people but also including Tahitian musicians. He made some recordings with Viking Records (Dad knew Bill Sevesi, a local Samoan musician and members of his band very well in the 50s and 60s). In addition to the band (Nat Mara and his Tahitians), Dad formed a Tahitian hula dance troupe. I was a member and performed in my first show at the Auckland Town Hall when I was seven years of age. Later, we did shows around Auckland night spots and at lots of socials and dances. We did "tours" to Hamilton, Gisborne, Te Kuiti, and even to Australia in 1971.

The practising and performing of our songs and dances became a big part of my teenage life. That was the only time I was allowed out of the home at night, because Dad was there to look after me. In this way, Dad held on to his culture and language over the years. As his New Zealand-born children we experienced that part of his culture. He worked to create a context where he could live out what he had learned in his own family/feti'i context in Avera, despite the fact that, at that time, there were not many Tahitian people in New Zealand.

We had some infrequent association with the Pacific Islanders' Congregational Church in Newton in Auckland and the wider Pacific communities because I remember being christened there when I was about 5 years old (my brother was 8 years old) by the founding minister, Reverend Challis. When visitors came from Tahiti we occasionally took them to the Newton church (it had become the Pacific 
Islanders Presbyterian Church) as there was a Tahitian lay preacher/deacon there called Va'a. We also attended the Te Atatu South Congregational Church from time to time. So the church was a part of my childhood, even though I abandoned it when I was a young adult. These experiences laid a foundation for my later reinvolvement in the Presbyterian Church and the rediscovery of my Christian faith as a mature adult.

Later, when I was in high school (mid to late 60s), Dad left his job as a waterside worker and started working full-time on something he had done informally over the years, as a translator for people who came from Tahiti for medical treatment. He was busy, day and night with his clients. Our house always seemed like a railway station, with people coming and going and always the French and Tahitian languages spoken, but I never learned to speak Tahitian although I could understand it. When I got to high school I studied French, which meant I could practise it with my relatives who came and went on a regular basis, mixing French and Tahitian together. I visited Tahiti for the first time when I was 14 years old.

Going to Tahiti was a very strange experience. In part it felt like a homecoming, but in other ways I felt as though I did not belong there. I was able to dance the hula very well and my relatives liked that, and thought I danced like a "real" Tahitian. Some of the older relatives were upset because I could not speak Tahitian. It felt wonderful at first to be with my Dad's brothers and sisters because the family likenesses were uncanny and to be in a room full of people just like Dad was an amazing experience. I felt a similar experience when, many years later, I went back to the island of Rurutu where Dad grew up (unfortunately it was for the unveiling of his gravestone), to stay in my grandparents' house and to explore his island. I felt very close to him there. I was able to imagine him in his life in the wider society in New Zealand, in England, France and Canada during World War II, and the memories he must have carried around with him for many years before he returned. My father regularly visited his Tahitian family in the last decade or so of his life (both in Tahiti and Rurutu). In fact, he and my stepmother were preparing to retire back in Rurutu when he died.

I relate my story to show how my life has been quite different from those of other European/pop'aa children growing up in New Zealand in the 1950s and 60s. A series of incidents beginning with going back "home" and my experiences at school and university shaped my first realisations of my ethnic identity. For 
example, one of the very first times I felt different was when students in my class at intermediate school (11- and 12-year-olds) were talking about what they ate for Sunday lunch. They talked about roast potatoes and the like, and I said, "Well we eat fish heads. In fact my Dad sucks on the fish eyes and spits them out.” My friends were disgusted, so I kept quiet after that. My family life was obviously very different in some ways from mainstream New Zealand, and it was incidents such as this that brought the differences into sharp relief.

At my West Auckland secondary school I was one of very few "brown" girls and I don't remember being treated differently because of that. I was not very dark skinned and my features are not distinctively Polynesian. Physical appearance can be a positive or a negative factor, depending on the context. I was often treated differently according to the different assumptions people had about me and about my background. My French teacher really liked me because I was good at the subject and she knew I was part-Tahitian. I did well at school academically, just above average in most subjects, although I was streamed into the top forms of 3 Latin, 4 Latin, 5A, and so on at secondary school.

\section{Why did I go to university?}

When I was at secondary school Dad was contacted by a young New Zealander who was studying French at Auckland University and was interested in how it was spoken in French Polynesia. He came to see Dad to get contacts in Tahiti for his fieldwork. From that time on he and his New Caledonian wife became family friends. I mention this because he was the first person I had ever met who attended university. So I guess that was my first impetus to work hard and get to university.

I had thought even then about being a teacher and going to Training College from school. I applied to get into the new North Shore Teacher's College, got accepted, but then decided to go to university first to do a degree, with a view to training afterwards. I went straight on to university with a few classmates from school, because in 1968 we all thought that it was the logical next step after high school, and university fees were minimal. Consequently, in the first year at Auckland University I did not feel lonely or different and although we all took different courses we met up at lunchtimes. It was all so exciting then: the freedom, sitting in the cafe all day putting the world to rights (before internal assessment at university changed all that), protests about the Vietnam War (including a visit to 
New Zealand by Lyndon B. Johnson, when our student body held big protests outside the Intercontinental Hotel). Not that I joined any of the radical groups myself, but there was an energy there that swept you along, especially when there were regular political events and rallies in the university quad including the memorable visit of Germaine Greer.

\section{How did I cope with my tertiary studies?}

I did well in my first year (1969) taking education, psychology, French and introduction to the Mäori language, and passed everything. Then in my second year I failed my papers in psychology and Mäori. I could not understand all the journal articles we had to read and the jargon associated with operant conditioning. No one had showed me how to use the abstracts, summarise, find key points or keywords, or any other study strategies. In those days you lost your fees bursary if you didn't pass, so in my third year of study, I had to work parttime in a home cookery from 8 am to $1 \mathrm{pm}$ and then go to lectures from $2 \mathrm{pm}$ to 6 pm every day. I took Mäori language again (my oral language was fine but my written translations were not so good) and I repeated psychology, except that I took the new optional course in social psychology and easily passed. I took sociology in my third year, but even then I still did not feel very confident about speaking up in tutorials in case I had totally missed the point.

When I was studying psychology I was very relieved when I met a young Samoan woman. We "found" each other one day in lectures. We were the only brown faces I remember. It was great, because we studied together and shared a few things about our respective families. In particular, we both found that the biggest fear our fathers had for us was that we would end up "on the streets". "No girl of mine will end up on the streets!” There were no Mäori or Pacific lecturers in any of our courses at that time, except for a vibrant young Mäori tutor called Donna Awatere, who took some of our lectures in social psychology.

I really enjoyed taking Mäori language (Te Reo Mäori) because its sounds are very close to the Tahitian language (Maohi). Through studying Mäori, alongside Mäori students, I started to become more aware of Mäori issues (indigenous grievances) both at Auckland University and in the wider society. My entry into tertiary education had caused me to reflect on my own cultural identity. I felt an affinity with the Mäori lecturers who seemed to be much happier on the whole about their subject, their teaching and, more interested on the whole, in their 
students. Although I enjoyed university there were times when I felt a bit overwhelmed. Finding rooms and student services was a bit difficult. The place seemed large and the campus spread over many buildings (although it is much larger now). I did not make great use of student union facilities and in my third year I was so busy studying part-time and working that I just went in and out of university and the library.

However, I loved my university courses in education and psychology. I felt challenged, I liked the freedom, I loved being exposed to new ideas, and I just gobbled up all the new knowledge. Reading and academic study was not a part of my parents' lives, but my Dad always had very high expectations of me and I wanted to make him proud of me. I did not like to see how some people treated him as an entertainer (not quite an equal) and yet he taught me much about putting other people first, and he was very proud of being Tahitian. Although he was on the fringes of the Pacific Islands church (we did not attend very much), most of the people in the church whom I met in the Pacific community knew of my Dad through his music and his community work. It was mainly during my initial tertiary study that I became more and more conscious of the differences between the world of my family and the wider society.

\section{My participation in other Pacific communities and the wider society}

In 1976 a new group bringing together Pacific Islands women living in New Zealand, started up in central Auckland. I saw an advertisement in the local newspaper about a meeting at the YWCA in Queen Street. It was called by the part-Samoan Auckland City Councillor, Paddy Walker, who had been involved with the committee for the United Nations International Women's Year. From that meeting was formed P.A.C.I.F.I.C.A. (Pacific Women's Council) Incorporated which became a national non-governmental organisation of Pacific women. ${ }^{1}$ When I mentioned to the women at the first meeting who my father was, they welcomed me with open arms, many knew him or knew of him, not only through his music and the dance group but also through his community work with Tahitian people. I had begun to engage in a social context in which being a Pacific woman

1 The name stands for Pacific Women's (Allied) Council Inspiring Faith In Ideals Concerning All. The organisation is still active today with members from at least seven of the main Pacific ethnic groups. In February 2005 I was elected National President after serving at many levels in the organisation including National Secretary. The growth of the organisation is described in FairbairnDunlop \& Makisi (2003, pp 29-32). 
and networking with them became important to me as a way of defining myself as a Pacific woman, born in New Zealand.

In 1977 when the organisation became an incorporated society, I was soon linking with Pacific women all over the country and, at a national level with other women’s organisations such as the Mäori Women's Welfare League (MWWL) and the National Council of Women (NCW). PACIFICA, at that time, got involved with issues such as the reform of the Contraception, Sterilisation \& Abortion Act. We held a very controversial seminar in Auckland for Pacific women led by a Samoan nurse from Family Planning. In the 70's these were topics that divided both Pacific and non-Pacific women. Within Pacific communities the issues were overlaid by conservative male dominated Christian dogma about the role of women, sexuality and the issue of abortion.

On reflection, joining the organisation of PACIFICA meant that I engaged with other Pacific women in ways similar to those I had learned within my family. I felt comfortable in terms of understanding the perspectives and viewpoints of the women I met there. In addition, we found fellowship in the migrant women's experiences and in our shared experiences of the treatment we received from the wider society, including stereotyping. It was the first grouping together of Pacific women outside the churches and one that spanned all of the main Pacific ethnic groups. The historical context of the United Nations International Women's Year and the national women's conventions was definitely a background and impetus to our formation, and it took an individual Pacific woman with a vision to bring us together. Even with the changes in political, economic and social contexts in the last twenty years for Pacific peoples in Aotearoa New Zealand, PACIFICA has survived. However, it now needs to re-shape itself as an organisation, and in its purposes and projected outcomes, so that it can respond to new generations of Pacific women and to accelerating changes in Pacific ethnic identities in this country.

\section{Further tertiary study and education policy reforms}

After my undergraduate degree my subsequent academic studies were taken in 1982, 1987-88, 1993-95 and 1998 to the present. In the 1980s I took Diploma of Teaching papers in teaching English as a second language. I then won a Department of Education scholarship to do the Diploma of Teaching English as a Second Language (Dip TESL) qualification at Victoria University of Wellington. 
I was on a full teacher's salary and the Department of Education paid for me to travel home to Auckland each term. This diploma qualification also involved me in migrant education and with the bilingual language needs of Pacific students and families.

I took Honours in Education in 1987 and 1988 at Victoria University of Wellington. I decided to do further study because my employer at the time, the Department of Education, paid study fees and I was given time off work to attend lectures. In my position in the Department I became involved again with indigenous issues and education policy and programmes as they affected Mäori and Pacific academic achievement, and Mäori and Pacific women in particular. In the late 1980s the far-reaching educational reform of the Tomorrows Schools initiative took place and I was seconded as an advisor into the Implementation Unit set up in the National Office of the Department of Education to effect those reforms.

While lecturing in Education at Auckland Teachers' College in 1993 I started a Masters degree at the University of Auckland. It was important in terms of my career because I was co-teaching a degree course with the university education faculty staff and it seemed there was a certain "looking down" on College staff because of our "lack" of academic qualifications. I found I could do a thesis-only degree, which suited my lecturing schedule and sole caregiving responsibilities for my 2 year-old son.

At that time I was also given the opportunity to write chapters for a sociology of education textbook for first year undergraduate courses. My research and academic interests in Pacific education in early childhood and in primary education were beginning to gain relevance and importance as more Pacific students were entering tertiary education. In addition, my Master's topic was about Pacific women in education. My main intention had been to profile the outstanding efforts of Pacific migrant women to establish early childhood language nests in which their own Pacific languages and cultures could be maintained. I wrote about the significant contribution of other Pacific women to a range of educational initiatives in Aotearoa New Zealand.

\section{The outcomes of a tertiary education and qualifications: reflections}

Since first entering a tertiary institution both as a student and a teacher, I have increasingly found opportunities to assert and make claims about the life and work 
of Pacific women in Aotearoa New Zealand, about the teaching and support of primary and tertiary Pacific students, and to do research into Pacific education and more latterly Pacific early childhood education. I have been able to advocate, promote and articulate different views and perspectives about teaching and learning and the role of Pacific metaphors, theories and methodologies in academic research.

The treatment I have received during my study and in the various positions I have held in relation to my cultural background and ethnicity I leave for the Pacific women in this study to describe. Suffice it to say that our experiences have been very similar in terms of contradictory responses, stereotyping and, possibly because of my physical appearance, not even thought of as a Pacific woman.

At a personal level, tertiary education has given me "another life" in my head. It has not only helped me in a material sense, but it has also provided me with a context in which to think about, reflect on, and analyse the social processes and structures that I am experiencing in the wider society. I now possess written skills to critique injustice or inequalities for Pacific women and their families, wherever I see them operating. My educational experiences have provided me with language, terminology, and discourses through which I can theorise about my social roles and responsibilities as a Pacific woman, and about my own ethnic identities.

\section{Conclusion}

My father, over his lifetime, lived in three geographical locations, and filled different occupational roles in those locations. The different aspects of his identity (such as maintaining three languages, Maohi, French and English) served different purposes in each of those countries and contexts.

As a handsome young airman in England he was no longer a man with a village background. There he had military status and was French-speaking. The social boundaries that had existed in other contexts were dissolved. Dad met and married someone outside his own racial and ethnic group. When my parents travelled back to Tahiti after the war my father returned as a war hero and worked as a radio operator at the meteorological station. When my parents journeyed on and settled in New Zealand my father acquired another identity as a manual worker, but his ethnic origin counterbalanced to some extent his position in the class system when he became known as an entertainer, an interpreter and self-employed. 
His knowledge of New Zealand systems, his languages and identity of origin that he could draw upon, meant that my father was able to help Tahitian visitors to this country to access medical treatment, accommodation, and travel within New Zealand. This enabled him to become self-employed and to provide employment for other family members, including my brothers, my brother-in-law and currently, my nephew who has carried on the family business. My brothers and my nephew are also fluent in Tahitian and French, having lived and worked back in Tahiti for periods of time. My elder brother and nephew have both married Tahitian women.

My father's cultural identity was shaped within his large extended family in Rurutu, French Polynesia. The changes in his cultural and ethnic identity have been shaped as a result of living in the settings and circumstances he found himself, how he saw himself, and how others treated him. In many ways these changes to the meanings of his ethnic identity precluded him from "returning” to previous social positions in previous locations. This study has provided an opportunity for me to acknowledge and to appreciate how my father actively set about asserting membership of his cultural group, Tahitian: in his family life, his work life, and in his interests in music and performance. He had a clear desire to maintain and celebrate his cultural background in changing historical circumstances and a “foreign” culture. Consequently, I can better articulate the meanings of my own cultural and ethnic identities: that I am a first-generation Tahitian English New Zealander and a beneficiary of the legacy of my father's (and mother's) ethnic groups' values, beliefs and meanings.

I will comment in later discussions about the effects of intermarriage on ethnic identification. Being from a mixed heritage meant that theoretically I could have chosen to identify equally with either my mother's and or my father's ethnic background and culture. However, the historical circumstances that existed during my growing up including the discrimination against Pacific ethnic groups by the wider society in Aotearoa New Zealand, the social class positioning of my parents, and the ways in which my father strongly claimed an identity for our family (with the consent of my mother), have meant that my ethnic identity has been only marginally under my control. My story and that of my father illustrate how heritage (descent and lineage) and social circumstances interact to shape cultural and ethnic identity and that these processes are ongoing as long as there remain distinct ethnic groups to identify with. 


\section{CHAPTER 3: SITUATING PACIFIC GROUPS IN AOTEAROA NEW ZEALAND}

\section{Overview}

This chapter begins by providing some factual information about Pacific peoples in Aotearoa New Zealand. This is followed by a short description of aspects of public policies aimed at addressing the educational, economic and other social needs of Pacific peoples, identified in the statistics. A critical view is taken of the work of central policy agencies. The chapter concludes with a short literature review of the work of New Zealand researchers from sociology and other related disciplines that already shed some light on the area of the construction of Pacific ethnic identities in New Zealand.

\section{The current status of Pacific peoples in Aotearoa New Zealand}

Peoples from the countries of the central and southeast Pacific have been migrating to Aotearoa New Zealand for over five decades. Since 1945 when Pacific peoples formed approximately 0.1 percent of the total population immigration and settlement has increased to the extent that in 2001 Pacific peoples formed 6.5\% of the population (Ministry of Pacific Island Affairs, 2005).

Of the total Pacific populations that reside in New Zealand (231,798), Samoans are the most numerous at 49 percent. Cook Island Mäori 22.6 percent, Tongan people 17.5 percent, Niuean 8.6 percent, Fijian approximately 3 percent, Tokelauan approximately 2.6 percent, and Tuvalu people approximately 0.8 percent of the total Pacific population.

The reasons for the migration of Pacific peoples from their small crowded island states to New Zealand included looking for better employment and educational opportunities, and better health and social services. Countries such as the Cook Islands, Niue and the Tokelau Islands are New Zealand administered territories or countries with free association which means there has been no legal restriction on migration from these three countries. Migration also provided opportunities for Pacific peoples to support their families and villages back home in the island states; remittances became a significant proportion of income to those countries.

Consequently, Pacific peoples have always lived in urban locations such as Auckland, the largest city in New Zealand, as these have provided the majority of employment opportunities. Indeed, in the 1970s most manufacturing and service 
industries in South Auckland relied almost exclusively on Pacific migrant labour (Challis, 1970; Mara et al., 1994) ${ }^{2}$. Two thirds (66 percent) of all Pacific peoples reside in the Auckland urban areas, while 30 percent reside in the remainder of the North Island and 7 percent in the less populated South Island of New Zealand. In addition, the profile of Pacific peoples is one of youth; the median age was only 21 years of age in 2001. Thirty-nine percent of all Pacific peoples in 2001 were under the age of 15 years.

In the 2001 census, 58 percent (more than half) of Pacific peoples who identified as members of Pacific ethnic groups were recorded as being born in Aotearoa New Zealand. Fewer Pacific people are born in the "homeland" countries and it is predicted that this proportion of New Zealand-borns will show an increase in the 2006 census. Another factor is that Pacific peoples have a higher fertility rate (3.2 per woman, compared to 2.0 per woman for the total population). The population profile for New Zealand-borns (as they are called) is also much younger. Almost a quarter of New Zealand-borns (that is, over 30,000) are under the age of five.

In 2001 in their Briefing to the Incoming Minister of Pacific Island Affairs, the Ministry of Pacific Island Affairs (MPIA; http:// www. minpac. govt.nz/ publications/ reports/ bim02) reported on the educational, housing, occupational, health, justice, immigration, and economic development status of Pacific peoples. In education, for example, the Ministry outlined ongoing issues and challenges including: low participation rates in early childhood and other sectors of education; academic underachievement at all levels; Pacific students gaining fewer formal qualifications than the total population; and under-representation in the teaching profession and at decision-making levels in educational institutions.

The MPIA report stated that in terms of labour force participation and employment rates the total for Pacific peoples in employment fell from 70 to 59 percent between 1987 and 1996 as a result of widespread economic restructuring and the decline of the manufacturing sector. Since then there has been some recovery, alongside improvements for the total population on these indicators, but Pacific peoples still occupy the lowest levels of labour force participation and employment. In fact, the annual personal income levels of Pacific peoples have still not regained the levels reached in 1986. In 2001 the median annual income of

2 See Krishnan, Schoeffel \& Warren (1994) for a profile of Pacific communities between 1986 and 1993. 
Pacific people 15 years and over was $\$ 14,600$, compared to $\$ 17,200$ in 1986 . In 2001, 61 percent of Pacific people earned less than \$20,000 per annum (compared to 53 percent of the total population). These figures reveal Pacific peoples in New Zealand have been affected by economic restructuring, reduction to social welfare benefits, and changing employment opportunities over this period.

The Ministry also signalled in its briefing papers the association of low socioeconomic status with poor health outcomes. Moves to develop Pacific service provisions and community health preventive programmes are being implemented. Immunisation campaigns to stop the advance of meningitis, for example, have been funded by central government. Other diseases associated with poverty and obesity are also the focus of health initiatives in areas such as South Auckland where most Pacific populations reside.

\section{Policy responses to the social position of Pacific peoples}

The policies of state agencies provide an important framework within which ethnic groups operate. The MPIA was set up in 1990 to provide policy advice to central government on issues affecting Pacific peoples in New Zealand. However, when it was first established it was a small unit with only 2 or 3 staff, and quickly became diverted into service delivery in addition to carrying out its policy development role. Consequently, the Ministry’s impact on government policy at that time was minimal. It was not until 1999 that MPIA was able to make a more effective and robust contribution to fiscal and social policy development through becoming a recognised advocate and consultative Ministry.

Since then the aim of the Ministry has been to alert all other ministries and government departments to the positioning of Pacific peoples in New Zealand society, and to encourage appropriate responses in all policy development to the needs of Pacific peoples. With increased staffing levels MPIA was able to develop a Pacific policy framework that was taken to all ministries and delivered through training seminars for policy analysts (Lealea, 1998).

Fuimaono Les McCarthy (2001), the Chief Executive of the Ministry, described MPIA's development of the Pacific Vision Strategy as having three phases: first, the publication of status reports on Pacific peoples in New Zealand; second, the holding of a national Pacific Vision Conference in 1999; and third, was the presentation of the Pacific Directions Report to the Closing the Gaps Cabinet Committee (CGCC) in February 2000. As a consequence of these first phases 
MPIA developed the Pacific Directions (Policy) Framework. Five themes emerged to guide strategic policy development: society, identity, leadership, prosperity, and partnership. For the theme of identity the overarching statement was:

We Pacific peoples take pride in our spiritual wellbeing and unique cultural identities. We want to contribute to a continual development of a national identity in a manner that acknowledges, reflects and enhances Pacific values and contributions to New Zealand society (2001: 285).

As a consequence of this major policy development MPIA has been given expanded roles (and staffing) in relation to initiatives such as working with chief executives across the Public Service to meet the new obligations to Pacific peoples. These obligations are now spelt out in chief executives' performance agreements. MPIA is now also responsible for the provision of advice to Treasury on Budget bids, and through the Pacific Communities Capacity Building Programme it works to enhance community engagement and involvement in developing plans of action in Pacific communities. Currently this mechanism is under review in terms of effectiveness in accessing Pacific communities' views on issues and on how these have been used to inform policy development. As McCarthy (2001) states:

Social and economic prosperity for Pacific peoples in New Zealand was the shared vision which emanated from the Pacific Vision Conference, and a unique attempt by Pacific peoples to articulate a way forward ...The Pacific Vision Strategy as a whole has afforded the Ministry a timely opportunity to prove its policy advisory capability, and has laid the foundations for the Ministry to play a significant role in advancing the present government's commitment to closing the social and economic gaps for pacific peoples in New Zealand. The Ministry welcomes the challenge and shares Pacific peoples’ optimism for their future (2001: 290-291).

Consistent with MPIA's vision of social and economic prosperity for Pacific peoples, and its mission to be a leader in public policy advice to improve outcomes for Pacific peoples in New Zealand, the Ministry has, in a political sense, become an important "broker" of Pacific ethnic identities. It has done this over the last four years through enhancing the profile and the promoting the diversity of Pacific peoples, as they represented in public policy development frameworks. A range of ministries and other government agencies received training by MPIA in the use of a Pacific Policy Analysis framework. In addition, by accessing government funding of targeted social programmes and funding and 
resources for Pacific projects and providers of services to Pacific communities, MPIA contributes to the strengthening of Pacific identities since being members of such communities, enables groups and individuals to apply and qualify for access to these resources. ${ }^{3}$ The ongoing existence and development of MPIA remains subject to political decision making and political agendas, over which Pacific ethnic groups have little or no influence.

In 2000 I wrote a discussion paper that critiqued the "Closing the Gaps" policy ${ }^{4}$ being pursued by the Government and operationalised by MPIA and the Ministry of Education in relation to Pacific Islands educational achievement. I raised some questions about the definitions and measurement of underachievement and educational "success", some of the drawbacks of referring to a "gap" between successes and failures when we already know the positions that groups in society occupy, and the reasons for this social stratification. In fact, I argued, in statistical terms the "gaps" for Pacific peoples in New Zealand appear to be growing rather than decreasing.

I argued for increased dialogue between policy makers, educators and Pacific communities so that the problems and deficits are redefined by making less use of marginalised knowledge paradigms and definitions of academic success. We need to make collective use of, and better represent, the complexity and diversity of the contexts within which we, as Pacific peoples, live. More importantly, educational "success" and "quality” need to be redefined in a range of ways so that policies and interventions build on cultural and ethnic strengths, rather than making Pacific indicators and benchmarks fit into dominant discourses that are ethnically exclusive (Mara, 2000a).

In the wider social and political arena, the presence of three Pacific (Samoan) members of Parliament in the last decade (including one Samoan woman member,

3 The question arises as to whether such ring-fencing of funding acts to perpetuate the marginalisation of Pacific peoples, particularly if they are prevented from applying for or accessing "mainstream" funding, as is the case for discretionary funding for Pacific early childhood centre buildings.

4 The “Closing the Gaps” policy was the Labour Government's response to inequalities and resulted in targeted funding to those groups not achieving educationally, or those not accessing services to which they were entitled. The policy came under fire from both intended "recipients" and opposition (more conservative) parties for simultaneously creating dependency and marginalisation. In the end the Government has had to withdraw its support and promotion of the policy. Further, in 2005 a review of "race-based" targeted funding by the Labour Government resulted in some of these programmes (including Pacific projects) being axed or diminished to appease such opposition. 
Luamanuvao Winnie Laban) is creating some political space for Pacific issues and concerns to be championed at the highest levels. Realistically, however, the improved social positioning of largely urbanised, young, poor, less well-educated groups of Pacific peoples, with only limited economic and political power and political participation, seems very unlikely to be increased or extended in the short or medium term.

\section{Pacific identities in Aotearoa New Zealand: a range of definitions and perspectives}

An over-riding question I need to answer in order to describe ethnicity and, in particular, Pacific ethnic identities in Aotearoa, is: on what basis do I determine who is positioned within this category and who is positioned outside it? Further, does it mean that we must make explicit the parameters or borders of this category, the processes by which people are counted in or out (by others), and the processes by which individuals count themselves inside or outside the overarching category of Pacific peoples. The whole issue of categorisation, naming and assertion, and their significance in ethnic identity construction, is discussed later in the thesis.

\section{Naming}

The terms that are used to describe an ethnic group are important in delineating and defining membership of that group. In terms of common usage, the overarching terminology of Pacific ethnic groups has changed historically from the 1950s when the term "Polynesians" (sometimes grouped with New Zealand Mäori, sometimes separate) was used. Then the category became Pacific Islanders (with no differentiation for specific groups) which was followed in the 1970s and 1980s by an increase in the naming of separate ethnic groupings: Samoan, Tongan, Cook Islands, Niuean, Tokelauan, Fijian, and so on. Within Pacific ethnic groups individuals have always been clear about their specific origins in terms of their village, extended family connections, their atoll or volcanic island within a larger grouping of islands and so on. These characteristics have been employed since the first migrations to differentiate people and their heritages and also to maintain links within the Pacific ethnic groups and "back home”.

Those outside the boundaries of Pacific cultural groupings (such as members of the European majority) are much less likely to be aware of the differences between each of the Pacific ethnic groups, let alone intra-group differences. As 
mentioned previously, the Ministry of Pacific Island Affairs has been proactive since 1999, in terms of its Pacific Vision Strategy, in informing all government agencies about some of the key ethnic differences within and between Pacific communities. In political and policy discourses it is now more evident that the names and characteristics of the separate ethnic groups are recognised. It is more widely known, for example, that Samoans form the largest Pacific ethnic grouping, and that there are some differences in values and practices between those born in New Zealand and those born in their Pacific country of origin. I am not sure, however, whether palagi (European people) could, if pressed, tell you exactly what the differences are beyond that.

Currently the most widely used term is "Pacific peoples" as the medial word "Islands" has been dropped, even though the Ministry of Pacific Island Affairs itself retains this word in its title. The terms "Pacific communities", "Pasifika" and just "Pacific", as referred to previously, are used in such contexts as the titles of Pacific provider services and alongside the use of ethnic specific names or titles. For example, Pasifika is now the main term used in all Ministry of Education documents to refer to Pacific peoples. Social service providers I have liaised with in the past year or so include: Folau Alofa Charitable Trust, Tanumafili Trust, and Pacificare Trust. ${ }^{5}$. Such titles are used by agencies, clients and individuals from the dominant ethnic groups in the course of (for example) approving funding applications, developing policy documents, and during the consultation processes that are now required for accountability purposes by most government agencies and contracts. The use of these multiple terms in the public domain plays a role in the formation and maintenance of the boundaries between Pacific ethnic groups and other ethnic groups in the wider society. Fleras and Spoonley (1999) use yet another term, “Tangata Pasifika”, in order to delineate Pacific ethnic groups from the indigenous Mäori or tangata whenua.

In the domain of academic research and literature, use is still made of the generalised term "Pacific" or "Pacific Nations” as well as ethnic specific group names such as Tongan, Samoan, Niuean, Tokelau, Fiji, Cook Islands (the six largest Pacific ethnic groups). When a research study such as this one is about

5 The first Trust works with Tongan communities, the second delivers services to Samoan communities and the third delivers medical services at reduced cost to all Pacific groups in their community. 
Pacific peoples, the correct ethnic groups represented should be named, together with their relative numbers. The members of these different groups expect acknowledgement to be made of their own unique languages, cultural values and practices, their own colonial history and relationships with New Zealand, their social structures, and their own immigration history. Studies should also now indicate place of birth (either New Zealand-born or island-born).

An important aspect of the cultural maintenance of Pacific ethnic groups is language and the use of Pacific languages in Aotearoa New Zealand. Limited research has been done in this area but some information has emerged in recent years. Taumoefolau, Starks, Bell and Davis (2004) in their survey of 120 Pacific people in Manukau City, Auckland, found that the older respondents reported that their first language was their Pacific language. Equally, however, speakers across all age groups showed a trend towards the use of English. They predicted that without "comprehensible input”, where the Pacific languages are spoken both in the home and in the community, a significant shift to English is bound to occur. Statistics New Zealand (2001) linked language retention rates with religious affiliation. They found that Pacific people who specified a religion were more likely to speak their language than those with no (reported) religion. Samoan ethnic groups showed the highest proportion, with 69 percent speaking Samoan, while Cook Islands was the lowest at 21 percent. Cook Islands Mäori were also the lowest in retention rates for those reporting no religion compared to the Samoans who were most likely to speak Samoan (16 percent) even though they reported no religion. The range and order of speaking their language was Samoan (69 percent); Tongan (61 percent); Tokelauan (45 percent); Niuean and Fijian (31 percent each), and Cook Islands Mäori (21 percent).

However, having made all these statements about categories (which are largely imposed upon Pacific ethnic groups by others outside them), the other crucial part of the equation is how Pacific groups and individuals identify themselves. Selfidentification (as recorded when using narrative methodology, for example) reveals that Pacific peoples identify in multiple ways, depending on the context and the level of specificity required in the situation. Self-report and self-assertion have been the most useful ways, to date, of establishing within-group categorisation in Pacific ethnic groups. Self report also parallels the social and cultural changes from intermarriage and changing economic and social 
positioning that are currently occurring in Pacific communities in New Zealand, and as subsequent generations are born in New Zealand.

Bedford and Didham (2001) discuss Pacific ethnic identification and the New Zealand Census and the drawbacks of self-report when looking at intergenerational differences. Since people are often able to include or omit descent links (for a range of reasons), responses can consequently influence Pacific groups' census statistics both upwards and downwards. In cases of selfreport of mixed ethnicity, it would be interesting to know the relative weighting that is given to each ethnic identification in the New Zealand Census statistics.

Macpherson (2001) writes about how identities, lifestyles and world-views of New Zealand-born generations of Pacific immigrants have been constructed in different social and economic circumstances, and as a result:

General agreement on the nature of identity is now more difficult to obtain: in place of a Samoan or a Tongan identity, one finds various Samoan and Tongan identities. These in turn are nested within an emerging Pacific identity which embodies certain common experiences of growing up as a person of Pacific descent in Aotearoa and which reflects the dynamic reality of being a Pacific person in a complex society (2001:67).

Further, Fleras and Spoonley (1999) suggest that:

\begin{abstract}
As with all cultures that have undergone colonisation and migration, the process of reestablishing an identity in a new land is fraught with difficulty. Major challenges to traditional cultural values and practices emerge, which means challenging those who embody such traditions. ... The very community that a younger member wants to support (and be supported by) is also the community that is being confronted, and the emotional commitment of those who wish to preserve traditions and of those who want to see them evolve provides an important point of tension. Equally, there is the question of how to identify yourself and explain that identity to Palagi, and those outside the community. Especially when many of the images of, and beliefs about, Tangata Pasifika tend to be negative ones (1999: 213).
\end{abstract}

There has been speculation about whether, even though the dominant groups in the wider society categorise all Pacific ethnic groups together as one group, members of each of the separate Pacific groups categorise themselves into one over-arching group. If so, this has potential for some political, economic and social influence. Macpherson (1996) looks at some of the reasons why a strong pan-Pacific identity has not been developed, at least not to the extent where a concerted, unified social and political agenda has emerged. The New Zealandborn and raised generations are growing up in a very different social context from 
that of their parents. They have been through key (and compulsory) institutions (such as the New Zealand education system) and have been categorised together as one grouping. Yet, while they might yet have some commonalities with peers from other Pacific Island ethnic groups, Macpherson asks how is it that they have not galvanised into a separate (pan-Pacific) community.

There are increasing opportunities for members of the New Zealand-born group to adopt and create a "Pacific" identity through music, literature, sport, film and drama, but this does not necessarily lead to a unified community with a common political agenda. Also, Pacific groups and individuals can now assert their rights as citizens in New Zealand. For people from some Pacific nations like Niue, Cook Islands and Tokelau, who are New Zealand citizens, there are now more nationals living in Aotearoa New Zealand than "back home”. Changing contextual factors such as changing family circumstances and societal processes and trends in New Zealand, together with a decline in speaking home languages, all affect the development and social construction of ethnic identity in Pacific groups resident in Aotearoa New Zealand.

\section{The blurring of Pacific ethnic boundaries}

The beginnings of the breakdown in Pacific ethnic boundaries can be seen in the slowly increasing upward mobility of Pacific individuals and the appearance of a small brown middle class, with high educational qualifications and entrepreneurial skills. The rate of intermarriage with members of other Pacific ethnic groups, Mäori and Palagi, and the setting up of networks external to the ethnic group are also contributing factors. This means that in the future fewer individuals, as members of a range of Pacific ethnic groups, will come to rely on the internal resources and values of their ancestral groups to construct and sustain their identities. In fact, Macpherson says, the "successes" in the wider society are held up as role models by Pacific communities. Such adulation encourages Pacific parents to attribute personal factors rather than structural obstacles as barriers to success, according to Utumapu (1992). Both these viewpoints may account for a degree of "opting out" by Pacific students of their cultural obligations and practices in order to achieve academic success.

Tze Ming Mok (2000) looks more closely at contemporary pan-Pacific identities in New Zealand by interviewing mostly New Zealand born Pacific professionals engaged in community projects or businesses in the greater Auckland area. The 14 
interviewees from 8 different Pacific community groups were selected because of their prominence in popular culture and projects such as: the Pasifika Festival, Style Pasifika, Urban Pasifika Records Collective, Tangata Pasifika Resources Development Trust, South Seas Health, Pasifika Healthcare, and Auckland University Pacific Islands Students Association (AUPISA). Several of these associations and projects involve socio-economic issues of status and participation in key social services. Individuals from these groups were asked about the ways in which they formulate and define a Pacific group.

Working under pan-ethnic Pacific terms appears to have most appeal for the generation of New Zealand-born Pacific people (Mok, 2000:18).

Most of the interviewees also claimed to be removed from traditional centres of Pacific communities' authority. Tze Ming Mok found that there is an autonomously generated discourse centring around constructing, projecting and representing an overarching, inclusive Pacific grouping. This grouping functions as a difference-based alliance. Through the groups' actions (such as cultural performance or social service provision) they construct and reconstruct a connection between group members that provides the possibility of social justice and future emancipation. According to Mok, a Pacific group concept may prove effective in shifting the discourses of difference, diversity and multiculturalism in New Zealand society, but it will only do so, she claims, when it resists the removal of a structural or systemic socio-economic critique from these discourses. In other words, the economic position of Pacific ethnic groups, Tze Ming Mok found, remains a descriptor of pan-Pacific identities in Aotearoa New Zealand and should not be ignored in our rush towards multiculturalism and cultural diversity.

In terms of the wider society and the potential for Pacific identity politics, Macpherson (1996) asserts that there is no unified external threat to Pacific ethnic groups in New Zealand that would operate to galvanise a pan-Pacific coalition. A degree of co-option of Pacific peoples has taken place with the establishment of the Ministry of Pacific Island Affairs and professional positions created within it, and across other government agencies. Devolution of funding and provision of services to Pacific providers has also provided an opening for the well-educated and more entrepreneurial individuals from Pacific communities to create employment and organisational spaces for themselves. Increasing participation of Pacific peoples on school boards of trustees, in local government and in Parliament means that spaces within social institutions are being created by and 
for Pacific peoples where different Pacific ethnic voices are beginning to be heard. Macpherson (1996) concludes that previous analyses of Pacific identity were based primarily on very general structural principles and were unable to take into account very important and less visible forces that divide groups. He thinks that there is room for more detailed work, not only on the structural level, but also at the levels of social construction and social processes that contribute to the formation of the range of Pacific ethnic identities present in the New Zealand context.

\title{
Maintaining Pacific ethnic boundaries
}

Pearson (1990) describes how Pacific peoples, along with other immigrant groups to New Zealand, have established associations and networks that assist them both to adapt to their new homeland and to maintain links with their countries of origin, its cultural practices, celebrations, and so on. Such associations and local networks add, according to Pearson:

\begin{abstract}
... yet another piece to the mosaic of ethnic politics. The dual referencing of 'home' and 'host' society identities is a familiar theme, and it is given added depth by the recency of Polynesian immigration to New Zealand and the proximity of island of birth or ancestry. The politics of the Pacific Islands are never divorced from the life of Pacific Island communities in New Zealand. In part this is because public and private lives are always inseparable, and there is a constant movement of people to and fro between the islands and Pacific communities in New Zealand. Moreover, the myth or actuality of return is still important to Pacific peoples, and in many cases this has a material as well as a psychological dimension (1990: 203).
\end{abstract}

Pearson mentions the role of aiga (extended family) networks, the Pacific Islands churches, community associations such as the Samoan Advisory Council, enua island associations in the Cook Islands communities, the Tongan Methodist, Catholic and Mormon church networks, and Tongan sports and cultural groups as examples of these associations. Although Pacific associations are not directly "political” they do operate in terms of self-help for each of these Pacific ethnic groups. Pearson also mentions PACIFICA (Pacific Women's Council) ${ }^{6}$ as a network, an organisation with which I have been personally associated with since 1976. Pacific women as a grouping will be referred to in more detail in a subsequent section of this chapter. If, indeed, any of these associations do have

6 The history and background of PACIFICA as a national Pacific women's organisation is described in: Crawley \& Morgan (1993); Leckie (1993) and Fairbairn \& Makisi (2003: 29-32). 
shared political aims, they tend to be focused on social justice and equality of opportunity in education, health, social services, housing and employment. Pacific associations, whatever their social purpose, also provide a context for Pacific peoples to engage in social interactions and in the practice of cultural values that affirm the meanings of being Samoan, Tongan, Cook Island, Niuean, and so on in Aotearoa New Zealand.

Pearson raises another important aspect of extending the influence of Pacific voices in government bodies and in the establishment and maintenance of positive, consultative relationships between minority ethnic groups and governments. This is the issue of who are seen as group representatives and its influence on how both group members see themselves and how those outside Pacific communities see Pacific peoples. Pearson quotes from Weaver (1985), who claims that "representivity" as she terms it, is as much a problem for governments as it is for ethnic communities. It can be used both as an important resource and as an instrument to divide and rule. Further:

Ethnic leaders can be discredited if politicians claim that they do not really represent their people, or ethnic representation can be ignored as an issue if governments wish to pursue their own policies without consulting anyone. However, the task of deciding who to take as representative of group interests can be a real problem for governments who do not have a genuine desire to consult with ethnic minorities... Spokespersons for ethnic minorities may not be able to claim representivity for the simple reason that they are in the process of creating it (Pearson 1990: 208-209).

Who gets to represent "Pacific" interests and agendas, and how these overarching interests are the same or different for Tongan, Tokelauan, Samoan, Niuean, Fijian and Cook Islands peoples, is a very interesting issue given Pacific ethnic intermarriage and the internal social hierarchies within every Pacific ethnic group.

Factors include both individual promotion and the relative size of the ethnic group itself. Samoans, for instance, as previously mentioned, form just over 50 percent of the Pacific ethnic population in New Zealand. The ethnic groups have their own internal politics and agendas, which are logical and understandable given the social capital and different hierarchical layers of loyalties within kinship, district or village, island of origin, and so on. Issues of leadership, status and ancestry consistently emerge within Pacific ethnic groupings.

The issues of representivity become important when sons and daughters acquire tertiary qualifications and are expected to represent their families and ethnic 
group's interests in public arenas. Suffice to say that this is a continuing issue which was perhaps more easily resolved in the 1970s and 80s when only male ministers of the main Pacific Island churches were deemed to be the leaders and spokespeople for each of the ethnic groups in New Zealand. This previously taken-for-granted automatic representivity is now changing.

The complexities of representivity also emerge when government agencies set out to consult Pacific ethnic committees, as an increasing number are being required to do. For example, MPIA has set up its own networks of advisory councils, Community Reference Groups (CRGs) and policy working groups. The ministry has broadened the opportunities for representation and increased the complexity of who is representing who, and in what policy areas. In addition, the Ministry of Education (2004) has 27 members on its Pasifika Advisory Group and seven ministry officials (six of whom are of Pacific heritage). The composition of the group appears to be a combination of ethnic group identification (the six largest Pacific ethnic groups), regional representation, and professional association membership. These two key government agencies are charged with ensuring Pacific consultation and representation in policy development. If these initiatives were considered in relation to their roles in ethnic identity construction, then it follows that these and other such agencies with Pacific advisory committees, Pacific managers, and Pacific liaison positions are involved in the processes of categorisation of Pacific peoples. They do this by setting up and promoting such representative groups and individuals as having power to 'influence' policy development, policy implementation and the provision of services targeted to Pacific peoples.

Loomis (1991) explains further the relationship with homelands that was raised by Pearson in his 1990 publication and again by Fleras and Spoonley (1999: 192194). Historically, various colonial nations (including New Zealand) have assigned certain categories to the inhabitants of the Pacific nations in order to manage and deploy them in various ways, both in New Zealand and in the homelands. This was very apparent in terms of educational developments in the Pacific (Mara, Foliaki \& Coxon, 1994: 192-196). More recently, this management and assignment of Pacific ethnic identity has included the implementation of policies for access to New Zealand, and for the removal of Pacific peoples from New Zealand (such as in the infamous Dawn Raids of the 1970s). Immigration 
policies that affect Pacific populations in this country have been changed and policed by and large without consultation with Pacific ethnic groups.

The outcome of the Lesa case (Fleras \& Spoonley, 1999:199-200) ${ }^{7}$ over Samoan citizenship in 1982 demonstrated how swiftly governments move to control Pacific immigration. In addition, socio-economic positioning has determined the housing areas where Pacific peoples were settled (usually close to venues of employment) which consequently determined the geographical concentrations of Pacific ethnic groups in the schools, and the social services and institutions located in those areas.

Loomis may have had a crystal ball when in 1991 he described this manipulation exemplified in the process of co-option of ethnic group members to Pacific advisory committees and boards and how it has been shaped and determined by government processes or according to the bodies involved. When the devolution of the provision of social services began in the 1990s Pacific providers sprang up, but the outflows of resources and funding have continued to be controlled centrally. As the 90s progressed, there were cases where the provision of services by Pacific providers was compromised because of onerous application processes, and the duplication of accountability and compliance measures. Different ministries and funding agencies imposed their systems in different ways, so that the energies of those "on the ground" were diverted into meeting their differential demands and systems. More recently there have been cases of financial mismanagement by some Pacific providers. Such situations have often arisen because of the lack of business or financial skills within Pacific communities. The contracting agencies have also contributed to provider "failure" through their own lack of clarity in their expectations and because they did not put into place strategies to ensure that skills and knowledge were enhanced as a condition of their funding. Such breakdown in the delivery of services helps to solidify negative stereotypes about the capability and reliability of Pacific peoples thereby calling into question their abilities to deliver and their capacity for selfdetermination.

7 In 1982 the Privy Council ruled in favour of Falema'i Lesa that all Western Samoans born between 1924 and 1948 (in respect of its historical protectorate status) should be New Zealand citizens. The New Zealand government later overturned the decision and negotiated a compromise with the Western Samoan government in regards to Samoans already living in New Zealand and those who could obtain permanent residence. See also www.teara.govt.nz/NewZealanders/New Zealand peoples/Citizenship/3/ for more information. Accessed 3 December 2005. 
Macpherson (1991) questions why assimilationist processes have met with varying degrees of success among Samoans living in New Zealand. To explain the variable outcomes of such processes, including the changing patterns of commitment to Samoan customs and practices, he proposes a model of ethnic identity. ${ }^{8}$ The model includes what Macpherson terms as the variables that shape Samoan attitudes to their language, culture and institutions. One component of the model includes language, belief and practice. Orientation (or strengths of affiliation) can change, so it is the second component of his model.

Thus, at any given time, a person can have different attitudes to the value and relevance of his or her language, beliefs and practices respectively. An adequate model of ethnicity must distinguish between its separate elements and between various orientations to them (Macpherson, 1991: 73).

Macpherson proceeds to provide examples of variations within the model through individual narratives. He assigns a positive orientation (a belief that this element of Samoan ethnic identity is significant and the person acts in a way to ensure its retention); a negative orientation (a belief that this element has no significance to their Samoan ethnic identity and is not acted on); and a neutral orientation (a belief that this element can be retained in a modified form and a set of practices are followed to reflect this judgement).

The model can be used to account for different elements and different combinations of elements of ethnic identity. It can also account for apparent contradictions, such as instances where a family decides not to speak the Samoan language but continues to hold beliefs and employ practices consistent with traditional values. It also accounts for modifications being made in terms of language (e.g., only on special occasions), or beliefs (e.g., limited church attendance and participation) or practices (e.g., does not give to all aiga fundraising requests or commitments). Using the proposed matrix, Macpherson suggests that profiles of individual and group orientations to elements of their cultural heritage can be constructed.

The matrix can also be used to chart changes in individuals' and groups' orientations to elements of their ethnic identities over time. With a clearer understanding of what is

8 For Macpherson "ethnic identity" in this instance is actually cultural identity and cultural maintenance and differs from the concept of constructed ethnic identity referred to in Chapter 7. Macpherson hints at how outsiders might influence the attitudes of Samoans towards their own languages, beliefs and practices, but the role of outsiders in cultural maintenance is not developed further in this 1991 work. 
happening to the contours of ethnicity, we are forced to ask more searching questions about the causes of various patterns (Macpherson, 1991: 76).

Underhill-Sem and Fitzgerald (1996) interviewed second-generation Cook Islanders and found that their interviewees recognised and acknowledged positive and negative aspects of their ethnic identification. They thought, however, that emphasising their ethnicity would endanger their social mobility and economic opportunities in New Zealand. One element of their culture was the idea that Cook Islanders are too "laid back" and will therefore be left behind in the competitive Papa'a world. Underhill-Sem and Fitzgerald conclude:

Identity is something that touches the very core of self; hence for many Cook Islanders-New Zealand raised or otherwise, the foundation of their identification as Cook Islanders is less Culture (with a large C), or status politics (with its goals of personal gain); but rather, it is a fundamental sense of belongingness-a kind of "shelter" in times of stress and rapid change. This research suggests that this positive function of identity may be as true of the second generation as it is of the parent generation (1996: 13).

Airini (1999) attempts to respond to questions of how Pacific visions of cultural identity can usefully inform policy for Pacific peoples, and how policy might be a vehicle for developing New Zealand's identity as a Pacific nation. Good policy making, she asserts, is policy that is well-informed, and from a range of sources, including life stories that illuminate the expertise of Pacific women. Airini's paper stresses cultural identity rather than ethnic group identity, but it does contribute to the debates on how culture and ethnicity can be taken into account in policymaking.

Anne-Marie Tupuola (2001) looks into the 21st century in relation to the construction of identities of Pacific youth. She notes how New Zealand Pacific youth are emulating Black African American lifestyles, slang, rap and urban street gangs. Cultural appropriation or cultural borrowing (as described by Payne, 1997; Henderson, 2000), is what Samoan youth are engaging in when adopting these lifestyles. At the same time they are also adapting those lifestyles to their own experiences as New Zealand-borns, in the New Zealand context. Payne describes the ambiguity of ethnic identity for these youth as they construct their selfidentifications and locational associations that reach across economic, cultural and global borders. The technological revolution provides new contexts for both immediate and virtual experiences of ethnicity. 
Consistent with Cerulo (1997) and her description of cyberspace identity construction, Franklin (2003) reports on two Internet discussion forums: the Kava Bowl and the Kamehameha Roundtable, as examples of where people from Samoa and Tonga meet online. The websites provide electronic spaces for the Polynesian Diaspora in the USA, Australia and New Zealand to communicate with each other. These websites have been operational since the mid 1990s and have created opportunities for personal exchanges, communication of political opinions, and the sharing of expectations and boundaries concerned with race/ethnicity and culture and what these mean for the participants in terms of maintaining and choosing identities in a diasporic context. Franklin claims that such dialogue in a post-colonial world reveals that Tongan, Samoan and Pacific cultures are negotiable. The mass of interlinking online text is evidence that Pacific participants are articulating "race” and "culture” on their own terms; perhaps this is the beginning of a new virtual politics of representation that will have an important influence on other forms of ethnic assertion.

It is clear that Pacific ethnic identity is interpreted differently by the various writers. Macpherson is interested in cultural maintenance; Underhill-Sem and Fitzgerald do acknowledge the role of "others" in New Zealand in the shaping of Cook Islands identity; while Tupuola stresses the of global youth culture in creating identity which may not necessarily be "ethnic". Franklin introduces the concept of "race" in relation to cyberspace identity construction but as is often the case, these terms are used interchangeably. Race, in this study, refers to the physical or genetic inheritance of different groups. Race, and the attitudes towards it, form a component of ethnic identity but do not solely determine it. ${ }^{9}$

\section{Pacific women in Aotearoa New Zealand}

Some of the earliest published work to look at the role of Pacific women (Vaine Pacifica) and Wahine Mäori in New Zealand was by Pihama and Mara (1994: 230-233), written for first year sociology of education courses. Their analysis was embedded within social constructionist, Western theories of gender. These theories had different foci in relation to the status and social roles of women: liberal feminism (equality of opportunity and the need for intervention to overcome inequality); socialist feminism (where location within a low socio-

9 For a more detailed explanation of the terms race, ethnicity and ethnic identity as used in this study see Chapters 5, 6 and 7. 
economic status and low paid employment acts as a barrier to women's independence and contribution to society); and radical feminism (oppression of women is the deepest form of oppression and the demise of male patriarchy can only be achieved by total removal of male privilege in public and private domains).

In 1994 Leonie Pihama and I critiqued the existing meanings and feminist analyses, because although some elements of the different theories could be seen to apply to Mäori and Pacific women in contemporary society in Aotearoa New Zealand, others did not. For example, they did not adequately take into account the forces of colonisation and conversion to Christianity in their Pacific homelands during the 19th Century, or how these continued to affect these women's roles in Aotearoa. These significant social forces had attempted to obliterate traditional Mäori and Pacific gender roles. They were replaced with Päkehä/Palagi Victorian roles in which male views and interests dominated all the social institutions and in turn reinforced the inferior social position of women relative to men. In addition, the mythologies that had been handed down in traditional songs and legends about strong female ancestors and their active roles in the survival of Polynesian cultures were rendered absent or marginalised.

There is some evidence of a pre-European Polynesian social structure in which women played complementary, and sometimes leading, roles. ${ }^{10}$ Every society has its hierarchies of power and status, and it can be asked whether the lives of Pacific women before the missionaries were any less affected by child-bearing and childrearing which largely precluded them from participating in political and community life than is the situation today. What is clear is that they did contribute to the survival of the group through culturally-based, predetermined fixed roles and societal expectations concerning women. Whatever the forms of social hierarchies and social processes in pre-European times, I do know for certain that the Christian missionaries brought with them to the Pacific another social hierarchy that promoted Victorian morality and male dominance which, as part of the Christian doctrine, was enthusiastically adopted by all Pacific peoples.

10 For example Doty (1964) in his preface to the reprinted diaries of Reverend William Ellis (Ellis, 1869), who set up missions in the eastern Pacific Islands (the Society and Tubuai Islands) from 1816 to 1825, backgrounds the social structures that Ellis encountered. Among them is the perceived high status of the indigenous women. However, such evidence needs to be examined further to discern whether these accounts were themselves influenced by the Victorian background (and expectation of male/females roles) of the observer. 
I also know from oratory, song and proverbial expressions that some women in Pacific communities held leadership roles through traditional matrilinearity. In fact, despite the best efforts of the colonising missionaries, elements of female positions of power have survived even into contemporary Pacific societies such as through the matai systems in Samoan society where women hold titles, and other such forms in the main Pacific groups. For example, the last indigenous leader in Tahiti was Queen Pomare, and the late Queen Salote of Tonga is still held in very high regard by Tongans today.

The change of contexts, as a result of immigration to New Zealand and the effects of policies and legislation in the wider society, have shaped the social positioning of Pacific women (Ongley, 1991). The most common categories of employment for Pacific women are clerical (24 percent) or service and sales work (23 percent) (Statistics New Zealand, 2001), with some decline in employment in manufacturing or low-paid service work such as cleaning. For other Pacific women, however, relegation and containment to workforce participation in lowpaid shift work remains. This is particularly the case for women with no school or tertiary qualifications. Pacific female life expectancy at birth is 76 years; that for Pacific males is 70 years. Both groups (Pacific males and females) are still four years below the life expectancy levels for the total Aotearoa New Zealand population. High levels of obesity, diabetes and heart disease have prompted concerted campaigns by the Ministry of Health to address these conditions in Pacific populations and Pacific health at a wider policy level in the Pacific Health and Disability Plan (Ministry of Health, 2000).

Wendy Larner's (1991) study of the labour force participation of Samoan women in New Zealand has shown differences between Samoan-born and New Zealandborn women. Her two groups of research participants expressed their differing expectations in terms of their domestic roles and duties. The New Zealand-born Samoan women were more likely to demand that their husbands assist with the children and domestic chores than the Samoan-born women. New Zealand-born women had expectations of achieving more non-manual positions in their employment, being mindful of the pressures of their mothers having to hold down two or more low-paid jobs, and, at the same time, looking after the household, and meeting their church or their Samoan community obligations. The situation of multiple employment was described in media and social policy reports as far back as the 1970s and 1980s (Tamasese et al., 1988; Pihama \& Mara, 1994: 230-233). 
According to Ministry of Education (2005) statistics however, Pasifika (sic) women are participating in tertiary education at a higher rate than Pasifika men. In 2002, 8,386 Pasifika women were enrolled in tertiary studies compared to 5,806 Pasifika men. Forty-nine percent of all tertiary Pasifika students were under 25 years of age, therefore, just over half are deemed to be "mature” students.

The work of a number of Pacific women involved in education during the 1980s and 1990s began to address the invisibility of Pacific women as educators and researchers in the education of Pacific peoples in New Zealand. These include Fairbairn-Dunlop (1984); Laufiso, (1988); Mara (1993); and Leavasa-Tautolo (1994). Since the mid-1990s there has been an increase in Pacific educational research by and about Pacific women, as well as an increase in the volume of research in disciplines such as sociology, anthropology, medicine and Pacific health research. However, most of that published research has until recently, followed the dominant research paradigms. Suffice it to say that much of the work in these areas of innovation and critique, both in New Zealand and in the Pacific, has been and continues to be largely spearheaded by Pacific women academics and researchers.

\section{Summary}

This chapter provides some background information on Pacific peoples in Aotearoa New Zealand and their social and economic positioning. Pacific ethnic groups are largely urbanised, young populations, with lower workforce participation rates, poorer health statistics, and lower educational qualifications than the wider population of Aotearoa New Zealand. Looking at the public policy agencies, structures and processes set up by central government it can be seen that they play a role in the defining of how Pacific peoples are categorised and how they position themselves in this country. This includes providing opportunities for Pacific peoples to contribute to policy development, and to act as providers themselves in the delivery of social and educational initiatives that are targeted to Pacific communities. The third and final part of the chapter reviewed some of the key work of New Zealand based researchers, Pacific and others produced over the last 15 years that has contributed to our understanding of Pacific peoples in Aotearoa New Zealand. Their work leads into a more detailed exploration of how Pacific ethnicities and Pacific ethnic identities are constructed, and in what 
contexts. Pacific women are also considered in relation to their social positioning in the wider society of Aotearoa New Zealand.

In the following chapter I introduce the key institutional settings and contexts that are the focus of this study of Pacific women graduates. I describe Pacific peoples' participation in the contexts of tertiary education, the family and church. 


\section{CHAPTER 4: TERTIARY EDUCATION, FAMILY AND CHURCH}

\section{Introduction and overview}

According to Hart (1998), a literature review should answer questions concerning some of the key theories, concepts and ideas in the area of study. This can sometimes present the researcher with particular challenges when the literature under review is written from a range of perspectives or disciplines.

The literature in this chapter has been selected to provide background to the main social settings pertinent to this study: that is, tertiary education institutions, the family and, for Pacific women in Aotearoa New Zealand, the institution of the church. Pacific churches are settings that are usually specific to their own population, places where the ancestral language is spoken, and cultural networks are supported. Cultural identity is shaped within the settings of family and church. This study, however, is focused on trying to find out whether, and in what way, ethnic identity was formed or influenced by tertiary education.

Initially, therefore, this review includes studies pertinent to the participation of Pacific students in tertiary education institutions in this country. I have included research completed between 1996 and 2003. Secondly, selected studies from overseas relating to minority ethnic students and tertiary education are reviewed in order to place New Zealand research within a global context. Thirdly, this review of contexts looks at research from related social disciplines on the family and the church. The chapter concludes with a section on Pacific women in Aotearoa and the links between tertiary education, Pacific underachievement in tertiary institutions, and the wider social context or setting.

\section{Pacific students in tertiary education}

In 1997 the Education \& Training Support Agency (ETSA) ${ }^{11}$ /Skill New Zealand, published an annotated bibliography of Pacific Islands Education and Training

\footnotetext{
11 Since 1997 ETSA has become part of the Tertiary Education Commission (TEC). The structure of the recently established Commission is outlined in: A new tertiary education landscape: Introducing the Tertiary Education Commission, November 2002. One of the six specific strategies the Commission must oversee is 5. Education for Pacific peoples to ensure development and success and to address issues relating to Pacific peoples capability, needs and skill development.
} 
that included tertiary education publications. It included a number of unpublished works as well as publications up to that date on the topic of Pacific tertiary education. The ETSA bibliography was preceded by Seen But Not Heard: Voices of Pacific Islands Learners (Pasikale, 1996) and was followed by the publication Weaving the Way (Pasikale, Yaw \& Apu, 1998) which looked at how Pacific Islands private training establishments (called PTEs) provide an effective alternative to mainstream tertiary education and training for Pacific students and trainees.

A particular feature of the six selected PTEs in Pasikale et al (1998) is the inclusion of Pacific cultural values and practices into their organisational life including Pacific ownership and leadership of these institutions. These two publications are significant because their research, collation and reporting were managed largely by Pacific researchers, using Pacific participants and employing Pacific research methodologies such as community consultation and accountability processes.

Cleverley (1996) looked at Pacific adult learning characteristics in a Pacific PTE through the eyes of the tutors and reached the conclusion that adult learning characteristics did not differ across their students. As with all other adult students, he found that the Pacific students had a clear sense of direction, a base of experience (since many were returning to study or retraining as mature students) and clear goal orientation. However, Cleverley found that the factors that do influence their learning include cultural and environmental factors such as: negative memories of past learning experiences, including schooling in New Zealand; the challenges inherent in balancing learning and family priorities and expectations; and the fear of failure in front of peers. In addition, cultural and religious factors, including gender differences, also influenced education and training success at this Pacific PTE. This and other such studies point to a cultural “conflict” situation that students have to resolve between the different and at times contradictory demands of study, family and culture, in order to succeed in tertiary education and training. Cleverley identified barriers to learning and factors that tertiary institutions and educational providers should attend to, in order for Pacific achievement to be raised.

Yet another line of research that has been followed throughout the literature is the concept of barriers to learning and achieving positive outcomes for Pacific 
students; that is, factors operating against completion of courses and gaining tertiary qualifications. Two such studies focused on Pacific students in teacher education institutions: Mara, Tuhipa, Falesima and Greenwood (1996a) and Dickie (2000). Both outline barriers such as: home and community demands on the Pacific students; institution-based factors such as learning support services; pedagogical approaches; relationships with lecturers; building on the Pacific knowledge students bring with them to the institution; and the impact of wider policies, such as the length of training period, the student loan scheme, and provider competition.

One of the main objectives of both studies was to make suggestions to the relevant teacher education institutions, (Auckland College of Education and Wellington College of Education) ${ }^{12}$ regarding possible future developments in their provisions for Pacific students. Changes have been made as a result of such studies although it probably took longer than the researchers envisaged for these institutions to establish compulsory Pacific Studies courses ${ }^{13}$ and other such innovations to address the issues they found to be significant.

The study by Tofi, Flett and Timutimu-Thorpe (1996) centred on one tertiary institution, Massey University in Palmerston North. Sixty-one Pacific students, all born outside New Zealand and attending university full-time in 1994, formed the study sample. Tofi et al. studied problems of adjustment to the institution, the kinds of social support available to them and the academic performance of these Pacific students. The main social supports for these students were found to be other Pacific students. The researchers found evidence of problems such as workload issues, homesickness, feelings of stress and family pressures. The level of reported problems was low, but it is thought they are significant factors in terms of adjustment to university. This is another study that asked the institution to take heed of the needs of Pacific students.

12 Both institutions are now merged into their neighbouring universities, the University of Auckland and Victoria University of Wellington respectively.

13 In 1999 Wellington College of Education established the first compulsory 50-hour Pacific Studies course in teacher education in New Zealand. It was taken in the second year by all Bachelor of Education students. Due to the restructuring of degrees the course was disestablished in 2003 and Pacific Studies was threaded through professional studies courses in the Bachelor of Teaching. Course hours for any Pacific education within the degree were significantly reduced. 
A study by Anae and Sua'ali'i (1997), based at the University of Auckland, surveyed the utilisation of the current student services by Pacific students. This study was carried out in response to the institution's concern over low overall Pacific student academic achievement levels, and low attendance at tutoring and Pacific student liaison services. The review highlighted the fact that the existing services for Pacific students were fragmented, and recommended that they be integrated and consolidated in order to become more effective. Secondly, it was suggested that the existing services (library, student learning centre and departmental Pacific tutors/liaison tutors) that were the four services most used, be enhanced and extended. Thirdly, the existing services, such as the Pacific Island Liaison Office, Fale Pacific, Departmental Pacific Liaison tutors and student representatives, should be reviewed and restructured so they could be used more effectively by the students. There was also a call for more content-based workshops within the Student Learning Centre and Fale Pacific. The structural changes that have been made at the University of Auckland, as a result of the findings from such studies, must be robustly monitored to find out whether, in fact, these measures do result in improved levels of achievement by Pacific tertiary students.

The following researchers have also focused on the experiences of Pacific tertiary students in the New Zealand tertiary education system.

Beaver and Tuck's study (1998) focused on the adjustment of overseas students at a tertiary institution and included a small number of "Pacific Islands subjects". Some interesting findings emerged that Pacific "Islanders" rated the provision of assistance with the English language as "very important”. Pacific students were found to be more positive about learning in ethnically mixed classes than were the Päkehä students in the study but they did not want to be socially isolated as a result of initiatives such as streaming of classes or grouping by ethnic group.

Factors such as the culture of learning and the attitude that regards the teacher as being someone in authority and not directly approachable seemed to be detrimental to good adjustment to the tertiary context. Beaver and Tuck noted the ambivalent responses and behaviour by Päkehä students to other ethnic group students and how these affected the adjustment of other minority groups. It was also noted that the female overseas students expressed more concerns about health and family issues, and were more anxious about approaching lecturers and asking 
questions in class. Although a relatively small sample was used, these researchers identified some of the student relationship processes occurring within a tertiary education institution. The processes that affect the adjustment and participation of Pacific students at tertiary level, Beaver and Tuck admit, require further study.

An important point is whether the changes referred to above made any difference to student achievement. However, Makita Bell (1998) looked at a bridging programme established to meet the needs of Pacific students at the University of Auckland (UOA). The aim of this and other similar programmes is to increase access to the tertiary institution by members of under-represented groups. Bell used quotations from students to show how they experienced the course, how it helped them to gain confidence in the university environment, and how it provided an opportunity to build up study skills such as writing essays. Bell's subsequent interviews with those Pacific students who did carry on to gain their degrees at UOA revealed a critique of the bridging programmes. A number of these Pacific graduates express their disenchantment and disappointment about the institution, partly because of the lack of "decent" employment following the attainment of their qualification, but also because of the cultural differences, the lack of understanding about their cultural values and the lack of incorporation of Pacific knowledge into their courses. As a result of her study, Bell calls for the full implementation of the UOA's charter and EEO policy which undertake to meet the needs of Pacific students. She suggests that bridging courses should be an integral part of implementing these policies. Further, issues of institutional governance and management, as well as the university's pedagogy and assessment procedures, need to be scrutinised, Bell reports, so that gains made in such precourses and second chance education provisions for Pacific students, also become part of the university's wider ways of operating.

Anae's (1998) doctoral thesis on Samoan identities is more extensively discussed elsewhere in this thesis (see Chapters 3 and 6). Reference to it is made here because she discussed with her group of Samoan participants the pressure put on them to go to university and to obtain further qualifications:

... none of the members expressed that going to university was a wrong move or a negative career choice (1998: 226).

She notes that in her focus group the females were more highly qualified than the males. The participants mentioned the support of their parents while they studied 
and the importance of reciprocal relationships with parents/aiga as factors in their academic success. A further cultural pressure placed on them included the fact that they carried with them the "honour" and name of their aiga into the university context so that their individual progress and success reflected well on their family. However, the implications of academic success for Pacific tertiary students not only includes representing their family, but may also represent all Pacific ethnic groups, as found by Middleton (2001) in her study of 57 Education PhD graduates between 1948 and 1998 across New Zealand universities. The study included a Pacific graduate and a number of Mäori graduates. For this grouping of students, “success” was only the beginning of further institutional demands placed upon them as a consequence of reaching the status of "doctor":

This was especially highlighted by the Mäori and Pacific Islands PhD graduates, who found themselves in demand as "ethnic representatives" on multiple committees: "in terms of trying to survive within institutions, being the only one with a $\mathrm{PhD}$ was very tough ...We had three Pacific academic staff and there was a high expectation for you to be involved. I was a member of the Academic Board, a member of that because you're Pacific with a PhD” (2001: 102).

To complement Pacific students' experiences of tertiary education, a consideration of research that looks at the responses of institutions to the participation of Pacific students is important. In 2002 the Ministry of Education published a significant and substantial research report on Pacific Peoples and Tertiary Education: Issues of Participation. The research was carried out by a team of researchers at the University of Auckland's Centre for Pacific Studies, headed by Dr Melanie Anae. It was a comprehensive study that included a literature review, an update on Pacific tertiary educational statistics, and results of a survey of tertiary institutions' policies, programmes and strategies aimed at recruiting and retaining Pacific students.

The research team also interviewed key informants with experience in recruiting, supporting and retaining Pacific students in the institutions; Pacific tertiary students, both those who had completed and not yet completed their studies; and Pacific ethnic community members. This study collated both institutional documentation (charters and policies) as well as Pacific voices to complete the picture of the following tertiary education institutions: three universities, two polytechnics, one college of education, and six private training establishments. 
In terms of the institutional policies, programmes and strategies this study found that across the various providers:

There was considerable variation in the perceptions of these documents by respondents. For some, these documents were integral to the planning of action and used on a daily basis to direct and evaluate provider practice. For others, these documents were seen as “wallpaper”, disconnected from daily activity and only referred to on an ad hoc basis to support or contradict activities initiated for purposes other than to progress the goals of equity (Anae et al, 2002: 52).

The point is clearly made that simply having policies and charter documents does not ensure that institutions become supportive of Pacific tertiary students, so that their backgrounds and values are positively acknowledged. The report also found that processes such as consultation of Pacific communities by the tertiary institutions were "limited, patchy or ritualised", and inconsistent with both the high value placed on tertiary education by Pacific ethnic communities and the aims outlined in charter documents.

Even more recently, the research publications by Davey (2002, 2003) and Davey, Neale and Morris Mathews (2003), derived from the study Education in Mid and Later Life by the New Zealand Institute for Research on Ageing at Victoria University of Wellington, provide some data on Pacific tertiary students. The sample of almost 1,000 mature students (that is, aged 40 years and above) attending Victoria University included mature Pacific women students. The results yielded data about the educational and workforce background of the students; their marital status and household composition; their community activities; their motives and decisions for studying; their satisfactions; the barriers they experienced; how they managed to finance their studies; the advantages and disadvantages of mature study; and their futures beyond study.

The Pacific students were less likely to have parents who attended university, although many had siblings or children who were (or had been) university students. The largest household composition out of the total sample of students (including a partner and dependent children) was noted in Pacific students (63 percent). In terms of personal income, 1 in 10 Pacific students had an income of $\$ 50,000$ or more, compared to 1 in 3 Päkehä students. Of Pacific peoples returning to education, 90 percent reported the highest rate of difficulties encountered (courses, teaching, administration, finance, family, health and so on). The main motive for attending university was to gain work-related knowledge (70 
percent of Pacific students) while almost a quarter of them said "setting an example” was their prime motive. This response by Pacific students was twice the level of any other ethnic group in the study.

The analysis of the sources of income during study reveals a very distinct pattern for Pacific students in comparison to all other students. Sixty percent of Pacific students said they relied on student loans as compared to 20 percent of Päkehä, 48 percent of Mäori and 25 percent of Asian students. The next most frequently reported sources of support for Pacific students were: full-time work and family support (both 37 percent); part-time work (27 percent); employer support and savings (20 percent each); and allowances and welfare (both 17 percent). Pacific students were found to have the highest percentage across all ethnic groups for these latter forms of support.

However, despite reported difficulties Pacific students said that their current study would have a positive or very positive effect on their future participation (83 percent) and 90 percent reported it would have a positive effect on their future income.

It is the Pacific Island group which appears to be encountering the highest level of problems and dissatisfaction. Despite this, they generally still had a positive outlook on the future benefits of their study-more so than any other ethnic group (Davey, 2003: 44).

Davey, Neale and Morris Mathews (2003) edited a book containing nine case studies arising from Davey's previous work in the Education in Mid and Later Life research project. These case studies featured the following groups: male students, Mäori students, teachers studying part-time, nurses at university, age, gender and career issues, job loss and mid life education, retirement and study, and mature students who withdrew from study. The researchers make policy recommendations to all tertiary institutions and to central government, which has the responsibility for the development and implementation of national tertiary education policies.

The outcomes that were described across the nine studies attest to the private and public value of studying at a university in mid-life or later. Therefore, according to Davey et al. (2003), institutions have to be responsive to the needs of mature students, including those returning to studying after a break. Firstly, universities should respond promptly and in a welcoming way to initial study queries. They need to "sharpen delivery" of administrative and study support services for mature 
students, who have little time to waste as they juggle other demands and responsibilities in their lives. Secondly, technology should be employed more efficiently in terms of enrolment, library resources, student ID cards and study records. To cater for working students, for example, staff need to be available and accessible after standard working hours. Older students often move in and out of study. If lifelong learning is valued, then the universities as institutions need to change their structures and processes to facilitate this, rather than to act as an elitist barrier to academic achievement by members of ethnic minority groups (Davey et al., 2003:185).

The most significant recent work to critically examine a tertiary education institution and the participation of Samoan students in New Zealand is that of Lorraine McAlpine Petelo (2003). She examines the ways in which 22 students of Samoan background experienced their education within the University of Canterbury. Petelo approached her research question in two ways. Firstly, she explored the ways in which the students constituted themselves and found themselves being constituted. Secondly, she critiqued how institutional policies and discursive practices produce and reproduce the power relations within the academy, their constitutive effects, and the ways in which the students responded to these institutional policies and practices.

Her theoretical approach was a critical sociological stance regarding the existence of dominant social forces and interests that are played out in the context of a tertiary institution. McAlpine Petelo examines social structures and human agency in line with feminist post-structural theory, the politics of positionality, and ideas about resistance and agency of the Samoan students and their multiple positioning in their family, church and Samoan communities, as well as in the university context.

McAlpine Petelo explores positionality in considerably more detail than do any previous studies of Pacific students within a tertiary education context in New Zealand. She asserts that, despite the overarching institutional discourse of equity and equal opportunities, the Samoan students in her sample are offered only certain positionings within the academy: positions of isolation, invisibility, and exclusion. Her study shows that the students simultaneously take up and resist these positionings, and in this regard Petelo sheds some light on the very processes pertaining to the social construction of identity that are the focus of my 
study. The theories of Foucault and Derrida inform Petelo's analysis in terms of discourse, power and power relations, discursive relations and practices, and theories of deconstruction. Further, Petelo makes reference to the notion of "intersectionality", which relates to the historical constructions of distinct groups in society, the relationships between and within groups, and the interconnectedness of race, ethnicity, gender, class and culture. The narratives recorded by Petelo revealed intersections between competing and contradictory expectations across the family, church, and university contexts.

McAlpine Petelo discusses deconstruction as a useful tool of analysis in critiquing social structures and institutions, since it helps to look at how a structure has been produced, constructed and held together. In other words, as a researcher I can critically examine the processes and meanings of power relationships, positionality and practices as they develop (by internal and external forces), how they are constructed, and how they are reproduced within any given social structure or social context.

As a tool of analysis, deconstruction enables us to look at meanings of terms such as "Pacific Islander", Samoan student, coloured, New Zealand Born, identity, and knowledge, and unpack how their fixed meanings have been contextually constituted and dependant on their preceding historical locations (McAlpine Petelo, 2003:49). ${ }^{14}$

Such studies as McAlpine Petelo (2003, 2002) and Anae (1998), together with pressure from Pacific students and Pacific communities, have forced tertiary institutions to review their provisions. They have begun to increase institutional services such as Pacific liaison tutors and to make other structural changes to address barriers to participation and academic success. It needs to be acknowledged that some tertiary institutions and private training establishments are providing “spaces” for Pacific student initiatives such as MALAGA at the University of Auckland, the Foundation Education Programme, Manukau Institute of Technology and BEST Training Limited in Auckland (Anae et al., 2002).

14 McAlpine Petelo criticises Anae et al's research (2002) on Pacific peoples and tertiary education for not including a South Island tertiary provider in its sample (because doing so would have provided a different geographical perspective, and taken into account the smaller concentration of Pacific students at Canterbury). Petelo's study includes recommendations to the University of Canterbury (and other tertiary institutions) regarding alterations to structures and processes that would change the present positionings of their Samoan students. As such, Petelo claims her findings should be added to the evidence presented in Anae's report. 
It is clear from the literature that Pacific Island students experience problems within tertiary education and that the institutions are being responsive by establishing provisions for the recruitment of Pacific students and support for them on entering their courses.

\section{Overseas research findings}

Several overseas studies have highlighted aspects of tertiary institutional settings as contexts that ethnic minority students or students from other "different" backgrounds enter.

Hurtado and Carter (1997), for example, looked at Latino students' sense of belonging to a university college campus in the United States. They claim that a sense of belonging has to exist before students believe they can assert their own identity in that context. Their study looked at the extent to which the students' background characteristics and their college experiences in the first two years contributed to their sense of belonging in the third year. The researchers contend that the degree of social integration for any student is influenced by the social networks constructed on campus, including friendship and support; by the degree of congruence between the individual's expectations, values and attitudes; and the attitudes and values encountered in campus peer groups.

Hurtado and Carter consider the context of college as an institution that constructs not only academic knowledge and identities, but also social and cultural connections, and show that minority students experience these constructions differently. This study also suggests that perhaps peer group membership can help students resist conformity and that, for Latinos in particular, they can feel part of the campus community "without acculturating, conforming, or adopting the values of the majority” (1997: 326).

Hurtado and Carter also cite studies that have found positive early transition experiences to facilitate peer group formation, and how these can be quite readily implemented by institutions. The institutional climate they maintain, and the value placed on diversity, can have a considerable impact on students' academic and social lives. Where the Latino students participated in groups with links into their communities and/or with other Latino students, this increased their sense of belonging to the tertiary campus. At the same time, however, Hurtado and Carter caution that such interactions can, in fact, emphasise students' marginality as they 
can provide opportunities to share with other Latinos the treatment they experience in their interactions with staff and other non-Latino students. In other words, the results are conflicting.

While Wilson (1997) focused mainly on mature students, not students from ethnic minority groups, she still makes the point that, while most tertiary institutions in Great Britain are trying to make space for "non-traditional” applicants, very few studies have looked at the subjective experiences of mature students to find out how institutions can appropriately respond to their learning and teaching needs. In one Scottish university Wilson used quantitative and qualitative approaches to describe the "lived experiences" of its mature students. She concluded that the social "reality" constructed by this group of mature students was contradictory. They wanted to be treated the same as all other students in some aspects, yet in other aspects they also wanted to be treated differently. They particularly wanted the lecturers to take into account their different backgrounds and previous life experiences, and to be given recognition for the wealth of experiences and knowledge they brought to their studies.

Wilson's research reminds us that mature (and perhaps other "non-traditional" students), as they reflect on and articulate their experiences, are always in the process of constructing their own realities in regards to the social (and cultural) connections they seek and endeavour to maintain within the context of tertiary institutions. Mature students (as active agents) construct, negotiate and renegotiate their realities within the tertiary education context.

Two reviews of publications from the United States raise further issues that help us to look more closely at tertiary education settings and the experiences of ethnic minority students within them.

Kenyatta (1997) reviews Levine and Nidiffer's book Beating the Odds: How the Poor Get into College. Successful students from poor backgrounds spoke of the importance of a mentor: parents, other relatives, teachers, or social workers who had helped them to decide to go to university and given them advice, encouragement and hope. In her review of this book Kenyatta is concerned that relying solely on providing mentors for students and scholarships in order to overcome race, gender, religion and birthplace barriers to attending college is politically naive. This study, and Kenyatta's review, reinforces the existence of a link between the tertiary education institutions and the wider society and, more 
importantly, stresses the issue of whether the tertiary education setting reproduces the inequalities present in society. In addition, it asks whether the dominant discourses from the wider society reproduce the forces within the tertiary education setting that in turn help to shape the construction of identities.

When black students attend white colleges and universities Feagin, Vera and Imani (1996) write that "the rhetoric of openness and equality" is not matched by their experience of the tertiary institution. Although the reviewed work concentrates on race (black/white issues) it makes some points about treatment by the institutions and about consequences for retention and achievement. In R D Coates' review of Feagin et al.: The Agony of Education: Black Students at White Colleges and Universities, he writes:

Both in and out of class, black students are placed in a situation where they must defend not only their right to be in these predominantly white institutions but the right of all Blacks to be recognised as viable and valuable contributors to society ... This means that you are always on the defensive, always a potential target, always facing the awesome weight of being a spokesperson for a whole people ... is it any wonder that the matriculation rates are so low? (Coates, 150: 1997).

Coates also warns about the growing political and policy u-turn in the United States regarding affirmative action and quotas to universities. This could undermine any gains made thus far, he claims, and could make study even less accessible and less comfortable for black students in white institutions. The challenge, he claims, is for the academy to examine "its own race problem" rather than to focus on black students as "the problem". Some black students do achieve under supposedly "hostile” conditions. More research about how this happens, Coates argues, could potentially help us to better understand racial and cultural identity and its construction within colleges and universities. The historical contexts of the United States and Aotearoa New Zealand are quite different the message about institutions looking at their own role "the problem" is clear.

Cuellar et al.'s (1997) and Dei and James’s (1998) studies of ethnic minority youth (Mexican-American and African-Canadian) from a social psychological perspectives add further evidence of how ethnic boundaries are constructed by the youth and by the settings in which they participate.

The literature in this section has been included as a background to understanding tertiary education institutional settings and their responses to the participation of Pacific students. In conjunction with overseas research, the literature has 
established that students and institutions interact with each other in sometimes contradictory ways (as evidenced by McAlpine Petelo, Bell, and Coates) to affirm students and the experiences they bring with them into tertiary education. Just how this dynamic works to construct the ethnic identities of Pacific women tertiary students in Aotearoa New Zealand is the subject of this study.

\section{Pacific family and church settings}

There has been only a limited amount of research about Pacific families in Aotearoa New Zealand. On the whole, the literature in this area does not come from a sociological theoretical viewpoint. Studies are included because they provide evidence from which to argue that institutional settings are areas for study and that family and church socialise children into the cultural beliefs, values and practices of their own Pacific groups.

\section{The family}

While there is very little evidence regarding the construction of cultural identity within Pacific families in New Zealand there have been a number of studies and published articles focusing solely on Pacific families as contexts for socialisation and human development. These include Mara et al. (1996) and Mara (2000), who review the home-based early childhood intervention programme for Pacific families, Anau Ako Pasifika; Schoeffel et al. (1996) on Pacific Islands attitudes to child training and discipline; and Meleisia and Schoeffel (1998) on the cultural context of Samoan families in New Zealand. Koloto (2000) has written about family roles and responsibilities within Tongan families and has articulated a Tongan perspective on human development. McCallin et al. (2002) describe parenting in New Zealand by Samoan people as "striving for the best of both worlds".

A longitudinal study of Pacific families the Pacific Island Families Study is being carried out through the Auckland University of Technology. It began in 2001 and follows 1,400 Pacific Island children and their families, gathering data on a whole range of health and development indicators. The project has funding from the Health Research Council and the Foundation for Research, Science and Technology until 2008. In its first three years it has collected a large amount of 
data on Pacific family life and socialisation processes, intended to inform health, education and other social development policies. ${ }^{15}$

A study of income allocation within Pacific families (Pasikale \& George, 1995) demonstrates how decisions pertaining to finances within the family are very heavily influenced by cultural values of reciprocity, including contributions to extended family resources and church and family celebrations, travel for reunions of family members, remittances back to the home islands, and so on.

In 2002 a research project was launched under the auspices of the Ministry of Women's Affairs to investigate the economic wellbeing of Pacific women in New Zealand that by direct implication will provide some evidence about economic decision-making and budget priorities within Pacific families.

The aforementioned studies are useful in gaining some general insight into Pacific families as contexts for the transmission of each Pacific group's beliefs, values and practices. However, more information needs to be collected on the specific ways in which Tongan, Samoan, Cook Islands, Niuean, Tokelauan values and practices have been adapted, consolidated or modified as a result of living in the context of New Zealand society. In many ways Pacific families and households share the position of all other minority immigrant groups (even though second and third generations are now growing up in Aotearoa New Zealand).

An equally important source of information about Pacific families comes from the biographical narratives of Pacific women, such as those of: Fairbairn-Dunlop (1996) in her collection of stories of Samoan women; Tanielu (2000) as she relates her educational experiences in Samoa and the influence of her family values on her education; Mulitalo (2001), who followed six Samoan people in Christchurch documenting their lives, beliefs and values; Fairbairn-Dunlop and Makisi (2003), in their documentation of the experiences and events that shaped the lives of Pacific Islands New Zealanders; and Avia (2004) who searches for her identity through the story of her father, who came to New Zealand in the 1950s and worked in Christchurch on the killing chain at the freezing works. These are just some of the narratives by and about Pacific women being produced in sound, print and through other multi-media presentations that are providing insights into

\footnotetext{
15 See http//www.aut.ac.nz/research_showcase/research_activity_areas/pacific_islands_families/
} 
Pacific families and how within these settings or contexts the construction of Pacific identities takes place.

\section{The church}

It is widely recognised that there is a close relationship in the lived realities of Pacific peoples in Aotearoa New Zealand between the family context and the church setting. As Macpherson writes in relation to the Samoan ethnic grouping:

\footnotetext{
Christianity, introduced by Protestant missionaries in 1830, has been embraced so completely that it is widely regarded as a central feature of Samoan culture and social organisation. It has become a central part of the fa'a samoa and has transformed precontact beliefs and practices so completely that Samoans claim with some pride that the fa'a samoa by which they live represents a morally superior version of the fa'a samoa followed by their ancestors in the aso o le fa'apouluiuli, the times of darkness. As the nation's motto proudly acclaims, Fa'avae i le Atua Samoa, contemporary Western Samoa is founded on God (Macpherson, 1991: 77-78).
}

Similar patterns of missionary education and the cultural consequences of pre- and post-contact beliefs were seen across many of the Pacific nations in the 19th and 20th centuries. The significant links between "missionisation" and colonisation of the Pacific are still apparent (Mara, Foliaki \& Coxon, 1994: 185-190).

Taule'ale'ausumai (2001) provides an historical overview of the history in New Zealand of Pacific religiosity within mainline Christian churches since World War II. Over the years since then, organisational splits, mergers and new developments have characterised the Pacific churches and patterns of Pacific worship. Consequently "settings" of worship have become more diverse and complex. Many Pacific peoples still attend the mainstream churches such as Presbyterian (formerly Congregational), Catholic, Methodist, and Church of the Latter Day Saints (Mormon). However, in the last 25 years there has been a move by more Pacific Christians into ethnic-specific churches such as the Samoan Congregational Christian Church (EFKS), the Cook Islands Christian Church and, increasingly, other charismatic and evangelical churches. A key feature of “church” for Pacific ethnic groups is this diversity. Churches as institutions are still undergoing significant structural and procedural changes that will have an effect on the formation of Pacific cultural identities now and into the future (Taule’ale’ausumai, 2001: 193).

Tiatia (1998) labels the church and fa'asamoa (the Samoan way of life and the economic, historical and moral order for Samoan people to live by) as "the 
Siamese twins” (1998: 21). She goes on to quote Anae (1995: 5) as saying that the very foundation of Samoan identity is a commitment to fa'asamoa, which is a portrayal of a unique relationship with God. This relationship between culture and Christianity, historically taken for granted, has become almost totally intermingled in the lives of Samoan people. However, this relationship is increasingly coming under scrutiny by New Zealand-born Samoans and youth from other Pacific ethnic groups.

While Tiatia records the conflicts experienced by her informants as they live between and across the two settings, family and church, she adds a third context as they move into the New Zealand education system. Her informants posed the question of why these conflicts occur, while sharing the insights and a critique of these cultural and ethnic conflicts. There are some examples where, although the young Pacific person rejects attending traditional church, their faith and beliefs are still so important that they are led into attending Pentecostal and other charismatic churches. In this way some beliefs and values remain the same, while the situation in which they are expressed and practised has changed.

The informants in her study provided Tiatia with accounts of the social mechanisms and activities within the church context, such as the memorisation of Bible tracts, involvement in youth groups, choir practices and teaching, or participation in Sunday School. The narratives revealed the polarisation of issues such as the emphasis on maintaining and promoting Pacific languages while many young New Zealand-born do not speak their Samoan, Niuean, Cook Islands or Tongan language. The demands of participating and engaging in the full range of church activities and the attendant cultural responsibilities and obligations, (including money and gift-giving) are described. Meanwhile having also to meet the daily obligations of employment and earning a living, family activities beyond church, the demands of study and so forth, are described as another set of competing forces.

According to Tiatia, a third and very important area of contestation where the fusion of family culture and church closely reinforce each other is the practice of unquestioning obedience and respect for traditional structures and authority figures. The young people in her study, aged between 16 and 25 years, were beginning to engage more fully in study, training and employment. In those contexts teachers and lecturers encouraged, indeed rewarded, questioning, 
discussing different viewpoints, and asserting oneself. Academic study demands that in order to succeed the individual student must remove her- or himself both physically and “in your head” from traditional church, family, and other cultural roles and responsibilities.

Tiatia argues for change within the church structures that go beyond simply "modernising" the church. What is necessary, she believes, is for all those who engage within that context (in terms of age, gender, place of birth, language fluency, and even interpretation of scripture) to come to a compromise and address the underlying issues of power and authority that exist in the traditional Pacific churches. It is the existence and maintenance of the traditional hierarchies of power that inhibit participation by young Pacific people in the churches, she claims. Should such a compromise be reached, it is more likely that young New Zealand-borns could find "their place" in the church. It would then be possible for them to further contribute to changes to the structures and processes within the church.

Tiatia's work confirms the social reality of different contexts or settings in the daily lives of these young people. While she describes young people "caught between" two cultures as leading a "shackled existence" (1998:13), she also describes how Pacific youth have also "exited” to other churches, or away from the church as an institution altogether.

Fei Taule'ale'ausumai (2000) records the stories of nine Pacific women from different Pacific ethnic groups who have been ordained to the ministry in the Presbyterian Church of Aotearoa New Zealand (PCANZ). ${ }^{16}$ The church has provided "spaces", she claims, for such women to serve their communities and maintain their ethnic language and identity. In the course of their unique positions within PCANZ, they continue to contribute significantly to the pastoral care and affirmation of their Pacific (and non-Pacific) congregations as well as influencing Palagi/Päkehä ministers who serve Pacific communities. It is interesting to note that in some cases being a minister (and being single) would be an impossible

16 In 2002 PCANZ set up its Pacific Synod thereby establishing at a national organisational level a structure to serve the needs of Pacific parishioners and parishes. It increased the power and influence of the collectives of Pacific groups within PCANZ such that they now play a key role in the development of overall policies and in the running of PCANZ. 
position for these women to achieve and maintain in their Pacific countries of origin.

The narratives in this book by Taule'ale'ausumai attest to the fact that being Pacific women ministers within the wider church means having the responsibility to empower themselves and to empower others. This group of Pacific women ministers continues to promote a theology of social justice for all women, and provides spaces for the spiritual growth of other Pacific peoples. Alongside the growing participation of women from all ethnic groups in ministry, the presence of Pacific women ministers in the church challenges the traditional hierarchies that for so long have been male dominated and culturally dominated by European, Victorian values and beliefs. The Presbyterian Church is not alone in its need to be more culturally inclusive, since the Pacific parishes are probably still the strongest in numbers and the highest in participation rates.

In Anae’s (1998) study, which has already been cited, her English-speaking New Zealand-born Samoan interviewees all belonged to the Pacific Islands Church in Newton, Auckland, which is part of PCANZ. In their narratives her participants share their experiences about being within the church structures and practices, but also about having the choice to "opt out” and/or being able to take their cultural identities into other social contexts with like-minded members of the English Speaking Group (ESG) ${ }^{17}$. Indeed, Anae describes the church as "a battleground of change" (1998: 257) and this description is consistent with her view of identity/identities moving from being non-secured towards more secured ones that remain fixed "regardless of further challenges” (1998:359).

The Pacific churches in Aotearoa New Zealand remain institutions in which Pacific values, beliefs and practices are part of the dominant discourse. In addition, the survival of most of the Pacific languages can be attributed to the early church missionaries across the Pacific who translated the Bible into the various vernaculars. As a result, literacy in the Pacific nations homelands was virtually universal in the 19th century (Mara, Foliaki \& Coxon, 1994:190). Consequently, the first and successive waves of Pacific migrants to New Zealand flocked to the churches as their main social institution where their cultures and

17 This was an initiative established within PCANZ which was given status and rights to ensure New Zealand-born members voices would be heard and heeded. Originally this group was formed at Edinburgh Street (Newton) PIC in 1972 and later adopted throughout the Presbyterian Church (Taulealeausumai, 2001). 
languages were heard and used. The church was also their main support in adapting to the new society. The decline in regular church attendance observed in the wider New Zealand society is not replicated in Pacific churches or congregations. Even though attendance patterns may be changing for Pacific peoples particularly the young (according to Tiatia), the rituals of prayer, the sharing of Bible passages and the saying of grace before meals are all still essential parts of any Pacific gatherings wherever they might be held.

Emotional, lineal and spiritual "ties" are particularly important within Pacific cultural groups, where the maintenance of extended family ties, as acted out in many cultural practices, are vital to the group's cultural survival in a society where they are not the majority. There can be harsh consequences for the individual of any real or imagined “moving away" from membership of the group, resulting in emotional and cultural alienation, or even banishment, from the family group.

\section{The wider society and Pacific women}

Across all social institutions and the wider society the norms and values of the dominant groups prevail. In the wider society of Aotearoa New Zealand Pacific women to some extent share the consequences of the ways in which women in all other groups are categorised and treated in relation to men. They also share some of the daily experiences common to all other immigrant groups to New Zealand, as members of minority groups, as workers, students, self-employed people, and so on.

Meanwhile, the large bureaucracies and institutions have been constantly changing and restructuring as a result of social, historical, economic and political conditions. It is not clear to what degree, if at all, the relative economic and social position of particular Pacific ethnic persons and groups in the wider New Zealand society has changed; although the social indicators relating to the position of Pacific peoples have already described in Chapter 3 suggest some variance in life chances. My study has not made gender or social class a specific focus in relation to cultural or ethnic group membership, even though a closer examination of key social indicators does to some extent link gender and social class disadvantage with ethnicity.

Writers such as Pearson (1990), Macpherson (2001) and Spoonley (2001) have documented the sociological processes relating to the construction of the various 
identities of Pacific peoples since the time they began to migrate from the various Pacific nations and settled in this country in the 1940s and 1950s. These sociologists have comprehensively described the history of Pacific peoples in Aotearoa New Zealand who came to this country primarily as migrant labour. Pacific peoples migrated willingly because of the employment and educational opportunities available, and as the strain on local resources, as a result of growing populations began to take their toll on the small island nations.

To a large extent, social relationships between Pacific and other ethnic groupings in this country have been limited to sensationalist reactions to "overstayers", the highlighting of criminal behaviour among immigrants and high profiling of Pacific individuals in the media. For example, general knowledge about Pacific ethnic groups is mostly limited to what is known about famous Pacific entertainers and high-performing Pacific sportspeople (Fleras \& Spoonley:1999).

According to Macpherson (2001), Pacific cultures and identities are being redefined in terms of the diversities within the wider grouping we call "Pacific". This has been caused by wider social and demographic influences (that are the contexts of this ethnic transformation) and political and legal changes in this society. Individual Pacific "actors" have also participated in the construction of new identities in response to these changes. Macpherson states that new social spaces have encouraged Pacific individuals to deconstruct existing beliefs and traditions. He comments specifically on the roles of Pacific women as social actors:

Changes in the role and influence of women occurred in Pacific migrant enclaves. Within the migrant societies opportunities for women to work and to earn extended their economic and political influence within family and village networks and within congregations. Within the host society, education, growing support for legal recognition and the enforcement of women's rights, the existence of social welfare provisions which allowed them to leave unsatisfactory relationships and to live independently as sole parents served to transform their influence in migrant societies (Macpherson, 2001:73).

It is not clear whether Macpherson is linking any changes in the role of Pacific women with all women in New Zealand across the same time span. He does, however, demonstrate clearly the importance of forces in the wider social context and their influence on the formation of Pacific identities, and confirm that Pacific women have begun to assert themselves in terms of accessing entitlements and 
other resources intended for them. In circumstances such as these they come into contact with members of other ethnic groups in the wider society.

Further reference to Pacific women is made in Chapter 6 as part of a discussion about the connections between ethnicity, gender and identity.

\section{The tertiary education institution as part of the wider society}

The relationship of tertiary education institutions with the wider society is an important one for Pacific ethnic groups. For these ethnic groups, the gaining of tertiary educational qualifications has historically been the accepted route out of poverty and a step towards wider career and occupational choices, greater wealth, increased security of position, and a greater measure of influence in the wider society in social, economic, cultural and political contexts. This change in social and economic position is not to be achieved for the advancement of the individual concerned, however, but for the honour and status of the wider family and for Pacific communities here in New Zealand. Many of the narratives collected in Anae (1998) and McAlpine Petelo (2003) attest to the value placed on group achievement and the implications of high expectations placed on Pacific graduates.

The main policy response to Pacific community expectations in relation to tertiary education and their place in it was the Tertiary Education Advisory Commission's (TEAC) 2002 Report that outlined issues related to tertiary education and Pacific peoples and the role of tertiary educational institutions in New Zealand:

\footnotetext{
The strengths that exist within Pacific communities cannot be sustained if their educational aspirations are not met and the opportunities for their participation in society are not radically improved. These are challenges that confront the tertiary system - firstly in relation to informing our identity as a Pacific nation, and secondly, in being informed by the contributions of the Pacific people. It is therefore equally important that the tertiary system recognises the contribution, and fosters the participation, of Pacific peoples and their cultures. The tertiary education system must enable effective engagement with Pacific communities and seek ways to ensure it is responsive to the needs of Pacific peoples (2002: 20).
}

This is an important statement about the role of tertiary institutions in the improvement of Pacific ethnic groups and communities in Aotearoa New Zealand across a range of social indicators. The commission subsequently published its strategy: Inspiring Excellence for Pacific Peoples throughout Tertiary Education: Pacific Peoples Strategy in 2004 to 2006 and Beyond, which detailed key 
outcome areas. These included capability building and sector accountability for Pacific outcomes, including opportunities and access for Pacific peoples to excel throughout the tertiary sector.

It is argued that, for Pacific students to take up opportunities for study, institutions have to provide more flexibility in terms of timing and opportunities for them to take up study. In response to a suggestion by the TEAC report in 2001 that open entry to university for those over the age of 21 be removed, Davey et al. suggested this would:

... curtail opportunities for prospective students who are older; who can benefit from study and who often go on to develop enhanced and secure positions in paid work ... people should be encouraged to prolong their working careers, reducing dependence on the state and premature retirement ... lifelong education and attendance at university should be promoted as a viable option for people of all ages and as a way of assisting people to cope in a changing society (Davey et al., 2003: 186-187)

Further, they note that policies related to employment, family support, income maintenance and ageing are all important and can potentially encourage or place barriers in the path of older students accessing tertiary education and training. Davey (2002) observes the increasing demand for more and higher formal qualifications that will determine access to many areas of paid work. In the wider context of technological innovation, globalisation, market liberalisation and greater destabilisation of labour markets, career paths are less straightforward. Consequently, retraining and upgrading of qualifications is already part of the contemporary employment scene. Any barriers to access would therefore have significant employment, housing and health outcomes for Pacific communities in Aotearoa New Zealand.

In the final analysis, however, changes to tertiary education institutions to ensure they are responsive to, for example, what Pacific women bring into them will only be made by concession and probably more by economic or financial imperatives than anything else. In conjunction with negative political agendas relating to race differences, and a growing backlash to the provision of so-called "special treatment”, Pacific women by entering tertiary education will not necessarily avoid the treatment and categorisation they are subjected to in the wider society. 


\section{Summary}

In this chapter I have considered studies from fields beyond sociology that provide a richer background to this study of Pacific women graduates. These studies confirm the importance of social settings when considering cultural and ethnic identities and how they may be formed. However, no work to date appears to have looked more closely or consistently at the social processes within these settings that contribute to the formation of ethnic identity, nor how it might change over time. Nor do they propose ways in which social realities and lived experiences can be interpreted to shed light on those processes. Research reviewed in this chapter confirm that social institutions such as educational institutions are legitimate contexts for study when attempting to find out how Pacific ethnic identities are constructed, and when describing the nature of ethnic identity construction processes within those settings or contexts.

In the following chapter I leave aside the discussion about settings for the time being and begin to explore the definitions and meanings of ethnicity and identity. 


\section{CHAPTER 5: IDENTITY AND ETHNICITY}

\section{Introduction and overview}

The terms identity and ethnic identity are represented variously in the literature and as such this review seeks some clarity on these terms. Most, but not all, of the following literature comes from sociological perspectives.

Spoonley, Pearson and Macpherson (1991: 10), sociologists who have studied Pacific ethnic identities in Aotearoa New Zealand, recommend that the meanings and ambiguities of such terms as "race", "ethnicity" and "identity" need to be acknowledged because they are always contestable terms. The use of these terms, they write, should not hinder but rather facilitate communication between researchers and policy-makers alike. This chapter therefore begins with two studies that review identity as a sociological concept. Included in these two reviews are suggestions about the ways in which sociologists should research identity, including ethnic identities.

\section{Identity, group identity and identity politics}

Brubaker and Cooper (2000) write about the "identity crisis" in the social sciences in regard to the term "identity". In their wide-ranging article "Beyond Identity", they trace the use of identity from Erik Erikson's “identity crisis” in the 1960s (arising from a psychological perspective), including the link between identity and ethnicity in Gordon Allport's book on The Nature of Prejudice (1954), in which he pioneered some of the key sociological definitions of identity.

Brubaker and Cooper suggest that the term "identity" should be used by sociologists both as "a category of practice” and as "a category of analysis”. By category of practice the writers mean the everyday use of the word "identity" by social actors to make sense of themselves, their activities, what they share with others, and how they are different from each other. In other words, when individual self-identified members of a defined social group (including an ethnic group) are describing themselves and the nature of their membership of that group, then the term "identity” is used as a category of practice.

By using the term "identity” as a category of analysis, Brubaker and Cooper say sociologists are theorising and conceptualising identity and attempting to explain ideas about identity. They admit that, while identity is used both as categories of 
practice and categories of analysis when referring to identity one cannot simply be substituted for the other. In fact, they suggest, researchers should make clear which category they are using, and in what situations different meanings apply. In reviewing the ways in which identity is used, Brubaker and Cooper argue that meaning depends on context, and the theoretical tradition it is derived from. “Identity”, as an analytical concept, has been used uncritically across a range of disciplines. Brubaker and Cooper contend that: "the term identity is made to do a great deal of work", is ambiguous, and "bears a contradictory theoretical burden” (2000: 8).

The writers also detail "strong" and "weak" understandings of identity. The "strong” understandings of identity are the "commonsense” meanings such as: identity is something everyone has, ought to have or is searching for; something all groups have or ought to have (ethnic, racial or national); or something people can have without knowing it, but can also discover subsequently by following a process of becoming conscious of that group identity, (e.g., social class). Further, collective identity implies strong notions of group boundedness and homogeneity, implying sameness within the group, a clear distinction exerted by people outside the group, and a clear boundary between those inside and outside the group.

In contrast, "weak" understandings are not everyday meanings of the term “identity”. They include conceptions of multiple, fragmented, unstable, negotiated, or constructed identities, which are now familiar in the post-modern, post-structuralist literature. Brubaker and Cooper say that it is not clear what meaning identity has in this fluid and diverse state. If, indeed, this conception of identity prevails, then it is contradictory to a unified "core” of identity that persists across a range of contexts which are themselves also changing. The "weak" understandings, therefore, make it difficult for researchers to use "identity" as a tool for serious analysis and theorising (Brubaker and Cooper, 2000). ${ }^{18}$

Brubaker and Cooper critique studies by Somers (1992), who uses narrative to describe identity. She places narratives within specific contexts of time, space and “relationality” and shows how narratives constitute social actors within the social world in which they act. However, Brubaker and Cooper still question how the

18 The concept of "multiple identities" is a term used by Pacific researchers such as Tupuola (1998). However, her analysis is based on developmental psychological definitions and accounts of Samoan identity in Aotearoa New Zealand. Her narratives are used to argue against a staged developmental formation of an ethnic identity. 
concept of identity is made clear from the use of narrative methodology. Somers' placement of narratives within contexts of time, space and relationality does not in itself, they argue, show how identities are then constructed.

Brubaker and Cooper "unpack" identity into three areas of understanding for sociologists: first, identification and categorisation; second, self-understanding and social location; and third, commonality, connectedness and groupness. Across these areas are overlaid the derivatives of "strong" and "weak" meanings of identity that subsequently have implications for social action (derived from strong meanings) and implications for analysis (derived from weak meanings). Consequently, according to Brubaker and Cooper, the role played by the researcher/social scientist may be either that of an analyst or of a protagonist, or both.

They describe the three areas of understanding identity as follows:

Identification and categorisation: relational categorisation is where one holds a position in a kinship web or a relationship such as client-patron or teacher-student; includes the broad categories such as ethnicity, gender and so on; being categorised by powerful “others" such as the state and through legitimated symbolic force (see Bourdieu, Freire, Foucault) and, identification as an outcome or a process, e.g. as a result of social consciousness

Self-understanding and social location: one's own understanding or perspective; selfconception; this is also influenced by the conception of others and external social processes such as colonisation, oppression, victim-blaming and self-fulfilling prophesy

Commonality, connectedness and groupness: the sharing of some common attributes with others in the same group; relational ties connecting to other people; the experience of a distinct belonging to a bounded solidary group; a feeling of belonging together shaped by events and wider public narrative

(Brubaker \& Cooper, 2000: 14-21).

The authors recognise there are differences between individual group members' self-identification, overall group self-identification, and being identified and classified by outside (possibly more powerful) others. Further, that how sociologists study identity, including ethnic identity, will depend on the meanings or understandings their work is based on. That is, strong meanings or understandings of identity can be used as a base for social action, while weak meanings or understandings can be used as a base for social analysis. 
Researching identity, Karen Cerulo (1997) reviews theories of identity construction since the 1970s and notes the refocus of attention by researchers away from interactions and processes that shape an individual's sense of self towards a focus on collective identities. That discourse, she claims, has been given higher priority, resulting in identity being more as a source of mobilisation rather than as a product of it. Since social constructionism, claims Cerulo, informs most of the research on gender, ethnicity and race, she notes a corresponding increasing scrutiny of socialisation and the family context.

Cerulo describes three trends in identity research over the previous twenty years. The first is toward increasing interest in group agency and political action. The second is interest in identification processes at the level of the collective and an examination of how distinctions are created, maintained and changed. Thirdly, identity is being studied as the establishment of "communities of the mind" and the negotiation of "co-present" and cyberspace identities. ${ }^{19}$ Such globalised definitions of ethnic identity and new definitions of cyberspace communities (beyond geographic location and migrations) provide researchers with a range of challenges, including ones of method and analysis.

Cerulo highlights a number of trends in identity construction research and ethnic identification processes. For example, she cites Waters (1990), who looked at how individuals cling to their ethnicity apparently in the face of great odds. Cerulo contends that ethnic identification must have some payoffs for people and must therefore be the product of individual choice-particularly for those with mixed ancestry, who can choose to "adopt or stress” their different primary affiliations. Waters suggests that a commitment to ethnic identity stems from a culturally based need for community or connectedness (1997: 389).

Cerulo describes the post-modernist deconstruction of identity categories, how the variation within categories such as women, working class, and so on are as important as variation between identity categories. Post-modernists, she writes, elevate concerns with public discourse as well as deconstruct traditional identity categories and the rhetoric that these categories do actually explore the full range and meanings of identity. These theorists claim to expose the ways through which

19 Spoonley (2001) and Franklin (2003) write about the trans-national, global, and virtual identities of Pacific peoples and how the use of new technologies has the potential to alter current perspectives of identity. 
discourse, which is "objectified as truth", forms and sustains collective definitions, social arrangements, and hierarchies of power.

As outlined earlier, the literature has raised debates about whether collective identities are formed as a result of mobilisation or social action, or whether collectivity per se leads to mobilisation. These processes are the domain of identity politics which are described by Cerulo, with reference to work by Melucci (1989), and Taylor (1985 \& 1989), in the following way:

Identity politics and new social movements suggest a special form of agency-a selfconscious “collective agency." Identities emerge and movements ensue because collectives consciously co-ordinate action: group members consciously develop offences and defences, consciously insulate, differentiate, and mark, co-operate and compete, persuade and coerce. In such a context agency encompasses more than the control and transformation of one’s social environment (Cerulo, 1997: 393-394).

As Cerulo says, the studies that are based on the analysis of discourse and the symbols of collective identity (cultural, material and spiritual) provide a multilayered analysis of collective identification and its supporting ideologies. Cerulo also raises the issue of how electronic media reorganise the settings of social interaction and reconfigure the boundaries of separate identities into those that are online and those who are not online. In terms of Pacific youth in New Zealand, the new communication technologies have meant the development of Pacific websites as well as the production of Pacific film, music and other artistic development and expression that can now instantly "go global” via cell phones and email.

Finally, Cerulo examines some cross-discipline issues in research examining identity construction. Social psychology, for example, looks at cognitive processes, social practices and symbolic tools that construct, enact and project identity. Sociologists, according to Cerulo, need to be prepared to take these factors into account when considering collective identities. She also examines the link between the sociological analysis of identity and the concept of identity from the position of a researcher in humanist or cultural studies. Culturalist paradigms consider symbols (material and nonmaterial), rituals and practices of groups, and their shared world views, as constructing identity. Sociologists, she claims, cannot ignore these explanations and processes that construct identities.

However, the difference, according to Cerulo, between the cultural studies position and the sociologist's position is that a sociological analysis focuses on the processes of actors, collectives and broader social institutions and their roles in the 
construction of identity. If sociologists give careful consideration to lived experiences, and the cultural products and rituals associated with them, then the links between social and cultural domains will be more clearly described (Cerulo, 1997: 401-402). ${ }^{20}$

It may at first appear convenient to separate psychological, sociological and cultural identity construction, but some examples from the literature blur these distinctions. One such instance, which is pertinent to this study of Pacific women, is Melanie Anae's (1998) study of Samoan identity formation in a group of non Samoan-speaking young adults in Aotearoa New Zealand. Anae employs the notion of "identity journeys" as a metaphor for depicting identity construction. She also argues for identity formation being contextual, although this is not clearly defined. The one context she describes as relevant to her research participants is the church and, in particular, the structures and social and cultural interactions enacted at the Pacific Islands Church (PIC) in Newton, Auckland.

Anae describes a process whereby "non-secured” identities become "secured". Once attained, these secured identities remain fixed "regardless of further challenges” (1998:359). Samoan identities are therefore formed during the processes of negotiation and construction of social roles. Anae argues that "at the core” is a persistent identity system (1998:361), in line with primordialist views of ethnic identity. ${ }^{21}$ Samoans, she writes, as enduring peoples, continue to possess this ethnic identity “core”. The narratives in her study provide evidence of many of these enduring or core values. These values are embodied within such symbols as Samoan proverbs, legends, poetry, fa'a Samoa (including the Samoan language), biblical and Christian values and Samoan worldviews.

Further, Anae makes the case that in the pursuit of more secured identities, her Samoan participants take time and space to "opt out” in order to act out their confusion, rage and anger, and that these can be described as features of a non-

20 Although Cerulo does not specifically refer to narratives in the same way as Somers (1992), the assumption could be made that the "lived experiences" of ethnic identity could be evidenced through personal and group narratives, thereby more clearly describing the links between the social and cultural aspects of ethnic identity.

21 The term primordialist will be discussed in more detail later in the thesis. At this point the primordialist explanation of ethnic identity relates to those aspects such as the physical, genetic inheritance including lineage and ancestry that are fixed, not subject to change in terms of environment or circumstance. The individual or group feelings associated with these aspects are also important in the primordialist explanation of ethnic identity. Tilley (1997) reviews the related terms of primordialism and constructivism and their relationship to ethnicity. 
secured identity. Within this "space” individuals develop coping mechanisms that assist them in attaining more secured identities. In this analysis, Anae concentrates on those "inside" the Samoan English-speaking group and only briefly describes how “outsiders” treat them. Anae's description of ethnic identity borders on the psychological as well as locating itself within the culturalist analysis and demonstrates how research evidence of people's own experiences can be interpreted using a culturalist (anthropological) approach, a psychological approach, or sociological interpretations of identity.

\section{The terms ethnicity and ethnic identity}

Pearson (1990) clarifies ethnicity as a concept in line with Anthony Smith's (1984) description of the characteristics of an ethnic community or ethnic group: they have a collective name, a common myth of descent, a shared history, a distinctive shared culture, an association with a particular territory, and a sense of solidarity. It is this solidarity that marks out an ethnic community from an ethnic group or category. Further, Pearson describes one perspective of ethnic identification which argues that ethnicity is not a fixed, timeless attachment, but one that changes in response to specific situations, wider social circumstances, and social changes within the dynamics of insider and outsider relations. For example:

Ethnic identification is a process of defining the limits of what constitutes "us" as a group and "me" within that group. Racism is related to beliefs and practices that define "them". Both of these processes are social constructions. What I am concerned with is how people make sense of their surroundings and the similarities and differences they see between themselves and others (Pearson, 1990: 17).

Pearson quotes Jenkins (1986), who provides a clear distinction between identification and categorisation of ethnic identity. According to Jenkins, ethnicity is identification within the group and racism is a form of categorisation from outside group boundaries. An ethnic group can take upon itself the categorisations imposed on it by others in both positive and negative ways. In some cases the ethnic group may come to believe, for example, that its own disadvantaged position is 'natural'. In other words, such an accepted and non-contested positioning of the ethnic group is an example of hegemony. Sometimes this subordinate positioning can also act as a spur to consolidate group determination to change this positioning and thereby strengthen group solidarity even further. Levels of self and group identity may vary over time and circumstances, but there 
is no doubt that ethnicity is constructed during the processes of self and group identification.

The terms “dominant discourses”, “dominant groups” and “dominant interests” are terms used throughout the literature in reference to the inferior position of minority ethnic groups such as Pacific peoples in Aotearoa New Zealand. Pearson provides a clear summary of the patterns of dominance in our society and the role of the state in establishing and maintaining these patterns:

[The state] is a set of institutions within which both majority and minority groups struggle to maintain or improve their power positions. The state can be the instrument of control or of emancipation. However, given the power imbalances between classes, sexes, and ethnic groups, the odds are always stacked in favour of the rulers as opposed to the ruled. In ethnic terms, it is Päkehä élites who have most influenced the shaping of political, economic and symbolic institutions, and they continue to have the edge maintaining this position (Pearson, 1990:145).

In their work on racialised boundaries and ethnicity Anthias and Yuval-Davis (1992) describe ethnic groups as being surrounded by boundaries that relate clearly to who can or cannot belong. They describe a wide range of criteria for belonging to a particular group, which correlate with those described by Pearson: being born into it (ancestry); conforming to cultural or other symbolic practices; speaking the same language; and behaving in certain kinds of preferred and valued ways. For example, most Pacific groups value humility and respect for elders and maintain social capital by ensuring such hierarchies of respect continue. Individual behaviours that are contrary to the expression of these values can bring cultural alienation or, at the very least, bring into question one's ethnic group membership by those with recognised authority within the group. Similarly, fluency in speaking Samoan, Tongan, Cook Island Mäori, or the Niuean language is often valued as one of a number of criteria for being a "real” member of those groups. However, even these criteria for group membership can change over time, according to usefulness and relevance and the power of those within or outside the group to define the criteria for membership.

Anthias and Yuval-Davis write that ethnicity and ethnic boundaries can become the basis for wider societal and/or political claims by ethnic groups:

Although the boundaries are ideological they involve material practices, and therefore material origins and effects. The boundary is a space for struggle and negotiation. Ethnic resources (such as language, culture, religion, gender relations) can be used in 
interplay with the class and political resources and positionings of the group. Ethnic processes are often implicated therefore in the pursuit of diverse political ends. They may include exclusionary and inclusionary practices for maintaining the privileges along a number of different dimensions, or for countering those of other groups. Ethnicity can therefore be a medium for class, nation or state formation (Anthias \& Yuval- Davis, 1992: 4-5).

Ethnic boundaries, therefore, do change over time and do change in response to economic, political or ideological conditions. Where and how boundaries are constructed depends on contextual and relational factors and as a result can vary. For example, an individual can identify as being "brown”, Pacific, Tongan, a coconut, FOB (fresh off the boat), and so on. These categories may imply different meanings and different boundaries to the outsider, but to members of the group it is acceptable for individuals to concurrently and/or sequentially identify across these groupings and boundaries. The key question here is: in what contexts and by whom have these categories been created and maintained? It is interesting to note that a number of these categories were originally used by dominant groups as negative stereotypes and put-downs. Subsequently, the terms have been adopted by the members of the groups themselves as "trendy", somewhat humorous, and marketable, particularly when placed on Pacific ethnic T-shirts.

Anthias and Yuval-Davis remind us that ethnic positioning affords the individual group member with different ways of interpreting the world. These worldviews are based on shared cultural resources and collective positioning in relation to other ethnic groups in the society. When members of cultural and ethnic groups express their differences in language or cultural practices in the wider society they immediately become located within structures of dominance and contestation such that social class, gender, and sexuality divisions within society, and the various ways they are positioned, have significant implications for them.

To take their argument one step further, ethnic, gender and class divisions involve differential access to resources and different processes of exclusion and inclusion; they involve different systems of representation of the capacities and needs of ethnic minority groups. Exclusionary processes and subordination can be legitimised by describing differences as deficient (victim-blaming) and the inability of ethnic group members to seize opportunities that are there for “everyone”. Such differences and deficiencies become "naturalised” (accepted as natural) and then become legitimate reasons for social and economic inequalities. 
According to Anthias and Yuval-Davis, the state has an important role to play in the structuring and implementing of policies for access to resources and for addressing unequal participation and inequalities of outcomes for marginalised ethnic groups. I have already discussed specific policy responses to Pacific peoples in Aotearoa New Zealand in Chapter 3.

\section{Summary}

In this chapter I have reviewed research that contributes to the discussion and clarification of the terms identity, ethnicity and ethnic identity. Brubaker and Cooper, Cerulo, Pearson, and Anthias and Yuval Davis have emphasised the sociological analysis of identity and ethnic identity in terms of group identity. They have used the terms "boundaries" and the role of "insiders" and "outsiders" (members and non-members) of the ethnic group and how they describe themselves and others. Such descriptions have varying force and influence to the extent that the groups have access to resources, and their social positioning involves economic, political and cultural power and status. Ideas about the processes of inclusion and exclusion in terms of group self-definitions also emerged from the literature.

The cited literature advanced my thinking to some extent about these terms, but none of the works provided an over-arching, coherent theoretical framework, derived exclusively from a sociological perspective, to assist me in the analysis of my data or in answering my research question. The major work that provided a framework for the study of ethnic identity construction for this study of Pacific women graduates, is that of Stephen Cornell and Douglas Hartmann (1998), which is described in more detail in Chapter 7: Constructing and Situating Ethnic Identities.

But before moving to a discussion of their perspective, in the next chapter I look at the connections made both by New Zealand and overseas researchers between ethnic and gender identities, and how they are socially constructed. 


\section{CHAPTER 6: ETHNICITY, GENDER AND IDENTITY}

\section{Introduction}

Although the main focus of this thesis is on the social construction of ethnic identity, the reasons for including background evidence that makes connections between ethnicity and gender need to be outlined. Firstly, the participants in this study are Pacific women and, like all women in Aotearoa New Zealand, are participants, consumers, and subjects of a range of social, political and economic institutions and a range of social forces in New Zealand society. Secondly, colonisation, migration and other historical changes that have acted to oppress and marginalise ethnic minority groups have affected the lives of Pacific women in particular ways and thereby determined their life chances and life choices, since thirdly, all racial and ethnic groups have throughout history assigned particular roles and responsibilities to their females. Alongside all other women in Aotearoa New Zealand, Pacific women, as a group, have been affected by the prevailing social and historical circumstances. As a consequence, Pacific women are now, in slowly increasing numbers, entering non-traditional roles and positions of responsibility in public institutions that were previously occupied exclusively by white European /Päkehä/popa'a males.

My own critical sociological analysis of the social construction of gender was developed in my Master's thesis on the role of Pacific women in education initiatives in Aotearoa New Zealand (Mara, 1995). There, I took the stance that, despite the marginal position of Pacific women in the wider society of New Zealand they have been critical actors in, for example, the establishment and growth of Pacific Island early childhood education groups. Such groups were set up to help Pacific communities maintain and promote their Pacific ethnic languages and cultures (Mara et al., 1994: 208). These educational initiatives have been analysed in terms of educational policy development in New Zealand (Coxon \& Mara, 2000: 177) and in terms of the traditional roles of Samoan women (Utumapu, 1998). In this way, Samoan and other Pacific women have asserted their cultural identities by establishing a small but important niche within the wider early childhood education sector in Aotearoa New Zealand in contrast to Mäori, Päkehä and other ethnic groups.

As more Pacific women enter tertiary and higher education these settings have provided opportunities for them to write about and to carry out research on their 
daily lives from their own cultural perspectives. As the volume of research by Pacific women has increased, so have discussions about Pacific ways of knowing and about constructing knowledge in the "Pacific way". It is interesting to note that to date most of this critique and analysis has been carried out by Pacific women academics rather than Pacific men. It is likely that they do not study subjects that lead to such analysis.

\section{Ethnic identity in the tertiary setting}

As more Pacific women enter into tertiary education, research by them and about them and their daily lives is increasing.

McAlpine Petelo (2003) in her study of Samoan students at Canterbury University discussed the concept of resistance in relation to their positioning within that tertiary education institution. Using a feminist post-structuralist analysis she developed a concept of resistance that mentions, in line with Sparks (1995), that individuals and structures are involved in the processes of resistance.

McAlpine Petelo described the range of ways that the students engaged in resistance in the tertiary education context. Firstly, she described non-participation or even withdrawal from tertiary study as a form of resistance to dominant and mainstream educational values. Like all other processes and actions, resistance is described as multiple, contradictory and complex. Petelo argued that a poststructural analysis produces alternate subjectivities and discourses that can be used to contest and struggle against the domination, exploitation and subjection of more powerful groups in society. McAlpine Petelo argued, in line with Foucault's view, that relations of power always allow for opposition and resistance to its effects. Since people are never fixed as subjects, her argument continues, this multiplicity leads to instability which then allows for struggle and change and consequently opens up the opportunities for resistance.

McAlpine Petelo shows that on one level the students' acceptance of the structures and practices of the university could be read as total compliance and conformity, since they did not engage in collective or confrontational behaviour.

But this does not mean that the students did not resist. A deeper analysis shows that silence is a culturally constructed strategy employed by the students, since confrontation of elders in Samoan society is not tolerated. In the tertiary institution, therefore, resistance can be shown by emotional withdrawal or musu, 
by relocating to the back of the classroom or lecture theatre, by leaving classes or tutorials without warning, by not confronting ill-treatment or stereotyping, and so on. ${ }^{22}$

McAlpine Petelo reported that the Samoan students' participation in her research and in the focus groups with other Samoan students was seen by them as a form of resistance-a way to voice their concerns without having to contemplate any repercussions for themselves individually. Just as the students found some "safe places” with other Samoan students, they also saw McAlpine Petelo's research as another opportunity to network as a resistance to being alienated and assimilated into the larger institution and the dominant discourses.

Resistance is also contradictory because, in theory, students can choose whether to stay or to leave the tertiary site. McAlpine Petelo found, however, that families/aiga played a very large role in students' choices in terms of courses and whether leaving the tertiary education context was indeed an option. She argues that as researcher-activists we need to be open to the ways in which our Pacific students "resist" within the tertiary educational institutions, since these hold out the possibilities of transformation within these settings.

Resistance is always possible, where acts of resistance within discourses do not necessarily disrupt existing power relations. It is possible to accommodate to discourse and undertake acts of resistance to discourse at the same time (McAlpine Petelo, 2003: 267).

In terms of social class position, Paasse (1998) investigated the ways in which identity can change or "shift" as a result of exposure to the discourses of university education in Australia. She used a case study approach with mature women students who identified themselves as working class. Her premise was that identity is multiple, shifting, and often self-contradictory, and is made up of diverse representations of gender, race, ethnicity and class. Paasse wanted to find out if there were any impacts to self-identification when mature women went back to study at university. Her research participants liked being treated as educated people, even though they felt embarrassed at first.

22 I agree with Petelo when she writes that the only problem with these passive forms of resistance exhibited by the students is that they do not necessarily lead to resolution or change in terms of the power relationships or structural elements of the tertiary education settings. Even though the students consciously and unconsciously resist, the dominant practices and processes continue to overshadow or impede any authentic inclusion or understanding of the cultural meanings of the resistant behaviour exhibited by the minority ethnic group students. 
Alongside the joys of newfound self-efficacy, of belonging to and participating in new discourses and social groups, Paasse's study also revealed the contradictions and the tensions for the women between themselves and their families regarding a number of “identity changes". These centred around now being labelled “feminist”, about always questioning things, being less tolerant of ignorance, and having less in common with friends than they had before they started studying. The narratives of these working class women also showed that they could articulate the "shifts" in their identities and that they were conscious how in different contexts (such as the family and the university) they experienced their identities differently. As one participant said in the study: "You can't put the toothpaste back in the tube”, meaning that the shifts in identity, resulting from tertiary study could never be reversed.

Deem (1996) writes about her own life as a lecturer in sociology, sociology of education and women's studies to demonstrate that over the course of her academic career boundaries between disciplines have "shifted, blurred, disappeared, and sometimes reformed”. At the same time her own academic identities had also extended and changed. The blurring, shifting, and reforming of borders, Deem argues, allows for the development of new approaches, and creates “spaces” for innovation and creativity. Deem writes:

Living in border territory, belonging neither to one camp or the other, can enhance the willingness to take intellectual risks and permits an openness to new ideas that may be less characteristic of those who live within more defined and more central academic areas ... Marginality has its uses (1996: 16)

Marginality can also act to exclude, so that only some people may traverse the borders and return safely while others may not be able to do so. The concept of making "border crossings" in terms of academic identity has resonance with ethnic identity because it implies there are boundaries and borders to negotiate, to affirm or transform. All such social actions or movements into other contexts or settings are indicative of perceived power or agency of groups or individuals to so "move”, for them to break through perceived constraints in order to play a part in the making of themselves. 


\section{Pacific women: ethnicity and gender}

The following selections are the work of Pacific women academics about Pacific women from their own perspectives and interpretations of the world, constructed within their own cultural frameworks and settings.

Pihama and Mara (1994) looked at the roles of Pacific women (Vaine Pacifica) and Wahine Mäori in Aotearoa New Zealand. As previously mentioned, various gender theories and analyses were also outlined in their writing. A growing number of Pacific women have written about and critiqued their social roles and position in the realities and contexts in which they live their daily lives.

Sua'ali'i (2000) is one of the few Samoan researchers who have attempted to deconstruct some of the meanings of being a Pacific Island woman in representations of Pacific women as “exotic beauties”. Sua'ali’i analyses pictorial representations of Pacific women in magazines, posters, postcards and other published material using definitions consistent with Said (1978) who writes about the "other" in comparison to the West and about the "foreign" or "exotic". She analyses the exotic images of Pacific women in terms of: the "Orientalised Other"; "Tourism and the Exotic"; "the Exotic as Occult”; and the "Exotic as pornographic”. These images of Pacific women have largely been constructed by “white male describers", expressly for the consumption of the white male, writes Suaali'i. These processes originated within a colonial and patriarchal paradigm where "brown” women are depicted as “actively savage and passively sensual, naive and sexually available”. Images of Pacific women have been used to market tourism, music, and movies. Deconstruction and critique, Suaali'i reminds us, is vital as Pacific women actively resist such oppressive social constructions of who they are and who they can become in the 21st century.

One site of resistance is exemplified in the work of Tafili Utumapu (1998), who reviewed the traditional and changing roles of Samoan women involved in the setting up and running of aoga amata (Samoan early childhood language groups). Utumapu compares the traditional roles of wife and mother, and in particular the domestic duties that were part of the colonisation of Samoa when early missionary education was aimed at "producing suitable wives for future ministers who were studying at Seminary College” (1998: 37). Village women's committees functioned to ensure that village hosting of visitors was carried out, that the 
village was maintained and taken care of, and the women continued taking care of village child care and health.

In addition, the church and its missionaries in Samoa historically provided opportunities for unmarried women and wives of the congregation to take part in Sunday school teaching, choir, youth group, and Bible study. Within the Congregational Church a widowed, divorced, or unmarried spinster could work towards becoming a deacon. The role model with the highest status was (and still is) the pastor or minister's wife. She is the leader of all other women and oversees all the duties and responsibilities considered as the domain of women: hosting, maintaining the home, caring for the family, providing food and fundraising for the church.

Utumapu commented that involvement with the aoga amata meant that some women had better access to childcare in order to go out to paid employment, training, or unpaid work in their community. However, the women she interviewed still experienced stress as an outcome of unequal power relations between Samoan men and women. The stress she implies is shared by women from all ethnic groups in terms of "juggling” their many roles and expectations, especially in relation to those of their husbands. Being involved in language nests adds one more role to the many these Samoan women already had to fulfil. Utumapu also reflected on the inability of key institutions such as the church to accept women who, as a result of wider involvements, have become more independent in their views and demands. ${ }^{23}$

The apparent contradictions in the lives of Samoan women where service (tautua) and respect (mamalu) both guide and ostensibly limit personal time and individual rights are highlighted by Fairbairn-Dunlop (1996). She argues that service does not equate to dependency or marginalisation, since Samoan women are expected to take into their marriage the skills of self-sufficiency and leadership. The cultural expectation of women making decisions on behalf of their families means that assertion about their identity may also be possible, particularly when it is

23 When Pacific early childhood language groups become fully funded by the government they are called Pacific Island early childhood centres. Samoan centres are called aoga amata. These centres have to be run as small business enterprises and, as a consequence, Pacific women are now taking on management, financial and employer roles. This was an unintended and unexpected outcome of their desire to maintain their languages and cultures in Aotearoa New Zealand by providing early childhood education for their own children. 
being confronted or challenged in a new and unfamiliar context.

Migration to New Zealand made entry into the paid workforce by Pacific women automatic and inevitable, because there were children and extended family members to support both in New Zealand and "back home”. During the 1970s and 1980s low-skilled jobs were plentiful, so Pacific women could get jobs relatively easily in such places as laundries, factories, post offices, and as cleaners. Tamasese et al. (1988) in their submission to the New Zealand Royal Commission on Social Policy accurately depicted the lives of many Pacific women at that time when they wrote:

The journeys of our parents to New Zealand in search of a better life-style and to provide their children with a better education have been at tremendous cost. For our women and especially our mothers the common denominator of economic survival has meant that for many two or three low-paid jobs have become their way of life. The nocturnal exodus of Pacific Island women from their families into the empty government buildings (as cleaners) is well known. And yet Pacific Island women are expected by society to fulfil their nurturing responsibilities to their family while at the same time making significant contribution to their families daily bread (1988: 584).

Although there has been an improvement in the growth of human capital (training and qualifications) in Pacific groups, and for Pacific women specifically, they are still mostly confined to certain occupations and socio-economic groupings (see Chapter 3).

A growing number of life stories and histories about Pacific women in New Zealand are being published. Fairbairn-Dunlop (1996), Taule’ale’ausumai (2000), Anae-Ostler (2003), and Uta'i (2003) have made important contributions to the biographical heritage of all Pacific women in Aotearoa New Zealand. These are the women's stories told in their own words (in English and in their own Pacific languages). Life histories and contemporary social histories of Pacific women are also being told through media such as visual art, film, drama, opera and other performances, and are an exciting strand of New Zealand's contemporary arts culture involving the mass media. For example, Tangata Pasifika (13 October 2002), Television New Zealand (16 October 2004) and Television New Zealand (15 October 2004) document the changing roles and increasing levels of influence and participation in the wider society by Pacific ethnic groups, including Pacific women. 
Fairbairn-Dunlop and Makisi (2003) collected narratives that included eleven Pacific women relating their own identity journeys. Most of these narratives provided rich material about the family/aiga/feti'i setting and its importance in the construction of their cultural identities. The women explained how they had subsequently taken those values and practices with them into other spheres such as education and sport, employment and social service delivery. ${ }^{24}$

Pacific women in Aotearoa New Zealand are framed within migrant discourses, and inherited colonial and Christian discourses, and are socially and economically positioned in terms of lower socio-economic status. Similarly, the extent to which they are able to retain their languages, values and authentic elements of their cultural practices, for example, will be indicative of the degree of assertion or agency they are able to make within the wider society and social settings.

In large part, it could be claimed that the continuing assertion of Pacific identities in Aotearoa New Zealand will depend on Pacific women maintaining their roles as mothers, grandmothers and aunties and fulfilling the expectations that go with those roles. However, the within-ethnic group resolution of power differentials (which are not solely male-female differences, but include issues of status and gerontology) may in due course be pivotal to the direction and nature of that assertion. In terms of a sociological analysis, it is now commonly argued that power relationships are always contradictory, changing and never completely resolved, and are located within a certain historical context.

\section{Ethnicity, gender and power}

As previously described by Anthias and Yuval Davis, the boundary between cultural and ethnic groups is a space for struggle and negotiation. In terms of academic knowledge, one type of boundary that is potentially a space for negotiation and struggle is in the articulation of indigenous research methodologies. Such spaces provide opportunities for self-determination and for the constructing of new knowledge within another possible complementary paradigm. What emerges as important is a different framework, including

24 These narratives are important in ensuring that subsequent generations learn about Pacific migration stories (symbolic repertoires) but they also need to be further analysed to find out two important aspects of identity construction. That is, who exactly is the intended "audience" (insiders or outsiders) for their assertions? More importantly, what effects do these assertions have in strengthening or weakening Pacific ethnic group identification individually and collectively in Aotearoa New Zealand? 
indigenous ways of knowing, of developing knowledge and ways of learning as instances of assertion of ethnic identity. In other words, Pacific women engaged in a knowledge construction process can begin to define the differences between their cultural knowledge and those of other ethnic groups in the broader academy. This section of the chapter features the work of Pacific and Mäori women and their articulation of Pacific ways of knowing and being. The purpose of including it here is that it provides some distinguishing features that can be asserted as indigenous or Pacific. Firstly, I outline the seminal work of Linda Tuhiwai Smith, herself an indigenous women researcher in Aotearoa New Zealand. Smith's work has been highly influential in the growth and encouragement of the emerging work of Pacific women researchers and in helping them to articulate Pacific research paradigms.

\section{Power and assertion in indigenous research methodologies}

Linda Tuhiwai Smith (1999), when writing about indigenous research methodologies in Aotearoa New Zealand, draws on the work of Sandra Harding, who makes the clear distinction between methodology and method:

A research methodology is a theory and analysis of how research does or should proceed ... Methodology is important because it frames the questions being asked, determines the set of instruments and methods to be employed and shapes the analyses (1999: 143).

In relation to an indigenous research framework Smith suggests that methodological debates are really about broader politics and the strategic goals of research. The implications of indigenous research are concerned with "cultural survival, self-determination, healing, restoration, and social justice”. Power, for members of ethnic groups, is therefore expressed as actively working to retain the language and practices of their ancestors. It is expressed as claiming their own stories and their own knowledge of the world. These claims are made within social relationships that are respectful, communal, and allow for healing the "scars" of colonisation. The migration stories and shared meanings are therefore the symbolic repertoires that are taken with members of ethnic groups wherever they may go.

Power is, therefore, according to Smith, having ways of knowing and being that are beyond the reach of the dominant paradigms. Smith describes this for indigenous peoples as: 
The values, attitudes, concepts and language embedded in beliefs about spirituality represent in many cases, the clearest contrast and mark of difference between indigenous peoples and the West. It is one of the few parts of ourselves which the West cannot decipher, cannot understand and cannot control ... yet (Smith, 1999: 74).

The separate "spaces" or contexts we create (or move into) can act both as a refuge (or place to escape) and simultaneously as a source of connectedness. The circumstances under which individuals and groups contribute to the construction of their own identities are also undergoing change. It means they can as individuals and as group members (in response to prevailing conditions and contradictions) maintain hope for the future while being required to exist, live and work within what are perceived as hostile and oppressive physical, social and political contexts. There are conscious and unconscious dimensions to the meanings and boundaries of ethnic identities, which are recognised by ethnic group members ourselves or those placed on them by others.

Indigenous research methodology can therefore provide a framework for articulating different ways of being and knowing, within a range of such social structures and social settings that largely remain shaped by the dominant ethnic discourses.

\section{Power and Pacific ways of knowing and being}

Consistent with Smith's comments about spirituality being a mark of difference and being beyond the control of the colonisers, Taule'ale'ausumai (2000) writes about a "liberation theology" that is possible within the Pacific churches and expresses it in this way:

Liberation for me is developing a spirituality for life that is sustained by the vision of justice, self-determination and well being of all creation. In the words of Ofelia Ortega 'it is necessary to say that if culture is to be liberating, it must be rooted in the real lives of women, and both women's and men's experiences must be seen as integral to local cultures. Any cultural analysis we do has to happen from a gender perspective in order to challenge the violence perpetuated against women daily.'

In our ministry and journey towards wholeness we need to remember those who's [sic] experience is not the same as ours, the down side of every success story, that's where we are called to minister. That is where we can bring liberty to the captives where we find Jesus huddling in the corners with the scared and the lost, Jesus in the faces of the rejected and the downtrodden. If we can recognise Him in them then we have learnt to see beyond ourselves (2000: 31). 
Fei Taule'ale'ausumai's views are both powerful and influential as other Pacific women ministers, and Pacific women more generally, seek to articulate a structural and spiritual critique of some aspects of current church hierarchy and organisation. ${ }^{25}$ The contradiction is that in the church setting the processes and practices of theology, scripture and worship, while demanding conformity and obedience, also promote social action against poverty, and raise consciousness about social injustice and the marginalisation of some groups in our society.

Tanuvasa (1999) wrote her doctoral thesis on the controversial subject of contraception and abortion in the lives of Samoan women in two languages: Part One was written in English, Part Two in the Samoan language (Gagana Samoa). She stressed that the second part was not a translation of the English volume. She used the medium she thought best expressed the ideas about contraception and abortion that could only be expressed in either Samoan or in English. She describes how she wrote each part in tandem. As one idea came through in one language, she could move backwards and forwards between the two.

Tanuvasa needed to go back to her village in Samoa several times during her writing up in order to become immersed again in Samoan culture to the extent that she began thinking in Samoan. Only then did the writing of the thesis flow. Tanuvasa was clear that the setting in which she wrote was key to the framing of her thesis and the expression of the discourses around Samoan women's fertility. She found it easier to be in a situation where her cultural identity was strongly supported, because the majority group was Samoan, rather than being back in Aotearoa New Zealand surrounded by its many ethnic groups and languages.

Tanuvasa retraced her thinking as she developed Samoanisi, which she defined as a way of thinking and being in a system of Samoan knowledge or epistemology. She also explored using Samoanisi as a theoretical framework and as a research tool while she analysed the narratives of the Samoan women she talked to about this very private and sensitive part of their lives. Tanuvasa not only asserted a way

25 It is important to note that Pacific women ministers of religion in Aotearoa New Zealand would not be able to practice as ministers in their Pacific homelands (such as Western Samoa). They would have to marry another minister (i.e., become a minister's wife) but even then would not be able to lead a parish, as some do in this country. This shows how boundaries and meanings about roles and identities constructed in the country of origin are sometimes different in the host country, and how they can be be reshaped or reinterpreted by a different set of constraints and opportunities. 
of knowing and being that includes Samoan language, but also included spirituality and the areas of Samoan life to which few, if any, palagi or European person has access. In this way Tanuvasa clarified the boundaries between Samoan and Western knowledge and, by implication, the meanings Samoan people hold regarding their identities, cultural capital and symbolic repertoires.

Other Pacific women have used traditional artefacts and metaphors to articulate how knowledge is shared and transmitted within settings such as the family and the extended family networks. Helu Thaman (1995) describes the Tongan Kakala metaphor for teaching and learning. The kakala is a circle of flowers (or lei). In order to make this kakala there are steps which must be followed, starting with the kinds of flowers to choose, the ways of picking, the ways of arranging and making, taking into account the person or people they are made for, and the reasons for the making the kakala. The final step in the kakala metaphor is always the giving away of the kakala, because knowledge means nothing until it is given away.

Teremoana Ma-Ua Hodges (2000) describes the Tivaevae metaphor of cooperative learning and teaching. The approach is described as being analogous to the making of traditional Cook Islands bedspreads. Again, there are steps to follow as the women work together to design the patterns, cut the materials into agreed shapes and sizes and lay them out. This step is followed by the sewing, which also has to be completed in an agreed sequence and through negotiation of who will complete which parts of the sewing. The women must all work together to produce the finished product. In this Cook Islands tradition, the work must be given away, usually as wedding gifts, but they are also given at other special occasions or presentations.

In an undergraduate teacher education course at the Wellington College of Education Teremoana Ma-Ua Hodges, another Samoan lecturer (Lisa-Jane Rogers), our palagi colleagues and I engaged all of our second-year students in the making of a tivaevae. The students worked in groups, using this pedagogical approach to sharing our different cultural identities. The resulting tivaevae became works of art and the journals kept by the students of the process, and the oral presentations of the meanings of the symbols, words, photos, colours, national flags and the natural materials they used to create them, were very moving. An important outcome was that all students, whatever their backgrounds, were able to 
articulate and become more conscious of their own values, practices and meanings about their own cultural identities (including palagi/Päkehä students).

Kiwi Tamasese and her colleagues (1997) developed the Faletu'i approach to social science research that requires the researcher/researchers to view their work from different geographical perspectives: from the mountains, the valleys, the shoreline, and from the sea itself. In this methodology she also describes the group cultural processes of sharing knowledge, the use of Samoan language and metaphors, the processing of that knowledge and, in the final stages, the making of decisions that all participants can agree with. To outsiders, the traditional Samoan processes and practices seem lengthy and cumbersome, but they have important cultural and social purposes, including the affirmation of Samoan identity in contrast to other Pacific and non-Pacific cultural identities. As collectives Pacific peoples live closely with each other and are accountable to each other, so that engagement in the processes, and the observations of certain protocols, act to consolidate ownership and to ensure outcomes are in support of the collective good.

Pacific women teachers and researchers have reached back into traditional ways of being and knowing, learning, teaching and articulating their worlds, and applied them in new and appropriate educational and research contexts. ${ }^{26}$ In so doing, they have initiated a change in the locus of control, the decision-making, the theorising and the circumstances and terms on which the necessary cooperative learning takes place. ${ }^{27}$

\section{Summary}

There is no doubt that Pacific women who have written and researched about themselves have added to the knowledge about Pacific peoples in Aotearoa New

${ }^{26}$ Nakhid (2003), for example, used a "mediated dialogue" approach when bringing together the different world views of Pasifika secondary students and their Palagi teachers breaking new ground in this field of education in Aotearoa New Zealand.

27 The future challenge for Pacific epistemologies or metaphors will be whether these are be used only by Pacific researchers. Further, will Pacific researchers seek to legitimise these approaches to the extent that they become part of a repertoire of approaches used by all researchers, Pacific and nonPacific? If the latter then effective communication will be required by Pacific researchers to articulate the differences (boundaries and meanings) between Pacific and non-Pacific methodologies. In addition, all researchers outside Pacific groups will need to re-examine some of their assumptions and firmly held stereotypes about knowledge construction and realise that research occurs within a cultural context, not an "objective" vacuum, and that diversity of approach is both possible and appropriate, methodologically. See also Mara (1999) for an outline of some the issues around research for/by/with Pacific communities in Aotearoa New Zealand. 
Zealand. In this chapter I have reviewed selected work that has influenced my thinking and theorising about the connections between gender and ethnicity. My ideas have since evolved out of a critical feminist analysis into a more sociological approach that takes into account settings and contexts, the social processes that occur in them, and the role of social actors in terms of how ethnic identity might be formed.

This chapter has provided some insights into the likely ways Pacific women in tertiary education might continue to assert themselves and their cultural identities in academic terms. Critical feminist analysis, I now find, while still addressing issues of power and oppression, no longer fulfils the requirement for a framework that adequately explains the "boundary making” between groups and how ethnic identities of Pacific women are formed within the settings they live their daily lives.

Thus, in the next chapter I introduce the work of Stephen Cornell and Douglas Hartmann (1998), who have developed a constructionist approach to ethnicity, race and ethnic identity. 


\section{CHAPTER 7: CONSTRUCTING \& SITUATING ETHNIC IDENTITIES}

\section{Overview}

Many of the studies of ethnic identity reviewed earlier were mainly about cultural identity rather than ethnic identity, in that they referred to that part of identity acquired through socialisation. In addition, several studies of identity formation were generally about processes from the point of view of an individual rather than a population group.

In contrast, Stephen Cornell and Douglas Hartmann (1998) take a comprehensive approach to ethnicity and race, examining both how group ethnicities are constructed and how these identities change over time. Their work differs from that of the studies previously discussed in that they distinguish the two aspects of an ethnic identity, one part acquired by socialisation within the family and community and the other part the result of processes involving contact with other population groups. This allows them to analyse the processes of ethnic identity construction involving assignment and assertion and to analyse the results of the processes of construction in the creation of ethnic boundaries between "us" and "them". They describe ethnic identity formation as taking place within construction "sites". These are broad areas of human interaction associated with social institutions as well as government policies and the belief systems held by others.

Cornell and Hartmann also provide case studies of changes in ethnic identification over time and discuss two axes of variation in ethnic identity: the extent to which ethnic identity organises social life, and the extent to which it is assigned or asserted (Cornell \& Hartmann, 1998: 83).

\section{The constructionist approach to ethnic identity}

Cornell and Hartmann summarise the constructionist approach as one that:

focuses on the ways ethnic and racial identities are built, rebuilt and sometimes dismantled over time. It places interactions between circumstances and groups at the heart of these processes. It accepts the fundamental validity of circumstantialism while attempting to retain the key insights of primordialism, but it adds to them a large dose of activism: the contribution groups make to creating and shaping their own identities (Cornell \& Hartmann, 1998: 72). 
Not only do ethnic groups actively and consciously construct their own identities, shaping and reshaping them and the boundaries around them, but they are also influenced by wider social circumstances, including how other groups in society describe them. History, cultural practice and pre-existing identities all contribute to how ethnic groups (and the individuals in those groups) define themselves. Ethnic groups and communities use different ways to construct and reproduce themselves in a given society.

Although Cornell and Hartmann write that the core of the constructionist approach to the formation of ethnic identity is the creative process by which ethnic groups construct themselves, they also say that this approach involves:

both the passive experience of being "made" by external forces, including not only material circumstances but the claims that other persons or groups make about the group in question, and the active process by which the group "makes" itself. The world around us may "tell” us we are racially distinct, or our experience at the hands of circumstances may "tell" us that we constitute a group, but our identity is also a product of the claims we make. These claims may build on the messages we receive from the world around us or may depart from them, rejecting them, adding to them or refining them (Ibid, 1998: 80).

It is through the articulation of personal narrative and the creation of social "spaces" for the voices of people who are experiencing these processes that we are able to become aware of the diversity of construction processes of identities, and the contexts within which they occur.

This interaction is continuous, and it involves all those processes through which identities are made and remade, from the initial formation of a collective identity through its maintenance, reproduction, transformation and even repudiation over time. Construction refers not to a one-time event but to an ongoing project. Ethnic identities are constructed, but they are never finished (Ibid, 1998: 80)

In addition, they point out the critical role of circumstances in collective identification and the collective action of ethnic groups, and how the degree of influence of circumstances varies across different groups, in different historical contexts. Although circumstances can construct identities, they are also capable of shaping and reconstructing circumstances because of the social actions that identities can set in motion.

The constructionist approach aims to answer the challenge of the theoretical divide between circumstantialist (appealing to the mind) and primordialist 
(capturing the heart) approaches to ethnic identity construction. The constructionist approach attempts to embrace two theoretical stances, both the theoretical thinking about identity construction and the interpretation of the daily experience of ethnic identity construction by the individual as a member of an ethnic group.

Before proceeding any further it is important to include Cornell and Hartmann's definitions of race and ethnicity and the relationship between the two terms. If we accept that both ethnicity and race are products of social change and circumstance, and of human interpretation and action, then it is also important to examine how ethnic groups and race groups can be both distinct and related.

\section{Definitions of ethnicity, race and identity}

For some groups, identity construction can depend on either race or ethnicity, while for others, ethnicity and race can both be important. As Cornell and Hartmann express it:

Ethnic and racial categories may be delineated first by others, but when groups begin to fill those categories with their own content, telling their own histories in their own ways and putting forth their own claims to what their identities signify, then they are engaged in a classical process of constructing ethnicity. When a racial group sets out to construct its own version of its identity, it makes itself both race and ethnic group at once (Cornell \& Hartmann, 1998: 30).

My contention is that Pacific peoples in New Zealand are now finding a range of ways, through stories, art, music, sport, academia and research, to articulate to the wider community what is significant in their cultural identities and are actively constructing the meanings of their identities for themselves. Therefore, Pacific groups within these definitions are both race and ethnic groupings. However, historically this was not the case. In the 1950s and 1960s when Pacific peoples were recent immigrants, their main positioning in this country was to occupy lowor non-skilled levels of the workforce. At that time no Pacific "voices” or interpretations of those experiences were visible. This social positioning determined the ways in which the dominant Päkehä/palagi society assigned them as a racial group, particularly on the basis of physical differences from Päkehä New Zealanders (and with no recognition of the differences between Samoan, Cook Islands, Niuean, Tongan, and so on). 
Consequently, in describing the process of identity construction in terms of ethnicity and race we need to consider whether ethnic identity is assigned or asserted. In reality it is both, but the nature of the power balance between who assigns and who asserts is key. Within their theoretical framework Cornell and Hartmann argue that for race groups identity is: based on perceived physical differences; typically originates in assignment by others; typically reflects power relations; implies inherent differences in worth (status), and is constructed by others (except of course when groups begin to self-construct and then become an ethnic group).

In contrast, in the case of ethnic groups it is argued that identity is based on putative common descent, on claims of shared history, and shared symbols of peoplehood. Further, ethnic identity may originate in either assignment by others or assertion by the group; it may or may not reflect power relations; it may or may not imply inherent differences in worth; and ethnic identity is usually constructed by a dynamic between selves and others.

Whether ethnic identity is determined by assertion or assignment, or by both processes, there are still some overarching factors that operate for any given group positioned within a society. These are: the boundaries that separate members and non-members; the perceived position (or status) of that group within the wider society; and the meaning/s attached to that identity. In the following description I will use the broad cultural categories of Pacific peoples in New Zealand in my attempt to describe these factors. I will refer to my own family experiences and those of my Pacific friends and colleagues, and in terms of the perceived position or status of Pacific peoples I refer the reader to Chapter 3, on Pacific groups in Aotearoa New Zealand.

\section{Boundaries}

Cornell and Hartmann discuss the formation of boundaries. In order to determine the boundaries between "us" and “them” in relation to our family's ethnicity and those outside our Tahitian group, we trace our ancestry back to a geographic location: the village of Avera, on the island of Rurutu in the Austral Islands in French Polynesia. We also define ourselves in a range of ways such as: being able to speak the Tahitian language (as my brothers and nephew continue to do); having extended family visits to and from Tahiti on a regular basis; expressing our cultural practices through music, eating particular traditional foods, and by getting 
together as a family; and so on. Immigration policies can also delineate "us" and “them”. My father was able to enter and stay in New Zealand (with a resident permit) in 1948 because my mother was a British citizen, but whenever Dad left the country he had to re-enter as an "alien”. ${ }^{28}$

As time goes by, however, some of the features that delineate us from others in this society are beginning to disappear (with fewer of the third and fourth generations speaking the language, for example). Boundaries are also changing due to intermarriage and emigration, for instance, now that some of our family have gone to live in Australia. In times of getting together we again renew some of the ties and the boundaries that may have been diminished due to separation and the daily requirements of working and living in a post-industrial, post-colonial society. As long as we know the stories of our parents' migrations and we continue to relate them to each other, and to the wider society, the boundaries, to some extent, will be maintained by the ethnic group.

Boundaries also exist between ourselves as Tahitians and other Pacific groups such as Samoan, Tongan, Cook Islanders, Niuean, Tokelauan, and Tuvaluan. The main boundaries are our distinct heritage languages (Maohi and French), our internal social hierarchies, networks and kinship systems (based on islands and villages), our colonisation histories (including French colonisation and political systems), and status in Aotearoa New Zealand as citizens or as "visitors" on work permits. Sometimes the boundaries between us lead to competition, at other times we gravitate together as groups under umbrella organisations and groupings of Pacific or Pasifika.

\section{Perceived position}

Position in terms of demographic and social status has already been discussed in Chapter 3. In addition, it is important to note how Pacific ethnic groups have historically been positioned alongside the indigenous peoples of Aotearoa New Zealand. Migration for Pacific peoples was country to country; for Mäori,

28 Over the years since my father first arrived in New Zealand in 1948 political relationships between France and New Zealand have been "variable", given French atomic testing on Mururoa atoll and the Rainbow Warrior incident. Conditions of movement between New Zealand and French Polynesia (i.e., visas, residencies, duration of visits by citizens of both countries) have affected the ability of our families to visit and/or stay with each other. Every time we contemplated a visit we had to check with immigration officials as to the current status of relations between the two countries! Only in recent years has French Polynesia been invited to join the main Pacific governmental forums and been seen increasingly as part of the Pacific rather than just an outpost of France. 
migration within Aotearoa New Zealand was rural to urban. Other Mäori social and cultural factors were similar to Pacific groups during the 1970s, with a younger population profile being disengaged from their reo (language) and whakapapa (genealogy). When I first began teaching in the 1970s in South Auckland, Mäori and Pacific people were always categorised together in terms of education, crime and health statistics. Terms in the media such as Polynesian were used to refer to Pacific and Mäori or sometimes Pacific (although Mäori are also within the wider Polynesian grouping). Currently, Pacific peoples have a distinct position as cultural groupings alongside Mäori as cultural revitalisation of tribal/iwi/hapu systems has progressed. Some intermarriage between Pacific and Mäori (as has happened in my family) has both consolidated and changed the positioning of both groups.

It has long been perceived by Pacific peoples that educational achievement and qualifications would address the lower socio-economic status of Pacific ethnic groups in Aotearoa New Zealand, both at an individual and at an ethnic group level (MPIA, 2002). It is for this reason that the education system, and what happens to our Pacific students as they go through that system, remains an important area of research as the Ministry of Education seeks to "raise achievement and reduce disparity”.

\section{Meanings}

Cornell and Hartmann refer to meanings (1998: 81-82). Assertion by individual members of the ethnic group, and assignment by outsiders, can provide contradictory meanings about what it is to be a member of that group. That is, how our family members see themselves as Tahitian provides social meanings about who we are. For example, if as members of Pacific ethnic groups we talk about ourselves as "survivors of the dawn raids", that we "are superior to other groups”, “inheritors of our ancestors' dreams”, “the chosen people”, “Godfearing”, that "we work hard to support our families and serve our communities", then those are assertions about what it means to be "us", in this place.

Conversely, outsiders may say of Pacific peoples in New Zealand that: "they're poor, dumb, speak languages we don't understand”, "good sportsmen and women”, “always committing crimes”, “ don’t get on with one another”, “don’t provide for their children”, “can’t handle money”, “can sing and dance”, and so on. Most “outsider” opinions and stereotypes about Pacific peoples are formed by 
secondary sources such as the media. The reality is that the middle class and the opinion-makers in the media do not usually have personal contact with Pacific peoples (except perhaps contact limited to individual members of the small Pacific middle class).

These factors are not static. Boundaries, perceived positioning, and meanings do change as a result of new assertions by groups themselves and by changing assignment in the wider society. The media (including electronic media) has also had a role to play in the promotion of Pacific sports people, musicians and creative performers to effect the changes to date of Pacific ethnic identities. The issues of power and relative power of assertion and assignment also come to the fore in the social construction processes of ethnic identity construction.

\footnotetext{
The extent to which assignment or assertion prevails in identity construction generally depends on the ability of the group to promote among members and the larger society an indigenous conception of boundary, position or meaning. Where substantial power lies in the hands of outsiders, or when circumstances have compelling effects on member understandings and interpretation, the identity is more likely to be more a product of assignment than of assertion. Where outsiders' power is relatively less, circumstances are ambiguous, or the group has the ability to promote its own conceptions, the identity will be more a product of assertion than of assignment (Cornell \& Hartmann, 1998: 82).
}

Any changes in boundaries, positioning and meanings as a result of new assertions or new assignments, of changed circumstances or contexts, can maintain, alter, reinforce, undermine or affect the identity of the ethnic group. In other words, these changes reconstruct identity. Pacific ethnic identities in Aotearoa New Zealand have been constructed and reconstructed with successive generations in response to wider cultural norms and values (social circumstances), resulting in varying degrees of assimilation. The collective social wellbeing as an immigrant grouping has also been related to the extent to which the majority of New Zealanders have valued or not valued cultural diversity. The predominantly negative valuing of diversity has in turn affected the desire and ability of groups to self identify and to assert their ethnic boundaries and meanings.

\section{Comprehensiveness: "thick" and "thin" identity}

If we accept "that ethnic and racial identities are changeable, contingent and diverse", then it follows that we need to be able to articulate how they change over time and what forms they can take. To further describe ethnic identity, 
Cornell and Hartmann relate assertion and assignment to the concept of comprehensiveness of ethnicity or ethnic identity construction. By comprehensiveness they mean:

the role of a given racial or ethnic identity in organizing social life in a given situation. We might think of this in terms of the comprehensiveness of an ethnic or racial category. A comprehensive or "thick" ethnic or racial tie is one that organises a great deal of social life and both individual and collective action. A less comprehensive or "thin" ethnic or racial tie is one that organizes relatively little of social life and action (Ibid, 1998: 73).

By applying both the variables of comprehensiveness ("thick" and "thin") and assertion and assignment Cornell and Hartmann suggest that useful ways of distinguishing among identities can be found. That is, we can begin to approach the process of identity construction by placing the aforementioned variables on two axes (thick/thin and assigned/asserted), enabling us to locate different ethnic and racial groups and to make informed judgements about their comprehensiveness. Cornell and Hartmann (1998: 83) use a diagram (reproduced in Figure 2) to illustrate this process, the two axes forming four quadrants. 


\section{"Thick" Identity}

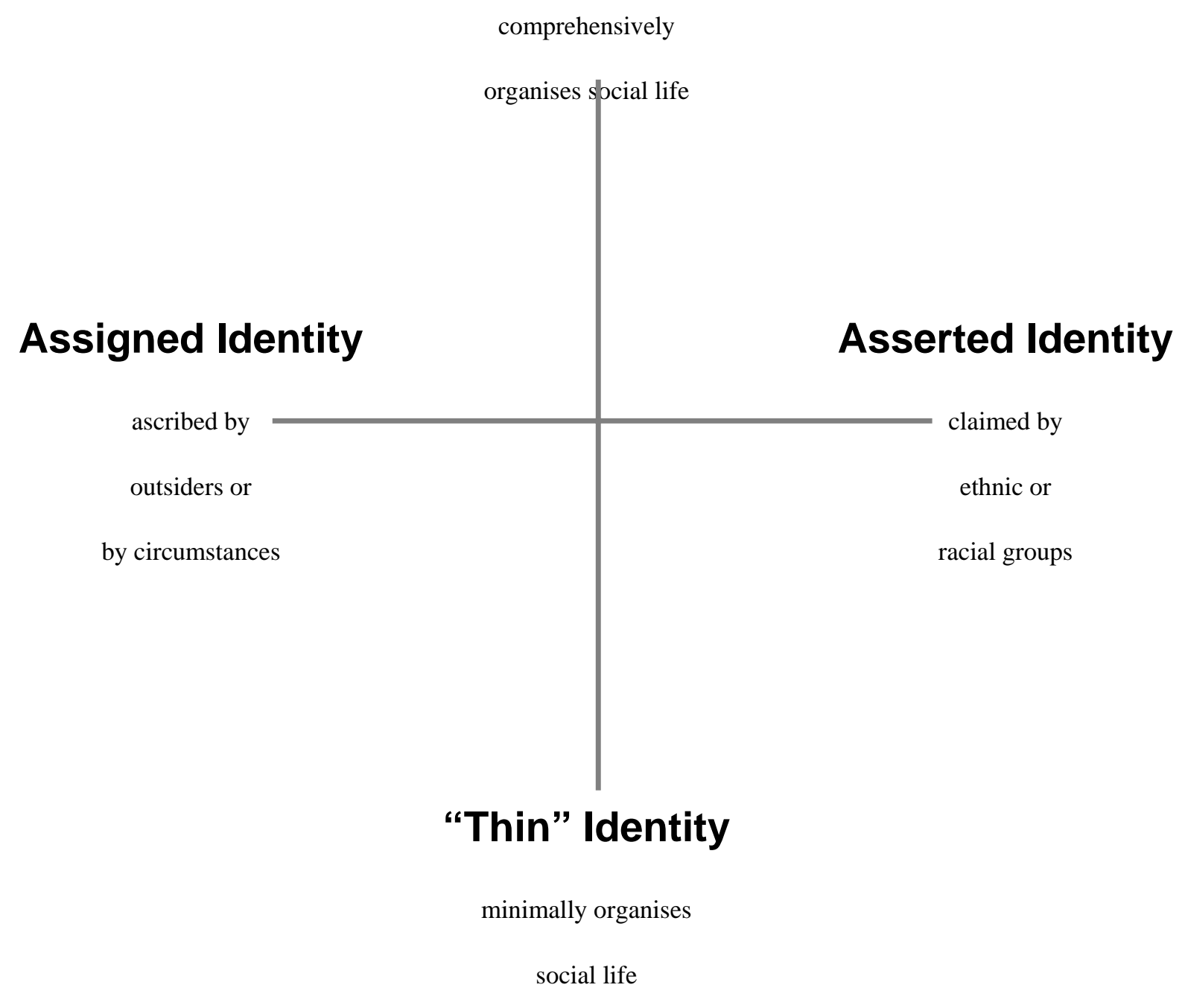

\section{Figure 1: Two Axes of Variation in Ethnic or Racial Identity A Constructionist Approach}

Using the example of Italian American ethnicity and comparisons between the early and latter parts of the 20th century, they show how the comprehensiveness of identity (i.e., the degree to which social life, individual and collective action are organised around a distinct set of meanings, values, history, ancestry, and so on) has declined or has become "thin" (lower quadrants of Figure 2). That is, in terms of the total group who assert they are Italian American (and are assigned by others as Italian Americans), less than 20 percent continued to identify as Italian in the latter stages of the 20th century. This shows how ethnic identity changes over time. This example shows the degree to which Italian Americans have mixed quickly with mainstream society or have become assimilated into that society. 
However, in other ethnic groups, both in the United States and around the world (e.g., the Hutu and Tutsi in Rwanda), Cornell and Hartmann argue that ethnicity has become more comprehensive or "thick" (upper quadrants of Figure 2), and that this change over time depends on a range of contextual factors and can be explained in those terms.

If we apply this conceptual perspective, albeit speculatively, to this thesis, we can suggest that social construction processes within each of the Pacific populations in this study will be affected to some extent by its relative size and history: Samoan, Cook Islands peoples, Tongan, Niuean, Tokelauan and other Pacific ethnic groups differ significantly on both dimensions. Size of population may determine the extent to which ethnic meanings will be maintained within changing circumstances, for example. Migration patterns, the timing of migration and the remembrance and commemoration of migration would certainly play an important role in the future of ethnic identity formation. Different ethnic groups will inevitably experience varying outcomes and trajectories as a result of these ongoing processes. Continuing intermarriage may simultaneously consolidate and undermine ethnic identification and assertion by these groups and their group members. Moreover, since the Samoan ethnic group forms over 50 percent of the Pacific ethnic populations in Aotearoa New Zealand women members of the Samoan community are more likely to be situated in the thick/asserted (top righthand) quadrant, according to Cornell and Hartmann's axes. This Pacific group is also able to take with them into other key social construction sites their relative size in numbers, their visibility, their cultural capital, and their fluency in the Samoan language.

In comparison Cook Islands peoples originate from relatively scattered communities, they have experienced different migration processes as New Zealand citizens, intermarriage with New Zealand Mäori and other Pacific ethnic group members, the relatively small size of the communities both "back home" and in this country, and the loss of Cook Islands Maori language. Consequently, it could be claimed that only limited aspects of their ethnicity and culture currently organise their daily lives, thereby affecting their positioning along the axes. They are therefore more likely to be located within the two lower quadrants: assigned/thin; asserted/thin. Ethnic assertion exemplified by the development of punanga reo (early childhood education centres) by Cook Islands women, by the expansion of the Cook Islands churches and their festivals, community networks, 
and, within the tertiary institution context the formation of Cook Islands' students networks secures a lesser, but still important positioning along the continuum towards asserted ethnic identity.

The experiences of the earlier migrants to New Zealand as seen through their children's eyes reveal aspects of their daily lives in the 1950s that are not unlike my own father's. Located in the historical circumstances of that time, their ethnic identities would probably be placed in the upper left quadrant (assigned/thick). They came to their new country with a cultural identity formed within their own cultural settings, and an identity that comprehensively organised their daily lives including their church involvements and extended family responsibilities. Simultaneously, the wider society and the dominant groups assigned them as “Islanders”, manual workers, and in need of "special language programmes” in schools and in the workplace in order that they adapt quickly to New Zealand and be “more like us”, the majority European ethnic grouping. There was a great deal of xenophobia on the part of the Pakeha majority at that time.

In the future, ongoing assertion will be influenced by what the Pacific groups remember or retain of their migration dreams, and migration stories. For the Niue people (which has the majority of its group members already in New Zealand) the social construction of ethnic identity and the migration stories that form part of that process are rapidly changing. The power and relevance of the Pacific migration stories may, over time, diminish for the New Zealand-born members of these groups.

Lessons from global histories tell us that with changing historical circumstances (perhaps more slowly in the Samoan case) distinct Pacific ethnic groupings may decline as ethnic identity within a New Zealand context becomes very "thin". The boundaries of difference become increasingly permeable and less defined. In other words, ethnic groups and group member identification may all but disappear and thence would occupy the bottom left hand quadrant of the axes: assigned/thin. Potentially, for educated Pacific individuals, they may become so divorced from their ethnic "roots" and intermarriage become so prevalent that their daily lives become very minimally organised by their ethnicity. Meanwhile, the wider society may still stereotype them and isolate them as members of an "outside" ethnic group. Pacific millionaires or sporting heroes may win a level of acceptability in terms of their wealth and role model influence, yet still be viewed by dominant 
groups, for instance, as "exceptions" to their groups of origin. In this way dominant groups may work to keep Pacific group members out of some aspects of social life.

There are contexts within which assertion may be strong, but the identity is "thin" (lower right quadrant of the axes) because most of the daily lives of Pacific peoples are likely to become the same as all other New Zealand citizens. In this kind of scenario Pacific ethnic groups may still be able to assert themselves but, assertion will be limited to external expressions and rituals such as food, clothing, dancing and other cultural expressions. Meanwhile, the majority of their lives become mainly organised by dominant cultural beliefs, values, and practices.

\section{Assertions of kinship and ethnic group identification}

Cornell (1996) claims that collectivities can only be treated as ethnic groups if their identity system includes assertions of kinship (whether these are real or not) and in the case of immigrant groups, a descent from a common homeland. Added to this should be a history of common culture, although culture is only one element of ethnic identity. It can be "thick" or "thin", practised or claimed, but on its own, culture does not comprehensively define ethnicity to the extent that it can be analysed.

Consequently, Cornell describes "three bases of attachment" of what he terms "the ties that bind" within ethnic groups: interests (where members consciously share a set of interests that are fundamental to their identity system); institutions (both formal and informal problem-solving networks such as kin relationships, healing practices, political organisations); and culture (where members share systems of understandings, interpretations, and world views that inform behaviour and action).

These three bases of attachment are interconnected so that the ethnic "ties" for individuals can be multiple. These bases can also be more or less salient (thick/thin or strong/weak) according to the ethnic group itself. Cornell consequently classifies ethnic communities as three interconnected types on the basis of the existence and strength of each of these bases: community of interests, institutional community, community of culture. He also describes a fourth possibility—a symbolic community, exhibiting none of the above characteristics. Further, Cornell outlines the relationship between social circumstance and the 
factors within ethnic groups and describes how these influence ethnic consciousness and ethnic identity construction.

It is not circumstance alone, but the interaction of content and circumstance that drives the trajectory of group life, determining the pattern of ethnic transformation and persistence. Circumstances create ethnic groups; this much is clear. But equally important are the various kinds of ethnic group, distinguished by the nature of intra group attachments, that circumstances create and the effect that this variable content has in subsequent group encounters with circumstance (Cornell, 1996: 283).

Cornell and Hartmann look at the ways historical events, social relationships and human action come together to create ethnic identities.

"The term ethnicity acknowledges the place of history, language and culture in the construction of subjectivity and identity (Stuart Hall, 1992: 257).” Race, in its colloquial usage at least, implies a naturalness that is difficult to overcome. Ethnicity, on the other hand, conveys both this constructed quality - something made by history and culture and therefore variable and changing - and, its emphasis on self-consciousness, the participation of groups themselves in the construction, reproduction, and transformation of their own identities (Cornell \& Hartmann, 1998: 37).

\section{Contextual factors and construction sites for ethnic identity}

In considering the situations in which ethnic groups find themselves located, Cornell and Hartmann describe contextual factors in the making of ethnic identities. They have termed the contexts in which ethnic identity construction occurs “construction sites”.

They make two statements about ethnicity and race that underpin their descriptions of construction sites. Firstly, that they are both products of social change and social circumstances and of human interpretation and action. Secondly, they are not static but variable, diverse and contingent on chance circumstances. The factors that account for the processes of ethnic identity construction can be grouped into situation factors and the resources and attributes that groups bring to those situations.

Cornell and Hartmann name six critical construction sites of ethnic identity (although there are many others) and describe the forces within them. These are: politics, labour markets, residential space, social institutions, culture, and daily experience. This study confines itself to one construction site - tertiary education as one kind of social institution. But it is important to keep in mind that educational achievement and qualifications play a key role (and are expected to 
play a key role by immigrant ethnic groups themselves) in group members' “success” within, and access to, other sites such as labour markets, residential space, other social and welfare institutions, and politics.

In relation to construction sites and contextual factors, Cornell and Hartmann (1998: 189-194) make the following points regarding the social processes of ethnic identity construction, and social construction sites of ethnic identity:

1. The contextual factors of any construction site can affect the salience of ethnic or racial identities, and the more salient the identity, the more likely it is to organise collective life and self-concepts. The more factors are brought into play, the "thicker" the identity is likely to be.

2. Not all sites or contexts are directly involved with ethnic identity construction, although sites are interrelated (especially those named above) and can have an impact on each other.

3. The effects in one construction site can counter those in another site. Patterns cannot be identified on the basis of studying one or two construction sites only.

4. Construction sites need description and explanation, because they provide both opportunities and constraints on ethnic identity construction and are influenced by forces outside the site that can affect the dynamics within the site.

5. Sites have histories, and timing matters in terms of identity construction: successive immigration, assimilation and adaptation, generational differences and the history that has shaped the sites themselves all demonstrate that construction processes are influenced by not only current forces, but also historical forces.

6. Because of changing social conditions and the history that has shaped these conditions, sites are not static. It is important to describe the potential for, and the processes within sites that can facilitate change.

Cornell and Hartmann (1998: 195) provide some insights into the making or constructing of ethnic identities within construction sites. Usually, they argue, the process of identity construction is "energised" when groups of people encounter new forces or altered circumstances within the sites. Further, when human beings 
enter construction sites "they do not enter ... empty handed or empty-headed". The characteristics that they bring to the site/s contribute to the construction processes in complex and sometimes contradictory ways to limit, resist, direct, or promote change. It is important, then, to take into account these forces and processes (between the sites and what the people bring to them), if we want to know more about how identities are being created, reproduced, or transformed.

\section{Peoples' contributions to the making of their own identities}

Peoples' contributions to the making of their own identities are both conscious and unconscious. Many contributions, such as physical characteristics or cultural practices are obvious. Any physical distinctions, including language, behaviour, or religious practices that are attributed to a particular group, lead to social categorisations, distinguishing "us" from "them”. Cornell and Hartmann say that the distinctions in themselves are not influential in ethnic identity constructionwhat is important is the social significance or social meaning that is given to those differences. When a group or groups decide to give these differences a major role in how social life is organised, then these differences play a part in ethnic identity construction.

Cornell and Hartmann (1998: 195-232), describe six group assets or characteristics that have implications for identity construction. The potential contributions of these assets may be less obvious, but are nevertheless important. These are: pre-existing identities, population size, internal differentiation, social capital, human capital, and symbolic repertoires. These group assets can be illustrated in relating them to the experiences of my father when he came to this country, and to the experiences Pacific groups in Aotearoa New Zealand.

1. Pre-existing identities. All human beings start from a basis of connectedness with others and a category with which they identify. However, with gradual or sudden social changes these primary systems of connectedness can be disrupted and changed (for example, through migration). Pre-existing identities can be constructed as a result of outsider classifications that can then become "owned" by the members of the group and be strengthened by outsider assignment. Identities can also be handed down by successive generations because of strong group identities and the existence of strong social relationships that determine all or most aspects of daily living. 
When my father came to New Zealand he brought his pre-existing identities from his homeland and the other countries he lived in. He still deliberately held on to his language and his cultural connectedness to Rurutu. In New Zealand in 1948 he was assigned an "alien" status in terms of immigration, but was also discriminated against in terms of his skin colour when he went to find accommodation. There were very few Tahitian people in New Zealand then. He knew most of them, and he widened his connections to Cook Islands people mainly because their language and customs are very similar. He organised a great deal of our daily lives around his values and beliefs. As an increasing number of Tahitian people (who are French citizens) came to visit New Zealand, his identity was altered again to a Tahitian New Zealander. Beyond these labels, how he saw himself was embedded in his identification and it became more established and enduring.

2. Size of population. Where ethnic groups are large enough to replicate themselves without outside marriage or when they can maintain their core institutions because there are enough people to carry out social tasks within them, then the group identity can be maintained. Where numbers fall, there could be consequences for group survival if contacts within the ethnic population decrease (weakening group boundaries) and the need to marry outside the ethnic group increases. Ability to mobilise or lobby for political change is also affected by the size of the ethnic group.

There have never been large numbers of Tahitian people living in New Zealand. Most of the families we knew as we grew up were married either to popa'a /Päkehä people or Cook Islands people (who are New Zealand citizens).

3. Internal differentiations. Factors such as gender, sex ratios, generational migration and class differences arise within ethnic groups.

- Gender ratio differences. Whether migration involved male-only or female-only groups is important. When there are strict (and observed) barriers to intermarriage even if sex ratio remains unbalanced, the group boundary is maintained. If the barriers to intermarriage are low, the unbalanced sex ratios lead to increased intermarriage.

- Generational differences. There is some research predicting that the probability of ethnic identification decreases with each generation born 
outside the "homeland". Ethnic language usage tends to decrease with each subsequent generation although that depends also on the size of the population using the language and whether it still survives in the land of origin.

- Social class differences. Ethnic groups that are largely concentrated in one social or economic class are more likely to maintain their collective strength and saliency. Changes because of increased employment opportunities and improved access to housing, resources and services, can decrease the saliency of the ethnic group.

My father married an Englishwoman, and in that sense crossed the boundary of his ethnic group. So did my mother, whose parents were so upset by her marriage to a foreigner they refused to attend my parents' wedding held in a little French church in Soho Square. My father tried to pass on his language to my brother and me, but it was not until my brother went to live in Tahiti in his twenties that he became fluent in Tahitian. When I went to high school I learned French, which I used to communicate with my relatives.

4. Social capital. Western Samoans in New Zealand, are used by Cornell and Hartmann (p.213) as an example of an ethnic group that has transported its social capital and used it as a resource for problem solving and meeting the challenges of daily survival. Samoans have also transported their own institutional frameworks as they exist in the homeland, the church, and the matai system and kinship networks that reinforce group membership roles and responsibilities. Consequently, there is less need for them to move outside the boundaries of the ethnic grouping. ${ }^{29}$ Immigration policies such as family reunification helped produce a relative equality of male and female migration over time (although not synchronicity) of the larger Pacific immigrant groups to New Zealand, such as the Western Samoans and the Tongans. These two ethnic groups, who do not have automatic right to immigrate, have been able to increase their numbers both by immigration and by increased birth rates, and thereby build up their social capital.

${ }^{29}$ Whether such social capital continues to consolidate Samoan group ethnic identification remains to be seen as each new generation is born here, and as social circumstances in the wider New Zealand society change. 
5. There was a limited pool of Tahitian people for my father to connect with, but he managed to maintain his culture and language and his musical skills through association with other Tahitian and Cook Islands people and through maintaining links with his Tahitian family and friends. They began to visit Aotearoa New Zealand in increasing numbers, even though they were not permitted to be resident in New Zealand, and mainly because my father and our family were here to host them. Because of their relative wealth they could come here for medical treatment and as touristscurrency exchange rate between the two countries was (and continues to be) very favourable to Tahitian people.

6. Human capital. Individual human capital aggregates into the group's human capital. This is subject to change as people who identify as members of the group gain education, training and skills that take them into other social contexts and construction sites. In such cases the boundaries or categories of the ethnic groups can become less defined and people can begin to choose to engage in multiple affiliations or identities. As members move into society's stratification system in terms of occupation, housing locations, entrepreneurial ventures, and so on, greater social dispersal and a weakening of the ethnic group identification can occur.

This highlights a dilemma for immigrant ethnic groups who must be educated and then trained for employment to survive in the host country. But this may have cultural consequences in terms of change and loss of group identification. This change is a "natural" process, unless the ethnic group develops a consciousness of its differences and follows that recognition by action or active assertion, so that immigrant ethnic groups can exercise a degree of control over that cultural and social change.

7. Symbolic repertoires. Ethnic groups share their stories of migration and practise and maintain cultural practices, rituals and celebrations, which all maintain group connectedness and ethnic group identity. Over time these repertoires undergo modification and re-expression in art, literature, plays, music and other forms. Where these repertoires continue to be practised in their new forms and where new forms are comfortably adapted or adopted by the group, then separate group identification can be maintained. 
Pacific peoples in Aotearoa New Zealand identify strongly with any or all of the Pacific sports people who are currently bringing international kudos to this country. ${ }^{30}$ Conversely, with the Dawn Raids in the 1970s, Pacific cultures and the differences between Tongans and Cook Islands people, for example, became crucial because only Tongans and Samoans could be deported as illegal immigrants. Unfortunately most police officers and palagi immigration officials were unable to tell the differences between Pacific groups and many people were mistakenly harassed both on the streets and in their homes. Such treatment by the authorities galvanised some sectors of Pacific communities into becoming more assertive while winning allies in human rights groups of the time. ${ }^{31}$

Migration stories and historical incidents (including colonial oppression by European powers, including New Zealand) have become part of the folklore of the Pacific migration story. These legends continue to be retold in drama, song, and other artistic and performance media. Pacific peoples in New Zealand still practice many traditions from "back home" as part of christening, wedding and funeral celebrations, and events on the church calendar such as White Sunday. Ethnic sports tournaments, cultural festivals, and competitions all set them apart from other ethnic groups. Pacific languages such as Samoan and Tongan still survive in Aotearoa New Zealand because of the numbers of fluent speakers. However, the languages of smaller Pacific ethnic groups, such as Niuean and Cook Islands Mäori, face imminent loss in the next couple of generations. Along with that loss it is likely some of the important symbolic repertoires could also disappear.

Cornell and Hartmann place the internal ethnic group assets and characteristics on a continuum from factors associated with an increase in the strength of ethnic or racial identities, to factors associated with a decrease in the strength of ethnic identities. However, context is also a part of the dynamic process of ethnic

30 It has been widely articulated by local sports commentators that our successful international sports teams such as the All Blacks rugby team are made up largely of Pacific and Mäori athletes. Moreover, without them New Zealand would probably not hold its world-class championship ratings in rugby football, rugby league and women's netball.

31 The social activist group the Polynesian Panthers was formed in central Auckland around this time in response to the Dawn Raids. Contrary to the negative stereotypes and "communist-inspired" labels placed on the group, they put most of their energies into social activism, such as starting up student homework centres. 
identity construction and wider social forces and agendas can at any time cut across internal group factors.

They remind us:

Identities are not inevitable outcomes of particular arrays of factors, of characteristics of populations or of the ways various sites are organized. Indeed, there is nothing inevitable about them. Instead, they are products of people's efforts to understand and respond to the situations in which they find themselves, using such resources as they command. Identities are human creations, existing only in the ways we come to think about ourselves and others. Ultimately, the construction of an identity occurs as an ongoing act of interpretation, shaped by the [above] ... factors ... Those factors may describe a particular set of conditions that render some identities more likely, possible, or compelling than others, but human beings still have to make their own sense of those conditions and, in the process, make themselves (Cornell \& Hartmann, 1998: 231).

\section{Some implications for Pacific ethnic groups in Aotearoa New Zealand}

Pacific ethnic identities in New Zealand have over time been made and remade, and this process continues. My descriptions and analysis pertain to the early 21st century when Pacific peoples in New Zealand are now into the third and fourth generations. What will happen in the future we can only speculate, but if there is a measure of agreement and clarity about boundaries, positioning and meanings we may be able to make some informed guesses about the ongoing reconstruction and even transformation of Pacific ethnic groups. Findings to date that may usefully help inform the debate come from researchers such as Macpherson (2001) and Spoonley (2001). Both have researched and written about Pacific identities in New Zealand and their work has been very influential.

Macpherson writes about the range of views about what it is to be a Pacific person, confirming that Pacific peoples are not turning their backs on their identities but that, because they occupy different social locations and experience, a shift in views has taken place.

... this shift is no more than the acceleration of a process of change which has always occurred and continues within the Pacific Islands. It is more useful to see the migrant enclave as a site in which people are free to draw ideas and icons from various cultures and recombine them in new cultures and identities which reflect new experiences of new realities as Pacific artists have done with great effect ... One might see this as the re-emergence of a shared Pacific identity from which the various populations diverged between 2000 and 800 years ago. Ironically, Aotearoa, the last settled of the Polynesian enclaves, may well be the site in which a Pacific identity re-emerges as the differences 
which stemmed from (the) group's separation from one another as a consequence of a thousand or more years of voyaging and settlement are rendered less significant by a new set of common experiences (Macpherson, 2001: 79-80).

Spoonley (2001) writes about how Pacific communities have become transnational.

An important demographic driver has been the growth of Pacific communities in the Pacific Rim, especially in Auckland, and the maturation of what were once, but are no more, migrant communities (Fleras \& Spoonley, 1999). These communities, made up of New Zealand-born Pacific peoples, are developing new cultural forms and identities which are challenging both the origin communities (or 'homelands') and cultural traditions, and the institutions and beliefs of the society of residence. They are renegotiating the rules of entitlement and belonging, coming as they do from a position of multiple loyalties and identities, and being a community that maintains strong transnational networks (Spoonley, 2001: 95-96).

\section{Implications of Cornell and Hartmann's approach for this study}

Cornell and Hartmann's framework helped me to articulate a research question that had been concerning me for some time as a Pacific woman with 30 years' participation in tertiary education both as student, lecturer and researcher. I had read studies about women from working class backgrounds (Paasse, 1998) who had become educated "away" from their working class "roots" and wondered if this also happened to women from Pacific ethnic minority backgrounds.

My view had always been that Pacific women, as immigrant women, are active social agents (Mara, 1995), particularly in early childhood education initiatives, but until I read Cornell and Hartmann I could not articulate whether or how these individual or ethnic group assertions were also important components of the construction of their ethnic identities.

In order to frame my research question I needed to know more about the social processes and mechanisms that constructed our ethnic identities in the first place, in order to see how these operated within social institutions such as educational institutions. I was interested in the influence of tertiary education on the ethnic identities of Pacific women and the research questions are related to them: 
a) Is tertiary education a site for the construction of ethnic identity?

Although this initial research question appears to be a closed one, in order to answer it fully I anticipated that a comprehensive answer, with reasons for my yes/no response would be essential.

Further questions therefore flowed from the basic research question:

b) What did Pacific women bring with them into the tertiary education site?

c) How did the tertiary institutions respond to these Pacific women on the basis of their ethnic identities?

d) What other settings are important in the construction of ethnic identities?

e) What relationship exists between the family, the church and tertiary education?

In the methodology chapter I will describe in more depth the approach I took to answer my research questions. In preparation, however, I outline here the sociological thinking that informs both my question and my methodology and the reasons why I have taken a sociological and constructionist approach.

In addition to Cornell and Hartmann I have been influenced by what Rob Stones (1996) refers to when considering how sociologists attempt to make links between the theoretical, the philosophical and the "realities" of social life. Stones, in making a case for a "past-modern sociology", describes two “opposing” responses by sociology to the complexities of the social world. He suggests that on the one hand previous theories and paradigms have been characterised by an underestimation of the diversity and complexity of the social world and, on the other, that sociologists overestimate the extent to which they can obtain accurate and "truthful" knowledge about the social world (1996: 1).

Post-modernists, Stones claims, tend to deny any difference between fictional or anecdotal stories and the knowledge acquired by social science research. Such approaches celebrate diversity and reveal the obstacles of obtaining accurate, truthful knowledge about the world. However, this approach moves quickly to the extreme in that it removes the ability to make judgements about the quality of the knowledge claims, thereby preventing any critical view of the knowledge that is gathered. In other words, according to this view researchers should not critique or even analyse narratives because they don't “belong” to the group of people who 
told them. That is, unless the researcher is female and a member of a particular ethnic group or social class, how can he or she "understand" or interpret these narratives?

Stones thinks we need to make bridges across these two views and move beyond them to emerge with a "past-modern" sociology that makes the links between the theoretical and philosophical, and the "realities" of social life. As sociologists, Stones argues, we can do this by keeping in mind at all times the fragility of our theoretical frameworks and a very high degree of reflexivity:

... to sustain a consistent and disciplined relationship between high theoretical assumptions and empirical knowledge claims.... The crucial benchmark here is one of total contextualisation. The answering of a research question with utterly exhaustive detail; absolutely everything relevant to a question....in order for an account to be exhaustive and closed to any further extension. This benchmark is of course Utopian, but it is a useful point of reference by which we can judge how far our accounts fall short of the rich reality of events. Some accounts (contextualised accounts) will be nearer to it and other (floater accounts) will be further away (1996: 7).

“Floater accounts” and analyses, according to Stones relate to sociologists taking a broader perspective in relation to social contexts, needing to gain a wider view, taking in a wider sweep of social contexts, taking less note of specific details. At times, however, we need to focus in on particular details, patterns and nuances of social interactions.

As a researcher, I need to make the "directions” along my theorising pathway as clear as possible, so that anyone who wishes to critique my work can travel, in a theoretical sense, along the same path. Stones refers to this as systematic argumentation.

Further, Stones describes the relationships between theory, methodology and the researcher/sociologist and how these are played out at a number of levels in the process of gaining knowledge. Firstly, we need to accept that social theories are informed by epistemology and methodology. Secondly, that meta-theory (which is universal and applies in all situations, across all theories) must be refined and limited to apply to a particular social situation or process—such as, in this study, the construction of Pacific ethnic identities in Aotearoa New Zealand. 


\section{Summary}

In this chapter I have described the constructionist approach and considered the definitions of ethnicity, race and identity as outlined in the work of Cornell and Hartmann. Their concept of construction sites is explained as contexts or arenas in which the processes of ethnic identity construction occur. In these arenas, various ethnic groups, some with power and some without, try to cope with the situations they encounter, pursue their objectives, make sense of the world around them, and identify themselves and others. Contextual factors and assets of ethnic groups provide more detail to assist us in understanding how ethnic groups are both products of assignment by others and assertion by themselves.

In the final section I showed how Cornell and Hartmann's work and Stones' sociological thinking about the links between the theoretical and the "realities of social life” have helped me to articulate my research question.

The following chapter outlines some methodology issues that emerged in my study and how I went about collecting my narrative evidence to answer these questions. The results are given in Chapters 9 to 12, and I return to the research questions in Chapters 13 and 14. 


\section{CHAPTER 8: METHODOLOGY ISSUES AND RESEARCH METHODS}

\section{Overview}

In terms of an area of study or discipline, this study fits within the field of sociology. I therefore take a sociological approach to methodology and analysis. Saha (1997) writes of a sociological approach as:

one which focuses on social factors rather than psychological, biological or physical ones ... the social factors of interest to sociologists include those which are related to social structures as well as social processes (1997: 3).

At the micro-level, a sociological approach provides a framework to study social processes within social contexts or sites that can include the construction of identity. At the macro-level Saha also refers to the emergence of a "new" sociology of education (post-1970s) with the growth of theoretical and methodological approaches such as "critical” sociology of education.

This chapter has two parts. The first establishes the rationale for the research methods I have used in this study. The theoretical perspectives that underpin the chosen methods consider the following: interviewing and the semi-structured interview; narratives and biographies; life stories and personal accounts. This is followed by a discussion about reflexivity and the relationship between researcher and participants, and qualitative data analysis. I conclude with a discussion on ethical considerations.

The second part of the chapter describes the research methods used in this study.

\section{Introduction}

I was confronted by a number of theoretical and methodological challenges in regard to interviewing Pacific women graduates about their experiences in tertiary education. Essentially, the data collected would be used to address my basic research question:

Is tertiary education a site for the construction of ethnic identity?

This question related to Pacific women in tertiary education in Aotearoa New Zealand. As a Pacific woman researcher, I have followed a particular theoretical perspective and a particular methodological pathway. I make that pathway as 
explicit as possible so that the reader and other researchers can follow my argument.

My theoretical foundation is based on the work of Cornell and Hartmann on ethnic identity. Therefore, if Stones' (1996) argument is applied to their work, the meta-theory is that ethnic group identity is fluid and not fixed. Their theory can then be articulated in these terms: that ethnic group identity changes over time according to context and process. If Cornell and Hartmann were to develop a research question derived from the theory and meta-theory, it would be something like: “Does change occur within specific construction sites?” Another research question might be: "Does change occur at the intersection of the claims a person makes about herself /himself and the claims others make about her/him?”

My research question is derived from the theory about construction sites advanced by Cornell and Hartmann. This in turn is based on meta-theory relating ethnic identity to construction sites that alter over time, as do the ethnic identities they produce. In accordance with Stones’ sociological reasoning, I have located my question in a particular social situation or social "reality”. That is, Pacific women graduates attending tertiary education in Aotearoa New Zealand.

\section{Theoretical and methodological perspectives}

In moving from the theoretical to the methodological, Stones argues that:

... the increased appreciation given by contemporary social theory to the richness and complexity of the social world needs to be accompanied by a parallel appreciation of the difficulties and obstacles confronting attempts to gain knowledge about that complexity (1996: 46).

Stones calls for a greater appreciation of social theory and for caution, particularly about post-modern claims to knowledge, about using the most appropriate methods and the most sensitive instruments in gathering the knowledge required to test our theories.

As noted in the previous chapter, Stones describes the tensions between a postmodern tendency to deny there is any difference between anecdotal or fictional stories, and a reliance on knowledge acquired through systematic social science research. This perceived lack of difference between the two sources of knowledge presents a challenge for this study. The consequential epistemological issue is that I gather the "stories" or narratives of my participants and then subsequently use 
that information based on personal accounts in an analysis of the social construction of ethnic identity. In addition, the personal narratives run the risk of representing only one half of the social process of the construction of identity. The other contributing factors will be found in what others say about these Pacific women or how they respond to the ethnicity of the Pacific women students in a given context or situation.

Scheurich and Young (1997) argue, moreover, that knowledge production in any civilisation is culturally and historically embedded:

Different social groups, races, cultures, societies, or civilizations evolve different epistemologies, each of which reflects the social history of that group, race, culture, society, or civilization; that is, no epistemology is context-free. Yet all of the epistemologies currently legitimated in education arise exclusively out of the social history of the dominant White race (1997: 8).

They also stress that research (as a social practice) is best understood when it is situated within cultural traditions and acknowledges that the cultural traditions are only from one racial or ethnic group's history. Thus research acts to exclude other epistemologies. The problem is not simply that research does exclude them, Scheurich and Young suggest that researchers are all therefore constricted because their work ignores other possibilities, or other complexities in what Stones terms the social "realities". While I am sympathetic to their arguments and would like to work within another cultural tradition that is currently not legitimated, I have used the Western cultural traditions and the methods derived from those traditions in this study. I have assumed that the interview method will yield data and that the participants can speak, not only for themselves, but for others in their Pacific cultural group.

Norbert Elias (cited in Mennell, 1989) wrote about a theory of human knowledge, defining how a researcher can study society and social processes in a dispassionate and detached manner. Elias redefines the objectivity-subjectivity debate by using the terms detachment and involvement and by doing this, he places human motive and self-control into the process of knowledge-building. The relationships between subject (involvement) and object (detachment) orientations are also factors we need to consider when reflecting on our roles as researchers. In reality, detachment and involvement are points on a never-ending continuum and their relative contribution to the knowledge-making endeavour varies according to the context. However, as Elias writes, knowledge has developed and advanced 
through engagement in levels of detachment by thinkers and researchers, such that knowledge becomes an object and leads to some control (especially in relation to technology) over forces that were hitherto not controlled or influenced by human beings. As researchers we have to employ some self-control and resist living simply "in the moment” in order to stand back and construct new knowledge and understandings in the light of our surrounding social predicaments. Although my experiences have been similar to the Pacific women I interviewed, it is important for me as a researcher to adopt a level of detachment to reflect on those experiences and then write about my understandings and interpretations through a chosen theoretical framework.

This study uses a qualitative research approach in which a person's own lived experience is used as a resource (Denzin and Lincoln, 1994). The present features of qualitative approaches include that: they allow the researcher to consider issues in terms of being public or private issues; and they provide opportunities for the researcher and the researched to think reflectively, historically, and biographically. Such approaches, Denzin and Lincoln write, allow for making connections between lived experience and larger, wider social and cultural structures. It can be argued that all knowledge is embedded in a cultural context, and for feminist, critical and structural analyses one must examine issues of power, "voice”, and "liberation" within that context. Therefore it follows that an analysis of narrative, and more specifically critical narrative, is a valid way to construct and co-construct knowledge concerning lived experiences and daily lives within social contexts and what Cornell and Hartmann refer to as social construction sites. This is a further counter to the criticism of narrative as a suitable research method.

Issues of validity ${ }^{32}$ and reliability are often raised about data gathered using qualitative approaches. For example, in terms of validity, we look to see how truthful, plausible or credible the verbal descriptions or explanations are. This can be proven by the concordance of elements of accounts across a number of respondents. In terms of reliability we can determine how the narratives relate to present theory/theories.

32 In qualitative research the term "validity” is often avoided in favour of "authenticity”. 
The research method used in this study was also designed to find out what the women believed their families and churches had contributed to their cultural identity and, in turn, what they then took with them into tertiary education. Personal narratives seemed appropriate for this purpose.

Silverman (1993) warns that employing contemporary qualitative research methods in a post modern age does not mean "anything goes", nor does it mean that data collected using methods such as open-ended interviews automatically illustrate "authentic" experience. Silverman says that we need to recognise that such "raw" data is "situated" and "textual” (1993: 199). Data must be put into context by knowledge of the features and organisation of the situations to which people’s accounts refer. In other words:

This means that qualitative research can no longer concern itself with discovering truths which are unmediated by the situated use of forms of representation (Silverman, 1993: 197).

Instead of sociologists "reducing” social phenomena to discern the psychological dispositions of people interviewed, Silverman recommends keeping within one level of analysis (i.e., the sociological) and seeing how much information and meaning the data at that level can reveal. Because I shared a similar background and a similar set of experiences I was in a position to understand the contexts my informants reported. In addition, I supplied contexts in the form of a diagram (see Figure 1) to anchor discussion during the collection of the narratives.

\section{Interviewing and the semi-structured interview}

The literature is extensive on methods and approaches to interviewing. In research the interview takes many forms: structured, semi-structured, or unstructured (Fontana \& Frey, 1998).

Fontana and Frey note that ethnographers have increasingly become concerned about the "control" exerted by the interviewer and about the assumptions and morality of the power relationships that exist in the context of interviewing. While a structured interview does not allow for flexibility in the way that questions are asked or answered, it also depends upon the interviewer taking a detached, neutral, or “objective” role. In addition, structured interviewing has its limitations when the main purpose is to foster the spontaneous thoughts and sharing of experiences by the interviewee. Semi-structured or unstructured interviewing methods are deemed more likely to provide data for understanding social 
processes and structures from the perspectives of the respondents, using their own language.

Mishler (1986) describes the interview as "a form of discourse" and as "a joint product of what interviewees and interviewers talk about together and how they talk with each other”. Each interview has its own qualities, problems and values. He contends that if we attempt to suppress discourse we disregard the social and personal contexts of meaning. The social and personal contexts of interviews should not be seen as technical "problems", but rather need to be accepted as essential components of expressing meaning and understanding. The "meanings" of the questions and answers in an interview are contextually grounded. Most importantly, Mishler reminds us that the questions themselves can have multiple meanings and be given various interpretations by the respondents.

Mishler (1986: 11) defines two aspects of interviewing. The first is the talk; structures, syntax, semantics, pragmatics, and so on. The second aspect is the behavioural component. Both aspects are framed and developed according to the nature and quality of past connections or associations between shared understandings of implicit rules of interaction, and the ways in which each participant reinforces or receives reinforcement from the other. In this study, additional cultural factors and non-verbal interactions had to be taken into account. When Pacific women talk to, and with, each other, certain kinds of verbal and non-verbal language and behaviour occur such as the sharing of humour, grief, irony and the making of family and community connections. In these interviews I still required a level of vigilance about our interactions, since on the surface we appeared to be from similar backgrounds and some "taken for granted" assumptions about that similarity were possible. Other cultural aspects (such as hospitality courtesies, the sharing of food, ensuring the comfort of the interviewee) all had to be taken care of by situating the interview in my home, their home, or a mutually comfortable and safe place.

Further, Barbara Sherman Heyl (1997) highlights the “politics” of interview talk and how an interview is about what is happening between the researcher and informant:

The interview can then be experienced as an opportunity to reflect on oneself with another. Even without the reflexivity that Fine (1994) urges, the interview is often presented as a time when someone else will give you, the interviewee, their undivided 
attention while you reflect on some issue or some aspect of your life. That in itself can have unanticipated consequences - a moment that can make all the difference (1997: 5).

In a number of interviews the women shared personal experiences about family, parents, communities as well as the incidents of being badly treated or disadvantaged. The interview created an opportunity to "air" these stories with another Pacific woman student who they thought would understand. It was also an opportunity for us to sit down and focus on common interests and topics for discussion.

Jonathan A Smith (1995: 9) makes the assumption that there is a "natural" fit between semi-structured interviewing and qualitative analysis. The features of a semi-structured interview, according to Smith, include: the establishment of rapport with the respondent, the ordering of questions being less important; the interviewer is free to use probes when interesting areas arise; and the interview, to some extent, can follow the respondent's interests and concerns. The respondent is the expert on the subject in question and needs to be allowed maximum opportunity to tell her story. The limitations of this method, however mean that the interviewer has less control of the process, the interview takes longer (because the informant is permitted the time) and in the end can be more difficult to analyse. However, the gains in flexibility and the fact that this approach is more likely to gain detailed data on the beliefs, perceptions and accounts of experience, made this approach the most appropriate choice for this study.

\section{Narratives, biographies, life stories and personal accounts}

In describing the biographical method, Denzin (1997), summarises the full range of concepts and terms relating to biographical approaches in qualitative research and analysis, including the term "method". According to Denzin, a method is a way of knowing about the world and what can be gained through biographies or life stories:

A way of knowing can proceed from subjective or objective grounds. Subjective knowing involves drawing on personal experiences, or the personal experiences of others, in an effort to form an understanding and interpretation of a particular phenomenon. Objective knowing assumes that an individual can stand outside an experience and understand it, independent of the person experiencing the phenomenon in question. Intersubjective knowing rests on shared experiences and the knowledge gained from having participated in a common experience with another person (Denzin, 1997: 283). 
In the final analysis, Denzin writes, stories are basically the same as the lives they relate to: opened-ended, ambiguous, inconclusive, and subject to multiple interpretations. Such are their strengths and weaknesses. He echoes the sentiments of other researchers such as Smith (1995) and Mishler (1986) that when people tell us their stories our obligation is first to the people we study, not to our project or to the wider discipline. We need to promise to protect what they have shared and to present it as a testimony to human dignity, to their lives led, their triumphs and setbacks. We must never pretend to understand when we do not, or to present life stories as coherent and neatly resolved when in reality they are not. I took my obligations as the interviewer very seriously. I saw myself as the guardian of the stories the women told me and that, in presenting them, I needed to do so in a way that demonstrated how valuable their experiences were in illustrating social processes of ethnic identity.

Two biographical studies provide examples of the role of narrative and the link between language and identity and the social positioning of ethnic minority women. Nancy Morrow (1997) compares two autobiographical accounts of immigrant women (Polish and Puerto-Rican) in two countries: Canada and the United States respectively. Morrow cautions the researcher about selfrepresentation discourses (in relation to being an immigrant) in two respects. The first caution is that the accounts may appear contradictory, competitive and success-oriented (they have overcome barriers and this is highlighted in their narratives, for example). The second, and very important caution, is that the women may be speaking in a language in which they are less comfortable and hence identity conflicts may exist for them in relation to first- or second-language acquisition demands and expectations. By using a semi-structured interview I was able to provide time for stories to unfold and for self-representation to develop. Also, I have known many of the interviewees over a period of time, so we could speak frankly. Because the women are all tertiary graduates I made the assumption that English would be a language they would be comfortable using, but also that their cultural references and meanings would be accepted and understood.

In her biographical study, Abelmann (1997) interviewed middle-aged Korean women concerning their perspectives on social mobility in the post-Korean War social and political context. She believes that the narratives of this group of women provided insights into how selfhood is constituted, and revealed that their 
perception of agency is linked to the wider social and historical forces that surrounded them as they rebuilt their lives in the post-war era. Abelmann terms these narratives "social mobility stories”, because they articulated the challenges of social origins and social destinations in that context. Further, the interviews provided time for the women to reflect on public and private meanings of social stratification. An interesting starting point for Abelmann's study was the assumption that, for the Korean women, this period in history was one of rapid social transformation in which social injustice was also created. The study then proceeded to find out to what personal and social forces the women attributed this injustice.

Abelmann's study is a reminder that life stories must be interpreted within an historical context, including the social history of any group of women. In order to understand the historical forces that frame Pacific women's lives, their history of immigration into New Zealand and the social and economic conditions under which Pacific peoples are positioned in the wider society must be taken into account. This is described in Chapter 3.

\section{Reflexivity and relationships between the researcher and the participants}

Issues of reflexivity in ethnographic research and the relationship between researcher/research participants, interviewer/interviewee, are important in this study. Charlotte Aull Davies (1999) makes the point that we cannot research something (or someone) with whom we have no contact, or from whom we are isolated. It follows that the results of our research and the influence of the researcher on the research processes are inevitable, particularly in ethnographic research. Aull Davies broadly defines reflexivity as:

turning back on oneself, a process of self-reference. In the context of social research, reflexivity ... refers to the ways in which the products of research are affected by the personnel and process of doing research. These effects are to be found in all phases of the research process from initial selection of topic to final reporting of results (Aull Davies, 1999: 4).

Issues of reflexivity are very important in ethnographic research, where the involvement of the researcher with those being studied is very close. Ethnographers engage in social interactions and participant observation that inevitably require both "involvement” and “detachment” to gain insights from the shared experiences, including narratives. The researcher is required to develop 
research methods that both acknowledge and promote the subjective experiences or explanations, while at the same time placing these within a socio-cultural and theoretical context. There is the potential, then, for a further reflexivity in terms of moral, social, or political implications of the research. In my account of my parents and their lives (Chapter 2) I have tried to share my own story so that the reader will understand my own subjective experiences and explanations.

Concerning indigenous Mäori research, Linda Smith (1999) links the issue of reflexivity with the ways in which insider/outsider research is complex and multiple. Traditionally, she argues, it has been assumed that the person researching indigenous groups and indigenous "problems” is an "outsider”. Smith writes that there are multiple ways of being both an outsider and an insider:

The critical issue with insider research is the constant need for reflexivity. At a general level insider researchers have ways of thinking critically about their processes, their relationships and the quality and richness of their data and analysis. So too do outsiders, but the major difference is that insiders have to live with the consequences of their processes on a day-to-day basis for ever more and so do their families and communities (Smith 1999: 137).

Further, Smith says, insider researchers have to be skilled in defining very clearly their research goals and their "lines of relating" to participants to make sure these are specific to the research project, and do not go into the participants' relationships within their own family or community networks. I have tried to make my own research goals clear to the participants and, although I call myself a Pacific woman, I was not related to or part of the cultural communities of those I interviewed (that is, I did not interview any Tahitian women). However, I do belong to PACIFICA (Pacific Womens Council) and as I am interacting with Pacific women from a range of cultural groups on an ongoing basis I do have a level of visibility and credibility to maintain and ensure I am able to represent Pacific women, whatever their background, in authentic ways and with understanding of the implications of this research for them.

Issues surrounding positionality and “othering”, in relation to research participants, are also raised by Petelo (1997). Her study required her to think about how she was "constructed", during the research process, that is, how the students and others constructed her, and vice versa. She argues the benefits and the drawbacks of sometimes being insider and sometimes being outsider; ethics that are acceptable to the university ethics committee and the dynamics of Samoan 
student networks; and issues of power and "othering of the researcher". Petelo was aware that her age, gender, and ethnicity had placed some limitations on the data she collected, but admitted that as these factors could not be changed, it was important that these "positionalities” be voiced and made explicit. As previously discussed, my interviewees either knew me previously or knew of my background through wider Pacific networks, so they knew I was not “of them” (being Tahitian), but that my community work with Pacific women made a connection with them on another level, as well as by being a student and a mother.

Bakalevu's (1996), research with her own Fijian people in her doctoral study about mathematically-based systems in the culture and socialisation of Fijian people also provided her with a number of challenges. In order to gather data from the elders about traditional mathematical processes and knowledge, Bakalevu reflects that she was required to follow traditional ceremonies of negotiation that no outsider would probably have been required to do. Being accompanied by men, and providing appropriate food and gifts were just such examples. The importance of kinship ties and relationships was also crucial to success. It placed many restraints on her in terms of time, and some limitations on the extent and size of her research sample. Gender issues arose when some suspicion was expressed about her age and her physical and mental abilities to do this work, and also that she was crossing the traditional divisions of labour in Fijian society. As a woman, her contributions of food in particular had to be plentiful. Presentations always had to be through a male, never directly. I interviewed females so the traditional gender boundaries did not affect my methods in that sense. However, I did offer food and shared food with the participants, and they were willing to speak with me because they hoped this research would help other Pacific women in tertiary education.

Bakalevu's qualitative research project, including oral testimonies and unstructured interviews, also (not surprisingly) brought her face to face with cultural differences in relation to research ethics, researcher accountability, and issues of who owns the knowledge. Despite the many challenges, Bakalevu concludes:

I collected much data, more than I needed. However, all information is useful as they have provided further insight and better understanding of the topic and the research context at home. While being Fijian was certainly an advantage in this research, I 
In both the aforementioned research studies it was clear that the researchers had to revisit many of their own assumptions. Even though she was an "insider", Bakalevu still had to re-examine her own role as a researcher in relation to her own traditions and values. Petelo, on the other hand, describes her research as cross-cultural, since she had to make the traverse between two cultural contexts, each with multiple meanings and with particular positionings experienced in both. As the interviewer I was associated most intimately with Tahitian culture, which has particular differences from other Pacific cultures, although there is probably a greater level of similarity and empathy between Tahitian and Cook Islands cultures. However, the experiences associated with Pacific migration to Aotearoa New Zealand, our early church affiliations and my father's involvement in wider Pacific cultural events and performances, together with his community work, provided me with some very strong bases of association as well as my own knowledge and skills in relating to other Pacific cultures. Most importantly, the topics for discussion were based around tertiary education, family and church, areas familiar across all Pacific communities in Aotearoa New Zealand.

\section{Qualitative data analysis}

Madill, Jordan and Shirley (2000) discuss the meanings of objectivity and reliability and what they mean in qualitative analysis from three different epistemological perspectives. They argue that:

qualitative researchers have a responsibility to make their epistemological position clear, conduct their research in a manner consistent with that position, and present their findings in a way that allows them to be evaluated appropriately (2000: 17).

Jonathan A. Smith (1995) makes the point that there is no one way to do qualitative analysis. Whatever method is used, meaning, he claims, is "central" and the aim of any analysis should be to try and understand the content and complexity of the meanings provided (by the interviewee, for example, rather than, say, by measuring simple frequency of occurrence). He suggests looking for themes and subthemes in the data and exhorts the researcher to be ready to find new emerging themes or variations. Smith reports that the levels of analysis that can be employed depend on the kind of argument or statement the researcher wants to make about the person's narrative. In the analysis I did not attempt to 
establish accounts of frequency of occurrence, but rather looked for examples and illustrations of the indicators and processes described by Cornell and Hartmann (see Chapter 7).

Smith makes the point that as the analysis proceeds and the researcher removes herself from the actual text, it is important to keep reminding oneself that the personal biographies and narratives are situated within specific contexts. Knowledge of the contexts from which they derive must ultimately help the researcher to understand them, and consequently allows her to make sense of the data. As I read through the narratives to analyse them I was able to relate the women's experiences, to them as Pacific women within their families and churches but also as their reflections on their tertiary education experiences.

Mishler (1986) also encourages researchers to engage in analysis and interpretation through various procedures informed by theoretical assumption and presupposition about the relation between discourse and meaning. The researcher must be aware of his/her own meanings, assumptions and interpretations of the narrative, which are in turn informed by memories of the interaction, the nature of interaction with each respondent, and the sharing of feelings within the interview itself. That is why it was important to work through some theoretical assumptions in regards to the narratives and to clarify my own meanings before being able to find the illustrations within the interview data.

Fontana and Frey (1998) acknowledge that the researcher has a great deal of influence on how the data are analysed and reported. The problems of the researcher start emerging, they report, when the researcher becomes slowly "buried" under a growing amount of data and must come to grips with the complexity and contradictory nature of the data collected. The researcher, while imposing some kind of order on the data, must always be explicit about the process and about the decisions he or she makes in "making sense" of reported experiences. Fontana and Frey refer to researchers making “confessions” about their role so that the study or project is more realistic and commensurate with social realities. I had a huge amount of narrative data and originally wanted to ensure all "voices" were heard. While imposing order on my data I had to make a number of decisions about what to include, and which stories were illustrations of an indicator such as boundaries between "us" and "them". 


\section{Ethical considerations and confidentiality}

An integral feature of current scientific and social research has been the attention and priority given to ethics, the ethical behaviour of researchers, the informed consent of participants, confidentiality (that is, participants' right to privacy), and protection from harm of the participants. Researchers such as Anne Grinyer in England, Linda Smith in Aotearoa and a team of Pacific women researchers led by Melani Anae have, from their own cultural and contextual perspectives, reexamined and critiqued the Western paradigms within which ethnocentric ethics and individual participant confidentiality in particular has held sway. This study had to be approved by the Victoria University Ethics Committee, and I am required to uphold its standard that all participants are assured of confidentiality and informed consent. I have followed this procedure but, given the visibility of Pacific women graduates (because there are few) and the fact that they could potentially be identified, I have had to re-think the issues of "privacy" and potential harm.

In relation to her recent book on young adults with cancer, Anne Grinyer (2002) reflected on the ethics around the narrative data written by their parents, and debates some of the long-held ethical criteria applicable to social research. She had to face requests by her parent participants to use their real names and refer to the real names of their young people. Some wanted this because they felt their "ownership” of their stories would be otherwise removed from them. They wanted their stories to be shared openly with other parents and felt the inclusion of the names of their young people would act as tributes to their struggles and in some cases, their lives. Grinyer made efforts to accommodate these requests and describes the processes she went through in order to meet those requests. Drawbacks she describes included people changing their minds at every stage of the feedback process, even after publication. Ambivalence was sometimes due to the personal nature of the content of what the parents had shared. Grinyer makes the point that each researcher must address such issues on an individual basis.

I had a very sad experience during the writing phase when one of my students died. I felt a duty to connect back with her family and I decided to offer them an opportunity to write to the Ethics Committee requesting the release of her taped interview, even though the transcript would have been in her personal effects. To date the family have not requested the material, but I have acknowledged the 
participant (see the Epilogue) and her privacy is maintained because I do not link her with any of the pseudonyms used.

Also, culturally, I will have to have a celebration after graduating to which the participants will be invited and where they will be publicly acknowledged (although not directly by name). Most will probably already know each other, but it will be up to them if they want to link their pseudonyms and real names, and some may not be able to attend. The ethical standard of "do no harm” also involves a measure of trust placed in the researcher to treat participants' contributions with respect and culturally, that is more important than being known as a member of a relatively small pool of people.

Linda Smith (1999) is in agreement with that viewpoint, describing ethical standards as being concerned with the nature of relationships and establishing relationships that protect both the researcher and researched (i.e., to do no harm). Smith contends that the lack of recognition and respect by researchers of indigenous peoples' and community rights and views about the nature and purpose of research has led to the present cynicism towards, and in some cases total rejection of , “outside” researchers.

According to Smith, Western ethics have been framed within a paradigm of the individual rights of a person to his or her own knowledge, and the right of the individual to give informed consent. Research ethics for Mäori go beyond this individual level of confidentiality to responsibilities to Mäori communities as a whole. Smith quotes the work of Ngahuia Te Awekotuku, who has identified a set of responsibilities that researchers have to Mäori communities when they seek to study them. These responsibilities are set squarely within Mäori cultural values and encompassed by the over-arching term, respect:

Through respect the place of everyone and everything in the universe is kept in balance and in harmony. Respect is a reciprocal, shared, constantly interchanging principle which is expressed through all aspects of social conduct (Smith 1999: 120).

Similarly, Anae et al. (2001) in their report to the Ministry of Education on Pasifika Education Research Guidelines, outline the western paradigms which have to date rendered Pacific world views invisible in the fields of social science research. These include:

Western democratic principles are based on the assumptions that

- the individual, his rights and freedoms, forms the basic unit of society 
- market-driven economies and ideology

- $\quad$ capitalist paradigms

- focus on the individual as opposed to the collective

- monocultural frameworks and methodologies

- $\quad$ androcentric nature of western societies

(Anae, Coxon, Mara, Wendt-Samu \& Finau: 2001: 12).

Further, they argue, any research that involves Pacific peoples must reflect Pacific world views underpinned by Pacific values, belief systems, and ways of sharing knowledge. Their guidelines emphasise the need for consultation and negotiation with Pacific communities at each stage of the research process and the development of partnerships with Pacific researchers and key people within Pacific communities. A common perception in Pacific communities such as South Auckland is that they are over-researched, and that the research that has been conducted has resulted in little or no social or economic benefit to the people themselves. This is the situation in the wider context and a cautionary tale for all researchers, including “insider” researchers who are trying themselves not to fall into some of the same categories as “outsider" researchers. Issues of power, Pacific research methodology, and the work of Tongan woman academic Taufe’ulungaki (2003) are pertinent here.

As stated previously, the present study followed traditional Western research methods, but as a Pacific woman my behaviour in the researcher-interviewee relationship was heavily influenced by my own cultural frameworks, beliefs and practices. I think the participants appreciated the situation in which we found ourselves, as graduates and having an understanding of the requirements and demands of academic research. They wanted to ensure, however, that their stories made a real contribution to change in understanding or recognising the needs of Pacific tertiary students, and they trusted me to ensure this happened.

What all the critiques of current methodology and ethical criteria reported above demonstrate is that epistemological assumptions need to be scrutinised in respect to what participants in the research believe is in their best interests or wellbeing. The role of the researcher is to ensure opportunities exist for this to happen. However, what has emerged for me from my study is that while ethical issues, issues of confidentiality and individual rights to privacy are clear they are not always straightforward in their application. While there are legal requirements and constraints on individuals and institutions that must be met, knowledge of the 
wider implications and the cultural interpretations of "do no harm” across participant groups are not wellknown.

\section{Research Methods used in this study}

\section{The main research question}

I had experienced tertiary education myself as a Pacific woman, and I was curious to find out if this educational experience contributed to the construction of my Pacific ethnic identity and/or the ethnic identities of other Pacific women graduates.

My research question was:

a) Is tertiary education a site for the construction of ethnic identity?

In responding to this question I considered the relationship of tertiary education as a construction site in relation to the family and the church. Family and church contribute to what the women took with them into the tertiary education site. For some of the students, entry into tertiary education did not occur until well after they had been socialised into their cultural identities.

Four further research questions were therefore necessary:

b) What did Pacific women bring with them into the tertiary education site?

c) How did the tertiary institutions respond to these Pacific women on the basis of their ethnic identities?

d) What other settings are important in the construction of their ethnic identities?

e) What relationship exists between the family, the church and tertiary eduction?

What did Pacific women take with them into the tertiary education institutions in respect of their cultural identities? Further, how did the tertiary institutions (represented by the lecturers, tutors, and the demands placed on students to complete their studies) “construct” Pacific women on the basis of their cultural identities?

\section{The research approach}

Two research instruments were used to collect data for this study: a questionnaire and questions for a semi-structured interview. 
A short questionnaire to record biographical and educational history of the participants was developed (see Appendix C). The questions were designed to gather basic factual information prior to a semi-structured interview with the participants. Information sought about each participant pertained to ethnic descent and heritage, place of birth, age, church affiliation and attendance, education history (primary through to tertiary), whether they studied as a full or part-time student, qualifications gained or engaged in, personal and family circumstances while studying, support received while studying (including financial), and any responsibilities for dependants or other family members while studying. The questionnaire was important in getting standardised information about family and educational background to set the scene for the focus in the interviews on tertiary education and ethnic identity construction. It was anticipated that gathering such information through the questionnaire would leave more time within the semistructured interview itself for dialogue and narratives.

The questions for the semi-structured interviews were designed to gather rich data about the women's perspectives on their own identity; their daily lives within their family; their reasons for entering tertiary study; and their initial experiences at the tertiary institutions that they attended. Further questions were designed to probe how they coped while studying: meeting course requirements; support while studying (including financial); the knowledge and content of their courses; the kinds of treatment they experienced from others while studying at the tertiary institution; and, lastly, what they thought the consequences or outcomes of tertiary qualifications were for them in relation to their cultural backgrounds (see Appendix E).

The interview questions were developed in line with the constructionist approach and with a focus on the relationships between institutions and construction sites. Prior to the interviews I developed a draft framework of cultural and ethnic identity formation based on my knowledge as it existed at the initial stages of the study. I developed a diagram, which depicts the chosen settings or potential “sites” for study and a proposed relationship between each of them (see Figure 1). I also included the notion of multiple identities as a possible outcome of how the women might see the influence of various institutional settings in their lives. As we will see, as this thesis unfolds, this diagram changed in response to the women's description of their lives and my own reflections on the empirical and theoretical aspects of my thesis. 


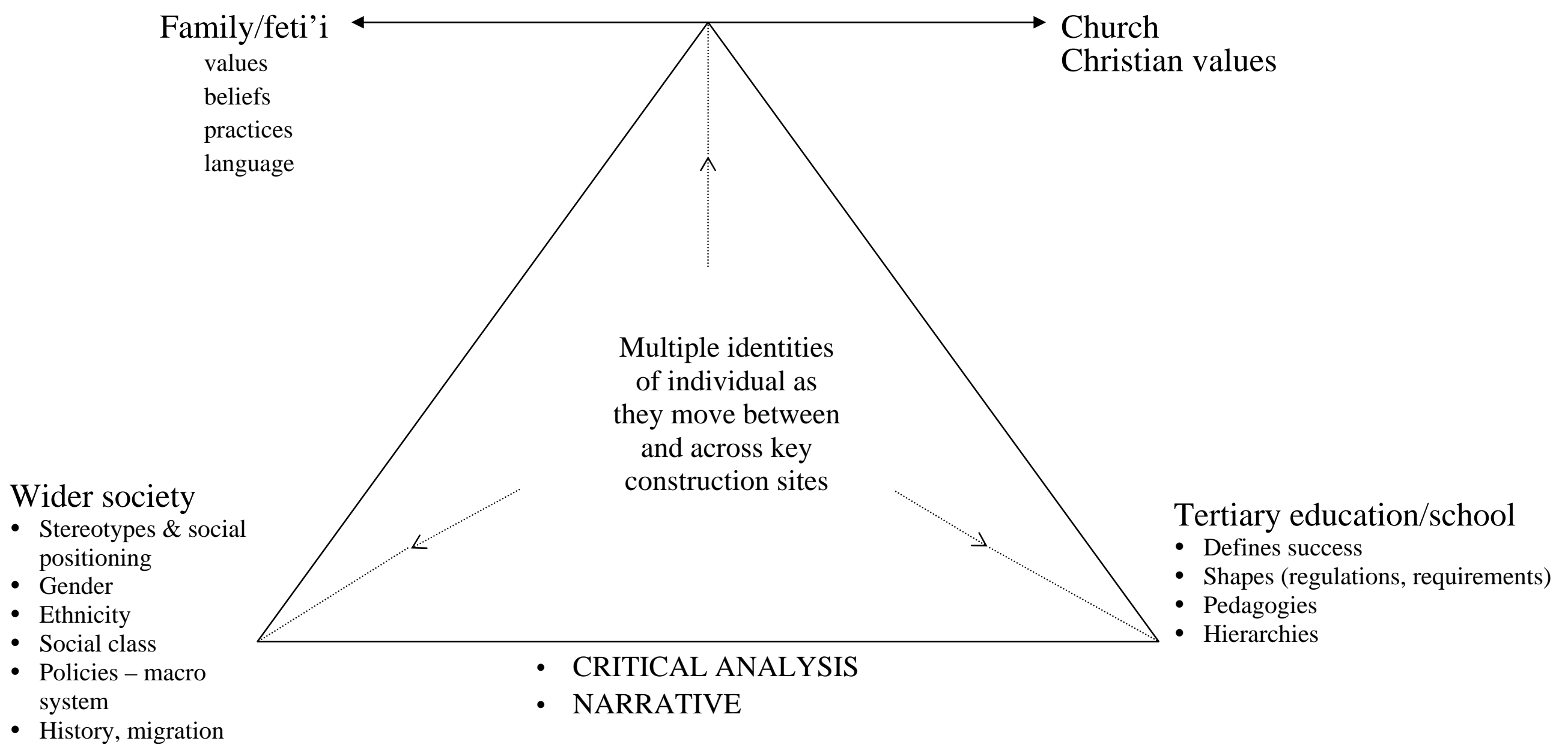

Figure 2: Tentative Theoretical Framework: Ethnic identity construction of Pacific women in tertiary education settings 
Before commencing the interviews I shared my diagram and the ideas it was based upon with three Pacific women lecturer colleagues at my tertiary institution. This small focus group, whose opinions I greatly valued, gave me positive feedback on the diagram. They confirmed that it would stimulate discussion in the interviews. I also held a pilot interview to "test” my interview questions and to help me estimate the length of time the interviews would take. I found my questions and probes to be robust and appropriate, so they did not need any further alteration. The interview took just over an hour and a half, which was approximately what I had estimated.

\section{The interview process}

Once the participants had agreed to be part of the study, they received a letter of information (see Appendix B); a consent form together with the two-page questionnaire to fill in (see Appendix C); and a list of the areas of discussion to be covered in the interview (see Appendix D). The questionnaire was either mailed back to the researcher before the interview or collected at the beginning of the interview. The full interview schedule (see Appendix E) was taken to the faceto-face interviews.

The 20 semi-structured interviews took place between October 2000 and July 2002. The Pacific women in the study were interviewed in three different cities. Seven women living in Auckland, two living in Christchurch, and eleven Wellington-based Pacific women were interviewed for this study. Although these women were living in Wellington at the time of the interviews, six women had also studied in tertiary institutions outside Wellington, including two at overseas universities.

Each of the tape-recorded semi-structured interviews took from between 1.5 to 2.5 hours. The interviews took place in a wide range of venues: in my home, in their home, at a cafe over lunch, in their places of work, at my place of work, in an empty polytechnic classroom, at a mutual friend's house. In some cases where time was available we continued to talk beyond our agreed time. This willingness by the women to keep talking indicated that the selected areas for discussion were important and relevant to them and they had much to say. In addition, where these informal discussions after the recorded interview time provided further useful background information, written notes were made. 
During the second half of the interview I shared the diagram showing social contexts and the relationships between family, school or education as an institution, and the wider society (see Figure 1) with the participants. Following my explanation of the diagram, I asked the women for their responses to it. In at least six interviews the framework acted as a stimulus for further discussion; in another six interviews it acted as a confirmation of prior comments made by the interviewee. ${ }^{33}$

The first interview was a pilot interview and was held in October 2000. The narrative from that interview was subsequently included in the final sample of 20 interviews. The interviews proper began in June 2001. The protracted time span of the interview phase was due to delays in negotiating times for interviews with the women, travel between three cities, and the need to allow for the researcher's work and family commitments.

All recorded tapes from the 20 interviews were transcribed and the transcripts were sent to participants within two months of their interview. The women had an opportunity to check the text for meaning and to make any additional comments or feedback. They were given a month to reply and return the scripts. Three women took the opportunity to do so and their comments were added to the narrative data.

\section{The sample}

I decided to interview 20 women who identified themselves as Pacific women (that is, Samoan, Tongan, Cook Islands, Niuean, Tokelauan or as members of any combination of these Pacific cultural groups). The second criterion for inclusion in the study was that the women would need to have graduated from a university, polytechnic, college of education, or private tertiary training institution. They would be Pacific women who were successful academically. This sample of 20 women would, I predicted, produce a sufficient body of narrative data for analysis to help answer the above research questions.

33 This diagram was reviewed as a result of the feedback during the interviews, and following the analysis of the interviews. The revised diagram is included, together with an explanation of the changes in Chapter 14. 


\section{Recruitment of the sample}

A number of informal methods of recruitment were used that best come under the main heading of "snowballing”. Most interviewees were found as a result of my own Pacific Island women's networks, including PACIFICA (Pacific Women's Council). Within my education networks over a number of years as teacher, policy analyst, researcher, and teacher educator, I already had a range of Pacific women graduate contacts that I was able to use in finding participants for this study.

The main criterion for the selection of the sample (as stated previously) was that the women would be of Pacific descent or self-identified as Pacific women from one of the New Zealand Pacific population groups. The second criterion was that they would have completed at least one tertiary qualification at a New Zealand educational institution. As the selection of the sample proceeded there was a deliberate attempt to include a wide range of Pacific ethnic groups and students from as many different disciplines of study as possible. The reason for widening my participant sample was that, should any patterns or commonalities be found across the sample, no one tertiary discipline or one type of tertiary qualification would influence those patterns.

Two women were recruited by chance at a meeting for Pacific Islands public servants. Personal contacts in my own church found two further women. The rest of the women were recruited through my existing Pacific networks. Twenty-six Pacific women in total were approached to take part in the study. These included a Fijian woman and other Pacific women with a range of qualifications including degrees in music, art history, health, public policy, sociology and law. Time constraints, and the inability to arrange interviews with some of the women meant that not all could be included. It was particularly disappointing that the Fijian woman graduate was unable to take part.

\section{Ethical and cultural considerations}

In compliance with the requirements of the university an assurance of confidentiality was made to the participants in a letter sent to them prior to their interviews (see Appendix B). They were permitted to withdraw at any time during the study, but only one became unavailable. A replacement was soon found to restore the sample to twenty women. 
In terms of the interview data, the three transcribers of the interview material were very experienced and aware of the need for confidentiality at all times. Participants were informed that their taped interviews and transcripts would be kept in a secure place and destroyed after five years.

To further ensure confidentiality, the participants were given pseudonyms. While I was writing up and analysing the data I wrote, emailed or telephoned the participants and asked them to choose their own names. Fifteen participants replied within the month requested and chose their own pseudonyms. In the case of the remaining five women, who did not respond to my request, I selected names for them from the Bible in line with their values: Ruth, Abigail, Rachel, Mary, and Naomi.

One important consideration for the interviewees was the language we would use. I confirmed with all of my participants that they were comfortable about speaking in English. Fourteen out of the 20 women reported being able to speak their heritage language/s, but there was a range of fluency levels across the group. Even though the majority of the women could speak a Pacific language, several said they preferred speaking in English when discussing the complexities of their lives and their time as students.

I could have offered the women the opportunity to speak in their own languages and provided a transcriber/translator afterwards, but that was not required. I had made the assumption that since all of the participants had been or were studying currently at a tertiary institution in Aotearoa New Zealand their spoken English would be sufficient for meaningful communication between us.

An important dimension to the interviews held with the women were all the cultural aspects, the non-verbal cues and aspects of communication, the humorous exchanges that are characteristic of Pacific peoples during any social interactions. Such interactions were anticipated by the researcher but since the interviews were only sound recorded only laughing and other sounds are evident as data. This was a limitation and could not be overcome without perhaps using video recording of the interviews. However that would have required time, equipment and perhaps less flexibility in terms of interview venue and opportunity. 


\section{Summary}

In this chapter I have commented on literature pertaining to some of the key methodological issues that were relevant to this study and described my responses. In the second part of the chapter I outlined the main research methods, research questions, the research approach, and the interview process. This was followed by a description of the research sample and the recruitment of the sample of participants.

The next chapter (Chapter 9) includes an analysis of the results of the questionnaire about the women participants summarised in table form. The womens' narratives are analysed in Chapters 10, 11, 12 Twelve and summarised in Chapter Thirteen. 


\section{CHAPTER 9: DESCRIPTION OF SAMPLE}

\section{Introduction}

This chapter contains a description of the sample of Pacific women graduates interviewed for this study. The evidence for this description is based on data from the pre-interview questionnaire: "Some Facts About Yourself”. A copy of the questionnaire mailed to the participants, prior to the semi-structured interview, is included in Appendix C. A summary table of the participant sample concludes this chapter.

\section{Description of the interview sample of Pacific women graduates}

The sample consisted of 20 Pacific Islands women living in New Zealand who self-identified as Samoan (12); Cook Island (3); Cook Island-New Zealand Mäori (1); Niue-Samoan (1); Samoan/Päkehä (1); Tongan (1); and Tokelauan (1). While there was an attempt to have the sample be representative of the population profile of Pacific peoples in New Zealand, this was not the overriding consideration. ${ }^{34}$ The sample was intended to cover the main Pacific groups, but this was also balanced against the sample including women who had studied in a range of tertiary subject areas or disciplines and at different tertiary institutions.

The range of qualifications achieved in this sample of 20 graduates was very extensive. At the time of interviewing, one of the students was completing a double degree. Four had completed their first degree and were enrolled in their second. Five had completed a second degree or tertiary qualification; three of these women were enrolled in their third degrees. Six women had completed a third tertiary qualification and four of these were enrolled in a fourth qualification or tertiary course. Two women had four degrees, including postgraduate diplomas, and two were, at the time of interviewing, studying for their fifth tertiary qualification.

The Pacific women in this study were mostly middle aged. The age ranges of the women were as follows: two in the 20-29 group; ten in the 30-39 group; five in the 40-49 group and three in the 50+ group. Some had gaps of time between their first, second, or subsequent qualifications. Most of the women were currently

34 The profile of Pacific peoples in Aotearoa New Zealand is detailed in Chapter Three. 
pursuing further qualifications, including five who were currently enrolled in doctoral studies in their respective fields.

The tertiary institutions they had or were currently studying at were located in six different New Zealand centres (Dunedin, Christchurch, Wellington, Palmerston North, Hamilton and Auckland). Four of the women had studied in overseas institutions (London School of Economics, University of Papua New Guinea, University of California Berkeley and University of the South Pacific, Suva). Many of the women had studied (or were still studying, in some cases) for qualifications at institutions in centres away from where they currently lived. At least two were studying extra-murally. Only one woman had attended a private training provider i.e. a Christian-based institution not funded by the government. Across the total sample this group of women had attended six different universities, three colleges of education (for teacher training), and three different polytechnics (primarily studying vocational courses). These Pacific women students had therefore experienced and been engaged in a range of types of tertiary education institutions in Aotearoa New Zealand, in a range of locations.

The women in the study were asked about their church affiliation and attendance. All the women in this sample, except one, identified as having had a regular church affiliation and regular participation. Seven women described themselves as members of the Presbyterian Church: five attended at least weekly, one monthly and one yearly on special occasions. Six women identified as belonging to "other" churches, which were referred to as: their own ethnic group church, charismatic, home/family group, and Pentecostal. The attendance at these "other" churches was at least weekly. Three identified as attending a Congregational Church, two said weekly, and one, said two to three times a year or on special occasions. Two women identified as Methodist Church members, both attending weekly. Two participants identified as Anglican; one attended weekly, one monthly. One woman identified as a Catholic and reported she attended church monthly and on special occasions. In interpreting this data it needs to be noted that several women identified with two denominations of church and consequently where women reported they attended church services twice a week it could mean they attended two different churches.

Participants were asked about their financial circumstances while they studied. There was a wide variation in experiences, depending on their marital or domestic 
status or situation, their ability to access part-time work, scholarships, benefits, and so on. Answers to this question depended upon where they studied and whether they were living at home, or in the same city as family, or living apart from family. Data collected in the questionnaires reveal a range of ways in which the women have survived financially during study. In most cases the changing circumstances for the women in this sample were such that sometimes, even within one course of study, they relied on a range of different sources of financial support.

The majority of the students relied on holiday or part-time work to support their studies, closely followed by financial support from family/aiga/fanau (including partners). Almost as frequently the source of financial support was scholarships, student allowances and student loans. In three cases students reported spending some time on the Domestic Purposes Benefit (DPB) and receiving the Training Incentive Allowance (TIA), which enabled them to return to study. Several used their own savings to pay for their courses of study. In two cases employers assisted the students with fees and some time from work to study. In another case the church paid for a postgraduate course for the student.

The questionnaire also asked the women about their roles and responsibilities within the family, including extended family. I asked them first whether they had studied full-time or part-time for their qualifications, to find out how they balanced their study lives with their other roles and responsibilities. Ten of the women studied full-time for each of their degrees and diplomas. Only one of the women reported that she had studied part-time for all of her tertiary courses. Nine women reported a combination of full- or part-time study across their various degrees and tertiary studies. Part-time study was generally at the postgraduate level, or in a second or subsequent tertiary course.

The women were asked whether or not they lived with their family while studying. Six women said that they lived away from their families throughout study. Seven reported that they lived with parents, or husbands/partners, or wider family while studying. Some of these women changed their family living arrangements such as moving from their parents' home into a home with their husband/partner, or moving from home to live with other family members. The remaining seven reported living changes during their studies such as when 
relationships broke up, when they chose to live alone, when they went home to parents, or when they went flatting with other people.

In terms of having dependants, and therefore ongoing or daily responsibilities for others, 11 out of the 20 women reported that they had no dependants to support or care for while studying. Nine women reported having dependants from the beginning of their studies; one reported that she started out single with no children, but this had changed within the course of her study. Two women were mothers of one child; three were mothers of two children; one woman had three children, and three women had four children. One of the mothers with four children had two of her own and bringing up two nephews. Three of the women with children also reported caring and living with elders such as a father, a grandmother and other extended family members. Another woman cared also for a grandson. One of the single women with no children reported that she had regular care responsibilities for her father, mother and sister.

The following table summarises cultural identity (as reported by the women), their place of birth, their time in New Zealand, their qualifications and their ages. Of the eight women were not born in New Zealand most had completed primary education and some secondary education in their islands of origin. The Samoan woman who had arrived mostly recently in New Zealand, had completed initial tertiary qualifications at an overseas university, in addition to primary and secondary education in her own country, and is currently doing post graduate study at a New Zealand university. 
Table 1 PARTICIPANT SAMPLE: Tertiary-educated Pacific women

\begin{tabular}{|c|c|c|c|c|c|}
\hline Name & Ethnicity & Born NZ & $\begin{array}{l}\text { Born IslandsI } \\
\text { years in NZ }\end{array}$ & Degrees \& Qualifications & Age \\
\hline Abigail & $\begin{array}{l}\text { Samoan/NZ } \\
\text { Päkehä }\end{array}$ & $\bullet$ & & BA/LLB; MSc & $\begin{array}{l}30- \\
39\end{array}$ \\
\hline Allegra & $\begin{array}{l}\text { Samoan/ NZ } \\
\text { Päkehä }\end{array}$ & $\bullet$ & & BA/LLB & $\begin{array}{l}20- \\
29\end{array}$ \\
\hline Destiny & Tongan & & 18 & $\begin{array}{l}\text { MBChB; MPH; DipCH; } \\
\text { DipPH; PhD (enrolled) }\end{array}$ & $\begin{array}{l}30- \\
39\end{array}$ \\
\hline Eleni & Samoan & $\bullet$ & & $\begin{array}{l}\text { BA; MA (Hons); PhD } \\
\text { (enrolled) }\end{array}$ & $\begin{array}{l}30- \\
39\end{array}$ \\
\hline Hana & Cook Islands & & 48 & TTC; MEd (enrolled) & $50+$ \\
\hline Judith & Samoan & & 29 & BA/LLB; MA; PhD (enrolled) & $\begin{array}{l}30- \\
39\end{array}$ \\
\hline Katalina & Tokelauan & $\bullet$ & & BA; DipTchg; MA (enrolled) & $\begin{array}{l}30- \\
39\end{array}$ \\
\hline Lee & Niuean/Samoan & & 32 & $\begin{array}{l}\text { DipKT; AdvDipTchg; DipEd; } \\
\text { MEd (enrolled) }\end{array}$ & $\begin{array}{l}30- \\
39\end{array}$ \\
\hline Lucy & Samoan & $\bullet$ & & $\begin{array}{l}\text { BEd; HDipTchg; DipESSN; } \\
\text { MA (enrolled) }\end{array}$ & $\begin{array}{l}30- \\
39\end{array}$ \\
\hline $\begin{array}{l}\text { Makasini } \\
\text { Tuatagaloa }\end{array}$ & $\begin{array}{l}\text { Samoan/ } \\
\text { Tongan }\end{array}$ & $\bullet$ & & BA; MBA & $\begin{array}{l}30- \\
39\end{array}$ \\
\hline Mapaia & Samoan & & 27 & BA; BTheol; MA & $\begin{array}{l}40- \\
49\end{array}$ \\
\hline Mary & Samoan & $\bullet$ & & BCom; DipTchg & $\begin{array}{l}20- \\
29\end{array}$ \\
\hline Naomi & Samoan & & 5 & MBBS; DipPH (enrolled) & $\begin{array}{l}40- \\
49\end{array}$ \\
\hline Ngariki & $\begin{array}{l}\text { Cook Islands/ } \\
\text { NZ Päkehä }\end{array}$ & $\bullet$ & & BA (Hons); MA (enrolled) & $\begin{array}{l}30- \\
39\end{array}$ \\
\hline Rachel & Samoan & & 27 & $\begin{array}{l}\text { BEd; BA (Hons); DipTESL; } \\
\text { DipTchgSN; MEd (enrolled) }\end{array}$ & $50+$ \\
\hline Rita & Samoan & $\bullet$ & & $\begin{array}{l}\text { BEd; DipTchg; AdvDipTchg; } \\
\text { DipEI }\end{array}$ & $\begin{array}{l}40- \\
49\end{array}$ \\
\hline Ruth & Samoan & & 34 & $\begin{array}{l}\text { BEd; MA (EdAdmin); } \\
\text { PhD (enrolled) }\end{array}$ & $50+$ \\
\hline Sarah & $\begin{array}{l}\text { Cook Islands/ } \\
\text { NZ Mäori }\end{array}$ & $\bullet$ & & $\begin{array}{l}\text { BA; MA (Hons); } \\
\text { PhD (enrolled) }\end{array}$ & $\begin{array}{l}40- \\
49\end{array}$ \\
\hline Siulia Tui & Samoan & $\bullet$ & & BEd; MA (enrolled) & $\begin{array}{l}40- \\
49\end{array}$ \\
\hline \multicolumn{2}{|c|}{ Wawine Wale Cook Islands } & - & & $\begin{array}{l}\text { Papers for BSW; Cert. } \\
\text { Journalism; BA (enrolled) }\end{array}$ & $\begin{array}{l}30- \\
39\end{array}$ \\
\hline
\end{tabular}




\section{Summary}

In this sample, just over half of the Pacific women graduates identified as Samoan, which very closely reflects the proportion in the Pacific population in Aotearoa New Zealand. Just over half of the sample had completed their second degree and were enrolled in a third tertiary qualification course. Between them, the women had attended six universities (out of a total of eight universities in New Zealand); three colleges of education (out of a total of four colleges); and three polytechnics (out of a total of 20). ${ }^{35}$ Nineteen out of the 20 twenty women reported regular church affiliation and regular church participation. The majority of the students relied on holiday or part-time work to support their studies, closely followed by financial support from family/aiga/ fanau (including partners). Ten women reported they had studied full-time for their qualifications, nine reported a combination of full and part-time study. Part-time study was the more likely while doing postgraduate study. Just over half of the women reported having no dependants to take care of while undertaking study. The other nine reported having had children to care for. Of these, three women had the highest number of dependants in this sample: four children each to look after. One of the single women reported having care responsibilities for her father, mother and sister.

35 Ministry of Education (2004). Directory of New Zealand Schools and Tertiary Institutions , Author, p2. 


\section{CHAPTER 10: RESULTS II: ETHNIC IDENTITY}

\section{Analysis of the Narratives: Overview}

In this and the following two chapters the analysis of the data is set out. In this chapter I include the narratives that show how the women identified themselves in terms of ethnicity. The data are examined to see the extent to which the constructionist approach is useful in demonstrating that primordialist and circumstantialist meanings are present within the women's definitions of their own ethnic identities.

In the following chapters the narrative data are grouped according to references to the three main contexts studied: the family, the church, and tertiary education. In terms of family, the narratives are analysed on the basis of indicators such as the family's immigrant status, the values reported to be passed on by parents, and the meanings and understandings developed over time in the family context about their ethnic identities. I made the assumption in this study, which turned out in the main to be true for this sample of Pacific women, that the family and church contexts are closely linked.

In terms of the tertiary education settings, the analysis of the narratives provides examples of transition experiences from family and church settings into tertiary education and what the women took with them. Other indicators include evidence of the assignment of these Pacific women by ethnic group outsiders, and ethnic group identification processes within the tertiary education context as perceived by the women. Their responses to that treatment, which they interpreted as both positive and negative, are also analysed.

Within each of the above contexts or settings the analysis produced illustrations of the processes outlined by Cornell and Hartmann of assignment and assertion, and of the extent to which ethnic identity organised the women's daily lives. ${ }^{36}$

\section{Ethnic identity}

The reflective statement by Abigail (New Zealand-born Samoan), reveals the complexities of articulating ethnic identity for Pacific women in Aotearoa New Zealand:

\footnotetext{
${ }^{36}$ The narratives quoted have been edited slightly to make clear the ideas expressed in the interviews.
} 
I do believe cultures change. There are lots of things about Samoan culture I don't agree with. Even some of the core kind of things but I would say that being Samoan for me in New Zealand means I get quite a strong sense of being part of a group of marginalised and repressed people. Our current position in New Zealand, as a group, is of an impoverished people, so that is part of my identity as being Samoan too, and that distresses me quite a lot ... (Abigail).

There were two main ways in which the women described their ethnic identities. The first group of descriptions related to parentage, heritage and ancestry, and genealogical descent, consistent with a primordialist explanation. For example, Lee was born in American Samoa but raised in Niue and,

My identity means that I have a place to relate to and that my father belongs to that place, so that is my strongest bond, knowing that my father is part of Niue, it gives me a sense of belonging, that he came from there and that he has taught me Niue things ... (Lee).

For Wawine Wale, born in New Zealand, there is both a family and an emotional dimension to her ethnic identity:

Well, my mother's from Pukapuka (which is in the northern group) and my father's from Atiu. What does it mean to me to be a Cook Islander? I find that actually a very difficult one to answer. I don't have a lot of contact with the Cook Island community at all but that doesn't mean I don't feel like I'm a Cook Islander, I do have that sense through my parents of what that means. It was about the stories I heard when I was growing up about the Cooks. I feel very strongly about my family and maintaining my links with my family ... mostly through this new generation like my nieces and nephews ... (Wawine Wale).

Establishing and re-establishing their family links in Samoa was important for both Allegra and Siulia Tua:

My sister got married in Samoa and it was like coming home. I met a lot of relatives there, and it's just so cool. If you said you are X's daughter, they knew who you are and the connections in the family and everything ... (Allegra).

My Samoanness was established when my mother took me home to Samoa when I was about five years old. I became so immersed in the culture and I learned the language to survive, basically. I think a lot of what I learned in that time is very ingrained in me. My culture is "gerontocratic, I guess the word is, where we respect our elders ... (Siulia Tui).

Our respect for authority is inbred. I am a first generation New Zealander but I still feel respectful. I'm proud of who I am, because my parents loved being Samoan and they were very important Samoans, my mother was a high chief, and they were both the most 
important Samoans in my life and in their own standing, and I will never forget that ... (Rita).

Physical appearance was also added to feelings, family and ancestry in the descriptions of the women's ethnic identities.

Being a Rarotongan person is what I look like. My face reflects my mother and my mother was born in Rarotonga. It is about the ability to understand and feel through the language some of the things that are unique to Rarotonga, for instance, the sound of the Cook Island drums. When they play I get real tingly feelings up my spine. It is knowing my history, having a passion, a deep passion, having a real understanding about the reason for the place, for the existence of Rarotonga, for the existence of my tribal affiliations, for the existence of where my family live. In Atiu, likewise, on my father's side. I can go there and take my shoes off and know that the sand and soil that I walk on is mine, I can walk around and my people would say to me "that taro patch, that's your family's and see that swimming hole down there, that's your family's and that marae down the road, is yours”. They even relate some of the things my ancestors did to how to behave now—oh you know, “you're pretty impulsive, just like your ancestors” ... (Hana).

Lucy had been adopted in New Zealand, as a child outside her birth family, and was re-united with her Samoa-based family in her 20s:

It wasn't until I was 22 that I made contact with my natural family. I felt a strong drive to find my father, who I knew was Samoan. When I made that initial connection with my father I felt that immediate bond with him. Other people describe our mannerisms and everything as similar, people who have met my father think we are strikingly alike. I can't see it myself, but I did feel something at the time. I mean, he is very, very Samoan and very committed to his country. He would love me to be living there and to totally become more fully Samoan ... (Lucy).

Family ancestry and affiliations came through strongly from all the women participants, as did the receipt of ethnic group values from parents and family, including extended family:

First and foremost I am Samoan. One is my genealogy, my birth, my land, my bloodline, and I think many aspects of Samoan culture. I do believe cultures change. I'm living with my sister at the moment but I go to see my parents, my father and my sisters, and I must say I am very close to my nieces. It is interesting that I am the only one in my family that identifies strongly as being Samoan and who has been to Samoa and can speak the language and has got this very acute political awareness of Samoa (Abigail). 
The values and the way in which I was brought up in my family and the culture-just the way in which my parents were within that culture, have their own way of defining the culture for me ... (Mapaia)

I'm very proud of being a Tongan, having grown up and lived half my life in Tonga. I think our Tongan values, our Christian values, are so important. I mean, our culture has so much meaning, and you can't separate out our Christian values from our Tongan values ... (Destiny).

I ask myself all the time when I'm asked to do things being Tokelauan. I suppose the first thing is knowing the values of my culture, through basic values I've always been told to respect, have and practice aloha, and knowing where you are, knowing who you are. Relationships and all that are involved. So I think if you know that and also your place in the family as well, you know your identity ... (Katalina).

Acknowledging two ethnic identities may appear to be difficult, but Lucy felt positive about her situation:

I guess I would see myself as having dual heritages. Samoan and Welsh. Some people may have different backgrounds but they may only identify with one, but I would say that sometimes I feel secure identifying with them both, because I don't feel secure identifying exclusively with just one. Somehow it is more authentic by saying both those areas are part of how I identify ... (Lucy).

The second group of descriptions of ethnic identity that came through the narratives were concerned with family circumstances and relationships, and the migration experiences of their families. These examples are more consistent with a circumstantialist explanation of ethnic identity.

For example, Wawine Wale felt she has had to make choices in terms of expected Cook Island obligations such as financial contributions to family and island community celebrations. Making these choices (which are more possible, perhaps, because she lives in another city) has, however, affected her relationship with her parents and extended family:

I've had too many arguments over the years about contributing to funerals with people I just don't know, or even people I remember as a child, which is not very nice. Neither of my parents coped with that very well. But they don't give me a hard time now about it. I kind of do have a sense of guilt because I would like to be able to dip into an unending pool of money, but I'm not exactly rich. So we kind of reached a bit of an understanding about what my involvement is and my obligations to the family ... (Wawine Wale). 
The changing social interactions within the family and the circumstances they found themselves in were also seen as important by Makasini Tuatagaloa, Siulia Tui, and Judith:

Certainly the importance of family, and surrounding that are issues of obligations, expectations, support, and conflict resolution. I think we learn about all these and about relationships with people within the family. I think that has rolled over into other areas of my life. But as I grew up I sensed through all that, that we were different as a family and that was because my mother was Tongan and my father Samoan. There were aspects of difference between their values and expectations going back to their islands of origin. I knew I was different because of that combination of races and the reactions to us by other Samoans and Tongans ... (Makasini Tuatagaloa).

I guess I'm Samoan, but not in the traditional sense of the word. The schools I went to even in Samoa were very multicultural and the teachers were mainly palagi. When people hear me speak they think “Oh you've got a very English accent.” I'd say, “That's how my teachers taught me to speak." So I see myself as a multicultural person at times, or even bicultural. I think it has shaped me a lot, being ingrained in the Samoan culture. We tend to be dogmatic, I think, at times! (Siulia Tui).

Having close links with your immediate family, definitely your brothers, sister, parents and grandparents, but also your extended family, first, second and third cousins. It's very much a part of a typical Samoan life, giving service to your family, being able to get along with your family members because of the underlying assumption that your family will always be there for you. You invest in your family rather than in financial institutions such as banks ... (Judith).

Opportunities to learn or maintain their Pacific ethnic languages were mentioned by all of the women when they came to talk about their ethnic identities. The following are examples of the kinds of comments made.

My father always made a point that we had to go to family gatherings such as weddings. Being together with the extended family was a very important part of our growing up. The family gatherings were where my father was comfortable, because he hardly spoke English at all and yet at home he really emphasised learning English. So we only heard the Rarotongan language spoken when we went to family gatherings and listened to our father talking to his extended family ... (Sarah).

At the time when my parents came to New Zealand the norm was, you don't teach your children to speak Samoan or two languages in the home because it was thought it would interfere with their learning. So my parents didn't teach us Samoan and I felt a bit deprived in that way, but they did still teach us and I don't know whether it was willingly, knowingly or not, the Samoan values came through all our upbringing ... (Mary). 
When I am asked I say I can speak conversationally but not with fluency. When I was five years old at home with my parents I was speaking Samoan, not English but when I went to school that changed. Now I am more fluent in English-in fact, I have got a couple of degrees in English. I would now say Samoan is my mother tongue but English is my main language, it is my language of communication. I can speak in Samoan but I find that limits me now in a sense ... (Eleni).

Further, when speaking your own Pacific ethnic language is both an assigned and asserted characteristic of being Tokelauan, Samoan, or Niuean the women expressed the contradictions about and the implications for the meanings and boundaries of ethnic identity.

The language is an issue with us. I'm actually not a fluent speaker in Tokelauan but if I'm asked to do things for the Tokelau community I always say to them, well they have to expect the mixtures of the two languages because of my lack of fluency ... (Katalina).

Yes, I speak Samoan fluently but mainly the everyday sort of language. I'm not very good at the oratory, higher, chiefly forms of traditional language ... (Siulia Tui).

I think the Samoan language is very important. I wouldn't say that it's necessarily the sole defining factor of being Samoan, nor should it be a defining factor. But having said that, in order to understand being Samoan you need to understand the cultural context of it and the best way to do that is through the language ... (Judith).

I was spoken to in the Niue language until I was nearly 8 years of age. Then we migrated to New Zealand and so I became bilingual. That's just how it worked out (Lee).

It was evident that all the Pacific women in this study had given a lot of thought to their cultural identity and perhaps the circumstances they found themselves had forced them to do this. They reflected on their own or their parents' migration to New Zealand, about the ways in which their visibility or differences influenced how they were viewed by outsiders and, consequently, how they were assigned an ethnic identity by the majority of palagi/popa'a/Päkehä in the wider society. The following are just two examples from the narratives:

I think our kind of identity at any given point in time is very much influenced by what we are currently doing and whom we currently know. I guess some of that is that we make choices about who we are in contact with. I thought I would give it two years here in this city and then go back and work with my mother's trust, you know, get involved in the community again. But life kind of doesn't unfold like that. I've certainly met many of my relatives who live locally over the years, who keep telling me: "I thought 
you had gone back, why don't you ring us?” But I just sort of smile. I have never really pursued those kinds of connections, that's been my own choice ... (Wawine Wale).

While Mapaia was growing up in Samoa she did not think her life was "typical”:

There were five of us in the immediate family, and always other children coming and going because my Dad was a pastor in the village. I was put out with different families because my parents travelled a lot. I was placed with my father's family, my mother's family, and as for my own parents, mum went to the States for five years for her theological training when I was twelve years old, and my dad went with her. My own upbringing was very different then from other Samoan children ... (Mapaia).

Other women commented on their upbringing as being "different" from other families within their own Pacific groups, either through intermarriage, or place of birth, or the occupations and social standing of their parents.

My father expected us to do well in school, even though I lived in a village where my father was the minister, about twelve miles from town. He encouraged us then to read and to do well and we were quite different from the rest of the children in the village that he was ministering to ... (Ruth).

I still remember the teachings of my father and how we were brought up with love, good education, but also with respect and reaching your goals and saying the sky is the limit. So I always think of him and how he managed to bring the twelve disciples up. (I have eight adopted brothers and four sisters, so we were called that.) With that background from home, and my father being a teacher, being an accountant before becoming a teacher, and a lay preacher, he is my foundation, he taught me my values, my beliefs, my practices, my language. (Rachel).

My dad has always been quite political, actually, because he was a watersider and he was a staunch unionist. I remember going to the wharf and collecting his pay packet on paydays and bringing it home to Mum. I would see how they were going to support the strike, but when he came home my father had different roles as our father, as a Cook Island church elder, and so on. (Hana).

The above narratives show that the women's location in Aotearoa New Zealand as members of a Pacific ethnic minority group forced them to consider their ethnic identity. In contrast, their parents or even themselves, back in their own Pacific Island countries where they were members of the dominant ethnic group, did not need to call themselves Tahitian (in my father's case), Samoan, Tongan, Niuean, Tokelauan or Cook Islanders. 


\section{Summary of results: indicators of ethnic identity construction}

The women's narratives provide illustrations of the constructionist approach to ethnic identity because both primordialist and circumstantialist perspectives are evident in the descriptions of their lived experiences.

Firstly, primordialist factors or indicators of ethnic identity construction are represented in the above excerpts from the narratives. These indicators include: the importance of geographical place of origin; the role of birth, descent and lineage; the collective memories of migration; how blood connections affect identification; and the consequences and implications of physical appearance in the definition and meanings of ethnic identity. In addition, there is a "feeling" dimension to those indicators that comes through in the women's narratives. Although this dimension can be labelled in primordialist terms, it is also relevant to the circumstances in which the women find themselves and in which they express those feelings. In this way, it can be seen how the constructionist approach incorporates both the primordialist and the circumstantialist views of ethnic identity construction.

The cultural indicator that was most salient in the women's descriptions of their social circumstances was the indicator of place or location. That included geographical location (in New Zealand or their home island country) and the social location of their family, including their extended family. Whether the family itself was situated in this country or "back home" is important to ethnic group membership. It is important in the sense that the necessity for calling oneself a member of an ethnic group in the home country is absent if the group identified with is the majority ethnic group, with political and economic power in that setting.

A further consideration is how the women experienced their daily family lives, the expected roles and relationships, and the expectations of meeting family and ethnic community obligations. Location and the social processes operating within the social institution of family illustrate the circumstantialist view of ethnic identity. Often parents themselves chose circumstances and opportunities to meet with other ethnic group members, to interact with them as ways of affirming and asserting their identity. A number of the women talked about community gatherings, weddings, funerals, sports and other celebrations that they were taken to as children where they were exposed to and took part in language and cultural 
activities. For most of the women, the common context outside the family in which their daily life was shaped by their ethnic values was the church. These contexts are explored more fully in the next chapter.

The narratives also provide examples of the existence of a degree of choice, in terms of meeting social and cultural obligations within the family. These Pacific women are aware of the consequences of their choices and actions in maintaining, consolidating or modifying their ethnic group membership, while actual membership of the ethnic group by accident of birth, genealogy and place of birth are not matters of choice in terms of ethnic identity.

Intergenerational differences between the lived experiences of their parents (who were in most cases born in their islands of origin) and the women's own circumstances in Aotearoa New Zealand are acknowledged by the women who migrated here after their initial schooling in the islands. Equally, intermarriage or having dual heritages provides individual members of Pacific cultural groups with dilemmas, choices and challenges, in both positive and negative senses, that are, in turn, influenced by the circumstances in which they find themselves.

The issue of being able to be fluent in one's own Pacific ethnic language, as the example narratives show, does not fit neatly into either of the aforementioned views of ethnic identity. In other words, the ability to communicate using one of the Pacific languages, as a defining factor of ethnic identification, is not clear. However, some members of those Pacific ethnic groups view the Samoan, Cook Island, Tongan, Tokelauan and Niuean languages, as integral to the group's heritage, and in that sense language can be viewed as a primordialist component of ethnic identity.

Passing Pacific languages on to successive generations in Aotearoa New Zealand is considered to be very important by some. To other individual ethnic group members, language is not crucial. However, when an ethnic group or group members migrate to a new country, where their heritage language is not spoken by the majority, the narratives clearly show that changed contexts and circumstances demand some deliberate action on the part of the speakers of that language, to ensure that their (now minority) language survives. The question is to what extent the majority of ethnic group members themselves think it is important to speak or to pass on the language, when the use of the English dominates every sphere of daily life, and whether a critical mass of speakers and material resources are 
available for them to do so. Further, the contexts within which the various Pacific languages are considered most important are still the family and church, but it is debatable how important Samoan, Tongan, Cook Islands Mäori and other Pacific languages are in other social institutions such as the education system and, more specifically, in tertiary education.

Finally, the women's narratives point us towards a reminder that ethnic identification to Niuean, Cook Island, or any other Pacific ethnic group must take into account intra-group diversity and how circumstances influence individual meanings and interpretations of ethnic group membership. This will be discussed in later analyses. In addition, within each ethnic group there exists a social and cultural hierarchy into which the women were born. It was evident in the narratives that the parents of many of the women were themselves highly educated, or occupied high positions such as daughters of ministers of religion, or, in the case of several of the Samoan women, held matai or high chiefly titles back in Samoa. A number of women noted that the social positioning of their parents as labourers or unskilled workers in New Zealand did not match the titles or status that applied in their countries of origin.

In Chapter 11 the focus of the analysis of the women's narratives is on the ethnic identity construction processes as they occurred within the family context and within the related context of the church. Within this analysis I explore further the key ethnic identity construction processes of assertion and ascription, and the extent to which the women's daily lives were organised within these contexts in terms of their Pacific group membership. 


\section{CHAPTER 11: RESULTS III: FAMILY AND CHURCH}

In the previous chapter, the women's narratives expressed their views and experiences about the meanings and origins of their ethnic identities and their ethnic group membership. In this chapter, the focus of the analysis is on the circumstances and identity construction processes within the family context, as experienced and reflected upon by the women. In the second part of the chapter the women's narratives are analysed in relation to the circumstances as they experienced them within the context of the church. In the analysis these two settings are considered separately. In reality, however, I found them in most cases in the women's narratives, to be closely linked.

\section{Family}

Eight out of the twenty Pacific women were born and brought up in their Pacific Island countries. Their family experiences and their family contexts are qualitatively different from those experienced by the New Zealand-born Pacific women. The first group of narratives are from Island-born women, the second group from New Zealand-born women.

Mapaia was born in Samoa. Her mother had a vision for Mapaia's future outside and beyond the traditional family roles, and beyond Samoa itself.

My mother was the one who instilled this idea of me studying and going into the ministry. She said, “You must give it a try.” You see, my mother had been to the States to study the ministry herself and had come back to Samoa, but she could not be a minister there. She had seen women in the United States being ministers of religion and so she said it was possible for me to be one ... (Mapaia).

Lee was born in American Samoa but was brought up in Niue, her father's birthplace. She values what he taught her about Niuean culture within the family.

I learned about what comes from the land, what food is eaten, about going through the bush, gathering food. All of those things that I saw him do, being what a Niue man is and should be: providing for the family and children and being loving and supporting. He was a great person and an amazing father. When we came here [to New Zealand] he always wanted us to be involved in sports and village get-togethers. He was proud of the fact that his daughter could sprint really fast, beat everybody. There was always the expectation from him for me to be successful and to have a good job, and foremost, not to work in a factory. In his interpretation, a good job was to be a typist or a receptionist and I aimed for that sort of job. I strived at high school to achieve such a position so that I would do my father proud ... (Lee). 
Destiny was born and brought up in Tonga as part of a large family that placed a very high value on education.

My father is the most significant person in my life and education was very important to him. He worked hard. I don’t know how he did it, getting $\$ 70$ a month to feed ten of us but the expectation was that when we finished our high school education that we went overseas. Being number eight in the family, all my brothers had gone overseas to study. My eldest brother is a surveyor, he came here to New Zealand, and my next sister she came here to polytechnic. One of my brothers has done medicine, too, he's now a doctor. So it was just a natural thing to do. There were lots of tears every time someone left, but no one was staying home after secondary school. What I really admire about my father is he has got really strong Christian principles. God has blessed him. He's given to the community; he's worked really hard as a full-time minister he has continued on working and supporting us even now we are grown up ... (Destiny).

Judith was born in Samoa but came to New Zealand as a young girl. As she grew up here she described a growing awareness of how family and how the collective responsibility to each other is important.

When you are at school you're always conscious that you're doing it not just for you, but also for the family. So that consciousness is typical of being Samoan. I took a law degree basically because my father wanted me to be a lawyer. Both my parents are teachers, you see, and there was an uncle of mine, he used to come back and forth, he lived in Samoa and he'd gone to Manila, to study at a veterinary school there, so I kind of became familiar with higher education because of him ... (Judith).

For Naomi, family life in Samoa revolved around the school and the church.

My mother was a teacher. My father was made an orphan when he was eight, and he had determination and ambition, and he believed he had the capability to succeed. Our family activities revolved around school or school activities. There were other community activities as well and my parents would say: "Speak you learn something, from village activities you learn something”. When I would come home my Mum would always say: "Well, what did you learn?” My father was a lay preacher so I used to go with him when he went to other parishes to preach and when I came home he would say: "What was the lesson?" Also in cultural activities and participation for example, in our youth group, we used to do a lot of speeches, the oratory always a lot of that. So we had all of that growing up ... (Naomi).

The New Zealand-born Pacific women graduates spoke about the daily lives of their parents and family, and the hard work that was required in adapting to and surviving in a new land, including the grind of their low paid or low status employment: 
We worked in market gardens, in fact, all of the family worked there. I just hated it, the early hours, the hard physical work. I was just so tired because my sister and I we were still studying and trying to get extra money because we were still paying our family house off. My sister had a year and a half longer studying than I had. She was in law and she was really struggling but my parents, especially my Mum, really encouraged her to finish and not to give up. The people I admire most are my parents and the struggles they have had. I am who I am today because of who they are ... (Eleni).

Rita remembers her parents telling her about the kinds of jobs they did after they first settled in New Zealand in the 1950s:

My father first worked on the trams, he drove taxis, then worked at an engineering factory, and then as a railways forklift driver. When my mother came to New Zealand she flew into Whenuapai Airport in West Auckland. She applied for a job as an airhostess but she could not do the training due to family commitments. So she got a job as a telephonist at the Central Post Office. Mum had other jobs as well. She worked at a female-only boarding house where she lived before she was married to Dad and she was "doing the books" and being the wages clerk at the old Edinburgh Hotel. When she married my father and got pregnant, my father did not want her to work anymore so she stayed home and looked after her five children ... (Rita).

Siulia Tui was born in New Zealand, but went back to Samoa at five years of age, and came back again when she was 12 years old.

My parents didn't have the opportunities we have now. Looking back, they were very intelligent people. For example, we had a library, which is really unusual for a Samoan family, and we read all sorts of things about the world outside Samoa. My parents were always reading in English and Samoan languages. During the war, when my mother was still a student, she was called out of school to teach. She was quite bright and she wanted us to do better than they did. I was the eldest in the family and the reason I came back to New Zealand was the whole extended family got the money together, to send me overseas to study. I wish they had never done that, because I really missed them. Now they are practically strangers to me, because all my communication was through letters. I have been away for 20 years now, so I have learned to cope on my own, with my own immediate family ... (Siulia Tui).

Sarah was aware of her father's sacrifices and hard work as a Cook Islands man in New Zealand, and the aspirations he had for his children

My father's words were: "You go to school and you get a good job". His idea of a good job was to get a government job and for that you needed to keep studying. He was a labourer and was in charge of staff under him, he was in many ways a role model even in that capacity. My mother had the same values, always said that if you're going to start something, then finish it. So I guess that mentality of never giving up was always in my mind from their example. I used to see my father working hard even at home. 
We'd moved into this brand new home in a newly established housing area, he must have been saving up for years, and he actually built practically every part of the outside of it. I can still see him working hard and that to me always influenced how I should apply myself, I should work at it, and if it wasn't right, try to correct it or do the best I can ... (Sarah).

Katalina felt her high value for education came from her parents, particularly her mother:

My main support is basically my parents. They've been my anchors, probably because they can see the value in education. I think, too, it's that migration dream for parents when they come here to New Zealand. Although they are both from Tokelau they did not meet and get married until they came here. We [all their children] have all chosen different fields, but they've given that same encouragement and support, but definitely for me it was my mother because we share the same passion for education ... (Katalina).

Eleni was in no doubt, either, of what her parents expected of her:

There was my Dad and Mum, always pushing me, especially my Dad. They had these high expectations that we were going to make it. Dad worked as a truck driver and Mum worked at factory jobs. They told my sister and me that we were going to have office jobs, we weren't going to struggle like they had. They had a dream for us to succeedthe doctor, the lawyer, that was the sort of thing, and so in everything they did, education was first and foremost and so we did no sport, had no friends ... (Eleni)

Like the Island-born women, the New Zealand-born women were brought up with high expectations from their parents of gaining a better education, gaining high qualifications and getting "better” jobs in the new country. However, even in the course of growing up in Aotearoa New Zealand the women were not always aware of the wider world outside their families or churches because within those relatively sheltered settings all of their daily lives were organised and focused on their parents' languages, values, priorities, and choices as to how they should live. Wawine Wale, for example, grew up in South Auckland and that was her total world for most of her young life.

I actually didn't know for quite some time when I was young that other people who were non-Pacific Island people existed. I mean, I think I did know that, but I never consciously did, because of where I lived, and the people I spent time with at my Pacific church. I really assumed and thought that most of the rest of the world was just another island group in one form or another ... (Wawine Wale).

Sara's mother is New Zealand Mäori and her father is Rarotongan. She grew up in a newly developed suburb in Auckland. 
Very few Pacific Island families were there anyway. I think we were about one of maybe half a dozen in the area that we lived in. That played a big part in working out who I was. I mean, people didn't kind of single you out or identify you specifically and say: "Where are you from?” kind of thing. In many ways it was assumed that I was Mäori and that was that. Nor did I ever say: "Well, actually I am Rarotongan”. Unless people specifically asked me, you know, “How do you identify yourself?” I was never really confronted with ethnic identity at all, right through school, and so it wasn't until I came to university that it became a bit of, well, it was kind of an issue ... (Sara).

Rita's parents had come to New Zealand from Samoa for a better life and they had dreams for her to succeed.

My mother was always telling me I was going to be the Prime Minister of Samoa, my father was just grateful I didn't go on the dole. I mean he was just as much a visionary as my mother was, I think, but he was also realistic about living in this country, and knowing how hard it was to be actually accepted and to get a job and do anything. So his desire for me was if I could work 40 hours a week, as long as it wasn't doing something morally unacceptable, then that would be worthwhile, whereas my mother was the one who had dreams ... (Rita).

Although most of the women reported living and growing up protected within the family (both here and in the islands) their lives took them beyond the family and they began to experience broader aspects of life, initially in the church and then in the wider society. The processes of socialisation as members of each of the Pacific groups continued. When they reflected on their lives beyond the family, a growing consciousness of differences between "us" (as Samoan or Cook Islands or Niuean), and "them" (outsiders, or people in the rest of the New Zealand society) began to emerge. The church also played its part in developing and strengthening ethnic boundaries and meanings of ethnic group membership for this group of Pacific women.

\section{Church}

Most of the women interviewed agreed the two settings (family and church) in their experience were very close: that church, Christianity, and Christian values constructed within the social institution of the church and practised within the family setting were mutually reinforcing. Family values were similar to biblical definitions and meanings, for example. One of the Pacific women I interviewed said that the church was not important in her life, and one of the younger interviewees made no mention of church, Christianity, or spiritual values in her life. 
In terms of geographical location and social positioning, the narratives reveal no differences between the church settings in New Zealand (as experienced by the women) and the church settings back in the islands. That is, the social construction processes within them such as expressions of Christian faith, expectations of regular church participation, the roles and responsibilities of ministers, lay preachers and parishioners, and the organisation of Sunday schools, church education and pedagogies, appear to have remained the same across both contexts. For this reason the narratives of Island-born and New Zealand-born are not necessarily separated out as in the previous section.

From the age of four I remember my father was a deacon at church and both of my parents were Bible Class leaders and teachers so were we very involved there. The people I grew up with from Sunday school and Youth Group are still friends today, even though I don't go to that church anymore ... (Rita).

The narratives reveal that for most of the women their church and Christian values remain very much a part of their ethnic identity, that is, being Tongan, Samoan and so on.

I think our Tongan values, our Christian values, I mean, our culture has so much meaning, you can't separate out our Christian values from our Tongan culture and that's all there is to it ... (Destiny).

The Christian Church has long been acknowledged as an institution for the promotion and maintenance of the indigenous Pacific languages, not only from the time Pacific peoples migrated to New Zealand, but also from the first contact with European missionaries in the Pacific in the late $18^{\text {th }}$ century.

I used to go to Samoan Catholic Church once a month, because it was the only place where I could go and speak my language and be with my people so to speak, and that was really important to me but, you know, the sermons were pitched I thought to a level as much as to say you were stupid and very subservient. I did not like that aspect, so unfortunately (in terms of my Samoan) I go to a Päkehä church now. I had a very hard time finding work a couple of years ago after coming back from London, but that time of my life was quite good in that it pulled me back to church as a mature person. And I see myself as really wanting to put God at the centre of my life, but it is so hard because I am such a high achiever ... (Abigail).

A number of the women talked about the centrality of their Christian faith and beliefs in whatever they did, not only in the family and church, but across into their working lives and other social institutions and contexts where they also live their daily lives. 
Rita has become an early childhood teacher.

All I knew was that I love children and I'm caring, and those were the sorts of things that were strengths in me, and this is where God has led me. Now I have a degree. I never thought it was possible, but the truth is that everybody is gifted with talents and I believe if you put them before the Lord, He will lead you into the way that you will know that it is God's will for your life. You will have self-respect, your life will get better. Like having an education is so good, it's a blessing. It really means something to me being a Christian, because if I wasn't I could easily have no integrity, and with my intelligence I could manipulate people, I could be so arrogant ... (Rita).

Destiny also finds her faith sustains her in her daily life in this country and in her employment.

The most important thing to me, you know, is my Christian values and to me, my identity. If there is anything that has helped me to survive, it's my Christianity. That is all about knowing that I am special in God's sight. It's what's made me strong here in New Zealand. I am a Tongan woman and Tongan women are like that: strong, because we know what the Bible says, that I am in God's family, that I am special and that God has a plan to bless me so that I can give that blessing to others. That's what keeps me going when I am up against this stuff at work and all the bureaucracy. I get angry and want to fight and then I think, no, no, no, I need to calm down, do it in God's strength and in God's time, and don't kill anyone in the process ... [laughter] ... (Destiny).

For Eleni, family and Christian values and beliefs are very close together, providing clear instructions to her, as a Samoan daughter, on behaviour and on patterns for living within the family.

I am still living at home because I have this enormous love for my family. This is taught as part of the church culture as well, these Christian values of honouring your mum and dad. I just love them so much. Of course we have had our major clashes at times, when I was ready to go and leave home! When I think back I thought I knew everything and I soon realised my parents, yes I do really value and respect them, they are amazing people. Even now, thinking about getting married, I don’t really want to leave them ... (Eleni).

Eleni, like some of the other, younger, New Zealand-born women in this study, is also aware of the hypocrisy within the institution of the church and the differences between what is said and what is actually happening.

Discernment is something I have learnt too, from church and in true Christian values my understanding is that love and true love does not seek to harm, it's not boastful, it's not that sort of stuff. That's what I espouse as being true love, but a lot of things that are said in the name of God, in the name of the church, in the name of Christianity it's like, wow, some things done and said are not really Christian ... (Eleni). 
Ngariki is also a young New Zealand-born woman who will not follow her faith uncritically, even though for her church is also a distinguishing aspect of her ethnic group membership.

I've become a church girl just for Nana. My grandmother was one of the founding members at PIC Newtown and, you know, very strong into the church. However, several kinds of incidents happened in our family that made me distrust the church. To me my church is cultural, that's part of my Cook Islands identity. All of my Cook Island women friends we've often talked about the issue of spirituality/Christianity/whatever. I can't call myself a Christian because I believe that that pigeonholes me, I'm much more than that. I feel that label puts me in a box, and my Cook Island friends completely understand. Yet if I say that to a Samoan they just won’t understand that, they say, "Well you're not Pacific then if you're not Christian". I do believe in God, I believe in Jesus and I believe all those things, but we all have our own relationship with Him. I've seen too much hypocrisy, going to church once a week, so to me that's not good enough, Christianity, it’s really the way that you live your life daily ... (Ngariki).

Alternately, there is a strong element of social and cultural reproduction between generations where daughters have carried on in the Christian faith and followed on the pattern of the church participation set by their parents.

I'm a Presbyterian. I am an elder in our church. I am an extension of my parents and everything they stood for. In the family and when I went on to the minister's school in Samoa I learned how to respect each and every person. I know exactly what to do when I go to the university I know how to behave accordingly. When I go into society I know where it is fitting for me to go, I know where my feet will lead me and where my mind will also direct me. I learned about respect, respect for yourself and others. Being a Samoan woman, you must carry yourself with dignity. You know that you are a woman rather than trying to be a man, because there are two kinds of people that God created, men and women, and they are different ... (Rachel).

Christian faith is also about trusting that your future is in God's hands.

Some people in my life have criticised me for not pushing myself forward, but to be honest I just think, if God opens a door, He'll open a door, and that's how I see it .... (Lucy).

For Judith also, her family and the institution of the church are very close together in terms of family roles being replicated in the roles and responsibilities within their church.

My parents have always been the leaders of the church as well as the leaders of their own family. My father is head of his family and my mother is the eldest in her family and so she always made decisions. At church they always lead different parts and so we 
[children] always used to get roped into having to do things. So we learned the art of organising, the art of communicating with others. Now that we're all married, we're in churches, we all still take the leadership roles there. Although they are leaders my parents have also been very low key about their abilities and I don't know if that's necessarily Samoan specifically but we've always been taught that you don't selfpromote ... (Judith).

And on reflection, Wawine Wale talked about how attending church from a very young age has continued to influence her as an adult:

Even though I don't have that much involvement in the church now in my adult life, it had such a huge impact on me as I grew up and even who I am now. My education began in the church because of all the organised activities, like Sunday school, from the time you could even walk. It was a very broad education, like musically, academically too, and all the scripture plans we had to do from year dot, and even before you could start writing we had to get involved with scripture exams. It was social education too, because it was a mixed Pacific Islands church, so all the time you were coming into contact with other different groups. I picked up a lot of skills from church that I know now are from that background. For example, the discipline of rehearsing long hours in the church choir means in my present singing that I can easily cope with the discipline and pressure of long rehearsals ... (Wawine Wale).

Siulia Tui still has strong beliefs but reports she has been on a spiritual journey in terms of practising her Christian faith since coming to New Zealand.

When I was in Samoa, of course, Christianity was very much intertwined with the culture and so I guess a lot of that is ingrained in me as well where we were taught there was only one truth. In this environment [New Zealand] there are many truths and many gods. I have to keep my mind open to that as well, but yes, Christianity is a big part of my identity. When I first started to study in New Zealand I studied theology and I was opened to other ideas like eastern religions. The church I went to was a Christian church, non-denominational, but we decided just two years ago to pursue another avenue and we are actually doing something at home within our own family in terms of worship ... (Siulia Tui).

Hana talked about her father's pride when as a student teacher she went on a Teaching Experience placement at her local school and her father thought that she was already a real teacher, so when they next went to church:

My father gave heaps of donations to the church that Sunday. I said to him "I'm not a teacher yet, I will have to go and do some more work in the classroom”. But my Dad did not understand, so off we went to church, Dad and me, we sat right down in the front row and he put heaps of money in the envelope and thanked God for this wonderful liberation, you know, in front of everybody he announced "My daughter is a 
teacher” and I said to Dad: “I'm not a teacher yet”. I felt really embarrassed, I am thinking please don’t let any of my Päkehä friends be around because they would say, “Oh, you're lying” ... (Hana).

Hana had also become aware of the differences between the family and the church in her life and the social circumstances of her own marriage to an Englishman, and her children with dual heritages, growing up in Aotearoa New Zealand.

I actually started to question my affiliation into the church, and what I was doing for the church. I find my situation problematic between family and church and there are some tensions. These are two contrasting hierarchical structures that I operate in, and I operate differently within those two different structures. For instance, at the church there is a marked hierarchy of minister, the deacons and the place of women is lower down. So when I enter into that I live in their structure and observe that. Then in my family at home there is no such hierarchical structure because I am equal in my house, in fact I am the breadwinner. My family, that is, my husband and my New Zealand-born children, won't go to my church because of the hierarchical structure and the way things are done in it. The Cook Island Christian Church in Aotearoa is actually very rigid, very hard to belong to, in that sense. So, I find myself always in the middle- the mediator trying to draw my family into my work and into my church ... (Hana).

Hana's narrative exemplifies the dimensions of geographic location and the challenge to traditional beliefs she experienced, and how ethnic identification and group membership becomes a source of tension-producing dilemmas for her. Hana also married outside her ethnic group, and her children are growing up in New Zealand, not prepared to be involved in a church context that has little relevance to their present daily lives and situations.

Lucy also reflected on the widespread rejection of Christianity and the negative attitudes towards the expression of Christian faith by the dominant ethnic group in New Zealand society.

The more exposed I have been to Christian things, the more over the years I have found that Christianity is just such an unacceptable viewpoint in the wider community. Even here at work when I first came I met staff members who ridiculed Christians, I mean overtly and cruelly. I have got a sense of humour and I can take "the micky" out of Christian things as much as anyone else, but there was actually a prejudice and I would say it was pretty yuck. Sure religion has been used as a tool to indoctrinate people, but to me, when you do have, as you say that lived experience, there are so many more dimensions to faith/belief that aren't made explicit and others don't understand ... (Lucy). 
Lucy articulates one very clear boundary that divides the "us" of Pacific peoples in Aotearoa New Zealand and others outside Pacific groups, that of Christian faith and relatively high levels of church participation.

The above narratives are typical of this group of Pacific women's perspectives of the relationship between what they experienced within their church and/or Christian beliefs and values, and what they experienced as shaping who they are within their family. The evidence provides some examples of the co-construction of ethnic identity across and between the two contexts, and the social positioning and the meanings about being a daughter, wife, mother and Samoan, Cook Island, Tongan, and Niuean that the women have come to identify with as members of their own Pacific ethnic group in Aotearoa New Zealand.

The connections between the two contexts however, are not experienced in the same ways by all of the women in their narratives. The historical connections between family and church have existed for a number of generations in the home islands and with migration the social and cultural construction processes within the church have only recently become subject to challenge by New Zealand-born Pacific women. Involvement in the church, however, has assisted them in maintaining their languages, providing training in music, singing and speaking in front of large audiences and rote-learning skills. Literacy in the form of reading and memorising passages of the Bible, taking leadership roles, and learning to serve others within the church, were also mentioned by the women.

\section{Summary of results}

The high expectations of parents and families of those Pacific students born in the Islands and those born in Aotearoa New Zealand both appeared to depend on the social positioning of their families, the qualifications and occupations of their parents, and the cultural values and practices constructed within the family and church, including Christian values and beliefs.

The Island-born and New Zealand-born women shared similar stories of a relatively protected and family-focused upbringing, characterised by encouragement to strive for goals, to apply one's best effort to anything attempted, to complete what was started, and most of all, the pride that would be brought to their families when they did succeed academically. As females they were kept well protected by family members and occupied by family, church and cultural festivities and responsibilities. Other defining features such as high 
expectations of collective responsibility, and family loyalty were described, as well as the high value placed on humility and not promoting oneself above others.

However, the narratives showed some qualitative differences when geographical location or social context was taken into account. The social processes within the family setting, when located in the Islands, were constructed and supported by wider social and cultural networks in which daily lives across all social institutions were shaped by their own Pacific languages and cultural meanings. The families of the New Zealand-born, however, were located differently in two main ways: geographically, in relation to other ethnic group family structures and values, and, in terms of their social positioning in the new country. In this context, ethnic group membership and the boundaries between "us" and "them" became stronger and clearer in the lives of the individual women.

Status and qualification differences were evidenced in my own family when during the course of my primary schooling I became aware of the differences in eating habits of my family and the families of my popa'a/Päkehä school friends. In terms of social positioning, my father was well educated and achieved a high status and regard in his own country and family as a distinguished war hero and musician, the eldest son. However, here in New Zealand the only job he could get was as a factory worker and later a cargo worker.

A number of the women also described the changes in status and lifestyle of their parents who migrated to Aotearoa New Zealand, how their lives were affected in terms of employment, where they lived, and the hopes and dreams of their families to not end up like themselves, in low-paid and low status jobs. Like all migrant groups within a newly-adopted country where their languages and cultural values are marginalised, undervalued, stereotyped, or even ignored, the women's families had to re-shape their own daily lives. For example, the women said that the church was a place where they could still use their languages and opportunities existed for them there to do so. In families such as my own, our parents decided to maintain the ethnic identities they had brought with them, and to somehow preserve what it meant to be Tahitian and so on. In my father's case, he formed a band and dance troupe to keep alive those aspects of his culture, he sought out opportunities to speak Tahitian, and subsequently became an interpreter for growing numbers of family and friends from Tahiti who visited New Zealand for medical treatment and for holidays. 
From the first migrations, the Congregational Church of New Zealand in Newton Auckland (now called PIPC) was an institution that assisted Pacific families to successfully make the transition and settle into New Zealand society. That original church and its numerous off-shoots provided a social, cultural and spiritual centre where Pacific languages and the Christian faith, by now so intertwined with the definitions of being a Pacific Islander in New Zealand, could continue to be practised and shape the daily lives of Pacific families. Many of the women in this study, and indeed my own family, have links back to that original church in Edinburgh Street.

The narratives also demonstrate that at an individual level the family and church had their own distinct meanings in terms of ethnic identity construction for the women in their growing-up years. The church often reinforced or even constructed the processes within the family setting, particularly in terms of roles and hierarchies between husbands and wives, parents and children, and their relationships and responsibilities to each other. These were so firmly coconstructed in most of the women's lives that they reported that these two contexts cannot be separated when they talked about membership in their Pacific ethnic group.

However, there is also evident a growing consciousness that church hierarchies and family hierarchies that do not respect free choice or do not take into account changes in other social institutions are slowing losing their power. They are being questioned and scrutinised by New Zealand-born, educated Pacific women. Indeed, although Pacific women have been ordained as ministers within the Presbyterian Church in Aotearoa New Zealand, their home islands of origin will not tolerate them as parish leaders. In addition, if highly qualified women in New Zealand marry ministers who go back to Samoa to work, they are not permitted to work in the occupation they are trained for, even if there is a shortage. They are expected to help their husband in his ministry work. Within these changing historical circumstances, however, almost all of the women in this study spoke about the important role of the church as a social institution, in the construction of their ethnic identities, the building up of their social capital, such that they feel a connectedness to others who also identify themselves as Samoan, Cook Islands, Tongan, Niuean and Tokelauan and who participate in church life. 
Within both the family and church contexts the meanings and boundaries of belonging were clear to these women. Both contexts were viewed as important, and ones within which the majority of their daily lives was lived out and constructed, according to their cultural group values and practices. Then, as they began to venture out from the enclaves of family and church into other social institutions, ethnic group boundaries and meanings came into sharper focus. The women, in effect, gave individual accounts and perspectives on the social processes that constructed and maintained the social capital ${ }^{37}$ of their Pacific ethnic groups in Aotearoa New Zealand. These processes also brought into sharper relief those who could claim membership of the ethnic group, and those who could not. Even more importantly, while the women could easily assert their "Samoan-ness" for example, in the contexts of family and church, this could not so easily be done when they entered into the wider social institutions. The dominant ethnic groups, according to these Pacific women, were already ascribing certain negative characteristics to Pacific Islanders, by virtue of their recent arrival, their social positioning, their lack of English language, their collective lifestyles and family structures, their Christian values, their perceived work ethic, and so on.

In this chapter, the women's narratives of their experiences in the social institutions of the family and the church settings were analysed. All of the ways in which these Pacific women described or asserted themselves as members of their Pacific ethnic groups brought into focus the boundaries between themselves and members of other ethnic groups. Their ethnic identities and ethnic group identification constructed within the family and church contexts are what this group of Pacific women took with them into another important social institution, tertiary education.

In the following chapter, selected narratives illustrate the experiences and the participation of the Pacific women in tertiary education institutions. These narratives provide evidence of the responses by others within the institutions to their ethnicity and ethnic group membership, and, in addition, the women's responses to the treatment they received.

37 See Chapter 7 for a description of social capital in relation to the social construction of ethnic identity. 


\section{CHAPTER 12: RESULTS IV: TERTIARY EDUCATION}

\section{Introduction}

The education system is a social institution that virtually all members of society enter and where they interact socially. The tertiary level of that system in New Zealand is an example of a social institution in which all groups in society (with some limitations in its membership) are represented. As noted earlier Pacific peoples in Aotearoa New Zealand place a high value on attending tertiary institutions and on gaining tertiary educational qualifications. Entering the tertiary education system, and being successful there, is one of the crucial ways in which Pacific populations can improve their social and economic position both as individuals and as members of their ethnic group.

As evidenced from the analysis of narratives in previous chapters, educational and academic success, however, has never been seen by Pacific ethnic groups solely as an individual achievement, but rather as bringing status upon the family, their village back in the islands, and the wider Pacific ethnic community to which they belong. Pacific tertiary graduates who have succeeded in the popa'a/palagi/Päkehä world are expected to assist in furthering the economic, social and cultural development of their own ethnic group and its claims for access to services and resources.

In the previous two chapters the family and the church, as viewed by the women themselves, are both separate, but in many cases, closely linked. Together family and church determined and shaped most if not all of their daily life experiences as they grew up. It needs to be kept in mind that both institutions also mediate directly with the wider society and its dominant values and discourses. As the women moved into tertiary education they took with them the cultural identities that were formed primarily within their families and churches.

In the following section I have grouped the analysis of the narratives into four main topics. The first topic includes illustrations of the women's experiences when moving from the relative protection of family and church (or enclaves) into the education system, and specifically, tertiary education. The second is the experiences of the women entering a tertiary institution where their ethnic identity became even more a point of differentiation from “others”. Thirdly, the narratives show how the women perceived the treatment they received, in relation to their 
ethnicity, from their teachers, lecturers, fellow students, and in the course of teaching, learning and assessment. In the fourth and final topic, the narratives show how the women asserted their ethnic identities both in response to the treatment they received, and in terms of actions they initiated themselves.

\section{Moving into tertiary education}

The women in this group had varying experiences and reasons for going on to tertiary training and their pathways were not always smooth. In the case of Rita:

I wanted to prove myself. At secondary school you had to have 200 marks in School Certificate to go into the Sixth Form. I got 200 but the principal of the school said I was not going into the Sixth Form because I had the "wrong" attitude and I did not work hard enough. My principal even suggested I leave school. I respected her judgement at the time but I just wanted a chance to prove myself. The principal had power over me and I accepted it without question. My parents expected me to stay on at school so I went back to school for a second year in the fifth form and I passed four subjects. Then I spent two years in the sixth form. The first year in sixth form I did Correspondence School UE English and passed with As so I thought I knew enough English to enrol at university. I got support from my palagi friend who was at Law School at the time and she kept on encouraging me: "You are intelligent, you can go to university". After she graduated I did go. (Rita).

Katalina felt the pressures from her Tokelauan community when she started tertiary study.

Not many Tokelauans go to tertiary institutions, so when the Tokelau networks heard that I was at Teacher's College, everyone kept saying: "You're going to be doing a lot of work for the community", but at the same time I was thinking, "No,hang on, I'm trying to find my place, to find out where I am in New Zealand society as well”. ... (Katalina).

Abigail also had high expectations placed upon her.

I have got three sisters and one brother, and I am the only person in my family that has gone to university. I see myself as having tremendous responsibilities and obligations to use my knowledge for the whole family. I think my education has placed me in a leadership position and my family would definitely agree with that. Both my family here in New Zealand and my family in Samoa ... (Abigail).

Wawine Wale enrolled for a tertiary institution in another New Zealand town.

I was always an achiever at school; I didn’t actually have to work very hard there to succeed. I think my parents stopped putting pressure on their children by about the fourth or fifth child about going to university. So I can't say that I got any explicit 
pressure put on me by them to go. They just decided, if she wants to go, go. I found my parents really supportive of me leaving home. The only question mark I can remember was my choice of study, which was a social work degree, and their concern, particularly my mother's, was whether at 18 years old I had the emotional maturity and the strength to be able to do that kind of work, which of course just sounded like a challenge to me. In addition, the university was a very long way away from home ... (Wawine Wale).

For several of the Island-born women, the move to tertiary education required not only a move away from their family but also a move overseas from their countries of origin. The move from the family to the tertiary education site must be viewed, although not exclusively, in social and geographical terms. Ruth won a scholarship from Samoa to come to New Zealand to study.

It was a cultural shock for me when I came here from Samoa. We were taken down to Wellington at the beginning of the year and we were put through an orientation to the New Zealand way of life. I found it really strange because, well, we all came here not really that conversant in English. We wrote good English, but speaking amongst each other, we were too scared to speak English in case we made mistakes, because that's how we were brought up in school back home. That orientation lasted for two weeks and then we were shuffled off all around New Zealand to where we were allocated to go ... (Ruth).

A number of the women talked about their migration and relocation to a new country. Naomi went to the University of Papua-New Guinea before coming on to New Zealand to study.

In Samoa and the Islands there is not much choice, you pass your School Certificate and your Sixth Form and then you go away. The only avenue is to get an overseas education. In secondary school I was streamed to science subjects according to my performance in the exams, so that was one good thing. When we arrived at the university most of us were children of teachers or some professions. We all had the same values and the same upbringing, very strict and authoritative parents and very overly protected, I think. Of course that was for good reasons, but when we arrived in this totally new place it was the novelty and then the homesickness, and then the freedom, and at first I think education probably was the footnote ... (Naomi).

Mapaia experienced some setbacks to her plans for ministry training.

When I was rejected I got this very burning feeling, I was determined I was going to do it. Then I got the opportunity. A cousin of mine was visiting Samoa from New Zealand. He was a Presbyterian and he contacted his minister, who contacted Knox College and they contacted me. This was the cousin I stayed with when I went to Otago. I was fortunate that Knox College said they would pay for me to come, but I had to go to high school and do Sixth Form in New Zealand before I started my degree. My marks for my 
University Entrance in Samoa were about 39, 30, 39, which were not good enough, so I had to come and get my UE accredited here. All my mates in Samoa went to the Seventh Form and I went to Sixth Form here and then we met up again at Otago ... (Mapaia).

In addition to seeing her older brothers and sisters leaving Tonga to study in New Zealand, and the family expectation she would go too, Destiny had her own dream.

I remember when I was probably seven years old at school in Tonga. We were reading those little books: My Home in Bangkok, My Home in Thailand, My Home in London and one of these little books was My Home in Dunedin. I was just fascinated and on the front of this was this big, you know, University of Otago clock tower. I thought even then that I would love to be in this place ... (Destiny).

\section{Initial experiences on entering the tertiary institution}

The participants were asked: "What were your most vivid memories of your first week/s of study at the tertiary institution?” The narratives were analysed to show the significant contrasts noted by the women between their social lives and daily experiences within the family and church contexts, and their life as they moved into tertiary education as a beginning student. They responded to the physical aspects of the institutions (large buildings, vast campuses, somewhat sterile hostels and lecture theatres) as well as to the people they met on their arrival in the institution.

There was a wide range of responses, from joy and excitement, to feeling scared, overwhelmed, and unsettled. One woman reported how significant the change to university was for her.

It was a big shock to me, going into university. I was a very quiet student and I never liked to answer questions and I always felt intimidated when we were asked to do group work. I didn't feel I had the informed opinions or background enough to know what to say. So I would just sit there and listen and sit there and absorb it and I hated group work, I really hated it. Through all my undergraduate years I always felt that I wasn't as good as everyone else. In fact, I felt that until I got into masters and then it changed, thank goodness. (Eleni).

Leaving family in Tonga, to come to New Zealand to study at Otago Destiny also felt shock and a sense of loss.

I walked into this strange place, the student hostel and it was on a Sunday. I think it was about 4 o'clock. The scholarship man had taken us there; there were about six of us Islanders. The warden took us to our room. I just walked into this narrow concrete thing 
and I just stood there stunned, you know, at last reality hit me, I'm here. "It's just you and the wall” I said to myself! So I closed the door of my room and bawled my eyes out. My reality was I was on my own now, I had to grow up and it was scary ... (Destiny).

Wawine Wale moved to another city within New Zealand to study and found she had to draw on depths she did not know she had.

I think the obvious one I can remember is being the only brown face in the classroom and on the street in that city. You just constantly feel lost; feel completely lost in that environment. I thought even then I was fairly good at asking questions and finding out who I could go to and so forth for information. I was fairly good at following instructions, or reading things, but I realised in a totally new situation you have to draw on another level of competence, one that I never had to, you know, at school, to push yourself and make yourself walk ahead and do things ... (Wawine Wale).

Two other women echoed the feeling of being different, of being on one's own and a response to the physical aspects of the setting.

When I went into the auditorium for lectures I suddenly realised I'm on my own now. The lecturers don't even care whether you listen or not and with four hundred people in a lecture room, I started to look around and see who was looking at me so that I could make friends, share notes and do things like that ... (Mapaia).

In the case of another student, first reactions were:

Absolutely bloody nervous! I had to fight strong feelings of thinking that I shouldn't be here. I had to work on that a lot and even when I was doing my law degree, I started off doing a BA and I had done that for about two years part-time even though I was into my degree I still felt like an impostor, for lots of reasons, I mean, there weren't many of us, Pacific students, so you stood out and there was nothing there about me, there was none of our beautiful Pacific art around the buildings then ... (Abigail).

\section{For Mary it was different.}

It took a long time to start, I think for me to settle. I sort of wandered around for the first week and thought: “Is this it? Is that all we have to do?” We had just been given timetables and sent on our way, which is such a big difference from school. We were at school from 9 till 3 and you are in classes the whole time, told what to do, but at university we were on our own. Fortunately I had a lot of friends from school there so I had a lot of people that I knew and familiar faces that I knew so I wasn't too uncomfortable .... (Mary).

Lucy had been adopted and taken to live in a small provincial town, so that when she went away to a major city to attend both Teachers College and university not 
only did she find differences between family, home and university town, but also across the two types of tertiary institutions.

I actually found the college as an institution overwhelming. I found the university even worse to cope with. When I went to university it was really quite a freaky experience, I just felt very isolated until I met another Samoan student. I had a major culture shock when I went to university, more so than Teachers' College though, because at College the institution encouraged the social environment and social relationships to develop ... (Lucy).

Students like Lucy who had attended different types of tertiary institutions often noted comparisons between them.

With Teachers College it was very welcoming because we had a powhiri, and then the Cook Islands welcome, the drums were so dramatic. We were put into our area groups, assigned to each room, helped to settle in. I thought the orientation week was really well planned and met our needs. But then varsity was a different story altogether. In my case I went to varsity after five years' work experience so I'm glad I did, because if I'd gone straight from school to varsity I wouldn't have lasted to be honest. Its not that they don't care, it's just the way the institution is. Everyone has to do his or her own work. You just went to the first lecture, they give out the course requirements, and then it's not until you go to your tutoring that it becomes a bit more one on one and you feel someone does care for you, type of thing. My major at university was education and they had Pacific Island tutorials, so I opted for that ... (Katalina).

I think the polytechnic environment was actually a lot more like when you were at school while the university environment was much bigger, it was a much more isolated environment to be in. Actually it took a wee while to begin to build up my confidence, to come more out of myself and be more myself in the university environment, it took more than it did in the polytechnic environment to settle. Even though the university had the smaller tutorial groups, I found them very hard to participate in. I was surrounded by so many people who were just so vocal. Quite funny, as I had come from a situation at school where I was the most vocal person in my classes and here I was in a very competitive environment and I had to perform, I had to go up a notch if you like. That was at university, particularly. It's not that I don't think that the polytechnic situation was less competitive, we weren't really competing against each other, and we had a different way of working, supporting each other to complete the course. Even the physical surroundings of polytechnic are much more pleasant than the university campus, which was so spread out, it felt like you were nothing, just this tiny speck in this huge sprawling mass of buildings ... (Wawine Wale).

Several women made reference to "the age thing" arising from being a mature student, as well as being Pacific, when they first went into tertiary education. 
I can just remember the excitement! I was like twenty-four and I kind of felt as if I should know what I'm doing, perhaps should have felt a bit more confident. But I think I was more excited, I wasn't daunted by the fact that I was the only Pacific student there, I mean the courses I did they didn't faze me, that kind of thing. I just really felt excited and interested in the learning aspects that I wanted to get involved in. At the time I had a little baby and what I learned on the course I did take, I could relate directly to bringing up my baby, the study of psychology and developmental psychology ... (Sarah).

I remember feeling very old. I was twenty-four [ a mature student] at the time and most of the other students in my classes had come straight out of school. I took a politics paper and I know I used to get really angry because I expected university to be a lot more intelligent, I suppose, to be a real place where people debated and argued about issues and politics. I'd go to the tutorials expecting debate but only to find that the students straight from school didn't really care about discussion they just wanted to do what they needed to do and leave, whereas I wanted to actually debate the issues and try to understand them ... (Ngariki).

Hana went to Teachers' College when she was much younger, and describes the feeling of freedom. As a young woman she had been betrothed by her family to a Rarotongan man and all she had known of the world was within her family.

When I went to Training College it was like a freedom I had never had before. It was a strange feeling to be given a whole lot of choices. I mean, I had been through hell at secondary school, failed miserably in School Certificate, but now here I was. It was just wonderful to have this freedom, you know, that I was moving into the world by myself. In my late teens I was and that was pretty big when I had been under the umbrella and watchful eyes either of my parents or grandmother, uncles, you know, everyone was around, they just monitored everything that I did up until I got away to College ... (Hana).

For Judith, too, university was liberating.

The strongest impetus for me going to university started back at intermediate school. I always wanted to go to university and it wasn't so much because I wanted to please my parents necessarily, although that was part of it, the main push was because I knew it would give me independence and I wouldn't have to rely on anyone, including my parents, because to me they were my biggest hindrance to my self development, I thought. I really enjoyed my women's studies papers and sociology because it was answering some questions for me at my time of life, and all my experiences ... (Judith).

Giving advice to other Pacific women students, Judith emphasised the particular demands of being a tertiary student. 
If they are having issues about what your parents say you can and cannot do, I suggest they do subjects they actually enjoy. They need to go in with an open mind and sort out their family stuff, because so much higher education and tertiary education is about having the "head-space" available for critical thinking, to develop your own understanding of the material you are presented with, because it is not a given ... (Judith).

For a number of students, their initial experiences were positive as the move into tertiary education, and the transition was relatively easy.

Everyone was saying you are just going to feel so weird and overwhelmed and I didn't at all. Maybe if I had come from a small town to university but I'm so used to this city anyway, so in that way it wasn't strange. If I'd known a lot more people that were doing things at varsity and sort of built up a support group, but actually in my first year I was totally happy just being there and tinkering along on my own and my first year was great, I was really into it .... (Allegra).

Back in the 1980s it was all quite friendly at the Theology College so I felt included and they understood why I didn't sort of graduate and they were very accommodating. Coming back to Teachers' College in 1996 was quite a strange feeling. Actually, the tutors were bending over backwards to accommodate me and I really got excited about the way that diversity and uniqueness were acknowledged. Yes, I felt like Teachers' College was much more inclusive and friendlier than the Theology College ... (Siulia Tui).

But for Rita, who had two opportunities at study (1986-89) and (1996-99) at two different institutions there were mixed feelings.

At university my first feelings were: I loved the smell of the intelligentsia and I wanted to be a part of it. I wanted to be respected, to be looked up to. But then I went into total confusion. I took economics and I was totally confused, and then I took some weird papers to get me into law and I was out of my depth, especially in metaphysics! I had information overload, I was confused because of the language used, but I was also full of joy! I was going to have fun!!! It was different when I got my second chance at tertiary study at the College of Education, it was at last having the realisation of being in the right place! I think relevance had been totally absent the first time at university but the second time, all of a sudden it was relevant to my life ... (Rita).

As the women moved into the tertiary setting it was clear they had taken with them the interests, cultures, languages, and priorities that made up their identity as it had been constructed within the family and the church. They were leaving situations where these had shaped and determined much of their daily lives. In other words, contexts where their identities were strongly defined and where they 
were encouraged to assert their Samoan, Tongan, Cook Islands, Niuean, Tokelauan and other mixed Pacific heritages.

In the tertiary institutions the women found that so much of the daily life of a student was shaped by different social processes, based upon different value systems and priorities, and different hierarchies of power and expectations from what they knew in their families and churches. For many of the women there was also a change for them from being dependent to being independent, with more perceived choices. Having entered their tertiary education setting, with all its attendant feelings and experiences, the women then shared how they were treated as Pacific women in a predominantly popa'a/palagi/Päkehä institution.

\section{Responses to the ethnicity of the women in the tertiary institutions}

As a Pacific woman I expect to be either ignored or watched very carefully ... (Rita).

Let's face it; at this level you are visible ... (Abigail).

This grouping of narratives illustrates the kinds of treatment the women reported in relation to their ethnicity.

Sarah spoke about the fact that her ethnicity did not become an issue, for her, until she went to university.

My identity literally blew up in front of my face because whenever cultural issues were mentioned I could feel all the eyes coming on me in the class, expecting me to put my hand up and say I knew all about these issues. It was really awkward, it reminded me of being at school when the teachers were up front there pointing to you and saying: "Right, you, stand up, give us your opinion”. In my psychology classes it was like that all the time. I was so shy and all of a sudden I had the limelight focused on me, being expected to know all the answers and sharing all my "cultural experiences". I used to think, well why ask me, each of us here in the room we all have different cultural experiences and we should all be able to talk about them. My first name was always difficult to pronounce, they'd flounder around then get me to stand up and say: "Could you please pronounce your name?”. I always felt that I was put into really embarrassing situations. When it came to a group discussion, the one or two of us who were different wouldn't make any contribution, consequently we were seen as very quiet and so we were kind of ignored. At that time there wasn't a Mäori [or Pacific] person on board in the department that you could actually go to if we had any questions, it was always a Päkehä person ... (Sarah).

Siulia Tui saw the treatment she received as a lack of understanding. 
As far as the institution goes, I've felt that sometimes people aren't sensitive to our Samoan ways. They think that because people aren't asking the lecturers' questions they have low self-esteem, or something wrong like that. They don't understand that we come from a culture where we respect people; sometimes, asking direct questions is rude. So I sometimes feel institutions need to understand the cultures of people, the students ... (Siulia Tui).

For Lucy there was a range of possible reasons why she felt uncomfortable during her education studies within the university.

What I am studying I believe is not as legitimate or as high up the scale as other people's and it is sort of looked down on educationally. The institution is almost competitive really in a funny sort of way, in an environment when there's a minority. The people I have admired the most, actually, who have often had the most to contribute in my studies, in my courses, are actually the quietest people, the most humble. I have felt a little bit labelled and singled out and stereotyped really and that is uncomfortable ... (Lucy).

When I asked Destiny if she had any Pacific lecturers she could turn to for help at medical school she said:

In 1980 there was nothing, there was absolutely no one, you just struggled on. I look now at what they are doing for Pacific Islanders at universities and it's just wonderful. I think maybe if there had been someone there for me, perhaps just having another Pacific person there to have a cry on, I probably would have got better grades. Back then I don't think they thought that Pacific students had any needs, whereas now they do, which is great ... (Destiny).

Katalina experienced a case of mistaken identity when she was categorised as Mäori by her tertiary institution:

I was quite interested how they had stuck me into the Mäori bilingual area group. I was not very comfortable with it. I think they put me in there (I'm just assuming here) because I put on my enrolment form that I did Mäori at school, so I was quite OK about speaking Mäori and since there weren't many Pacific Island students there at the time and it's the same feeling, OK, who are the brown faces here? Who can I click to straight away? When they gave the study programmes out, it didn't kind of shock me in terms of my expectations of their knowledge about Tokelauan people ... (Katalina).

Allegra was happy in her first year studying by herself until her status as a student who identified as Samoan was challenged. Even when institutions, for the best of reasons, put in place initiatives to encourage more Pacific students to enter and stay, studying there can have negative outcomes for individual students. 
There have been some really patronising things I've witnessed at Law School about Pacific people and so-called special treatment. This woman said something one day about there no longer being a mature students' quota and then turning to my friend and I and saying: “But they still have the Pacific Island quota, don’t they?” Looking at us as if we only got in by the quota. We went: "We got here on our marks thank you very much”. Things like that happened. I remember once somebody wrote up on the board: "Pacific Island tutorial” and students behind me going: "Well we don't get any extra tutorial”. There's that kind of backlash that happens all the time. I don't get upset about it. They bring up arguments that I thought were resolved years ago, like you always forget to argue with them because you just thought we were all beyond that discussion, surely ... (Allegra).

And Rita felt there was always a reaction to her being Samoan.

There have been times when I have felt like I stick out like a sore thumb. I am the token Islander and things like that. I think Islanders are pretty scary in the first place because let's face it, palagis don't know many Islanders. I've found that I just have to stand still and let them look at me and just allow my presence to enter into their surroundings. I think it's because all Islanders are really "big” when they enter a room, they make an impact as a whole person: their spirit, body, mind and soul. Another difference is, I'm not so sure that palagis acknowledge their spiritual side like we Samoans do ... (Rita).

Help/support provided by lecturers/ tutors, counsellors

It was outside the parameters of this study to ask the lecturers and other students as to the reasons behind their treatment or their assignment of the Pacific women students.

As my informants acknowledged, lecturers and tutors were also very influential in terms of encouraging students to bring their own previous knowledge and perspectives into their learning, challenging students with new ideas, enthusing them about their discipline and their own areas of research. They were seen to be important as social actors, not only in the passing on of knowledge to students, but also in maintaining the position of students within the institution:

With the lecturers, I used to find a lot of them, especially in geography, put me to sleep, they were really boring. All those funny old guys, all they were doing was talking with this flat monotonous tone. But the ones who fascinated me were the ones who had slides, pictures that I could link in with, anything that had ethnic examples or aspects to them. I think I became more aware of ethnicity there at university, this whole idea of difference. That was why I took anthropology and geography, it was my fascination with the world outside of whom I was, and English literature opened me to different ideas of how people viewed the world, not just the Samoan world view, not just the Bible, so I was fascinated by that. The challenges came when I had to respond and that 
was when it was hard for me but the lecturer taught me how to answer the right parts ... (Eleni).

There are some lecturers who I've had, they were like mentors for me, they've got this passion, and you can just see it in them. They have this spiritual element to their teaching and I tend to connect with those lecturers who have a lot of interest in Pacific people, you know, it could be non PI lecturers as well as Pacific ones ... (Katalina).

I was very fortunate to have people like $\mathrm{X}$ lecturing. For me, he just offered me the whole thing of being able to be different and write about things I was interested in. He was innovative. He changed all the assignments round in the second half and said: "I see there are some people here interested in spirituality. Do you want to do an assignment on that?” So there I was doing an assignment looking at spiritual aspects to education. Isn't that wonderful? ... (Makasini Tuatagaloa).

And now that I am doing these Masters papers on culture and identity and my perception on just going into that course, I was just blown away. It wasn’t because I was downhearted by the whole thing and all the issues about identity, no, it has blown me away because there are more things to be learnt and I am so excited ... (Lee).

I managed to get through my law papers mainly because of R. She's a law lecturer down there. She's such a passionate woman. Because of her I was starting to get to a place where I could relate the law to my experiences. She was very methodical about her teaching, she actually lectured the stuff, but she framed it in such a way that I could actually relate to it and so it was brilliant ... (Judith).

Mary found that co-operation across university departments helped her to maintain a Pacific Island management scholarship and get enrolled in the correct course.

When I applied to go to university it was to do law and management combined, and then they sent me a letter saying that I had got the scholarship. Then a week before I went up there, the Pacific Island Business Management Trust rang and said, "Sorry, you can't do law, this scholarship is just for management so you have to go and change your course”. I was a bit frustrated by this because I was going to a new campus, a new university, I had no idea of what to do, but they rang up the Management Department and the Law Department and by the time I got there it had all been sorted out. So if anything, the university was actually very good to me at that particular time, later I did have a bad experience ... (Mary).

Two students mentioned the support by counselling staff in times of grief and personal change as being crucial to them remaining at their tertiary institutions. Their ethnic and cultural ties and values were also a part of the changes they had to confront. 
During my Masters my father died and that was my last year, when I was doing my dissertation. I went back home to Samoa for his funeral and I was very upset. I thought, well, what is the purpose of all this studying? The very person who had drilled into me the value of doing well has gone. He won't be there to see me graduate even though he dearly wanted to be there for that. When I got back I went to see B the counsellor and he said: "Well, you're almost there, you've almost finished, why give up now? If your supervisor and lecturers can give you time you can still finish and with first class honours”. I don’t know how I did it. I must say, God works in mysterious ways ... (Ruth).

I was finding life really hard, so I went to the Counsellor. I was just walking past and I saw this counsellor sign so I just went in. I don’t know if everyone would do what I did, but for me it worked. I had felt like giving up because when you learn something new you never know whether you are prepared to go through that pain of having to deal with it. A lot of things come up, don't they, when you are learning, facing contradictions and realising about family, racism, and even personal stuff, especially in education. And dealing with relationships in general, personal relationships and my having to go through a break-up ... (Katalina).

\section{Evidence for negative treatment or assignment within tertiary education settings}

The women shared some examples of positive help and support, but overall, these were far outweighed by what they described as “negative treatment”. Although narratives have been analysed separately in positive/negative terms, it will be argued later in the discussion on indicators that both positive and negative responses are part of the social processes in the construction of ethnic identity. That is, both kinds of treatment can result in assertion of ethnic identity by ethnic group members either taking advantage of the resources available to Pacific students, or, responding to low expectations by working hard to succeed in order to prove the doubters they were wrong.

A number of my respondents were willing to share examples of what they saw as being treated unjustly or unfairly while they were attending their tertiary institutions. They reflected that in hindsight they would probably have dealt with it or responded to it differently. Several testified that these were instances that also galvanised them into "hanging in there" and most likely deepened their resolve to succeed.

It was not always easy for them to discern whether the treatment arose from the direct power relationship of lecturer to student, gender difference, or ethnicity. Or, indeed, whether the treatment was simply a case of bad manners and being at the wrong place at the wrong time. The women had different interpretations of all of 
the above and this is why the following narratives contain elements of all of these possibilities.

I have felt a little bit labelled and singled out and stereotyped. I feel inadequate to the stereotypes. I don't think other people [outsiders] really even understand what they mean when they say, "That Pacific Islander over there”, or, "We'll show this bit about Pacific Island education. She'll know what we mean.” What are they expecting me to know? I will never be able to speak on behalf of all groups of Pacific people. A professor came up to me once to get me to translate something into Samoan. I mean I have done a few Samoan courses but I mean I couldn't do it and he said, "I have heard you are a bit of an expert” and I just thought, nervously, "Oh my goodness, who has he heard that from?” I mean, he was being amicable and nice about it all and everything, but it's been like that all through my tertiary studies. Really, if you do choose to identify yourself as Samoan or whatever, and I have always reluctantly done so, then that's the responses you get. I have only ever done it when I am in a group, when something needs to be said, and I think no one else is going to clarify this. Then when you have done it then you are seen as an expert and of course I know I'm not ... (Lucy).

Behaviour on the part of some lecturers and tutors was a source of concern as well:

My journalism tutor, she must have really had a hard time teaching us. She was always crying. She used to think we were a really difficult bunch to tutor, our Pacific class. She couldn't cope with our humour, for one thing. She would always go on at us about our time management skills: "You can't show up late to an interview". She used to think that our mistakes were her failures, but I don't think they were really our mistakes; we got a hard time for her failure. I would say that within a period of six months she probably would cry in front of us about once a month. She would tell us one of the hardest things for her as a tutor with a Pacific Island class was, you know, she was encouraging us to ask questions, and "You have to be curious to be a journalist, you have to be proactive in asking questions so you have to have a wide general knowledge". I thought it was actually incredibly unfair of her because some of these socalled shortcomings of ours could not be changed. I remember the younger ones got a lot of support from the older ones. We would encourage them and tell them not to get so upset by her tirades ... (Wawine Wale).

From the beginning of her master's course Ruth felt threatened by being labelled as a Samoan.

In my first year my lecturer was talking about the fact that there was this Samoan guy who did this course last year and never came back. I felt really small when she said that. I was not sure whether she was saying this to discourage me or whether she wanted me to strive to finish, but I felt really bad about it. I thought it was a racist remark and demeaning. But the funny thing was, the whole two years there that comment made me 
strive more. When we had our farewell dinner after we finished the course, I bought a bottle of wine and put it down in front of her and said: "That is for giving me 78\%, two more marks to an A-minus”. She thanked me and another palagi guy for being the brightest in the class and yet I did not get an A. I told my husband about the whole incident and the background to my comment. He said, "Why not go to negotiate with her, if you deserve an A, you deserve it”. I said, “ No I'm too proud. I am not going to beg, I have my pride as a person, as a Samoan”. But, you see, I knew when she sent my assignment out to an external marker, it came back as 36 over 40 and I got an A minus. I could see that someone had rubbed it off and put 34. I mean, I am not blind. Afterwards I was told that this particular lecturer never gave an A. So no way would I ever go back to her to negotiate. My other courses pulled up my marks anyway and I got First Class Honours. So that whole incident, it made me really think hard about our struggles as black people ... (Ruth).

Ruth spoke elsewhere about how her tertiary education had increased her knowledge about racism and the struggles of black and indigenous peoples, so she aligned herself and identified her struggle as a Samoan student with those of members of these other ethnic groups.

Abigail was also singled out, both negatively and positively.

Occasionally some of the lecturers would ask my opinion on something because I was the only Pacific woman in the class. Not a nice feeling at all, imbalance and all that sort of stuff. And in law school I was a misfit. Let's face it my father was no judge and in classes I think the law lecturers could have been nicer to all the students. I was going to see the Dean to change a course once, all the while still feeling like an impostor, I gave him my paper and I don't know what his problem was but he just threw it back at me. I remember being really hurt and taking that quite personally. Quite ironic, really, how I turned out to be an international scholar in law. I remember their attitudes did change towards me once I won that honour, getting to go to the UN and all this kind of stuff. It was quite interesting how the HOD, the Dean, all of a sudden wanted to talk to me, they were nice to me. Before that I was just an underdog kind of person ... (Abigail).

Allegra, another law student (at a different university from Abigail), took issue not only with the tutoring but also assessment and administrative decisions.

I can't ask for help, in fact, they don't want you to ask for help. I think it was part of finding out who had got what it takes to do law. They make it clear that if things take more than 30 seconds to answer, you're not going to be accepted. I mean, I had big issues with the Law School because they decided to let a whole lot more students in and as soon as that happened they stopped having tutorials. So you have a whole lot more students with not very good support. As a result there are a whole lot of law grads that don't know how to write legal opinions because it takes too much effort for the lecturers to mark their essays. So most courses are assessed now by one 50-minute test and a 2- 
hour exam at 300 level, which isn’t really, I think, very good. It makes it sound like that is easy but it is actually not, you don't have much considered work that you are doing, it's kind of rushed, spontaneous reactions to questions, no matter how much you study it ... (Allegra).

Like several other students who were interviewed, Lucy thought her lecturers' attitudes were a problem.

The only problem I would say I had with some lecturers was their snobbiness, I just think some of them were a little bit arrogant in their attitudes in the way they spoke, it made them unapproachable, so I wouldn't go for help ... (Lucy).

Many students (members of all different ethnic groups) find that they don't like their lecturers. However, the consequences for these Pacific women students was also their lack of confidence in approaching lecturers because of their high status within the institutions (which means they must be shown respect), and also the risk of appearing “dumb” by asking questions.

The following narrative relates to an experience on a business management course where Makasini Tuatagaloa had paid all her own fees $(\$ 25,000)$ and yet did not get any attention from her lecturer in class.

He would refer to people by name to answer questions. He said it was based on the Harvard model. Yet I would say to the other students, "Look! He deliberately avoids addressing me because of my name”. One day I was sitting in class. I noted he asked the person in front of me a question, the person sitting behind me a question, the person on both my sides, but not me. That was what it was like throughout that whole course, he never spoke to me directly or asked me a question. My way of rebelling is, I'd say nothing. To this day I dislike the man because of that. On reflection, I think I should have approached him and said: "Look my name is, and this is how you say it". But I didn't. Mind you, he gave me very good grades on my assignments. I got a low grade on participation though [laughter]. It didn't do any good for my own self worth by letting it go. If I had at least attempted to do something about it ... (Makasini Tuatagaloa).

A number of students at postgraduate level (not only Pacific students) have difficulties in finding or securing good supervisors. The following narrative is just such an example of this problem.

The other reason for doing the $\mathrm{PhD}$ was because I had a supervisor, G, who's just such an amazing man with a worldwide reputation and I wanted to catch him before he went somewhere else. When he agreed to be my supervisor I was really excited. We got the scholarship arranged and everything, but just before we started the thesis in August he got an offer in Canada that he couldn't refuse. So then I thought, oh no, I had decided 
totally that I was going to do the $\mathrm{PhD}$ because of him, and I thought, what am I going to do now? So it took me a while before I actually put my head into it again and went and got another supervisor ... (Judith).

Ngariki also had the experience of going through four supervisors for her Masters thesis. There was no one available with the background in her area of Pacific education at that time to supervise her. She found the whole process very disheartening and gave up her postgraduate studies to become employed in a government agency.

Rachel appealed against her grade of C in Mäori Studies (for Honours) and it became a very long and protracted process to get her mark improved. It delayed her Masters enrolment. She wrote to the lecturer concerned and to the Head of Department (HOD). It took a number of months for a reply but then a hearing was set up which involved several HODs in the Arts Faculty.

The HOD of Mäori at the time, he was there, the HOD for Science, too. One from the Arts Faculty, from History, were all on the panel. I presented my case three-quarters in Mäori because in so doing that would let them know that I understand exactly what I am saying in both languages. I put it into English and then I put it into Mäori. The lecturer concerned and the HOD came empty-handed to the panel, nothing, not even a piece of paper, so I did not know if they would take me seriously or listen to my case. In the end the lecturer said: “How about if I give you a B+?” And I said, “Thank you”. The whole panel agreed so I got up and thanked everyone. I turned to the lecturer concerned and the HOD and thanked him. You see from the Samoan perspective whether you are wrong or right you still apologise to people in that situation and they responded to me so that was the end of it. That is why my Masters is like this too now, it's not finished, because my case was so prolonged, and then dealing with the Ethics Committee. They took their time also to respond to my MEd thesis proposal ... (Rachel).

Ruth probably best summarises the main feelings of the women who shared their stories. Even though she had felt discriminated against in her master's course, she kept going.

Like I say, I'm a plodder. I plodded on. Even though there are all these things that I thought were negative, I just plodded. I just kept going in my own sort of quiet way. My advice to other Pacific women: “Don’t be bogged down by these and other negativities around you, it is not going to do your work any good”... (Ruth).

The Pacific women graduates in this study described their responses to this treatment (or assignment) by others, and they also described the ways in which they asserted themselves and their ethnic identity in the tertiary education setting. 


\section{Responses to their treatment as Pacific ethnic group members}

One common way of asserting their ethnic group membership was for the women to find other Pacific or even "different" students to get alongside them, so they could help each other in this largely unfamiliar and alienating environment. Thus they became visible.

The first thing I did was go and sign up with the Samoan Students' Association and get to know them. I was given a hardship grant and a management scholarship from the Pacific Island Business Development Trust so I wanted to get together with other Samoans. The Samoan Students Association was really neat. I got heavily involved in them, there was always something happening, something to work towards ... (Mary).

Lucy met another Samoan student when she started university.

He had been at university for a year and he hated it. We just stood in line, actually while we were getting our student ID cards and we just immediately made a connection. It ended up that a group of us hung out together throughout the whole thing. I think we just supported each other because we felt culturally comfortable and we didn't really call it an ethnic identification, it was just something inward, that easiness. I mean, I was able to mix probably a little bit more than some of my friends with the Päkehä environment and Päkehä friends and things like that, but I did feel I had more in common my Samoan group ... (Lucy)

Probably took me a couple of years to actually build a network of friends, we were kind of the oddballs. The ones, you know, either we were generally a bit older than everyone else, who hadn't come to university with large crowds of friends. So that's how it was ... (Ngariki)

Makasini Tuatagaloa was even asked to be a mentor to other Pacific students at university.

I used to see PI students around and a lot of them would look at me and think she is one of us, you know, the younger ones. I'd watch some of our people coming back as arts students but they just weren't cutting it and so the lecturers said to me: "Look we'd love to have you talk to some of the PI students because a lot of them are failing at education”. I suspected there would be a number of Pacific people that find study a difficulty so I was able to help Pacific students with writing and other study skills ... (Makasini Tuatagaloa).

Wawine Wale spent the first six months of her first year at university in a hostel and she found support from other Pacific students.

It was a very, very small hostel, about twelve of us. We were quite a diverse range of women from vastly different backgrounds. I was one of two Pacific women there. The other one was a Samoan woman. The supervisor of the hostel who lived in, her father 
was married to a Cook Island woman, and she was a New Zealand Päkehä and so, we immediately kind of struck up a very good sort of friendship. In the second, third and fourth year there was maybe twenty, twenty-five Mäori and Pacific students in social work across the four years. They had established a Polynesian Collective, which was a support group for Mäori and Pacific students, and we used to meet every week. We really stood out on campus, visible. The older ones in the collective really kind of took the younger ones under their wings. A couple of the older ones were from Newton PIC church so that was a huge, huge source of support for me. I really didn't realise how difficult it was being in that tertiary environment until maybe about my fourth or fifth Polynesian Collective meeting. It was really tough being there and I didn't realise that I missed home as much as I did until then ... (Wawine Wale).

Rita has a clear sense of being both an insider and an outsider and wondering to what extent her qualification will make her an outsider to her own Samoan ethnic group.

I have gone right through my studies with both Pacific Island and palagi students alike, but I prefer the humour and company of my PI friends. They have been a great support to me mostly because they understand the difficulty that your background brings to being able to achieve in these institutions, getting our diplomas and the rest of it. There's no hint that any one of my friends would let me fail and I support them too. While I do feel good about my qualifications and my family are proud, I wonder if all this education will make me feel more 'white'. I think to myself, perhaps I am just kowtowing into the system and, all I am doing is just buying into the image of what is successful, and forgetting about where I'm from and what really counts ... (Rita).

The women also reflected on how their tertiary education, and some of the courses they took, had helped them to assert themselves and how this affected their Pacific ethnic identities.

The whole tertiary experience for me has strengthened who I am and my understanding of my background. It has given me the choices to make the decisions for me, it has made me understand who I am in the world, and I think that has brought my understanding of my family a lot closer. I would never feel as if my own education or qualifications has isolated me from my family ... (Ngariki).

Eleni came face to face with issues of identity when she took a Canadian literature course, but this had some unexpected positive consequences for her masters in geography.

We had to keep a journal. I have actually still got the journals. Even now I read them and I realise, wow, this is the struggle I went through. I went through my identity sort of crisis in a sense during my undergraduate years. I didn't really know how I fitted in. I knew, of course, a lot of Pacific people, but coming here was very strange in the sense 
that it was leaving all the people that I know-their values and hopes for me. Like I didn't really make any lasting friends. There are people that I knew and we got together. In fact, I found I got involved with the other ethnic people because there weren't really many Samoans at all in any of our classes, especially when I moved into my masters. That's why I ended up doing geomentality about Samoa and ideas on the environment, and how we as Pacific people relate to our environment. I began to see how I could use my own culture to do something of academic value ... (Eleni).

Lee also found other students to link up with, and she describes the lip service given to Pacific culture in her courses.

I was quite fortunate in that I had three other Pacific students in my particular class out of the total of 40 students that were taken in as a quota. At that time there was only one Pacific lecturer in the primary area, and there wasn't a commitment to Pacific people as such in the programme as it is now. It just didn't feature, and if it was, the lecturers just wanted something like get together and teach an ethnic song, sort of thing in their courses, just tokenism to me ... (Lee).

Mapaia was not content to be passive during her studies at the seminary.

I was arguing with the lecturers, even in theology. I asked them: "Why am I doing the history of England? Why aren't I doing the history of the missionaries when they went to Samoa?” I really wanted to get into the history of the Pacific, which would, to me, speak something of who I am, and the place I belong to ... (Mapaia).

Mapaia also related an incident when a palagi friend walked out of an exam they were sitting together. She realised that she would never even contemplate doing that.

I said "Can you really do that?" My friend said: “Oh yeah, you can do anything you want to do in this world". Oh no, to me I cannot do that. Do you see the difference between us? I said: "Look I cannot do that, walk out of the exam". She said "Why not?" "I have to do this, I have to pass, because over here, it is not just me going to school; it is my whole family going to school. It is my whole community going to school. If I fail this paper, to me, it is failing my mother, it's failing my father, it's failing my sisters, it’s failing my brothers, it’s failing my country”. And she said, "No, for me, if I fail, it's just me” ... (Mapaia).

During her tertiary studies Siulia Tui also became very conscious of her ethnic identity and she was able to articulate what that meant.

I think my tertiary education has opened up my mind to other sorts of ways of thinking, and my language has broadened, my vocabulary, and it has broadened my political thinking, for the good. I think it's made me confront my identity crisis, although I didn't know I had one! I always tell people I'm proud of my Samoan and my German 
heritages, but it made me think — what on earth does that really mean? I'm also very Samoan, and so it made me really curious about this identity conflict and I delved into that all last year. I read a lot and the person who has had a lot of influence on my ideas is Anne-Marie Tupuola. I felt like she was talking to me when I read her PhD thesis. I opened it up and I thought, oh no, I didn't realise many other people felt the same way as I do. So I'm comfortable now, with being Samoan, but also acknowledging my European side is also important ... (Siulia Tui).

Katalina could compare the difference between attending tutorials set up for Pacific students and those that were not set up for them.

My major's education and I had Pacific Island tutorials, and I opted for that. That was good, because I've also been in the non PI tutorials. I can see why they have the PI tutorials. The students would probably speak more in those. I was okay to sit in both, probably because of age and because I had work experience behind me, I felt quite confident. So there were a couple of Pacific students straight from school that kind of kicked out with me because I kind of knew what they would be feeling ... (Katalina).

Even within each Pacific ethnic group, intra-ethnic differences between individual students were apparent to the women. For example, Abigail and Lucy were both very aware of the intra-group differences between themselves and other Samoan students at their universities:

Most of the Samoan students there were either kind of the middle or upper classes on scholarships, people with money and power. So they were kind of a bit Europeanised, even though they were full Samoan, whereas my family were not like that at all. Even though, I did hang out with Samoan students and other Pacific students, the majority were scholarship students at that time and they weren't really as politically motivated as myself. They were probably struggling with all this freedom in New Zealand, in comparison to being back in Samoa. So I found it difficult to establish deep rapport with some of my Samoan colleagues at university ... (Abigail).

I had two Samoan boyfriends and they just accepted me as being like them, which was quite strange. They assumed I was Samoan because I had Samoan blood in me, even though I didn't speak the language and I wasn't familiar with the culture. But, interestingly, I did become immersed in their family backgrounds, they came from very Samoan families, but quite influenced by New Zealand and Päkehä culture too. To be honest, one of the most impactful things between us was not our culture but, actually, the economic differences ... (Lucy). ${ }^{38}$

38 There were many more narratives that could have been included here about the women's experiences in tertiary institutions. I have tried to select those that illustrate the approach I have used and the theories underpinning the social construction of ethnic identity for this group of Pacific women in Aotearoa New Zealand. 


\section{Summary of results: indicators of ethnic identity construction within tertiary settings}

The narratives are the descriptions of the lived experiences of this group of 20 Pacific women graduates within the social institution of tertiary education. Moreover, what they brought with them from their family and church lives had an influence on the social interactions and social construction processes that took place within their tertiary institutions.

Some of the key evidence of the existence and influence of social contexts on the construction of ethnic identity in this study is about the effects of migration on identity construction processes. For the Island-born women, the migration entailed not only geographical re-location to New Zealand and New Zealand institutions, but also moving away from familiar social and cultural networks and interactions with familiar and like people, and from places where their cultural identities shaped the major part of their daily living. The New Zealand-born women who migrated to cities away from their families and church networks, reported a similar process. Both groups of women entered into new and unfamiliar institutions, each with their own social hierarchies, social networks, and expected roles of students and learners. These social re-locations brought into sharp relief the meanings and definitions held by others in those institutions about them as insiders and outsiders, and the boundaries between "us" and "them".

The Pacific women brought with them a number of different expectations that were characteristic of their cultures and the families they grew up in. Some burned with intellectual curiosity, most came with a real desire to succeed, and with a clear understanding that their academic success or failure would bring either honour or disgrace upon their entire extended family, village and Pacific community in this country. A number mentioned that they were the only children in the family who had reached this level of education. Others noted they were following in the footsteps of elder siblings by moving to New Zealand or some other country for tertiary education. The majority of the women also brought with them into the tertiary settings their Christian faith and ideals, and an understanding that they were blessed to be there and on a path that would be guided, if not wholly determined, by God.

The complexities and contradictions inherent in social processes and social construction, were also evident in individual women's stories about the potential 
blurring of the boundaries between "us" and "them", and their anxiety about whether their educational qualifications would make them forget who they were, and where they came from. The feelings of freedom and release from the restrictions of family roles and obligations, and the structured life of church and family, were tempered by homesickness, and separation from familiar contexts and activities. Added to this, were the feelings of inferiority within a large institution devoid of any features they could identify with, being afraid to push themselves forward, and being, at times, the only "brown" person in the city, institution or course. These were all ways in which ethnic differences and boundaries were built up from the "insider" perspective.

The more powerful groups of people within the tertiary institutions already had their own meanings and definitions of what Pacific people were like, what they were capable of and, most of all, what they did, or did not need. Therefore, on entry, the Pacific women were categorised in a number of contradictory ways. The treatment they received from lecturers was consistent with the stereotypes and sets of beliefs and expectations the lecturers held of “them”. The women's narratives included examples of being ignored, being singled out to represent all Pacific ethnic groups, and lecturers mispronouncing their names, or not even attempting them. Sometimes the women's reticence, respect for authority, and reluctance to ask questions, were interpreted as a lack of intellectual ability. Where provisions such as Pacific tutorials were made available, the women's experiences were contradictory. Such provisions were welcomed in terms of providing a lessthreatening learning situation for the Pacific women, but they also had to suffer the aggression and ignorance of other (non-Pacific) students, who saw them as being given "special treatment" above and beyond what other students were given. Other provisions, such as Pacific quotas, ${ }^{39}$ operated in the same way for these women students. Whatever the intention of such provisions, the result was

39 Universities in New Zealand have used quota systems in courses such as medicine and others where Mäori and Pacific students are under-represented. In this system, places are set aside for them to build up the numbers. The use of quotas has been hotly debated. Those that support them point to the increase in the diversity of the membership of these professions and their ability to respond to diversity in the community. It is argued that once enrolled these students have to achieve at the same level as others, with appropriate support. Those who oppose quotas on the basis of race and ethnicity call it "reverse racism", "back-door" entry and predict the lowering of standards in the fields of study where quotas apply. There are also the personal consequences for those who get in by quota and those who do not. Allegra made specific mention of the personal consequences of quotas in the law school she attended. 
still the same: the ethnic boundaries between "us" and "them" within the institution were strengthened and maintained.

All of the women, without exception, soon realised that as a result of the contradictions and the contrasts between their cultural beliefs and standards, and those of the dominant groups, boundaries were clearly defined. The women also realised they related differently to those in authority over them because of the way they had been brought up. They came to understand that unless they achieved in a very specialised or significant way, their position in these institutions as student/woman/Pacific ethnic group member added up to being fairly powerless. They reported that their positioning improved somewhat when they reached postgraduate level studies and could, at times, bring aspects of their background into their assignments.

The narratives included several instances where individual women experienced positive responses in their times of personal crisis. Counselling services were mentioned as being very helpful, as were some of the lecturers, particularly where the women felt they had the "right heart" or when they allowed them to incorporate some aspects of their own culture background or beliefs into their assignments or theses. As women, these Pacific women had experiences that are common to all women within tertiary education. The factor of ethnicity, however added some qualitative differences to those experiences, relating back to the cultural beliefs and values they brought with them into tertiary education, from family and church.

Nor were these Pacific women graduates passive within their tertiary institutions. Many women mentioned actively seeking and finding other students "like themselves". Being members of associations such as the Samoan Students Association, or the Polynesian Collective, and even getting together with other student "outsiders" or those "on the fringes", were all ways in which they could, albeit in a limited way, assert their ethnic backgrounds and identities as part of their daily lives as tertiary students. Several women said they were asked by lecturers to mentor other Pacific students who were struggling in their courses. Other women in the study said that in the formation of informal study groups, and by attendance at Pacific tutorials, they were helped to achieve within the tertiary education institutions, simply because they were with others who understood what they were going through with family, as well as the community demands and 
expectations placed upon them. Several women also said that reading research written by other Pacific women and men as part of their courses, and the availability of Pacific lecturers, gave them a boost in believing they could also achieve their qualifications.

Several women who had attended two types of tertiary institutions, such as teacher training institutions, university or polytechnics mentioned how the different institutions responded differently to their cultural backgrounds, and to ethnic diversity. Even in those institutions where there was an acknowledgement of difference, several women mentioned lip service or trivialisation that occurred when songs and dances were welcomed, but nothing that went beyond those surface expressions of their identity. A number of women also noted the negative reactions they received to any expression of their Christian beliefs, so that they kept those beliefs to themselves, in anticipation of those reactions.

In the following chapter, the findings of the results chapters are summarised. 


\section{CHAPTER 13: SUMMARY OF FINDINGS}

\section{Introduction}

In this chapter I summarise key findings from the previous results chapters. The analysis of the narratives provides some examples of the processes of the construction of cultural identity within the family and church as settings; and what the women took with them into tertiary education, the treatment they reported receiving in relation to their cultural backgrounds, and their response to that treatment. This chapter brings together the main indicators from each of the three previous chapters, in preparation for the final discussion and conclusion.

\section{The nature of the construction of ethnic identity}

The women's narratives provide illustrations of the usefulness of the constructionist approach to ethnic identity, including both the primordialist and circumstantialist perspectives. (Insert from Cornell's feedback)This thesis argues that both perspectives are important but also acknowledges that sometimes primordialist factors have power and meaning for group members beyond what can be explained purely by circumstances.

The cultural indicators for a primordialist view included: the importance of geographical place of origin; the role of birth, descent and lineage; the collective memories of migration; how blood connections affect identification; and the consequences and implications of physical appearance in the definition and meanings of ethnic identity. In addition, there was an "emotional" dimension to those indicators that became evident in the women's narratives. Although this dimension can be described in primordialist terms, it is also relevant to describe "feelings" about ethnic identity in relation to the circumstances in which the women found themselves, and in which they expressed those feelings. In this way, the constructionist approach that incorporates both the primordialist and the circumstantial aspects, as outlined by Cornell and Hartmann, is evident in the narratives.

The cultural indicator that was most salient from a circumstantialist view, in the women's descriptions of their ethnic identities, was the indicator of place or location. That included geographical location (in New Zealand or their home island country) and the social location of their family, including their extended family. Location is important, in the sense that in one's own Pacific country the 
necessity for calling oneself a member of a cultural group is absent, particularly when the group one identifies with is the majority cultural group that has social, political and economic power in that society. However, when the family re-locates to Aotearoa New Zealand, assertion by themselves as insiders and their categorisation by outsiders, and the differences between them and other cultural or ethnic groups, become important to the group members, particularly in their position relative to the most powerful ethnic groups. In addition, Aotearoa New Zealand is a society within which Pacific peoples have been marginalised as unskilled workers who tend to live in poorer suburbs that have high concentrations of Mäori and Pacific ethnic group populations.

A further consideration is how the women experienced their family lives on a daily basis. Often their parents chose circumstances and opportunities to meet with other cultural group members, to interact with them, and to affirm and assert their cultural identities. A number of the women talked about community gatherings, weddings, funerals, sports meetings and other celebrations where they were taken as children, being exposed to and taking part in language and cultural activities.

There was a small degree of choice in terms of meeting social and cultural obligations within the family. These Pacific women were aware of the consequences of their choices and actions in maintaining, or consolidating their cultural group membership, while acknowledging that their group membership was also determined by accident of birth, genealogy, and place of birth, and that these aspects of their racial or cultural identity were not, therefore, matters of individual choice.

Intergenerational differences between the lived experiences of their parents (who were in most cases born in their islands of origin) and the women now living in Aotearoa New Zealand, in terms of location and historical circumstances, are acknowledged. Equally, intermarriage or having dual heritages provides individual members of Pacific ethnic groups with dilemmas and choices that are, in turn, influenced by the circumstances in which they find themselves.

The Pacific women in this study expressed differing and contradictory views about whether the ability to communicate using one of the Pacific languages was a defining factor of ethnic identification. Some viewed the Samoan, Cook Islands, Tongan, Tokelauan and Niuean languages as integral to each group’s heritage, 
and in that sense language can be viewed as a primordialist aspect of ethnic identity. Other women shared an understanding of the circumstances that led to their parents not insisting that they keep up their Pacific ethnic language ability.

Circumstantialist views of ethnic language maintenance would also suggest that speaking or maintaining one's own ethnic language could depend on circumstances and opportunities in a foreign, predominantly monolingual, society. When the various Pacific ethnic groups or group members migrated to Aotearoa New Zealand, their languages were, and largely still remain, minority languages. The narratives of the women in this study clearly show that changed contexts and circumstances demand some deliberate action on the part of the speakers of a minority language to ensure that their language survives within changing circumstances. Much depends on the extent to which the majority of Pacific cultural group members think it is important to speak or to pass on the language, when use of English dominates every sphere of their daily life and indeed, depending on whether a critical mass of speakers, whether culturally authentic situations exist, and whether material resources are available for them to maintain their ethnic languages. ${ }^{40}$

Further, the contexts within which the various Pacific languages are considered most important are still the family and the church. Evidence from this study, even taking into account some increase in the teaching of Pacific languages at the tertiary level as subjects and as the means of instruction, shows that Pacific languages do not predominate or influence social interactions in any other social institutions or critical construction sites (such as the political system, labour markets, or residential space).

Finally, the women's narratives point us towards a reminder that identification with Niuean, Cook Island or any other Pacific cultural group must take into account intra-group diversity and how circumstances influence individual meanings and interpretations of ethnic group membership. Within each Pacific cultural group there exists a social and cultural hierarchy, shaped by their own historical circumstances, into which the women were born. The parents of many of the women were themselves highly educated, or held high positions within

40 The Samoan language in Aotearoa New Zealand is maintained through churches, radio stations, newspapers, and by the many festivals, celebrations and other social opportunities where it is used as the main means of communication. 
their home societies (such as being ministers of religion). ${ }^{41}$ The parents of several Samoan women held matai or high chiefly titles back in Samoa. In a number of families the social position of their parents as labourers or unskilled workers in New Zealand did not match the titles or status that was applicable to them in their countries of origin. Such contradictions of status, the women reported, have influenced their choices and their opportunities both in terms of their ethnic group membership and also as members of the wider grouping of New Zealand citizens.

\section{Family and church}

As previously mentioned, the narratives showed some qualitative differences when geographical location or social context was taken into account. The social processes within the family, when located in the Islands, were constructed and supported by wider social and cultural networks in which daily lives across all social institutions were shaped by their own Pacific languages and cultural meanings. The families of the New Zealand-born however, were located differently in two main ways, certainly geographically, but also in relation to other ethnic groups, family structures and values, and social and economic position in the new country. In this context, ethnic group membership and the boundaries between "us" and "them" (outsiders), became stronger and clearer in the lives of these Pacific women graduates.

This study focuses primarily on how tertiary education may shape or contribute to the construction of the women's ethnic identity. This group of Pacific women entered their tertiary education with a clear sense that they belonged to a group of people with origins in the Pacific. Logically, the family and, in this study of Pacific women graduates, the church were both frequently mentioned when the women were asked about their cultural identity and ethnic group membership.

The Island-born and the New Zealand-born women shared similar stories of a relatively protected and family-focused upbringing, characterised by encouragement to strive for goals, for applying one's best effort to anything attempted, to complete what they start, and, most of all, the pride that would be brought to their families when they did succeed academically. As females,

41 In this small sample it might be tempting to argue that the process of social reproduction is taking place, since these women came mainly from families with a higher status in their home islands. However, when Pacific families migrated to Aotearoa New Zealand they lived by reference to two cultural and social settings, and for the New Zealand-born, two "origins". 
protection by other family members (particularly older brothers) was culturally based, as was being fully occupied by family, church and cultural festivities, and their roles and responsibilities within their families. Other defining features, such as high expectations of collective responsibility and family loyalty, were described as important, together with the high value placed on humility, and not promoting oneself above others.

A number of the women also described the changes in status and lifestyle of their parents who migrated to Aotearoa New Zealand, how their lives were affected in terms of employment (which determined where they lived) and their hopes and dreams for their families not to end up like themselves, in low-paid and low-status jobs. Consistent with ethnic migrant groups across the world, the women's families had to re-shape their own daily lives in response to their new situations in Aotearoa New Zealand. For example, the women said that the church was a place where they could still learn, and where opportunities existed for them to speak their Pacific languages. In some Pacific families, such as my own, parents decided to maintain the ethnic identities they had brought with them, and to preserve in whatever ways they could what it meant to be Tahitian, Samoan, and so on.

From the first migrations of Pacific peoples to Aotearoa New Zealand, the Congregational Church of New Zealand in Newton Auckland (now the Pacific Islanders' Presbyterian Church) was an institution that assisted Pacific families to successfully make the transition from home countries into New Zealand society. That original church and its numerous off-shoots provided a social, cultural and spiritual centre where Pacific languages and the Christian faith, by now intertwined with the definitions and meanings of being Pacific Islands in New Zealand, could continue to be practised in an ongoing way. Many of the women in this study, and indeed my own family, have links back to that original church in Edinburgh Street. In this way church organisations and networks have been the key institutions within which Pacific social capital has been maintained over many decades.

The narratives also demonstrate that, at an individual level, the family and church had their own distinct meanings for the women during their childhood. The church often reinforced or even constructed the processes within the family, particularly in terms of roles and hierarchies of husbands and wives, parents and children, and their relationships and responsibilities to each other. These were so 
firmly and consistently reinforced in most of these women's lives that they could not separate these two contexts when they talked about membership of their Pacific cultural and ethnic group.

However, there is also evident a growing consciousness that church and family hierarchies do not respect a measure of free choice, or do not take into account changes in social institutions in the wider society. They are very slowly losing their power and influence over New Zealand-born Pacific peoples for this reason. The Pacific church, as an institution, is being questioned and scrutinised by New Zealand-born, educated Pacific women. I have already referred to the fact that while Pacific women have been ordained as ministers within the Presbyterian Church in Aotearoa New Zealand, their home islands of origin will still not tolerate them practising as ministers, even if they are married. Samoan women who marry ministers and go back to Samoa to work are not permitted to work in the occupation they are trained for, even if there is a labour shortage in that occupation. Wives are expected to devote themselves solely to work in their husband's ministry.

Within the changing historical circumstances in Aotearoa New Zealand, however, almost all of the women in this study spoke about the important role of the church as a social institution in maintaining their cultural identities, and in the building up of their social capital, so that they feel a connectedness to others who also identify themselves as Samoan, Cook Islands, Tongan, Niuean, and Tokelauan and those who also participate in the networks and the institutions of the Pacific churches.

Within both family and church institutions the meanings and boundaries of belonging to a Pacific cultural group were clear to these women. Both contexts were viewed as important, and ones within which the majority of their daily lives were lived out and constructed, according to their group values and practices. Then, as they began to venture out from the enclaves of family and church, into other social institutions and key construction sites of ethnic identity, as described by Cornell and Hartmann, ethnic group boundaries and meanings came into sharper focus.

\section{Moving into tertiary education}

What the women took with them from their family and church lives also had an influence on the social interactions and social constructions that took place within their tertiary institutions. This setting also brought into sharper relief who could 
and who could not, claim membership of the ethnic group. While the women could easily assert their "Samoan-ness" for example, in the contexts of family and church, this was not always the case as they entered into tertiary education. The women soon found dominant groups at their tertiary education institutions were already ascribing certain negative characteristics to Pacific Islanders. Stereotyping of Pacific women as a group was in terms of their recent arrival, their economic position, their perceived lack of English language, their low academic achievement, their collective lifestyles and family structures, their Christian values, their perceived lack of work ethic, and so on.

For the Island-born women, migration entailed not only a geographical relocation, but also a move away from familiar social and cultural networks, and a degree of social separation from interactions with familiar and similar people. Migration meant moving from places where their cultural identities shaped the majority of their daily living. Even for the New Zealand-born women, migration to cities away from their families and church networks to take up tertiary study meant they underwent a similar cultural re-location process. Both groups of Pacific women, therefore, entered into new and unfamiliar institutions, each with their own social hierarchies, social networks, and cultural expectations of them as students and learners. These social re-locations brought into sharp relief for both Island-born and New Zealand-born the meanings and definitions held about them by outsiders.

\section{Treatment within tertiary education}

The groups of powerful people within the tertiary institutions already had their own meanings and definitions of what Pacific women were like, what they were capable of and, most of all what Pacific students needed or did not need. Therefore, on entry, the Pacific women were already categorised in a number of contradictory ways and the treatment they received by lecturers, in particular, was consistent with those sets of beliefs and meanings of "them” as opposed to "us".

In summary, the women's narratives included examples of being ignored, of being singled out to represent all Pacific ethnic groups, lecturers mispronouncing their 
names or just not attempting to call them by their real names. ${ }^{42}$ The narratives included several instances where individual women experienced positive responses in their times of personal crisis. Counselling services were mentioned as being very helpful as were some of the lecturers, particularly where the women felt they had the "right heart" or when they allowed them to incorporate some aspects of their own culture background or beliefs into their assignments or theses.

In all cases, however, the women reported that their position improved to a certain extent when they reached post-graduate level studies and at the times when they could bring areas of knowledge and aspects of their ethnic background into their course assignments.

This group of Pacific women graduates possibly had experiences that are common to all women within tertiary education and thus some of the reported treatment within the narratives could have been common to all women tertiary students. This similarity on one level, with other female tertiary students, is not disputed. However, what is pertinent to this study is that it reveals there were some additional and specific types of treatment by others and responses by these women in respect of their cultural identities. For example, one of the women was told by her lecturer that a Samoan student had taken her course last year and had failed. In this way the boundaries and meanings were strengthened within the tertiary education setting.

Nor were these Pacific women graduates passive within their tertiary institutions. Many women mentioned actively seeking and finding other students "like themselves”. Several women said they were asked by lecturers to mentor other Pacific students who were struggling in their courses. Other women said the formation of informal study groups and Pacific tutorials helped them to achieve within the tertiary education institutions because, as a group, they all understood what they were going through with family and other community demands and expectations. Several women also said that reading research written by other

42 Readers may query why the mispronunciation of names is considered offensive by members of Pacific ethnic groups. In my family, as in many others, our names have been "given" by elders to signify special events or to retain a family name from many generations back. It also has a special meaning that only speakers can interpret and understand. The child is said to have inherited not only the name itself, but also the characteristics of that person. Mispronunciation is thereby considered to offend not only the person addressed, but also her ancestors of the same name and the people who gave her that name. 
Pacific women academics, as part of their courses, and the availability of Pacific lecturers, gave them encouragement to believe in their own ability to be successful and to complete their qualifications.

Several women who had attended two types of tertiary institutions, such as teacher training institutions, university and/or polytechnics mentioned how the different institutions responded differently to their Pacific ethnicities, and to ethnic diversity in general. Even in those institutions, where there was an acknowledgement of difference several women mentioned lip service or trivialisation that occurred where songs and dances were welcomed, but nothing beyond those expressions of their ethnicity was ever considered worthwhile such as Pacific knowledge or Pacific paradigms. A number of women shared that they received a negative reaction to their expression of their Christian beliefs, such that they began to keep those beliefs to themselves, in recognition of anticipated reactions. One student, for example, reported how she had been allocated to a Mäori bilingual class because she wrote on her application form she had taken Mäori language at school.

\section{Narratives and theories}

On page 110 I introduced Cornell and Hartmann's axes of variation in relation to ethnic identity construction and proposed how Pacific ethnic group identities in response in adapting to local historical, social and economic conditions in Aotearoa, may broadly be characterised as moving through certain trajectories and pathways. Similarly, the narratives collected for this study allows for an analysis of individual trajectories of these Pacific women graduates bringing the narratives into an analytical framework of analysis.

Using the terminology from the axes of variation most of the women in this study started out with identities that were "taken for granted", not even consciously asserted and could be termed as "very thick". Yet as they ventured out from their family and churches (for those New Zealand born) or immigrated from their home islands (for the Island-born), other things such as social relationships began to organize more of their daily lives. Their taken for granted identities became more asserted, less taken for granted, and “thinner”. Concurrently, whilst these processes were being played out in the social contexts they engaged in, assigned identities (as Pacific, Samoan, Tongan and so forth) also played a greater part in the women's lives. Indeed when the women entered tertiary institutions assigned 
identities become very prominent, and in response to them these women became more assertive (in a range of ways) about the identities they wanted to retain and defend. They drew on the rich materials of childhood, the church and homelands that were not quite so prominent when their identities were "thick" and less contested.

For example, Rita, who is New Zealand born had two Samoan-born parents who protected her as a child, sent her to church and reinforced Samoan and Christian values throughout their daily lives. At her Pacific church she met other young Samoan women who were also changing and growing as school influences and wider social networks became a part of their lives. Rita relates a "going away" from her faith and laments not being able to speak her Samoan language but still fiercely "feeling” Samoan and knowing what that means. Being assigned as not a "real” Samoan because she does not speak her language concerned her initially but no longer. Tertiary education experiences gave her some "words” to articulate her identity and by associating with other Pacific women at College her ethnic identity consciousness was widened. She describes finding greater confidence to assert her identity across a range of social contexts, including her subsequent employment.

Destiny was born in Tonga and during her childhood her identity as Tongan was "thick", taken-for-granted. She knew at some stage she would have to, as her older brothers and sisters did, go overseas to study as a doctor. She experienced very strongly the differences in climate, values and perspectives when she came to New Zealand to study medicine. After initially trying to "lose" herself within her studies she realised how she stood out physically and how people reacted to her. Changing cities and subsequently working in the bureaucracy has even further galvanised her assertions as a Tongan woman. She finds she is well-known both a mentor and an advocate for Pacific research and policy. Meanwhile, she draws on her early family experiences and Christian faith to maintain her assertions of Tongan identity in the New Zealand context.

Allegra's trajectory is different again and may become more common with increasing New Zealand-born Pacific generations and children being increasingly born of mixed marriages. Allegra's mother is Samoan, her father New Zealand Pakeha. Most of her life she has grown up within a family heavily influenced by the dominant cultural context, encouraged by her mother who was also educated 
in New Zealand to achieve academically. Allegra's ethnic identity could be described as "thin" initially. However, when she went to Law School and found herself associated with other Samoan students, who were assigned as receiving "special” treatment, her response was to become more assertive of her Samoan identity. Further, when Allegra visited Samoa for the first time in her 20s, she experienced some "homecoming feelings" through her recollection of her mother's stories of her childhood, and when meeting extended family members. Her identity was much less contested and taken-for-granted in Samoa when people knew her as her mother's daughter.

A larger sample of participants and indeed a larger number of narratives could be used to discover whether any of the variations in patterns or trajectories correlate with variations in circumstances or contexts. For example, what are the patterns for New Zealand-born as opposed to Island-born? What are the patterns across tertiary institutions they attended, or do unique Samoan, Tongan, Niuean, Cook Islands or Tokelau trajectories exist? This thesis argues that using the theoretical framework of the axes of variation in ethnic identity construction narratives can be very usefully analysed to discover these patterns and provide a fruitful area for future research.

\section{Summary}

This chapter summarized key themes that emerged from the narratives and demonstrated how the women's narratives were positioned within a theoretical framework featured and how the approach taken in this thesis extends our knowledge about the construction of ethnic identities. In the next chapter, Chapter 14, the research questions posed in this study will be answered and the implications for tertiary institutions of this study will be stated. The chapter will conclude with suggestions for further research and with reflections on the knowledge gained as a result of this study. 


\section{CHAPTER 14: DISCUSSION AND CONCLUSION}

\section{Introduction}

In this chapter I restate the current social position of Pacific peoples in Aotearoa New Zealand and discuss how the constructionist approach adopted in this thesis sheds new light on how tertiary education experiences affect the social construction of Pacific ethnic identities; particularly for the women in my study, but, more speculatively, for the increasing numbers of Pacific peoples entering these institutions. This initial section provides a background to answering the following research questions:

a) Is tertiary education a site for the construction of ethnic identity?

b) What did Pacific women bring with them into the tertiary education site?

c) How did the tertiary institutions respond to these Pacific women on the basis of their ethnic identities?

d) What other institutions are important in the construction of ethnic identities?

e) What relationship exists between the family and church and tertiary education?

Implications for action by tertiary education institutions are discussed. The chapter concludes with some suggestions for further research beyond this study on Pacific ethnic identities and a number of reflections on the knowledge gained as a result of this study.

\section{The social position of Pacific peoples in Aotearoa New Zealand}

In Chapter 3 I reviewed research and statistics about the social position of Pacific peoples, an immigrant grouping that for sixty years has come to Aotearoa New Zealand for work and education. I described the growing urbanised and youthful New Zealand-born population. There has been a discernible shift in separate regional based and collective Pacific ethnic group identities since the 1940s and 1950s that has been influenced by various factors. Changes have been brought about largely not only by wider social forces, affecting all New Zealanders, but also because Pacific groups are minority ethnic groups, influenced by the contacts between Pacific and other ethnic groups in Aotearoa New Zealand. 
In the early years of migration members of Pacific groups were categorised by the dominant mono-cultural group (palagi/Päkehä) as a generalised racial category they called "Islanders". Increasingly, over time, Pacific peoples became more visible as members of the diverse groups so categorised participated in and met their daily needs within wider social institutional settings. In contrast to the earliest period of settlement Pacific ethnicities, and membership of a Pacific ethnic group, to a far larger extent now relies on factors of choice, and upon the influence of specific social circumstances relating to the socio-demographic dynamics of movement within and between groupings.

Not all ethnic or racial groups, of course, are migrant groups, nor do the processes of identity construction depend on migration. Migration, however, is a common element in such processes, and migration frequently sets such processes in motion, putting previously unacquainted groups in contact with one another, precipitating competition among individuals and groups as they struggle to obtain the resources and rewards that attracted them to a new location in the first place, and upsetting old arrangements and old understandings of who people are and what their place is in the social order...(Cornell \& Hartmann, 1998: 216-217)

All the Pacific Islands populations in Aotearoa New Zealand are migrant based, although many have been here for more than one generation.

For succeeding generations the stories of migration, immigration injustices, and the Dawn Raids in the 1970s, continue to be told and re-told. Numerous family histories describe the successive waves of relations who came to stay in their small homes, and the extended family members who came and went, depending on the immigration policies at the time. There have been the remittances "back home" as family or village obligations had to be continued. Donations have had to be made to church and family gatherings in the new urban environment, not just in money but also in time and in material contributions. Therefore the women's narratives provided some insights into how they were influenced by two reference groups, making two sets of ethnic demands: one in the homeland and one in Aotearoa New Zealand. For most of the New Zealand-born women "home” in a Pacific island nation was still a cultural reality through their parents' stories and through being able to travel back to their home islands.

Their narratives showed that migration meant a degree of choice for parents and grandparents about what elements of culture to retain or what they thought they could try to retain. Music, food, family and church celebrations constituted 
symbolic repertoires ${ }^{43}$ which acted as remembrances of heritages and pasts while affirming ethnic group solidarities in Aotearoa New Zealand. Part of the decisionmaking required of first generations included, for example, whether to actively retain their Pacific languages. This involved maintaining their use within family contexts, continuing their attendance at church where their languages were comprehensively used, and in the communication required as part of meeting wider family and village obligations. This key process formed an important part of their lived experience and how they saw themselves and others in changing circumstances.

The "identity" of Pacific Island peoples in Aotearoa New Zealand has been a popular research topic over the last three decades and the major works in this area were outlined in Chapters 3 and 6. The models and methods of investigation used included: structuralist explanations (including social positioning) by Macpherson (1984) and Spoonley (1993) in which Samoan and other Pacific groups are described along a number of social dimensions; anthropological and culturalist perspectives such as the work of Anae (1995) in which individual Samoan identity is the product of a journey to singular identity resolution; and from developmental psychology perspectives in the work of Tupuola (1993 \& 2001) who argued for the existence of multiple identities of young Samoan women and against unidimensional explanations of adolescent development. Wendt (2004) provided some insights into the Samoan diaspora in contrast to Samoan identity in Aotearoa New Zealand. These accounts and studies differ from each other in terms of their originating disciplines, but all have described to varying extents identity formation predominantly from the point of view of the "insider" without a full description of a relationship between identity and context and social contacts between two cultural groups within social settings.

None of these previous works have provided the whole picture of how contact between two groupings within social contexts constructs ethnic identities and in this particular aspect this present study differs from previous studies of Pacific ethnic identities in Aotearoa New Zealand. A further difference is that I did not focus on one specific Pacific cultural group such as Samoan as other research has tended to do, but I included members of a variety of Pacific groups in my sample.

43 See Chapter Seven 
This allowed me to see if patterns of similarity or differences in the processes of ethnic identity construction across such groups could be discerned.

In contrast to previous studies, the framework for the study described in this thesis was based on Cornell and Hartmann's social constructionist model of ethnic identity in which:

... identity construction is a product of the interaction between the situations groups find themselves in under conditions of social change and the resources and attributes they carry with them - that is between context, and in a sense, characteristics (Cornell \& Hartmann, 1998: 189).

The constructionist model explains ethnic identity as the outcome of the interaction of at least two population groups that Cornell and Hartmann refer to as "us" and "them", and the associated operation of the processes of assignment and assertion that continue between those groups over time. They explain the processes in these terms:

Ethnicity and race are not simply labels forced upon people; they are identities that people accept, resist, choose, specify, invent, redefine, reject, actively defend, and so forth. They involve an active "we" as well as a "they". They involve not only circumstances but active responses to circumstances by individuals and groups, guided by their own preconceptions, dispositions and agendas (Cornell \& Hartmann, 1998: 77).

This study has focused on the relations between the "us" of Pacific cultural groups, and, the "them" of the majority dominant ethnic group in Aotearoa New Zealand whose values shape and underpin the social institutions in which everyone participates.

Ethnic identity construction in this view arises in situations of contact. Where contact does not exist, ethnicity may not be experienced. Although it might have been expected that all the women in the study would have been aware of a cultural identity well before they entered a tertiary education institution, nine of the women in the present study said that it was migration from their home islands to New Zealand that made them aware that their ethnicity was a distinguishing feature. "I did not call myself Samoan until I left Samoa”, said one.

In the social constructionist approach to ethnic identity construction Cornell and Hartmann describe six key construction sites: politics, labour markets, residential space, social institutions, culture, and daily experience in which all ethnic groups members in society participate. They point out that changing social and historical circumstances shape and reshape these sites. The sites are places where all ethnic 
groups in society may come into contact with each other and it is through social interactions within them that boundaries between ethnic groups are constructed, become apparent, and take on a range of meanings and differences across and within ethnic groups.

Settings such as Pacific families and Pacific churches will continue to change over time. As the proportion of New Zealand-born and educated increases, the demands of employment affect relationships, peoples' networks and priorities, so the maintaining of ethnic boundaries will occur both as a consequence of "insider" changes in response to circumstances, as well as assignment by "them" (outsiders) of Pacific group members. One example of this interaction of processes can be seen in the change over time to speaking a Pacific language as an indicator of ethnicity amongst the New Zealand-born. Once used automatically as the home language of the first generation Pacific born migrants, it is increasingly seen as a sign of reinvigoration of Pacific identities in the face of language loss by current Pacific New Zealanders. At the same time there is also another viewpoint emerging that being Pacific does not automatically mean you can speak your heritage language.

Cornell and Hartmann do not categorise the family as a construction site. In their account it is treated as a setting for socialisation into the culture of a particular community. The family provides the beliefs, attitudes and norms that may come into conflict with those of others in the key construction sites. Although Cornell and Hartmann cautioned against considering single construction sites in attempting to describe the construction of ethnic identity, this study adopted the limited goal of looking at one possible construction site, tertiary education. However, two further settings were also examined, the family and the church ${ }^{44}$ through which Pacific Islands peoples gain an understanding of their own culture with relatively little interference from external groups.

Tertiary education provides a site that is, in a formal sense, open to all groups in Aotearoa New Zealand. However, only a small proportion of Pacific men and women, to date, have been successful in achieving post-graduate qualifications. Nevertheless, education and qualifications are highly valued by all Pacific

44 Cornell and Hartmann refer to the church as a key construction site within the wider society. However, in Aotearoa New Zealand, the Pacific churches are not usually places where regular contact between Pacific peoples and outside groups occurs. 
immigrants in Aotearoa New Zealand as a path to social mobility. Despite this, the role of tertiary education's contribution to ethnic identity among such migrants has not previously been investigated.

The 20 women who provided the data on which the analysis was based, had experienced postgraduate education in a tertiary institution, in several cases to doctoral level. They represented a range of Pacific ethnic groups in Aotearoa New Zealand close to the proportions of those populations. The data on which the conclusions are based were gathered in the form of narratives provided through personal interviews and only to a limited extent on sources such as official documents.

\section{The research questions}

Answers to the research questions are provided under each of the following headings:

\section{a) Is tertiary education a site for the construction of ethnic identity?}

It was soon apparent that even if I could answer in the affirmative or the negative, the response required more detailed description and explanation, requiring additional connected questions and answers, namely:

1. To the extent that awareness is part of ethnic identity construction, tertiary education as a site contributed to the process of that construction.

On entering the tertiary education institution it was clear that the women took with them the cultural identities that had been gained within the settings of the family and the church. Aspects of identification such as physical appearance, having an apparently unpronounceable name, having a friendly and open disposition, meant that others focused attention on them. The women reported that some of their first impressions were that they were often the only "brown faces" in their classes or on campus. They found that cultural and ethnic differences entered into social interactions and this led to particular behaviours. For example, the women reported that they did not want to talk in class discussions or even attempt to ask questions, but realised that by doing this they were stereotyped as less academic, or less intelligent than other students. It was frustrating for them to sit silently while hearing obviously false or misleading information being given out by 
lecturers about "Pacific peoples". A number of women also reported incidents of being either singled out in class, or alternately, totally ignored. These contrasting types of response by "outsiders" had the same effects of bringing into sharp focus the experience of encountering ethnic difference.

2. Pressures from the social institution encouraged the construction of a Pan-Pacific identity through association with students from their own and other Pacific Islands groups.

The relatively small numbers of Pacific students in the courses taken by the women, and the feelings of alienation in the unfamiliar environment of the tertiary institution for most led them to seek out students who looked familiar and who might have understood the challenges they were facing. Consequently, the women found the tertiary institutions to be settings where they could assert their own cultural identity by associating with other students who identified as Samoan, Tongan or as members of other Pacific groups. These patterns of association produced both complementary and contrasting results since ethnic boundaries were being broken down between Pacific groups, while at the same time boundaries in relation to other groups were reinforced.

3. The women reported many examples of the processes described by Cornell and Hartmann as associated with ethnic identity construction.

The women described their own ethnicity and its social construction in ways consistent with Cornell and Hartmann's descriptions. The narratives provided evidence of the use of primordialist indicators, acts of assertion, awareness of boundaries and meanings and of intermarriage as a source of change in ethnicity identity. The primordialist indicators of their ethnicity included physical appearance, lineage and the "feeling” dimension of ethnic identity growing out of the family and church settings and the socialisation processes within them. These indicators related to generally experienced social factors primarily not chosen and often taken for granted. In contrast, circumstantialist explanations called upon particular life experiences and circumstances such as being married to someone from another ethnic group. The women also described times when they were able to exercise some choices about their individual expressions of cultural identity such as when they might speak their own language or when they might assert themselves 
as Pacific women and share their cultural beliefs, practices or values with outsiders.

Cornell and Hartmann describe the process of assertion when group members themselves are directly and knowingly involved in the dynamics of the construction of identity. The Pacific women asserted their cultural identities by bringing some of their background knowledge and experiences into their studies to the extent they were permitted to by their lecturers and the requirements of their courses. They protected themselves from discomfort or the inordinate attention of others by gaining strength from their Christian values. They also received practical and moral support from their extended families.

The narratives clearly showed how difference became salient on entry to tertiary education. This led to an awareness of boundaries and how these boundaries in turn influenced how others treated them. In tertiary education institutions the treatment experienced by the women, and their own assertions in response to that treatment reinforced differences between them and the Päkehä/European students from the dominant ethnic group. The characteristics of their appearance, their languages and their different names led to differential treatment. In the face of common problems, and shared ways of dealing with them, the basis for an emerging group identity among these Pacific students was formed.

But boundaries between separate Pacific ethnic groups also became evident within the tertiary education institution. There are examples in the women's narratives of the boundaries between "us" and "them" referring to members of Pacific groups beyond their own. At other times, the definition of "us" was complicated because a number of the women had affiliation to two or more cultural groups. The concept of ethnic boundaries for Pacific peoples in Aotearoa New Zealand is often complex. Potentially a study of ethnic identity can increase our understanding of how members can identify with a number of groupings simultaneously, including a Pan-Pacific grouping, rather than seeing ethnic identity arising solely from contact with the most powerful groups.

In turn the women attributed meanings to "them". For example, the women believed that passing exams had family and community consequences for 
them to the extent that failure (or giving up) could not be countenanced whereas they often thought, rightly or wrongly, that for many of their Palagi/Päkehä student colleagues passing or failing had only an individual, personal consequence.

The awareness of their ethnic difference and knowledge they had about how others viewed them led them to adopt coping mechanisms. Their views of academic success or failure affected in turn how the women perceived they were being treated. The women may have wanted to stay in the background during their classes and "keep their heads down", but a number of the women said this was very difficult to do. They understood that such behaviour on their part maintained stereotypes, as did being required to be an "expert" on all things Pacific might have repercussions within their own cultural group.

In summary, the processes such as assertion and meanings attributed to other groups all contributed to the maintenance of ethnic boundaries within the tertiary education site. However, tertiary study was seen by one of the women as a resource and as the means of creating "an intellectual space" that belonged just to her. This was a counter to her sense of being highly visible and under pressure to succeed, a pressure that came equally from the institution and from family expectations. Most likely this view was shared by most of the women since they were all juggling many roles and responsibilities in work, family and church settings.

4. The site offered the women opportunity to meet a marriage partner from another ethnic group including Palagi/Pakeha thus opening up, in succeeding generations, the likelihood of change in the formation of ethnic identity.

In the matter of intermarriage, Cornell and Hartmann claim that

$\ldots$ it is the central role of the family in processes of socialisation that gives to intermarriage so potentially profound an impact on the continuity of ethnic identity (1998: 170).

Although the main emphasis of this thesis was on individual experience, the evidence in this study also provides insights into group trends, patterns of intermarriage being a prime example. Several of the women in this study said they were products of cross-cultural marriages: New Zealand Mäori and Cook Islands Maori, Samoan and Tongan, Samoan and Welsh, Samoan 
and Pakeha New Zealand, Samoan and Niuean, Cook Islands Maori and Pakeha New Zealand and in my case Tahitian and English. (See Table of Participants: Chapter 9). In my own narrative I described the circumstances under which my parents met and married in England during World War II. Many of the women from mixed heritages would also have similar stories to tell about how and where their parents met and married. In the present historical circumstances social institutions such as tertiary education sites contribute to the ongoing changes to ethnic identity formation because they are places where all groups in society are represented.

One of the women in this study was betrothed in the traditional Cook Island way prior to beginning her tertiary education. However, when she got to teachers' training college and met an Englishman and married him, these traditional cultural protocols, and pre-determined cultural boundaries were broken as a result of her changed circumstances.

In several other cases women who went into tertiary education found themselves either educated away from their Pacific male partners and friends who did not possess high qualifications, or whose occupations did not require tertiary education and training. This led to their relationships breaking up or to friendships not being sustained. One interviewee found that even though she had married another Samoan graduate there were some important differences between them because she was Island-born and a recent immigrant, and he was New Zealand-born. She reported that he had a more "laid-back" approach to decisions whereas she had very black/white perspectives, from the strongly held cultural beliefs, practices values and religious values that she had brought with her to Aotearoa New Zealand.

In addition to the initial question of whether tertiary education was a construction site for ethnic identity, further research questions were asked:

\section{b) What did Pacific women bring with them into the tertiary education site?}

Prior to tertiary study the women in this study had associated mainly with members of their own Pacific community and came to have beliefs associated with their own particular cultural group. They took with them into the tertiary institutions an identity influenced largely by the social interactions and processes shaped within a cultural framework which differed from the rules and norms of tertiary education. In particular, this was illustrated through the contrast between 
the values of individual treatment espoused by these institutions and the norms of collective obligation that stemmed from migrant community experience.

The women also brought with them the desire for education as a pathway to socioeconomic mobility that was the dream of their Pacific migrant communities. This had consequences that once again illustrate the particular challenges encountered by the women in this study. Their studying at tertiary level involved expectations that failure was not an option and that, on gaining tertiary qualifications, the women should "give back" to the community. For example they should facilitate access to services and resources from government agencies and programmes targeted to Pacific communities. In several cases the women said that once qualified they would go back "home" to help out with family issues including those concerning land and economic development.

One woman explained how her church involvement, from the time she could walk, had shaped her behaviour around service to others. She referred to the discipline learned in relation to church music and singing practice, formalities to be followed, Bible verse memorisation skills, and experience of speaking in front of large groups. She believed these early processes helped her to face the requirements of tertiary education as well as her roles in the other key construction sites such as employment and in her own daily life and interests.

\section{c) How did the tertiary institutions respond to these Pacific women on the basis of their ethnic identities?}

To this point the construction of ethnic identity within the tertiary education site has focused on the feelings, behaviour and responses of the women who were interviewed but the tertiary site and the other groups within them played a role independent of the women. Hence, we need to ask: "What role did 'they' play?”

The tertiary institutions and the staff did not ignore the Pacific students. In fact, a number of the tertiary institutions represented in this study had provided initiatives and programmes specially designed to recruit and retain Pacific students. These included the provision of targeted scholarships and quota systems. They also provided Pacific student tutorials, Pacific Student Liaison Officers, and increasingly Pacific lecturers acted as mentors to their Pacific students in addition to their teaching specialties. Research and writing done by Pacific women was also included in course readings. 
While these provisions were intended to help Pacific students they also highlighted the differences between "us" and “them”. In particular, as noted earlier, when the women felt singled out in their classes and asked to express a "Pacific" view they were faced with a contradiction. Firstly, if they responded they would be labelled an expert, if they did not or tried to explain as one woman did that she was New Zealand-born and could not speak her parent's language, she felt she would be labelled as not a "real" Pacific person. Such comments are familiar within Pacific groups and relate to definitions of a "real" Tongan, Samoan etc. as well as definitions coming from "outsiders". The dynamic processes between assignment and assertion are also visible where the women started to accept that view. For example, that perhaps they were not a "real” Cook Islander or Samoan etc because they could not speak "their” language. In one very unusual case the lecturer cried in front of the students as she told them how difficult it was to teach them and get them ready for their working lives. She attributed the characteristics and behaviour of the students (their lack of punctuality, their inability to ask questions and their lack of general knowledge) to producing her lack of confidence and her inability to "get them through".

Several institutions provided courses such as Pacific studies and Pacific languages as part of their degree and diploma courses. They were established with good intentions such as, that Pacific students would have opportunities to maintain (or in some cases) learn their Samoan or Cook Islands languages. ${ }^{45}$ The provision of such courses have increased the academic status of these languages and it would be interesting to find out how many palagi/Päkehä students have enrolled in them. Nonetheless, whatever their overall aim, such courses still act to maintain the boundaries between Pacific ethnic groups and all other groups studying at tertiary level. However positive the intentions, the double bind of, possibly, inadvertently, creating and maintaining the negativities of attributing special categories (also called “privileges”, for particular groups), is ever present.

Generally, the lecturers were described by the women as supportive but whatever they did the outcome was still to reinforce the boundaries of identification.

\footnotetext{
45 Galumalemana Afeleti L Hunkin, Head of Samoan Studies, Victoria University of Wellington, addressing a UNESCO Diversity Conference in Wellington 23 August 2005 commented that although currently there are adequate numbers speaking the Samoan and Tongan languages in Aotearoa New Zealand we are actually observing the rapid decline of Pacific languages and current conscious efforts to retain them may not be enough to stem the decline.
} 
Several narratives showed how through a lack of cultural knowledge lecturers caused cultural offence to the students. For example, in most Pacific cultures the naming of children is a highly valued process involving those who have been given the honour of naming, and the name itself might commemorate an ancestor or a past event that occurred within the extended family. Therefore, when a name is mispronounced such behaviour offends not only the person with the name but also the extended family and ancestors. Hence the student concerned might feel discomfort. Even though this type of treatment by the lecturers was unconscious it still resulted in the maintenance of "us" and "them" boundaries.

\section{d) What other institutions are important in the construction of ethnic identities?}

As previously mentioned, Cornell and Hartmann cautioned against only considering single construction sites when attempting to describe the construction of ethnic identity. I accepted the need for this caution.

A focus in this study on the tertiary education site did not give an opportunity to directly study the other five types of ethnic construction sites listed by Cornell and Hartmann. However, it became clearer as the narratives were analysed, that wider social forces had effects within the tertiary site. For example, official classifications by national statistics and government funding agencies may provide categorisations used within tertiary institutions. In other words, tertiary education reflects the dominant values and stereotypes in the wider society.

In terms of adapting to Aotearoa New Zealand migrant groups such as Pacific peoples usually relied on family, church and other cultural networks when they first started arriving in Aotearoa New Zealand. Cornell and Hartmann describe the concept of social capital as relationships, interpersonal networks, sets of obligations, shared norms and mutual trust as aspects of social interactions that bind people together. They describe the role of social capital in identity construction as a resource:

Those who can solve life's problems by recourse to existing relationships within their own ethnic or racial group have less reason to cross the boundary of the group in search of solutions. Those who cannot solve such solutions within the boundary of the group, on the other hand, must turn elsewhere to deal with these problems (1998: 213).

The "problem" of adapting to a new country forced all Pacific groups to move fairly rapidly outside of their own cultural boundaries to gain employment, 
housing, education and other social services. This trend was very evident in the sense that women in this study were actively "pushed out" by their Pacific families (even overseas in some cases) to hasten and enhance this transition process of becoming successful in the new country.

The social institutions and social construction sites the women participated in, such as tertiary education were ones where they had to interact with the dominant group, serving to highlight and reinforce cultural and ethnic differences, boundaries and meanings of their ethnic identity, often in unanticipated ways. The narratives reveal that the women saw their families and churches as a resource to "retreat to" as well as positive material and spiritual support in relation to succeeding in sometimes challenging and "alien” contexts beyond family and church.

\section{e) Relationships between the family and church settings and tertiary education}

My ideas on how these settings related to each other were originally expressed in a diagram that was presented to the participants during the course of the interviews (see Figure 1, Chapter Eight).

The second revised diagram (see Figure 3) therefore recognises the influence of the constructionist approach on my thinking and an increasing acknowledgement over the course of my study of its relevance and importance. As a result I have reviewed the original diagram to more closely reflect the key findings from my narratives, and to represent the relationship between the individual narrative data and the social construction of ethnic group identity in two social settings (family and church) and the tertiary and wider society sites. Note that I have re-named family and church as settings rather than sites but have retained their role and function as development of the values, beliefs and practices of each Pacific cultural group.

I have changed the description of the wider society from that which appeared in the first version of the figure so that it is consistent with Cornell and Hartmann. The former wider society "site" now comprises six key ethnic identity construction sites. The re-drawn diagram now depicts an internally consistent constructionist framework that takes into account the narrative data and the analysis of that data. 
The social settings of family and church are where the formation of cultural identity takes place and therefore form the apex of the revised framework. These two settings continue to be influenced by wider societal changes and by internal changes in the lives of the individuals within them. This diagram assists in demonstrating how the women took their cultural identity and its meanings with them from the family and church settings into social institutions and construction sites. Within the family and church settings ideals and social values such as the importance of family obligations and the consequences for families of the behaviour and success of their children in the wider society, was formed. When the women went into tertiary education they were able to draw on both the material and spiritual support of their wide family networks and members of their church congregations.

Arrows point downwards beyond the links between family and church through compulsory education to higher education in the tertiary education institutions/sites. Lines are purposely curved because movement is not always "straight-forward" into the wider society or to tertiary education. For most Pacific women (although not in this sample) their pathway beyond compulsory education is straight into the wider society. A growing number of Pacific women are gaining tertiary qualifications in later life as they make a transition from one occupation to another or where their jobs demand further training. For example, more Pacific women are training for early childhood education teaching and must upgrade their qualifications consistent with new government regulations.

The curved line connecting tertiary education and the wider society has arrows at both ends denoting the movement backwards and forwards by these women between the two types of sites. It confirms the existence of a relationship between positioning within several of the societal ethnic construction sites, and tertiary education qualifications. I asked the women near the end of their interviews about their perspectives on the consequences of achieving their educational qualifications, and their participation in subsequent and concurrent employment situations. Many of the women thought that their ethnic background and their ethnic group membership influenced their choice of career or occupation. It was also a factor in their employers' interest in employing them, usually to work with Pacific peoples or in areas of Pacific social policy, service or programme delivery, Pacific health, or Pacific research. 
The revised diagram summarises the changes made to my thinking about the construction of Pacific ethnic identities within the tertiary education site.

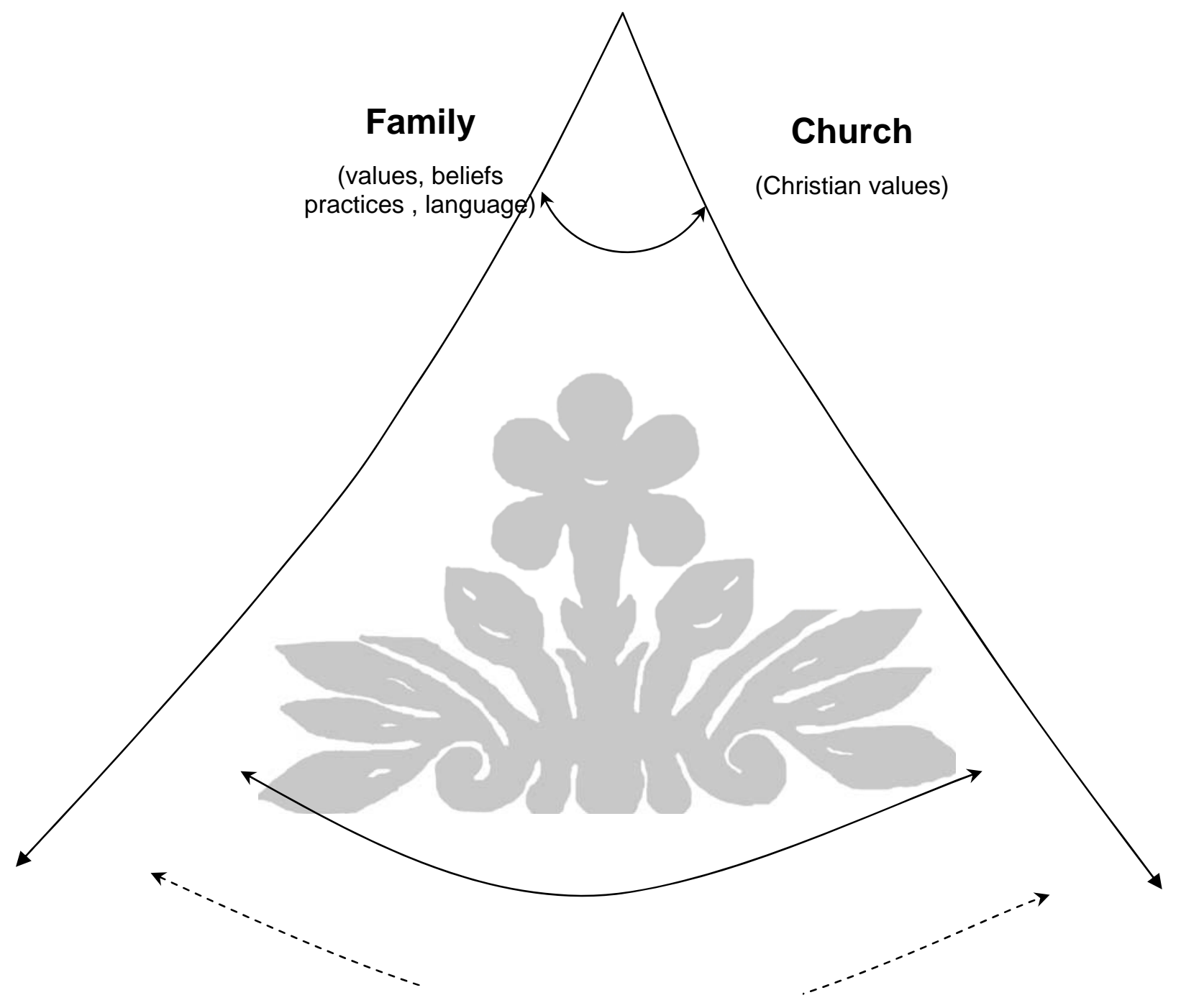

\section{Wider society}

key ethnic identity construction sites

- politics

- labour markets

- residential spaces

- daily life

- other social institutions

- culture

\section{Construction of} ethnic identities
Tertiary education

Figure 3: Revised Framework for ethnic identity construction: Pacific women graduates 


\section{Implications for tertiary education institutions}

This study has shown that the social processes that operate within tertiary institutions are complex. However, from the evidence gained in the narratives provided by these Pacific women graduates the following recommendations can be made:

1. When developing initiatives, programmes and support for their Pacific students tertiary institutions could survey Pacific students from time to time about their feelings and views of these provisions. Most institutions have laudable intentions when they establish such targeted services aimed at increasing Pacific student achievement. However, these do construct and maintain ethnic identity boundaries and divisions between the ethnic groups represented in the institutions. Tertiary institutions might ask themselves whether their aims and practices imply assimilation or ethnic identification, and what the full implications of a greater recognition and acceptance of the latter would mean for them.

2. Tertiary institutions need to more robustly monitor these provisions to discern whether they do actually contribute to student retention and enhanced academic achievement, or whether they are a factor in Pacific student “drop out”.

3. Tertiary institutions should continue to address the different needs of Pacific students but they should do so in a more informed way about the implications of the exercise of power and responsibilities of those in decision-making positions within the institutions. Their values, beliefs and even stereotypes underpin the assignment processes that occur both structurally and professionally to maintain boundaries and categories. This is an inevitable consequence of the social processes of identity construction and cannot be easily altered but institutions need to ask themselves if these boundaries and categories are ones from which Pacific students are not permitted to escape. Assignment processes currently prevail. What will institutions do to increase opportunities for Pacific students, graduates and lecturers to assert their cultural identities, such that there is more of a balance between assertion and assignment?

4. Tertiary institutions and the lecturers within them do not on their own construct the ethnic identities of Pacific students. Pacific communities, 
cultural groups and Pacific students themselves are all involved in the processes of assignment and assertion as they unfold within social construction sites. What may be more difficult for institutions based on one set of beliefs, values and practices is to promote an increased awareness of the social processes being played out within their institutions in regards to the interfaces with students from “other” ethnic groups.

5. The women in this study are examples of successful graduates and as a result of tertiary education and the social processes they have been a part of, their ethnic identities have been constructed and maintained in varied and complex ways. Institutions could take note of some of their experiences and plan to isolate the success factors for their Pacific students. From such evidence institutions could design ways in which the interactions in which these students participate are supportive to them, rather than hindering their academic progress and success.

\section{Reflections on the narrative approach}

In Chapter Eight I described the methods used in this study and issues were raised about the validity of the narrative method in providing evidence for group identification.

Brubaker and Cooper (see Chapter Five), for example, criticise individual accounts about identity on the grounds that they do not show how group identities are constructed. In their preface (1998: xvíii) Cornell and Hartmann write that they are not concerned with individual identity formation but rather how ethnic and racial groups form and act as groups. Their methods are based on historical accounts and case studies. Brubaker and Cooper subsequently concede however, that there is a link between an individual's own understanding and perspective of identity and the category of identity to which he/she relates or feels a sense of belonging. Where there exists a sense of belonging to wider social events and public narratives, and an awareness of social location associated with membership of a category of identity (such as gender and ethnicity), they say there is a link between personal narrative and the social reality of belonging to a group.

The narratives provide evidence across 20 accounts of changes in ethnic identity in the settings and the site I was studying. The narrative approach, I believe, proved to be capable of showing glimpses of the meanings of group identification, group formation and to a lesser extent group action within two social settings and 
within one institution where contact occurs between ethnic groups. The experience of the researcher was that the shared cultural understandings between researcher and interviewees provided a qualitative dimension and depth to the narratives that could not be captured solely through sound recording. The sharing of similar experiences, parent expectations and requirements placed on all Pacific daughters of family roles and responsibilities, for example, provided opportunities to express both mirth and sadness, sometimes simultaneously. It is difficult for a thesis to adequately reflect such cultural understandings but is important to note that these were present.

The analysis of the narratives of these Pacific women graduates provides a fresh perspective on the processes of ethnic identity construction, the dynamics of relations between "us" and "them", and the boundaries and meanings of cultural and ethnic group identification. The constructionist approach taken by Cornell and Hartmann provides an insightful framework for demonstrating and explaining those relationships to the extent that individuals and groups can act to assert their identities and respond to the assignment processes in the circumstances they find themselves. This approach has not previously been applied to Pacific Island populations in Aotearoa New Zealand and I believe this thesis illustrates its merits.

In this study and throughout its development I have also worked to show a relationship between theoretical assumptions about Pacific ethnic identities on the one hand, and personal narrative on the other and the way in which both are located within a social context and shaped by the processes of ethnic identity formation. Further research using such approaches may continue to provide a fuller picture of “us”, “them”, circumstances, assertion and assignment processes for Pacific groups in Aotearoa New Zealand.

\section{Suggestions for future research}

Further to this study an opportunity exists for a more wide-ranging piece of research to find out about how the construction of Pacific ethnic identities might continue to change over time. For example, it was apparent from the literature that the Pacific churches within Aotearoa New Zealand have changed since migration. This could be attempted by examining the influence of historical circumstances, the nature of key construction sites, and the social processes of assignment and assertion as they proceed. Most importantly, it would be interesting to find out 
about the salience of Pacific ethnicities within more of the key construction sites beyond the social institution of tertiary education. Time and space has precluded this study from fully exploring the concepts of "thick" and "thin" as outlined by Cornell and Hartmann. Any data gathered in a wide-ranging study would need to be analysed according to the constructionist framework, including commenting on what role Pacific peoples have in "making themselves" or their own ethnic identities.

Another interesting area of research concerning Pacific communities in Aotearoa New Zealand is what Pearson (1990, drawing on Weaver, 1985) described as the issue of ethnic representivity. While Pacific peoples still remain a minority ethnic group towards which resources and programmes are targeted, and large government agencies are required to consult with them, then who should represent Pan-Pacific interests or Samoan, Tongan, Tokelauan, Cook Islands, Niuean, Tokelauan, Fijian, Kiribati interests? Since assignment processes operate within large institutions that define who these Pacific groups are, their behaviour, their characteristics and their social outcomes what effects do these processes have on Pacific groups and what are their responses/assertions as a result of such assignment processes?

Intermarriage (in formal and informal partnerships) is literally changing the face of Pacific ethnic groups in Aotearoa New Zealand. This area would also make a worthwhile subject for study to track how young people from mixed heritages identify themselves, for example in the urban situation, divorced, distanced, or reviving their "roots". Such a study could document the ways in which they are asserting their cultural identities and then in response how the dominant ethnic groups assign meanings and boundaries to these Pacific youth?

Whatever areas are considered important for future research it has been very useful in this study to clarify the difference between cultural and ethnic groups and identities. Cornell and Hartmann are clear that ethnic identity is a product of the contact and interactions between two different groups such that ethnic boundaries may not be formed where a group and its members meet all their daily needs within their own networks. Ethnic difference does not become an issue where ethnic boundaries do not exist or are not clear. Where a population group owns a territory or holds the power boundaries are only created where groups align themselves against others or where the differences become important to 
them. For example, since Pacific peoples have in the past been viewed as taking jobs and resources from "real" New Zealanders when they migrated to this country, from that point boundaries were created. Social mobility has been achieved, to a small extent, over the period since first settlement so it would be interesting to find out the nature of the change in ethnic boundaries in construction sites such as employment and housing.

\section{Conclusion}

A number of studies of women from working class backgrounds attending university had shown that these women got "educated out" of and away from their social class origins (see Paasse, 1998) and at the beginning of this study I assumed that the ethnic identities of Pacific women would be changed or reconstructed as a result of them entering and participating in tertiary education.

However, since completing this study I have a much deeper understanding and appreciation of the social processes of how ethnic identity is constructed and how in turn, historical circumstances and wider social changes can influence such processes. Moreover, the narratives of the 20 Pacific women graduates in this study revealed that they are indeed active in the social construction of their own identities to the extent that they can respond to the assignment of "outsiders" and assert their identities in a range of ways within tertiary education institutions. In many ways they became more articulate and clearer about their ethnic identities as a result of their tertiary education. A number of the women interpreted their treatment as "unjust" on a number of occasions and they reported that their studies had provided a language and discourse that led to structural analysis about the position of Pacific peoples in Aotearoa New Zealand. However, their cultural beliefs (including their Christian beliefs) mitigated against any temporary feelings of inferiority or oppression caused by their self-consciousness of difference because their tertiary education and qualifications were always a means to an end, not usually the goal itself.

Direct implications for action do not readily arise from the findings of this study because a wide variety of groups and institutions play a role in the construction of boundaries and meanings of ethnic identification and belonging. Historical circumstances and often unforeseen events that could trigger mass migration (including natural disasters) could disrupt social networks, institutions and social interactions thereby drastically affecting ethnic identification, requiring little or no 
action by group members or "insiders”. In the case of my father the Second World War took him far away from his island home in the South Pacific to Europe with unforeseen circumstances, and while individual cases always have their unique characteristics general implications of change may ultimately show some similar trends.

Ethnic identities also change over time and this study has shown how a constructionist framework, used sensitively to capture particular circumstances and social relations, provides a useful sociological framework to examine how these changes can be observed and analysed. Pacific ethnic identities are formed as a result of the ongoing dynamic between assignment and assertion and in response to the circumstances Pacific peoples have found themselves in Aotearoa New Zealand. The meanings and boundaries created through contacts between Pacific ethnic groups and the dominant ethnic group within the tertiary institutions and other social construction sites, will continue to have influence and power as long as people believe they do.

For Pacific peoples in Aotearoa New Zealand, as they continue identifying as migrant groups, intermarrying and asserting themselves in and across different construction sites of the wider society, including social institutions like tertiary education, then ethnic meanings and boundaries will continue to change. This study shows that it is possible to study the formation of ethnic identity in a systematic and sensitive way, particularly when the meanings, definition and analyses of cultural and ethnic identities take place within a constructionist framework. It has been clearly shown how useful narratives can be in illustrating the dynamics between assertion and assignment processes, and it is through the narratives of a group of 20 Pacific women tertiary graduates that this study provides a new perspective on the social construction of Pacific ethnic identities in Aotearoa New Zealand. 


\section{EPILOGUE}

Where the coconut tree does not grow

Like everyone else

We have a place in the sun

Born of the state ghettos

Raised on palm tree and lagoon reminiscences

Straddling two islands

We boogie to the hula

And rap out songs of the church

Home is where the roots lie

Stretching across vast seas

Their tentacles like vines

A vice grip on our identity

But our life unfolds

In the Land of the Long White Cloud

Where the coconut tree does not grow

Instead, the pohutukawa

Resplendent in red

Becomes our shelter

From whence we emerge

To claim our place in the sun

Ta'i George

(Used with kind permission of the poet) ${ }^{46}$

\section{Aneriueta Teta Pa’ö- Sopo’aga (1951-2005)}

It was with great sadness I received the news of the passing of Teta on 27 April 2005. Teta was one of the Pacific women graduates involved in this study. A wonderful mother, teacher, student, and an example to us all. Tofä! Tofä! Tofä!

46 Education Training Support Agency (1998). Our Place In the Sun. Wellington: Author p.13 


\section{REFERENCES}

Abelmann, N. (1997). Narrating selfhood and personality in South Korea: Women and social mobility. American Ethnologist, 24 (4), 786-812.

Airini (1999). Pacific visions of identity: Pacific life in New Zealand policy. Paper presented to Pacific Vision Conference. Wellington: Ministry of Pacific Islands Affairs.

Anae, M., (1995). Papalagi redefined: Towards a New Zealand-born Samoan identity. Paper presented to New Zealand Association Social Anthropologists (NZASA) Conference, Wellington, 26-28 August.

Anae, M. S., \& Sua'ali'i-Sauni, S. (1997). Pacific Island student use of student services at University of Auckland. Auckland: University of Auckland.

Anae, M. (1998). Fofoa-i-vao'ese. The identity journeys of NZ-Born Samoans. Unpublished Ph D thesis, Anthropology, University of Auckland.

Anae, M., Coxon, E., Mara, D., Wendt-Samu, T., \& Finau, C. (2001). Pasifika Education Research Guidelines. Wellington: Ministry of Education.

Anae, M., Anderson, H., Benseman, J., \& Coxon, E. (2002). Pacific peoples and tertiary education: Issues of participation. Wellington: Ministry of Education.

Anae-Ostler, L. (Ed) (2003). Coffee, coco \& nuts. Manukau City: Soulton House Publishing.

Avia, T. (2004, January 11). RPM: Rewind-which way to paradise? Wellington: Radio New Zealand.

Bakalevu, S. (1996). The native researcher experience: Constraints and advantages. Paper presented to New Zealand Association for Research in Education Conference, Nelson, 5-8 December.

Beaver, B. B., \& Tuck, T. (1998). The adjustment of overseas students at a tertiary institution in New Zealand. New Zealand Journal of Educational Studies, 33 (2), 167-180.

Bedford, R. D., \& Didham, R. (2001). "Who are the 'Pacific Peoples'”? Ethnic identification and the New Zealand census. In C. Macpherson, P. Spoonley \& M. Anae (Eds.), Tangata O Te Moana Nui: The evolving identities of Pacific peoples in Aotearoa/New Zealand (pp. 21-43). Palmerston North: Dunmore Press.

Bell, M. (1998). Aga'i pea i luma o le Sini ole Manumalo. "Stepping forward” victorious. Unpublished M A thesis, Education, University of Auckland.

Bhaba, H. (1994). Between identities. International Yearbook of Oral History and Life stories, 3, 183-199. New York: Oxford University Press.

Brubaker, R., \& Cooper, F. (2000). Beyond “identity”. Theory and Society, 29 (1) February, 1-47.

Cerulo, K. (1997). Identity construction: New issues, new directions. Annual Review of Sociology, 23, 385-409.

Challis, R. L. (1970). Pacific Islanders in New Zealand. Wellington: Department of Education. 
Cleverley, M. (1996). Pacific Islands learners-Cultures apart. Report of national symposium Pacific Islands learners: The answers are within us (pp. 104-113). Wellington: Education and Training Support Agency

Coates, R. D. (1997). The agony of education: Black students at white colleges and universities by Feagin, J.E., Vera, H., \& Imani, N. (Review). Social Forces Volume, 75 (4), 1501-1502.

Cornell, S. (1996). The variable ties that bind: content and circumstance in ethnic processes. Ethnic and Racial Studies, 19 (2), 265-289.

Cornell S., \& Hartmann, D. (1998). Ethnicity and race: Making identities in a changing world. Pine Forge: Sage Publications.

Coxon, E., \& Mara, D. (2000). Education policy for Pacific nations peoples. In J. Marshall, E. Coxon, K. Jenkins, \& A. Jones (Eds.), Politics, policy, pedagogy: Education in Aotearoa/New Zealand (pp. 157-166). Palmerston North: Dunmore Press.

Coxon, E., Anae, M., Mara, D., Wendt-Samu, T., Finau, C. (2002). Literature review on Pacific education issues: Final report. Wellington: Ministry of Education.

Crawley, L., \& Morgan, P. (1993). PACIFICA 1975. In A. Else (Ed.), Women together: A history of women's organizations in New Zealand/Nga Ropu Wahine o te Motu. Wellington: Historical Branch Internal Affairs \& Daphne Brasell Associates.

Cuellar, I., Nyberg, B. R., Maldonado, R. E. \& Roberts, R. E. (1997). Ethnic identity and acculturation in a young adult Mexican-origin population. Journal of Community Psychology, 25 (6), 535-549.

Davey, J. A. (2002). Going for it! Older students at Victoria University of Wellington. Wellington: Victoria University of Wellington.

Davey, J. A. (2002). Funding education in mid- and later life: A case study from Victoria University of Wellington. Social Policy Journal of New Zealand, 18, 178-190.

Davey, J. A., Neale, J., Morris Matthews, K. (2003). Common themes and policy pointers. In J. A. Davey, J. Neale, \& K. Morris Matthews (Eds.), Living and learning: Experiences of university after age 40, (pp. 178-188). Wellington: Victoria University Press.

Davies, C. A. (1999). Reflexive ethnography: A guide to researching selves and others. London \& New York: Routledge.

Deem, R. (1996). Border territories: A journey through sociology, education and women's studies. British Journal of Sociology of Education, 17 (1), 5-19.

Dei, G. J., \& James, I. M. (1998). Becoming black: African-Canadian youth and the politics of negotiating racial and racialised identities. Race, Ethnicity and Education, 1 (1), 91-108.

Denzin, N. K., \& Lincoln, Y. S. (1994). Qualitative research. In N. K. Denzin \& Y. S. Lincoln (Eds.), Handbook of qualitative research. Thousand Oaks: Sage. 
Denzin, N. K. (1997). Biographical research methods. In L. J. Saha (Ed.), International encyclopedia of the sociology of education (pp. 282-288). Oxford, England: Pergamon.

Denzin, N. K., \& Y. S. Lincoln (Eds.) (1998). Collecting and interpreting qualitative materials. Thousand Oaks: Sage.

Dickie, J. (2000). Pacific nations students in primary teacher training: Investigating their learning needs. Unpublished MEd thesis, Victoria University of Wellington.

Education and Training Support Agency (ETSA). (1997). Pacific Islands education and training: A selected annotated bibliography. Wellington: Author.

Ellis, W. (1969). Polynesian researches: Society Islands, Tubuai Islands and New Zealand. Vermont \& Tokyo: Charles E. Tuttle.

Fairbairn-Dunlop, P. (1984). Factors associated with language maintenance: the Samoans in New Zealand. New Zealand Journal of Educational Studies, 19 (2), 99-113.

Fairbairn-Dunlop, P. (1996). Tamaitai Samoa: Their stories. Suva, Fiji \& California: Institute of Pacific Studies, USP \& KIN Publications.

Fairbairn-Dunlop, P., \& Makisi., G. (Eds.) (2003). Making our lace: Growing up $P I$ in New Zealand. Palmerston North: Dunmore Press.

Fleras, A., \& Spoonley, P. (1999). Recalling Aotearoa: Indigenous politics and ethnic relations in New Zealand. Auckland: Oxford University Press.

Fontana, A., \& Frey, J. H. (1998). Interviewing: The art of science. In N. K. Denzin \& Y. S. Lincoln (Eds.), Collecting and interpreting qualitative materials (pp. 47-78). Thousand Oaks: Sage.

Franklin, M. (2003). I define my own identity: Pacific articulations of race and culture on the internet. Ethnicities, 3 (4), 465-490.

Grinyer, A. (2002). The Anonymity of research participants: Assumptions, ethics and practicalities. Social Research Update 36. Retrieved 18 October 2002 from http://www.soc.surrey.ac.uk/sru/SRU36.html

Harding, S. (1998). Multiculturalism, postcolonialism, feminism: Do they require new research epistemologies? Australian Educational Researcher, 25 (1), 3751.

Hart, C. (2003). Doing a literature review. London: Sage.

Helu Thaman , K. (1995). Concepts of learning, knowledge and wisdom in Tonga and their relevance to modern education. Prospects, $X X V(4), 723-733$.

Heyl, B. S. (1997). Talking across the differences in collaborative fieldwork. The Sociological Quarterly, 38 (1), 1-18.

Hurtado, S. C., \& Carter, D. F. (1997). Effects of college transition and perceptions of the campus racial climate on Latino college students' sense of belonging. Sociology of Education, 70, 324-345.

Jones, A., Herda, P. \& T. M. Sua'ali’i (Eds.) (2000). Bitter Sweet: Indigenous women in the Pacific. Dunedin: University of Otago Press. 
Kenyatta, M. (1997). Editor's review: Beating the odds: How the poor get into college by Arthur Levine and Jana Nidiffer, 1996. Harvard Educational Review, 67 (4) Winter, 828-831.

Koloto, A. (2000). A Tongan perspective on development. In W. Drewery \& L. Bird (Eds.), Human development in Aotearoa: A journey through life (pp. 3439). Auckland: McGraw- Hill.

Krishnan, V., Schoeffel, P., \& J. Warren (1994). The challenge of change: Pacific Islands communities in New Zealand 1986-1993. Wellington: New Zealand Institute for Social Research and Development Ltd.

Larner, W. (1991). Women and migration. In P. Spoonley, D. Pearson, \& C. Macpherson (Eds.), Nga Take: Ethnic relations and racism in Aotearoa/New Zealand (pp. 51-66). Palmerston North: Dunmore Press.

Laufiso, E. (1988). A Samoan woman's perspective on sexism. The Social Studies Observer, 21 (2), 15-16.

Lealea, S. (1998). Framing policies from Pacific perspective: Policy analysis framework. Newsletter of the Ministry of Pacific Islands Affairs, 4. Wellington: Ministry of Pacific Islands Affairs.

Leavasa-Tautolo, F. (1994). Educational excellence and cultural identity. Paper presented to NZEAS Conference, 16-19 January, Auckland, New Zealand.

Leckie, J. (1993). Pacific Islands women's organizations 1954-. In A. Else (Ed.), Women together: A history of women's organisations in New Zealand/Nga Ropu Wahine o te Motu. Wellington: Historical Branch Internal Affairs /Daphne Brasell Associates.

Loomis, T. (1991). The politics of ethnicity and Pacific migrants. In P. Spoonley, D. Pearson, \& C. Macpherson (Eds.), Nga Take: Ethnic relations and racism in Aotearoa/New Zealand (pp. 37-50). Palmerston North: Dunmore Press.

Ma-Ua Hodges, T. (2000). Ako Pai ki Aitutaki: Transporting or weaving cultures. Research report of field experiences to the Cook Islands. Wellington: Wellington College of Education.

Macpherson, C. (1984). On the future of Samoan ethnicity in New Zealand. In D. Pearson, \& P. Spoonley (Eds.), Tauiwi: Racism and ethnicity in New Zealand. Palmerston North: Dunmore Press.

Macpherson, C. (1991). The changing contours of Samoan ethnicity. In P. Spoonley, D. Pearson, \& C. Macpherson (Eds.), Nga Take: Ethnic relations and racism in Aotearoa/New Zealand (pp. 67-84). Palmerston North: Dunmore Press.

Macpherson, C. (1996). Pacific Islands identity and community. In P. Spoonley, C. Macpherson, \& D. Pearson (Eds.), Nga Patai: Racism and ethnic relations in Aotearoa/New Zealand (pp. 124-143). Palmerston North: Dunmore Press.

Macpherson, C. (2001). One trunk sends out many branches: Pacific cultures and cultural identities. In C. Macpherson, P. Spoonley, \& M. Anae (Eds.), Tangata O Te Moana Nui: The evolving identities of Pacific peoples in Aotearoa/New Zealand (pp. 66-80). Palmerston North: Dunmore Press. 
Madill, A., Jordan, A., \& Shirley, C. (2000). Objectivity and reliability in qualitative analysis: Realist, contextualist and radical constructionist epistemologies. British Journal of Psychology, 91, 1-20.

Mara, D. (1993). Forward together? A Pacific Island woman's viewpoint 19721993 and beyond. Paper presented to Women's Studies Association Conference, Waipapa Marae, University of Auckland, 14-16 May.

Mara, D., Foliaki, L., \& Coxon, E. (1994). Pacific Islands education. In E. Coxon, K. Jenkins, J. Marshall, \& L. Massey (Eds.), The politics of learning and teaching in Aotearoa-New Zealand (pp. 180-214). Palmerston North: Dunmore Press.

Mara, D. L. (1995). Te Puai no te Vahine: Pacific Islands education policy and education initiatives in Aotearoa/New Zealand: A critique. Unpublished M Litt thesis, Education, University of Auckland.

Mara, D., Tuhipa,T., Falesima, T., Greenwood, A. (1996). Teacher education: Implications for Pacific students and their communities. The Proceedings Report, National Symposium 1996 Pacific Islands learning: The answers are within us. Wellington: Education, Training and Support Agency.

Mara, D., Morgan, T., Robertson, P., Watts, M., Enoka, N., \& Lemihio, S. (1996). Evaluation report of the Anau Ako Pasifika project: A home based early intervention programme for Pacific Islands families in New Zealand. Tokoroa: Anau Ako Pasifika.

Mara, D. (1999). Why research? Why educational research for/by/with Pacific communities in Aotearoa-New Zealand? Paper presented to the Pacific Islands Educators' Conference, Mangere, Auckland, 13-14 April.

Mara, D. (2000). Never mind the quality-feel the width: A Pacific perspective and commentary on closing the gaps. Paper presented to the New Zealand Association for Research in Education Conference, Waikato University, 30 November - 3 December.

Mara, D. (2000). The growth and development of Pacific Island early childhood education in Aotearoa New Zealand. In L. Bird, \& W. Drewery (Eds.), Human development in Aotearoa A journey through life (pp. 109-111). Auckland: McGraw-Hill.

Mara, D. (2004). Views of Pacific women at mid-life. In W. Drewery, \& L Bird (Eds.), Human development in Aotearoa: A journey through life (pp. 308310). Second Edition. Auckland: McGraw-Hill.

McAlpine Petelo, L. (2003). Fa'alogo i leo o le fanau: A qualitative study of the ways in which students of Samoan background experience their education within the University of Canterbury. Unpublished PhD thesis, Education, University of Canterbury.

McCallin, A., Paterson, J., Butler, S., \& Cowley, E.T. (2001). Striving for the best of both worlds: Samoan parenting in New Zealand. Pacific Health Dialog, 8 (1), $6-14$.

McCarthy, F. L. (2001). A Pacific Vision: The search for opportunity. In C. Macpherson, P. Spoonley, \& M. Anae (Eds.), Tangata o Te Moana Nui: The evolving identities of Pacific peoples in Aotearoa/New Zealand (pp. 276-291). Palmerston North: Dunmore Press. 
Meleisia, M., \& Schoeffel, P. (1998). Samoan families in New Zealand: The cultural context of change. In V. Adair \& R. Dixon (Eds.), The family in Aotearoa New Zealand. Auckland: Longman.

Mennell, S. (1989). Norbert Elias: Civilization and the human self-image. Oxford: Basil Blackwell.

Middleton, S. (2001). Educating researchers: New Zealand PhDs 1948-1998. Wellington: New Zealand Council for Educational Research.

Ministry of Education. (2004). Talanoa Ako Pasifika Education Newsletter, 6 (1), June. Wellington: Author.

Ministry of Education (2005). Pasifika peoples in New Zealand Education: A statistical snapshot 2004. Wellington: Author.

Ministry of Pacific Island Affairs. Pacific progress: A report on the economic status of Pacific peoples. Retrieved 10 December 2005 from http://www.minpac.govt.nz/publications-specialreports.htm

Mishler, E., G. (1986). Research Interviewing: Context and Narrative. United States: Harvard University Press.

Mok, Tze Ming. (2000). In the name of the Pacific theorising Pan-Pacific identities in Aotearoa-New Zealand. Unpublished MA thesis, Political Studies, University of Auckland.

Morris Matthews, K. (2003). Is it worth it? Full-time teachers who study at university part-time. In J. A. Davey, J. Neale \& K. Morris Matthews (Eds.), Living and learning: Experiences of university after age 40 (pp. 76-92). Wellington: Victoria University Press.

Morrow, N. (1997). Language and identity: Women's autobiographies of the American immigrant experience. Language and Communication, 17 (3), 177185.

Mulitalo, T. (2001). My own shade of brown. Christchurch: University of Canterbury/Shoal Press.

Nakhid, C. (2003). Comparing Pasifika students' perceptions of their schooling with the perceptions of non-Pasifika teachers using the "mediated dialogue" as a research methodology. New Zealand Journal of Educational Studies, 38 (2), 207-226.

Ongley, P. (1991). Pacific Islands' migration and the New Zealand labour market. In P. Spoonley, D. Pearson, \& C. Macpherson (Eds.), Nga Take: Ethnic relations and racism in Aotearoa/New Zealand (pp. 17-36). Palmerston North: Dunmore Press.

Paasse, G. (1998). You can't put the toothpaste back in the tube: The impact of higher education on mature age students. Australian Educational Researcher, 25 (1), 91-109.

Pasikale, A. (1996). Seen, but not heard: Voices of Pacific learners. Wellington: Education \& Training Support Agency.

Pasikale, A. (2001). Skills Pasefika: Contributions to educating Pasefika positively. Paper presented to Educating Pasifika Positively Conference, Auckland, 10 -12 April. 
Pasikale, A. \& George, T. (1995). For the family first. A study of income allocation within Pacific Islands families in New Zealand. Wellington: Destini Incorporated.

Pasikale, A. \& Yaw, W. (1998). Weaving the way: Pacific Islands peoples' participation in the provision of learning pathways for Pacific Islands learners. Wellington, Education \& Training Support Agency.

Pearson, D. (1990). A dream deferred: The origins of ethnic conflict in New Zealand. Wellington, Allen \& Unwin/Port Nicholson Press.

Petelo, L. (1997). Researching my other, my self. Paper presented to New Zealand Association for Research in Education Annual Conference, Auckland, 4 - 7 December.

Pihama, L. \& Mara, D. (1994). Gender relations in education. In E. Coxon, K. Jenkins, J. Marshall, \& L. Massey (Eds.), The politics of learning and teaching in Aotearoa-New Zealand (pp. 215-250). Palmerston North: Dunmore Press.

Robie, D. (1982, 4 July). War hero rolls back the years. New Zealand Times, p. 3.

Saha, L. J., (Ed). (1997). International encyclopedia of the sociology of education. Oxford, England: Pergamon.

Said, W. E. (1978). Orientalism: Western conceptions of the Orient. London, Routledge \& Kegan Paul.

Scheurich, J. \& Young, J. (1997). Coloring epistemologies: Are our research epistemologies racially biased? Educational Researcher, 26 (4), 4-16.

Schoeffel, P. (1977). The origin and development of women's associations in Western Samoa 1830-1977. Journal of Pacific Studies, 3.

Schoeffel, P. (1979). Daughters of Sina. A study of gender, status and power in Western Samoa. Unpublished $\mathrm{PhD}$ thesis, Canberra, Australian National University.

Schoeffel, P., \& Meleisia, M., David, R., Kalauni, R., Kingi, P., Taumoefolau, T., Vuetibau,L., \& Williams, S. P. (1996). Pacific Islands Polynesian attitudes to child training and discipline in New Zealand: Some policy implications for social welfare and education. Social Policy Journal of New Zealand, 6, 134147.

Silverman, D. (1993a). Methods for analysing talk, text and interaction. London: Sage.

Silverman, D. (1993b). Six rules of qualitative research. In D. Silverman (Ed.), Interpreting qualitative data: Methods for analysing talk, text and interaction (pp. 196-211). London: Sage.

Smith, J. A. (1995). Semi-structured interviewing and qualitative analysis. In J. A. Smith, R. Harre, \& L. Van Langehove (Eds.), Rethinking methods in psychology (pp. 9-26). London: Sage.

Smith, L. T. (1999). Decolonising methodologies: research and indigenous people. London: Zed Books.

Spoonley, P., Pearson, D., \& Macpherson, C. (Eds.). (1991). Nga Take: Ethnic relations and racism in Aotearoa/New Zealand. Palmerston North: Dunmore Press. 
Spoonley, P. (1993). Racism and ethnicity. Auckland, Oxford Unity Press.

Spoonley, P., Pearson, D., \& Macpherson, C. (Eds.) (1996). Nga Patai: Racism and ethnic relations in Aotearoa/New Zealand. Palmerston North: Dunmore Press.

Spoonley, P. (2001). Transnational Pacific communities: transforming the politics of place and identity. In P. Spoonley, D. Pearson, \& C. Macpherson (Eds.), Tangata O Te Moana Nui: The evolving identities of Pacific peoples in Aotearoa/New Zealand (pp. 81-96). Palmerston North: Dunmore Press.

Statistics New Zealand (2001) Chapter Six Religious Affiliation. Retrieved 1 August 2005 from http://www.stats.govt.nz/analytical reports/concerning-language2004/chapter6.htm

Statistics New Zealand (2002). Pacific progress: A report on the economic status of Pacific peoples in New Zealand. Wellington: Ministry of Pacific Island Affairs.

Stones, R. (1996). Sociological reasoning: Towards a past-modern sociology. London: Macmillan Press.

Sua'ali'i, T. (2000). Deconstructing the 'exotic' female beauty of the Pacific Islands. In A. Jones, P. Herda, \& T. M. Sua'ali'i (Eds.), Bitter sweet: Indigenous women in the Pacific (pp 93-108). Dunedin: University of Otago Press.

Tamasese, K., Masoe-Clifford, P., \& Ne’emaia-Garwood, S. (1988). Pacific Islands Peoples' Perspectives. Royal Commission on Social Policy, Report Volume IV. Wellington: Government Printer.

Tamasese, K., Peteru, C., \& Waldegrave, C. (1997). Ole Taeao Afua: The new morning. Report on Samoan mental health. Wellington: Health Research Council of New Zealand.

Tanielu, L. (2000). Education in Western Samoa: Reflections on my experiences. In A. Jones, P. Herda, and T.M. Sua'ali'i (Eds.), Bitter Sweet: Indigenous women in the Pacific (pp. 49-60). Dunedin: University of Otago Press.

Tanuvasa, A. E. F. (1999). The place of contraception and abortion in the lives of Samoan women. Unpublished PhD thesis, Nursing Studies, Victoria University of Wellington.

Taufe'ulungaki, A. M. (2003). The role of research: A Pacific perspective. In Coxon, E. \& A. M. Taufe'ulungaki (Eds.), Global/local intersections: Researching the delivery of aid to Pacific education (pp. 19-40). Auckland: Research Unit of Pacific Education (RUPE): University of Auckland.

Taule'ale'ausumai, F. E. (2000). Pacific treasures: Our journey thus far Pacific Island women in ordained ministry in the Presbyterian Church of Aotearoa New Zealand. Wellington: Presbyterian Church of Aotearoa New Zealand.

Taule'ale'ausumai, F. (2001). New religions, new identities: the changing contours of religious commitment. In C. Macpherson, P. Spoonley, \& M. Anae (Eds.), Tangata $O$ Te Moana Nui: The evolving identities of Pacific Peoples in Aotearoa/New Zealand (pp. 181-195). Palmerston North: Dunmore Press.

Taumoefolau, M., Starks, S., Bell, A., \& Davis, K. (2004). The role of second language acquistion theory and practice in Pasifika language maintenance in 
New Zealand. In Language Acquisition Research (pp. 41-55) Wellington: Research Division, Ministry of Education.

Television New Zealand. (13 October, 2002). Tangata Pasifika: Pacific identity. S Stehlin, Producer.

Television New Zealand. (15 October, 2004). The brown factor. Documentary New Zealand (DNZ), NZ On Air.

Television New Zealand. (16 October, 2004). Children of the migration. L. Rolls, Producer. Island Productions.

Tertiary Education Commission. (2002). A new tertiary landscape: Introducing the Tertiary Education Commission. Wellington: Author.

Tertiary Education Commission. (2004). Inspiring excellence for Pacific peoples throughout tertiary education: The Tertiary Education Commission's Pacific peoples strategy 2004 to 2006 and beyond. Wellington: Author.

Tiatia, J. (1998). Caught between cultures: A New Zealand-Born Pacific Island perspective. Auckland: Christian Research Association.

Tilley, V. (1997). The terms of the debate: Untangling language about ethnicity and ethnic movements. Ethnic and Racial Studies, 20 (3), 497-522.

Tofi, T., Flett, R., \& H. Timutimu-Thorpe (1996). Problems faced by Pacific Island students at university in New Zealand: Some effects on academic performance and psychological well-being. New Zealand Journal of Educational Studies, 31 (1), 51-59.

Tupuola, A.-M. (1993). Raising research consciousness the Fa'aSamoa way. In H. Manson (Ed.), New Zealand Annual Review of Education, 3, 169-189.

Tupuola, A.-M. (1997). Pacific Islands education and training: A selected annotated bibliography. Wellington: Education \& Training Support Agency \& New Zealand Council for Educational Research.

Tupuola, A.-M. (1998). Adolescence: Myth or reality for Samoan women? Beyond the stage-like toward shifting boundaries and identities. Unpublished $\mathrm{PhD}$ thesis, Education, Victoria University of Wellington.

Tupuola, A.-M. (2001). Art as meaning making: Diasporic youth, multi media and the achieved identity status. Paper presented to Pacific Island Postgraduate Seminar: A new generation, a new community, Victoria University of Wellington, 9 June.

Underhill-Sem, Y. J., \& Fitzgerald, T.F. (1996). Paddling a multicultural canoe in bicultural waters: ethnic identity and aspirations of second generation Cook Islanders in New Zealand. Monograph. Christchurch: Macmillan Brown Centre for Pacific Studies, University of Canterbury.

Uta'i, S. (2003). Mama rules! Christchurch: Spearhead/CEG/Pacifica.

Utumapu, T. L. P. (1998). O Le Poutu: Women's roles and Samoan language nests. Unpublished $\mathrm{PhD}$ thesis, Education, University of Auckland.

Utumapu, T. L. P. (1992). Finau i mea sili: Attitudes of Samoan families in New Zealand to education. Unpublished MA thesis, Education, University of Auckland. 
Wendt, A. (14 December, 2004). Lecture 2: Samoan diaspora. Macmillan Brown Lectures. Wellington: Radio New Zealand.

Wilson, F. (1997). The construction of paradox? One case of mature students in higher education. Higher Education Quarterly, 51 (4) 347-366. 


\section{APPENDIX A: NEWSPAPER CLIPPING: WAR HERO \\ ROLLS BACK THE YEARS}

\section{War hero rolls

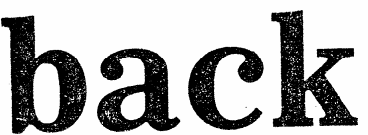 \\ the \\ N2 Times $4 / 7 / 82$. \\ P.3.}

BY DAVID ROBIE

\section{Times correspondent}

WHEN Aucklander Nat Mara flew to Paris 39 years ago his mission was simple - to drop bombs. To day he will be flying back there Only this time it will be as a feted wartime hero.

Natapu Mara, 59, has been invited by the French Government as one of three Tahitians to represent the South Pacific territory in the annual Bastille Day parade on July 14

Mr Mara, who has lived in New Zealand for the past 30 years, expects to meet Mitterrand, along with other Free French veterans, in a reception at the Elysee Palace.

And he hopes to meet one fellow wartime airman in particular former Prime Minister Pierre Mendes-France.

"It's a great honour for me to go "it's a great he many of my old wartime comrades after so long," he said this week.

He will leave Auckland for Tahiti

tonight on the first leg of the journey to team up with the other two Tahitians, a soldier and a sailor.

They will be feted by French high commissioner Paul Noirot-Cosson in Pàpeete, where Mr Mara will turn 60 on Thursday before leaving for Paris.

To Mr Mara, now a social worker for the Tahitian community in New Zealand and living in the Auckland suburb of Te Atatu, his first visit to Paris is as vivid as if it were yesterday.

He remembers seeing the Eiffe Tower for the first time with excitement on that 1943 mission. But he is also sad that his task then was to drop bombs on a target in the city of his dreams.

He has scars on his right leg which are permament reminders of his service with the Free French Air Force.

Mr Mara's other wartime souvenirs include the Medaille Militaire, Croix de Guerre with three palms, Medaille de Resistance. Medaille Com memoratif and the lanyard of the Legion d'Honneur.

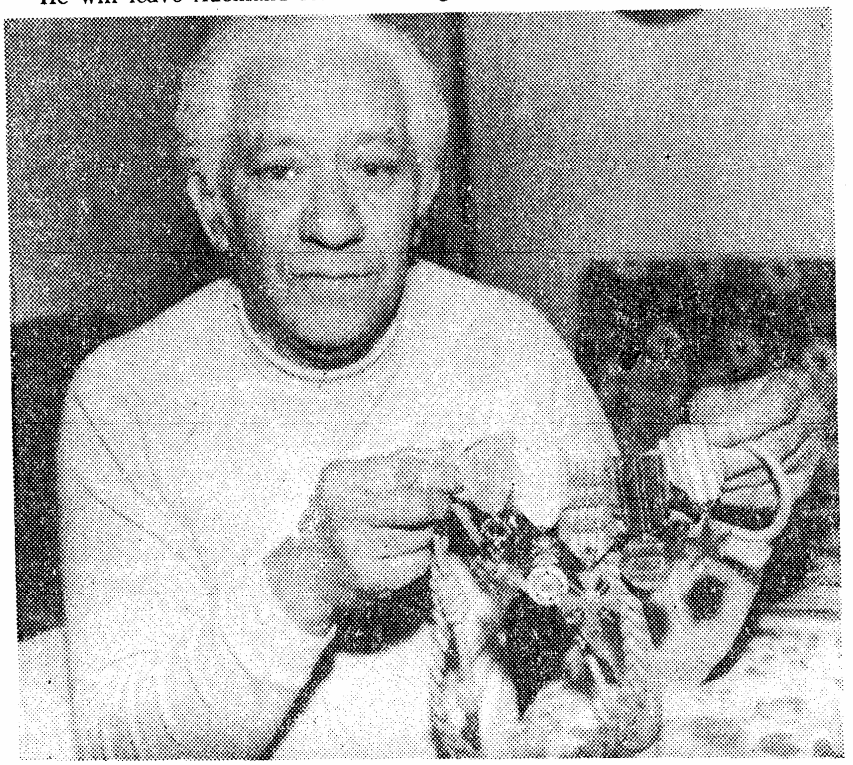

NAT MARA with his wartime and knighthood medals Guerre tells how he saved the life of a French pilot when their Boston medium-range bomber was shot down over the English Channel shortly before his 21st birthday.

In 1941, after the collapse of France during World War II, Mr Mara came to New Zealand with 21 other Tahitian volunteers to join the RNZAF - but only 12 were accepted. They were eventually trained in Canada and Free French forces.

Six of the volunteers joined the Lorraine Squadron. Mr Mara was the only one who wasn't killed or taken prisoner.

Two died in training, two were killed over Europe and the sixth was captured by the Nazis.

Mr Mara, a wireless operator and air gunner, flew a total of 51 operational flights.

"They used to call me the last of the Mohicans," he said with a chuckle. "They wouldn't let me fly any more after those 51 missions".

Ten years ago, he was awarded a French knighthood - Chevalier dans l'Ordre National du Merite second only to the Legion d'Honneur, for his social work in New Zealand.

His work among Tahitians here includes interpreting for them in their consulations with doctors, and arranging accommodation. About 500 Tahitians a year come to New Zealand for medical treatment.

$\mathrm{Mr}$ Mara has also been president of the Tahiti Nui club in Auckland and has managed a group of Tahitian dancers for more than 20 years.

He led the first group of Maori entertainers to visit Tahiti, and exported prefabricated houses to the Frenchspeaking Pacific in collaboration with a brother in Noumea.

Though still a French Polynesian, Mr Mara is married to a New Zealander, Julie, and has five children. They're all delighted he is off to Paris. When he gets there, one place $\mathrm{Mr}$ When he gets there, one place $\mathrm{Mr}$
Mara will certainly not miss is the famous girlie cabaret Folies Bergere.

"That last time I went there I was never so embarrassed in all my life. went with an Irishman and he just got so excited and carried away when everybody else was dead quiet." 


\section{APPENDIX B：PARTICIPANT INFORMATION SHEET}

\section{Talofa lava! Malo e lelei! Fakalofa lahi atu!Kia orana!Bula vinaka! Taloha ni! a orana! Kia ora! Greetings!}

My name is Diane Mara and I am currently studying for my Doctorate in Education at Victoria University, Wellington. I am a woman of Tahitian and English descent, a first-generation New Zealander and mother of Henry, ten years old. I am currently Principal Lecturer at the Wellington College of Education with a long-term involvement in Pacific Islands education in New Zealand.

My doctoral research follows on from my Masters thesis which focussed on the participation and contribution of Pacific Islands women in education initiatives in Aotearoa/New Zealand. My present study seeks to identify some of the processes operating in tertiary education contexts which may have shaped or reshaped how Pacific women identify themselves. I am therefore seeking to interview selfidentified Pacific nations women who have completed some kind of tertiary education course at a university, polytechnic or college of education in New Zealand.

I have been developing a theoretical model to describe the various contexts within which we live out our 'multiple' identities as Pacific women. I would like to explore this model through face-to-face interviews of individual women across a range of Pacific origins and disciplines of study. My aim is that we the interviewer and the interviewee) work collaboratively to construct some ideas about how identity has been developed, or shaped, in different areas of our lives. In this study I place myself in the role of the learner as well as the researcher.

The interview would probably take about one and a half hours, at a time or place most convenient to you. It could be spread over two sessions, for example, if required. Interviews will be tape-recorded and transcribed and the transcription will be sent to the interviewee for addition, alteration and approval before it becomes part of the research data. All tapes and transcripts will remain confidential. Your name will not be reported. Any information gathered will not be directly attributed to you. The data will be kept securely locked in my office at the Wellington College of Education and only the researcher and her supervisors will have access to it.

The research data from the interviews will be collated and used in answering the main research questions of my study. The tapes and transcripts of the interviews will be kept (except if otherwise specified) for a period of 5 years. Should you agree to participate, you may decline to give information at any time or to withdraw from the study. 
This study has been approved by the Education Department, Human Ethics Committee of Victoria University, Wellington.

If you have any further questions or would like further information about this research please contact me:

Home phone : $\quad$ 04-970-2982

Work : 04-476-8699 x 8650

E-mail : Diane.Mara@wce.ac.nz or

:d.mara@paradise.net.nz

Mauruuru,

Diane L Mara 


\section{APPENDIX C: SOME FACTS ABOUT YOURSELF \\ Victoria University of Wellington \\ Consent Form : \\ Doctor of Philosophy Research by Diane Lysette Mara}

Working Title : Pacific Islands women in higher education in Aotearoa-New Zealand : Identity, ethnicity, gender and 'sites of construction'.

I have read through and have understood the information given by the researcher to inform me about this study. I have had the opportunity to ask questions of the researcher and have had them answered to my satisfaction. I understand that I can withdraw myself (or any information provided) at any time without having to give any reason.

I understand that my name and identity will be kept confidential to the researcher. The information I give will be available to her supervisors, and to another person (apart from the researcher herself) who transcribes any tape recordings. Every step will be taken to ensure that the information supplied remains confidential.

I understand that the data collected will be securely stored for five years and then be destroyed. I understand I will receive transcriptions of my interview and can make alterations to them before being included in the final research data.

At the completion of the research I will receive a copy of the executive summary of the main findings and receive an invitation to attend a function where the findings will be shared.

$\mathrm{I}$,

agree to take part in this research study under the terms outlined above.

Signed

Date

It would be very helpful to me if you would answer these questions about yourself before I interview you. 
Please write your answers in the spaces provided or tick the boxes. If you wish to add any extra explanation and run out of space you can write on the back of the pages.

1. In which country were you born?

If you were not born in New Zealand in what year did you first come here?

2. In what country were your parents born?

Your father

Your mother

If they were not born in New Zealand in what year did they come to New Zealand?

Your father

Your mother

3. You religious affiliation is

$\begin{array}{llllll}\text { Anglican } & \text { [ ] } & \text { Catholic } & \text { [ ] } & \text { Congregational } & \text { [ ] } \\ \text { Methodist } & \text { [ ] } & \text { Presbyterian } & \text { [ ] } & \text { Pentecostal } & \text { [ ] } \\ \text { Other } & \text { [ ] } & & & \text { No church affiliation [ ] }\end{array}$

4. If you are affiliated with a church, how would you describe your attendance?

]

Weekly

Monthly

Yearly

Only special occasions

]

5. Please tick the box which represents your age.

$$
\text { 20-29 [ ] 30-39 [ ] 40-49 [ ] 50-50+ [ ] }
$$

6. In what country/countries were you educated?

My primary schooling was completed in

My secondary education was completed in

My tertiary education has been in 
7. In what year did you begin your tertiary education?

8. What type of institution did you attend? You may tick more than one.

\begin{tabular}{lll} 
University [ ] & College of Education & [ ] \\
Polytechnic [ ] & Other & [ ] \\
(If other, please state) & & \\
\hline
\end{tabular}

9. Were you a full-time or a part-time student?

10.

$$
\text { Part-time [ ] Full-time [ ] Part-time and full-time [ ] }
$$

(Explain if you wish)

11. What tertiary qualifications have you gained?

Are you still engaged in tertiary study?

$$
\begin{array}{ll}
\text { Yes [ ] } \\
\text { No [ ] }
\end{array}
$$

12. What were your personal circumstances while you were undertaking tertiary study? Were you living with your own Pacific family/aoga/fanau/kopu tangata?

$$
\begin{array}{ll}
\text { Yes [ ] } \\
\text { No [ ] }
\end{array}
$$

Please explain more fully 
13. How did you manage financially?

While you were studying were other people dependent upon you?

Yes [ ]
No [ ]

If yes, please describe who you were responsible for looking after.

Thank you very much for answering these questions. I have enclosed a s.a.e. for the return of the form. I look forward to interviewing you.

Ia orana 


\section{APPENDIX D: AREAS OF QUESTIONING FOR FACE-TO- FACE INTERVIEWS}

1. Family background and ethnic identification, religious affiliation, age, basic details of educational history, courses of study pursued etc.

2. Reasons for entering tertiary education and the nature of the course/s taken.

3. Initial reactions/experiences on entry to the educational institution.

4. Experiences of meeting course and administration requirements, including assessment and examinations.

5. Sources of support while studying including financial, family, community, academic (from lecturers and other students), and spiritual.

6. Content knowledge of the course or discipline studied which posed a challenge/or not to the student's own background knowledge, values, practices.

7. Differential treatment, expectations of the student while studying.

8. Outcomes/success of tertiary study including future expectations of self, expectations of parents/family and wider Pacific community?

NB Responses will be related to a theoretical model of ethnic identity construction and interviewees will be presented with a simplified diagram of the model during the interview/s. 


\section{APPENDIX E: INTERVIEW SCHEDULE}

\section{Interviewees will be shown diagram of theoretical model}

\section{I: Profile of informants}

(Refer also to details on questionnaire already received)

- You have mentioned that you have (Samoan/Tongan etc) heritage/s: what in your opinion are the main features of being....

- Describe your roles at entry to tertiary education (pre above date) and current roles (after completion): mother, wife, sister, employee (current occupation/s), community or cultural positions held etc.

\section{II: Reasons for entering into tertiary studies}

1. What made you take up or go on to tertiary study? (i.e. what were your reasons for that decision) : Probes : family expectations? Who/what influenced you? What were your hopes at the start and were these realised?

2. Did this decision differ from educational choices/decisions made by other members of your family? If so, how?

\section{III: Initial/First Experiences}

1. What are your vivid memories of the first week/s of study?

(Probes: did you meet other Pacific students there? Was there an induction programme provided for Pacific students, did the institution provide Pacific Islands liaison people or other staff for students to access support? Was there a quota system or special assistance available for entry into your chosen course of study? If any of these were present were they helpful to you?).

\section{IV: Meeting course and administrative requirements}

1. What advice would you give to another Pacific woman who was contemplating study at the same institution in terms of meeting and complying with the course and administrative requirements? (Probes: draw out any particular events or incidents that challenged you. How would you deal with them now that you know both yourself and the system better?)

\section{V: Sources of support while studying}

1. What were your most important sources of support/help (including financial help) with the new demands of study? (Probes: describe sources which were particularly helpful: in material/people (family, community)/spiritual terms that helped you in : meeting assignment 
deadlines, reading of texts, course/paper choices, managing time etc. Did you have a space to actually study in?/where did you study?).

2. Were there times when you felt like giving up on your studies? Describe such a time and how you got through those times? (Probes: what dreams/aspirations sustained you? Were your family/husband/children/ peers supportive through those times? In what ways were they supportive? Did you feel uncomfortable about asking for support at any time and to whom? Note differences between support offered and support sought and support given).

3. Was the nature of support you sought the same or different from previous sources of support (prior to studying)? How? Why?

\section{VI: Knowledge/content of courses}

1. Were there any papers/topics studied which presented you with new ideas, perspectives, viewpoints that you were not aware of before you began your tertiary studies?

(Probes: For example, topics such as feminism, racism, political activism, critical thinking, the teaching of evolution may have been "new" knowledge which conflicted with or challenged values from your own upbringing.) Please describe.

\section{VII: Unfair practices/treatment}

1. Were there any instances where you felt any of the following: singled-out, labelled, made to feel uncomfortable, visible, "different" or conversely ignored during your studies? Describe a situation/s and your responses to it/them?

2. As an outcome of unfair treatment what awareness, skills, strategies do you think you have developed as a result that you would share with other Pacific women?

\section{VIII: Outcomes of your study/qualifications}

1. How would you describe yourself and your life and status now in comparison to what it was prior to your studies?

- Education

- Home environment

- Interaction with family

- Interaction with community

- New relationships 
- Employment

(Probes: in what ways did you think you have changed? Does your family treat you differently since you have completed your studies? What are the material conditions under which you live/intend to live from now on? Who do you choose to spend most time with now? Why?)

2. How would you describe your future as a result of your studies? (Probes: would you describe yourself as "educated" and what meaning do you give that term? Have your roles, responsibilities, obligations changed as a result of your new qualification? What is your status, income and life choices available to you now?

\section{Any other comments?}

